

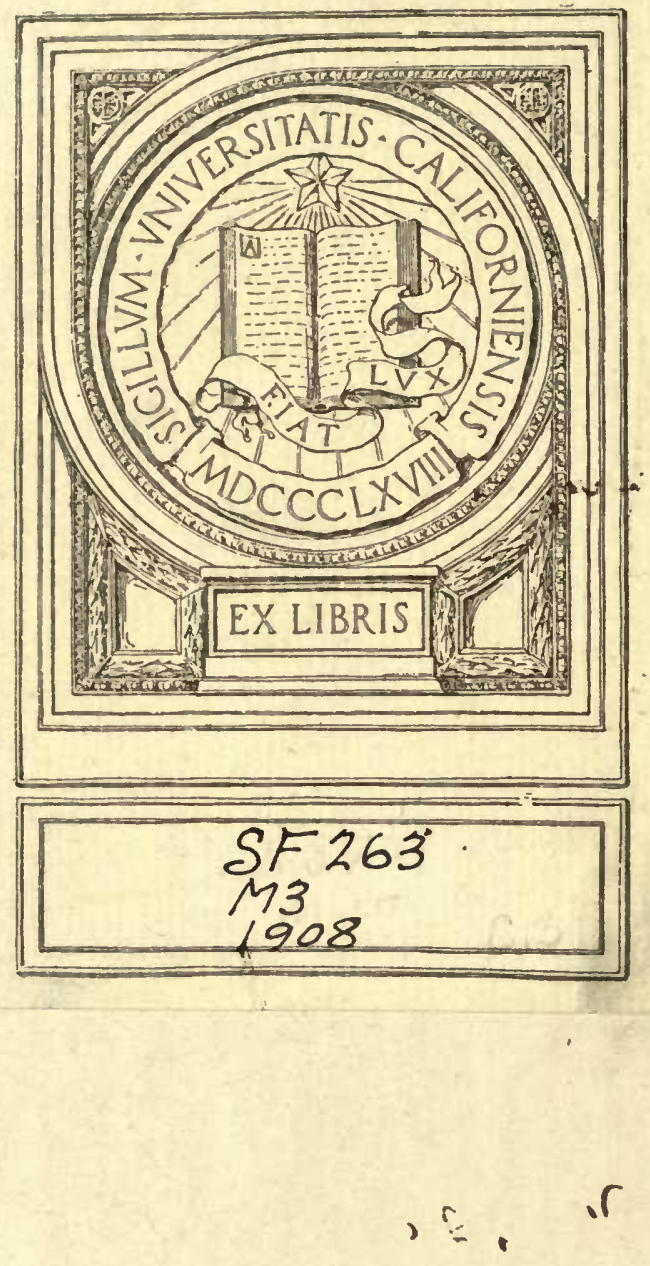


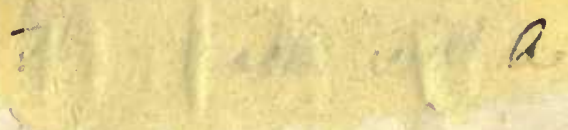

28 Ja 22

$25 \quad 5$ '22

MAY 221923 


CIDURATET

UNIVERSITY

oliformia 


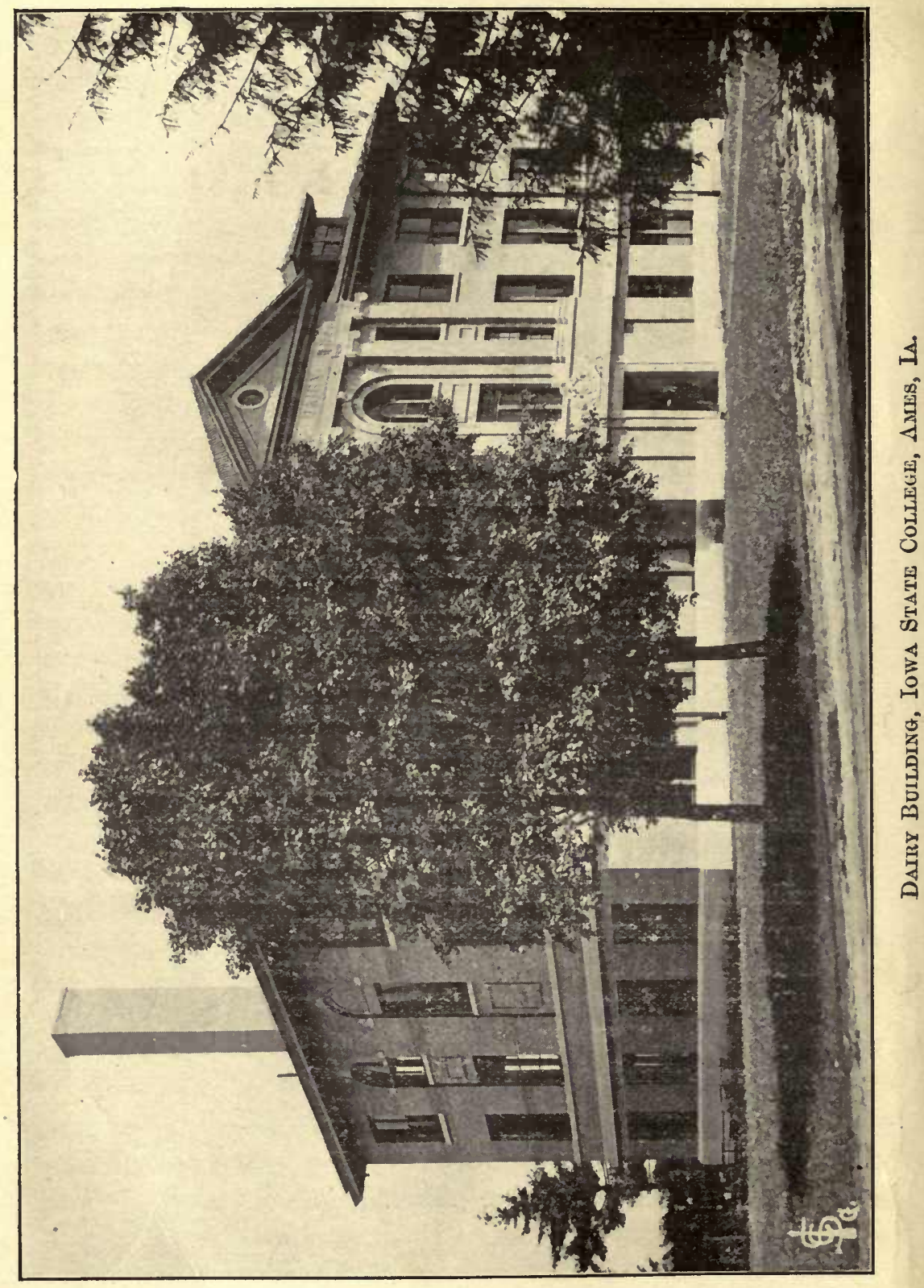




\title{
PRINCIPLES AND PRACTICE
}

\section{oF \\ BUTTER-MAKING}

A TREATISE ON THE CHEMICAL AND PHYSICAL PROPERTIES OF MILK AND ITS COMPONENTS

THE HANDLING OF MILK AND CREAM, AND THE MANUFACTURE OF BUTTER THEREFROM

\author{
BY \\ G. L. MCKAY,
}

Professor of Dairying in the Iowa State College, Ames, Ia.

AND

C. LARSEN, M.S.A.

Professor of Dairy Husbandry, So. Dak. State College, Brookings, S. D.; formerly Associate I'rojessur, Iowa State College, Ames, Ia.

SECOND EDITION, REVISED AND ENLARGED.

FIRST THOUSAND

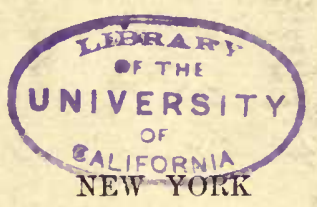

JOHN WILEY \& SONS

LONDON: CHAPMAN \& HALL, LIMITED

1908. 
Copyright. 1906, 1908,

BY

G. L. MCKAY AND C. LARSEN

The firtutific

Bobert Bamminit anì Comprany

Ifew 


\section{PREFACE TO SECOND EDITION.}

THE science of dairying is constantly broadening. The methods and art of manufacturing the best quality of butter have gradually changed in conformity to the scientific principles involved, and no manufacture of butter should now be undertaken until a careful study has been made of the principles governing the best methods of manufacture.

The authors admit that, in our present state of knowledge and experimental progress, it is in some instances difficult to distinguish well established facts from those not universally confirmed; hence it has been the object of the writers to give only information supported by the preponderance of experimental evidence.

The first edition of this book has been, in a manner, well received, indicating the work has met with general approval. The second edition has been carefully revised, and two chapters, one on "Creamery Refrigeration" and one on "Economic Operation of Creameries" have been added to meet an indicated demand, and the authors hope that this will justify the use of the book in our dairy schools, and also as a general reference book for those engaged in dairy pursuits.

The authors believe that the subject of dairying should no longer be treated as a whole, and for this reason such subjects as Testing Milk and its Products, Dairy Bacteriology, Cheesemaking, and Technology of Milk and its Products, have not been treated comprehensively in this work. In connection with the practical phase of butter-making the writers have 
endeavored to give such scientific information related to it as may be of interest and value.

The scientific knowledge has been acquired from time to time through work done by various investigators at the different Experiment Stations. To all of these men who have searched for and discovered facts bearing upon dairying the authors wish to express their thanks and acknowledgment.

It may be added that the statistics and tables given in this work have been quoted from noted, reliable authorities, as indicated.

The authors are also indebted to the following parties for the use of electrotypes: Mower-Harwood Co., and Cherry Bros., Cedar Rapids, Ia.; Creamery Package Co., Waterloo Cream Separator Co., and Iowa Separator Co., Waterloo, Ia.; Vermont Farm Machine Co., Bellows Falls, Vt.; Jensen Mfg. Co., Topeka, Kans.; Ox Fiber Brush Co., Davis Cream Separator Co., Borden \& Selleck Co., and De Laval Separator Co., Chicago, Ill.; Wagner Glass Works, and J. H. Monrad, New York, N. Y.; Burrell \& Co., Little Falls, N. Y.; Empire Cream Separator Co., Bloomfield. N. J.; Dairy Queen Mfg. Co., Flora, Ind.; Dairy Record, St. Paul, Minn., and W. D. Hoard, Fort Atkinson, Wis.
G. L. McKay.
C. Larsen. 


\section{CONTENTS.}

\section{CHAPTER I.}

Composition of Milk

1. Definition of Milk............................ 1

2. Composition of Milk......................... 2

3. Variation of Total Solids......................... 3

4. Water................................... 4

5. Fat in Milk. ................................. 5

6. Properties of Fat. . . . . . . . . . . . . . . . . . . . . . 7

7. Glycerides of Fat........................... 8

8. Theories in Regard to Films Enveloping Fat-globules........ 9

9. Classes of Fats. . ............................ 10

A. Volatile............................. 11

B. Non-rolatile........................... 12

10. Composition of Butter-fat...................... 13

11. Casein................................. 15

12. Albumen.............................. 16

13. Sugar. $\ldots \ldots \ldots \ldots \ldots \ldots \ldots \ldots \ldots \ldots \ldots \ldots \ldots \ldots \ldots \ldots \ldots, 16$

14. Ash. ................................... 18

15. Gases or Taints of Milk. ....................... 18

16 Coloring Matter. . ............................ 20

17. Other Constituents of Milk....................... 20

\section{CHAPTER II.}

Milk Secretron................................... 22

1. Mammary Gland as a Secretory Organ ................. 22

2. Internal Structure of Cow's Udder.................. 22

3. Theories of Milk Secretion. . ..................... 25

4. Conditions Affecting Secretion of Milk................ 28

5. External Appearance of Udder.................... 29

6. Milk-fever.............................. 30 
Properties of Milk........................... 31

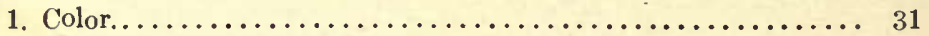

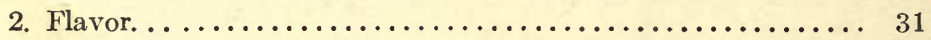

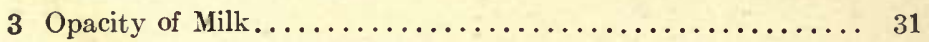

4. Chemical Reaction of Milk. .................. 32

5. Specific Gravity of Milk. . ................. 32

6. Natural Separation of Milk and Cream............ 35

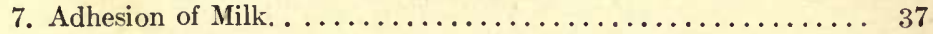

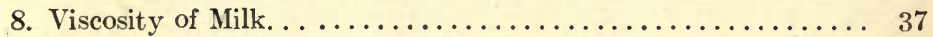

9. Specific Heat of Milk. .................... 38

10. Effect of High Heat on Properties of Milk. . . . . . . . . 38

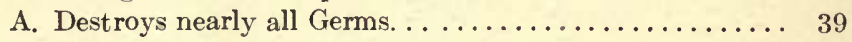

B. Diminishes Viscosity or Body. . . . . . . . . . . 39

C. Drives off Gases.................... 40

D. Imparts a Cooked Taste................ 40

E. Precipitates Albuminoid and Ash Contents......... 41

F. Destroys Properties of Enzymes. ............ 41

G. Divides the Fat-globules. ............... 42

H. Caramelizes the Sugar. ............... 42

I. General Remarks................... 43

\section{CHAPTER IV.}

Ferments in Milk. ......................... 44

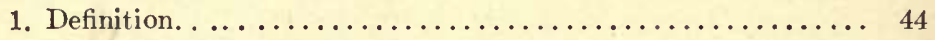

2. Size and Shape of Bacteria............... 45

3. Favorable Conditions for Bacterial Growth........... 45

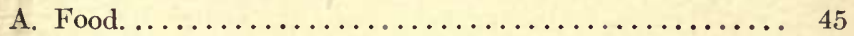

B. Temperature...................... 46

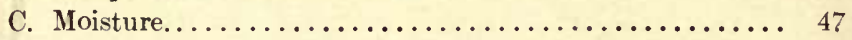

4. Unfavorable Conditions for Bacterial Growth........... 48

5. Kind of Germ Found in Milk. ................ 49

6. Number of Bacteria in Milk. .................. 51

7. Sources of Bacteria in Milk. . . . . . . . . . . . . 52

8. Effect of Thunder-storms on Souring Milk .......... 53

\section{CHAPTER V.}

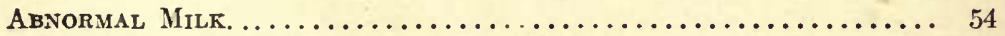

1. Colost rum Milk. ...................... 54

2. Salty Milk........................ 55

3. Bloody or Red Milk. ...................... 56

4 Blue Milk............................... 57 
5. Yellow Milk............................ 57

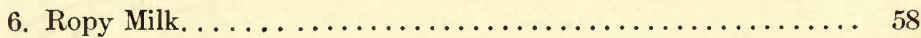

7. Bitter Milk. ........................ 58

8. Milk from Cows which have been in Milk a Long Period. . . . . 60

9. Milk from Spayed Cows. . .................. 61

10. Milk from Sick Cows...................... 62

CHAPTER VI.

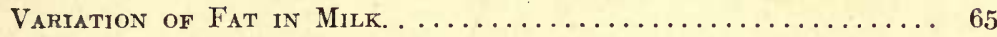

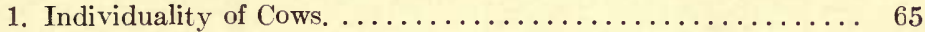

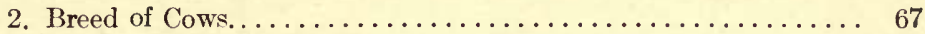

3. Time between Milkings. ................... 68

4. Manner of Milking. ..................... 70

5. Milking-machines. . ................... $71 a$

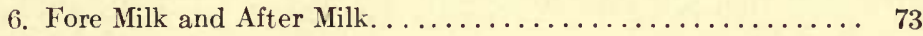

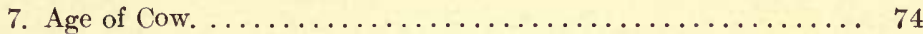

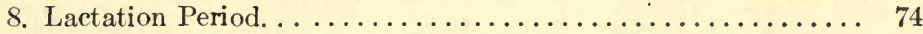

9. Food of Cows. .............................. 75

10. Environmental Conditions. .................. 76

\section{CHAPTER VII.}

Receiving, Sampling, and Grading Milk and Cream......... 77

1. Receiving and Grading of Milk and Cream............ 77

A. Detection of Abnormal Milk Through the Senses...... 79

B. Use of Acid Tests..................... 80

C. Use of Fermentation Tests. ................ 81

a. Gerber and Wisconsin Curd Tests........... 81

D. Grading Milk by Heating. ............... 82

E. Use of Babcock Test and Lactometer. .......... 84

2. Necessity of Good Milk. . . . . . . . . . . . . . . . . 89

3. Sampling of Milk. ...................... 93

4. Sampling-tube. . ......................... 94

5. Sampling Churned Milk..................... 96

6. Frozen Milk. ................................ 96

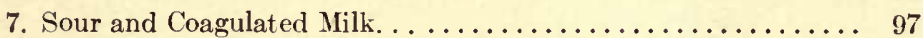

8. Apportioning Skimmed Milk. . ................ 97

CHAPTER VIII.

Compostte Samples. .......................... 99

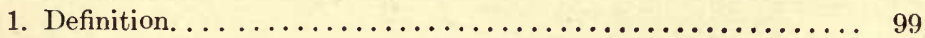

2. When to Sample................................ 99 
$e$. Proper Utilization of Steam Turned into the Pasteurizer. . ................... 182

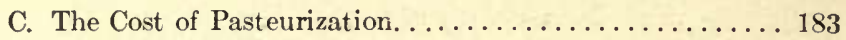

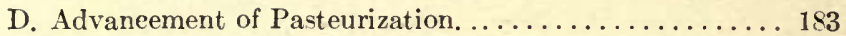

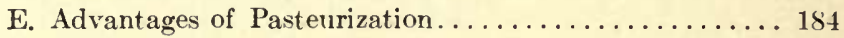

F. Disadvantages of Pasteurization. ............ 186

\section{CHAPTER XIV.}

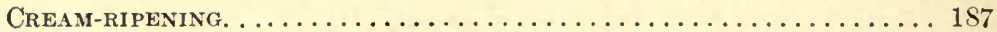

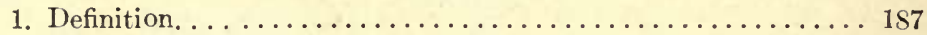

2. Objects of Cream-ripening. . . . . . . . . . . . . .

A. Produetion of Flavor and Aroma. . . . . . . . . 187

B. Inereases the Churnability of Cream. . . . . . . . . 191

C. Inereases the Keeping Quality of Butter. . . . . . . . 192

3. Ripening Temperature of Crcam. ................. 194

4. Amount of Starter to Add to Cream. . . . . . . . . . . 196

5. Stirring of Cream during Ripening. . . . . . . . . . . 197

6. Natural Ripening. . . . . . . . . . . . . . . . . . . 198

7. Artifieial Ripening. ....................... 199

8. Ripening Cream when Chuming is Done Every Other Day. . . . 201

9. Mixing of Cream. ... . . . . . . . . . . . . . . . 202

A. Quality of Cream..................... 203

B. Kind of Market. . . . . . . . . . . . . . . 204

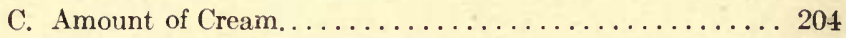

D. General Creamery Conditions.............. 205

10. Examining and Testing Cream for Acidity during Ripening. . . 205

11. Mann's Test. . . . . . . . . . . . . . . . . . . . . . 206

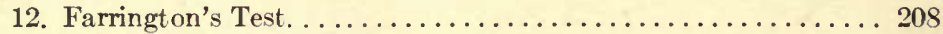

13. Amount of Aeid to Develop. ..................... 208

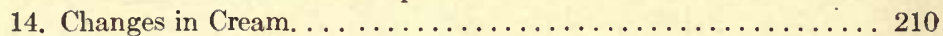

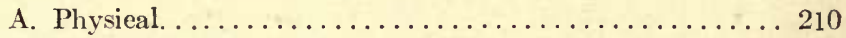

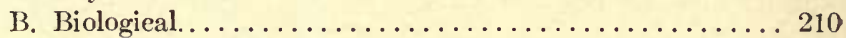

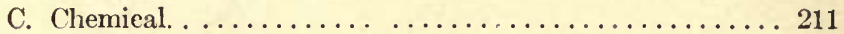

\section{CHAPTER XV.}

Starters. . . . . . . . . . . . 216

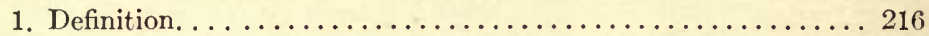

2. History. . . . . . . . . . . . . . . . . . . . . . 216

3. Classifieation of Starters. . . . . . . . . . . . . . 216

4. Preparation of Natural Starters.................. 217

5. Commereial Starters or Pure Cultures. . . . . . . . . . . . 217

6. Preparation of Commereial Starters.............. 218

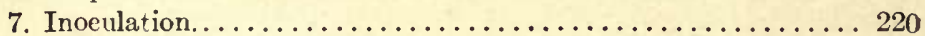


8. Length of Time a Starter Can be Carried............. 222

9. Poor Starters. . . . . . . . . . . . . . . . . . . 223

10. Under-ripening and Over-ripening of Starters. . . . . . . 223

11. Amount of Starter to Use..................... 224

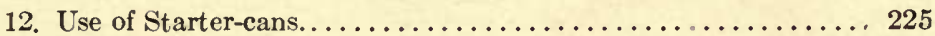

\section{CHAPTER XVI.}

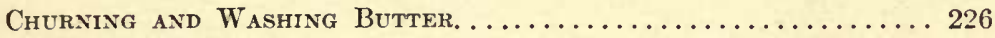

1. Definition . . . . . . . . . . . . . . . . . . . . 226

2. Conditions Affecting the Churnability of Cream......... 227

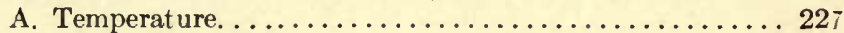

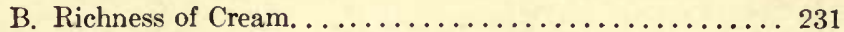

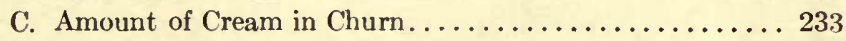

D. Degree of Ripeness. . . . . . . . . . . . . . 234

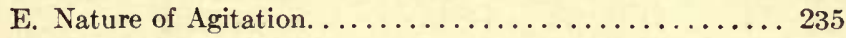

F. Size of Fat-globules . . . . . . . . . . . . . 236

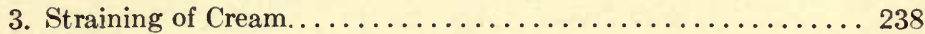

4. Color. . . . . . . . . . . . . . . . . . . . . . . . . . 238

5. When to Stop the Churning Process. ............... 239

6. Churning Mixed, Sweet, and Sour Cream. . . . . . . . 243

7. Difficult Chuming. . . . . . . . . . . . . . . . 243

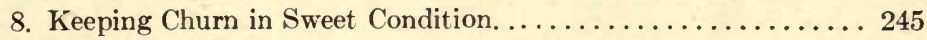

9. Washing of Butter. ....................... 247

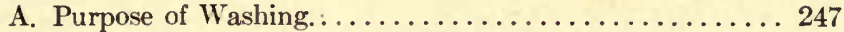

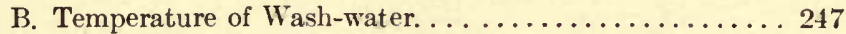

C. Kind of Wash-water to Use. .............. 248

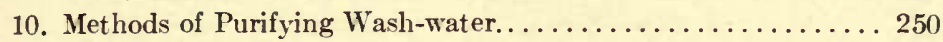

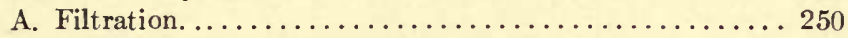

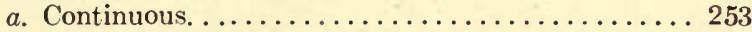

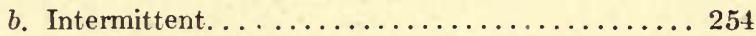

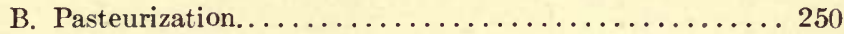

11. Advantages of Purification of Wash-water. . . . . . . . . . 255

\section{CHAPTER XVII.}

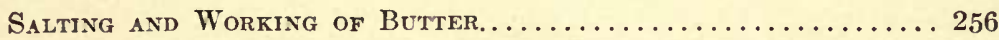

1. Amount of Salt to Use to Produce Proper Flavor......... 256

2. Effects of Salt upon Keeping Properties. . . . . . . . . . 258

3. Salt Facilitates the Removal of Buttermilk. ............ 259

4. Salt in Relation to Water in Butter. . .............. 259

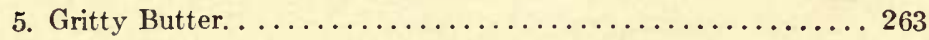

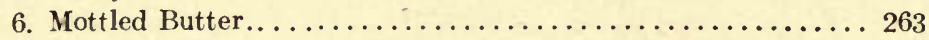

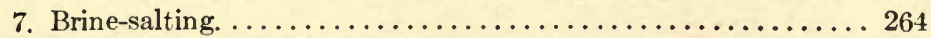

8. Objects of Working Butter................. 266 


\section{CHAPTER XVIII.}

1 Kind of Pack ange to Use. ..................... 269

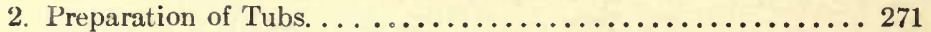

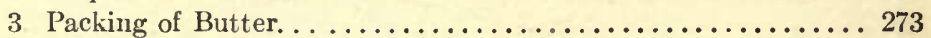

4. Packing Butter for Exhibition Purposes. ............. 275

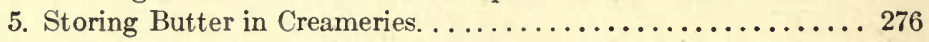

6. Cost of Producing One Pound of Butter. ................ 278

\section{CHAPTER XIX.}

Composition of Butter. ......................... 281

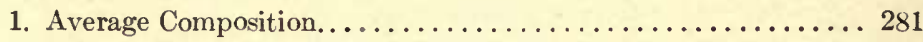

2. Effect of Composition of Butter on Quality. . .......... 281

A. Curd and Sugar. . . . . . . . . . . . . . . . 282

B. Salt. ................................. 282

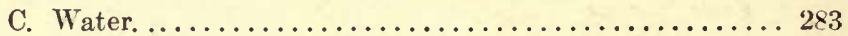

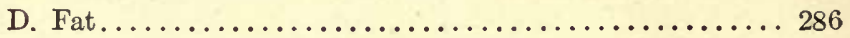

\section{CHAPTER XX.}

Jedging and Grading Butter. . . . . . . . . . . . . . . . . 287

1. Standard for Judging. . . . . . . . . . . . . . . 287

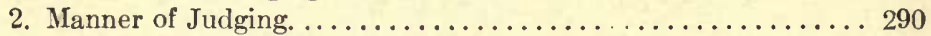

A. Body. . . . . . . . . . . . . . . . . . . 290

B. Flavor. . . . . . . . . . . . 290

C. Color. . . . . . . . . . . . . . . . . . . . . 291

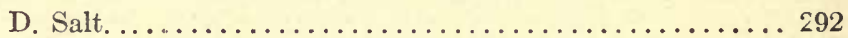

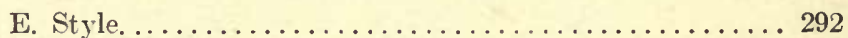

3. Classification of Butter. . . . . . . . . . . . . . . 292

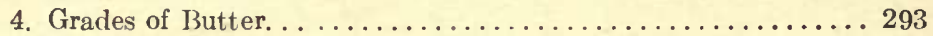

5. Export Butter......................... 307

\section{CHAPTER XXII.}

Cooling Factlities for Creaneries .................. 309

1. Cooling Systems...... . . . . . . . . . . . . 309

2. Natural Ice-system. . . . . . . . . . . . . . . . 312

A. Kind of Ice-house . . . . . . . . . . 312

B. Size and Shape of Ice-house ............. 316

C. Filling the Ice-house . . . . . . . . . . . . . . . 319

D. Source of Ice . . . . . . . . . . . . . . 321

3. Usage of Ice in Cooling Cream................... 321

A. Directly.

B. Indirectly 


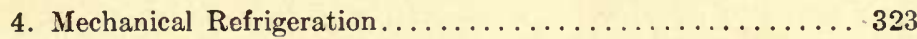

A. Application of, in Creameries............ 323

B. Chemicals Used for Mechanical Refrigeration....... 324

C. Principles of Producing Cold Artificially .......... 324

a. Compression.

$b$. Condensation.

c. Expansion.

D. Transferring the Cold

\section{CHAPTER XXII.}

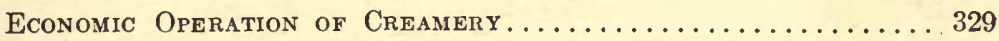

1. Firing the Boiler..................... 329

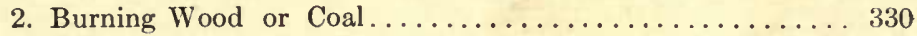

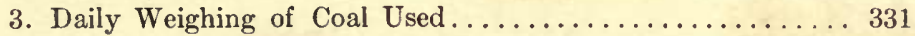

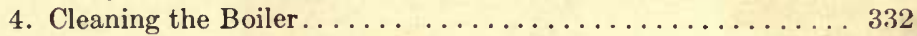

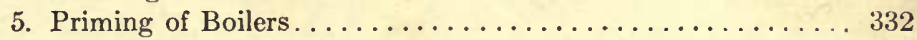

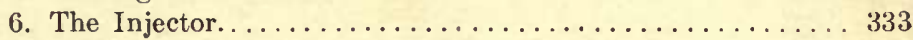

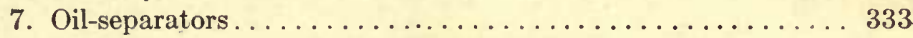

8. Belts, Pulley, and Speed Calculation.............. 334

\section{APPENDIX.}

I. Legal Standards for Milk-Dairy Laws............. 335

II. Metric System of Weights and Measures with Tables for Converting them into Customary United States Equivalents and the Reverse................ 336 



\section{BU'TTER-MAKING.}

\section{CHAPTER I. \\ COMPOSITION OF MIIK.}

Definition.-Normal milk is a liquid secreted in special glands of all females belonging to the mammalian group. It is composed chiefly of water, proteids, fats, sugar, and minerals. Coloring-matters and gases and some organic acids are found in small quantities.

All normal milk from the different classes of animals, such as mare, buffalo, goat, ewe, ass, and cow, has a general resemblance in that it all contains water, fat, proteids, sugar, and ash. But milk from different animals varies in the relative proportions of its constituents. The chemical and physical properties are not alike. Human milk, when treated with half its volume of ammonium hydrate and the mixture kept at a temperature of $60^{\circ}$ centigrade for about twenty minutes, assumes an intense red color. Cow's milk turns faintly yellow if treated in the same way. This test was reported by Unikoff, of St. Petersburg, at the meeting of the Medical Section, Royal Academy of Medicine, in Ireland. The various kinds of milk also differ from each other in their behavior towards rennet. Richmond has divided milk into two classes: Class I includes milk from the ewe, buffalo, goat, and cow. When rennet is added to the milk from these animals, the casein coagulates into a firm curd. Class II includes human milk, milk of the ass, and mare. When rennet is added to the milk of these animals, a soft curd or none at all is formed. The latter class seems 
to include the animals without horns, while the first includes those with horns.

As the cow's milk is used chiefly as a food, it has been subjected to more extended and more careful investigation than the milk of other animals, and, as a consequence, more definite knowledge has been obtained concerning its composition, properties, and uses. The succeeding discussions have reference to cow's milk, if not otherwise stated.

Composition of Milk.-It is impossible to get accurate figures on the composition of milk, as each of the milk constituents is subject to fluctuation from various conditions, such as individuality of cow, breed, season of the year, lactation period, milking, and environment.

The average composition, as determined by 200,000 analyses reported by Richmond as follows:

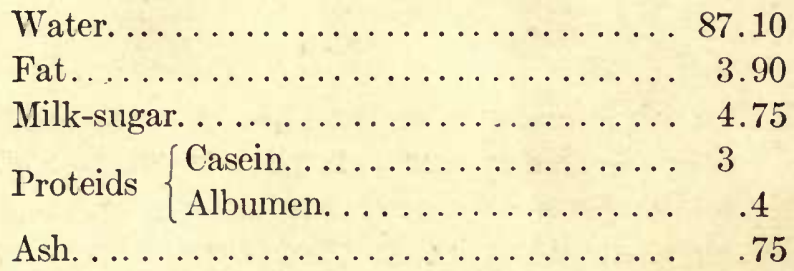

The composition of various kinds of milk is given by König as follows:

\begin{tabular}{|c|c|c|c|c|c|c|c|}
\hline & $\begin{array}{l}\text { No. of } \\
\text { Analy- } \\
\text { ses. }\end{array}$ & Water. & Fat. & $\begin{array}{c}\text { Casein } \\
\text { and } \\
\text { Albumen. }\end{array}$ & $\begin{array}{l}\text { Milk- } \\
\text { sugar. }\end{array}$ & Ash. & $\begin{array}{l}\text { Specific } \\
\text { Gravity. }\end{array}$ \\
\hline Human. & 107 & 87.41 & 3.78 & 2.29 & 6.21 & .31 & 1.0270 \\
\hline Mare. & 50 & 90.78 & 1. 21 & 1.99 & 5.67 & .35 & 1.0347 \\
\hline Buffalo... & 8 & 82.25 & 7.51 & 5.05 & 4.44 & .75 & 1.0350 \\
\hline Ass............ & 7 & 89.64 & 1.64 & 2.22 & 5.99 & .51 & 1.0345 \\
\hline Cow. & 793 & 87.17 & 3.69 & 3.55 & 4.88 & .71 & 1.0316 \\
\hline Ewe. . & 32 & 80.82 & 6.86 & 6.52 & 4.91 & .89 & 1.0341 \\
\hline Goat. & 38 & 85.71 & 4.78 & 4.29 & 4.46 & .76 & 1.0328 \\
\hline Sow & 8 & 84.04 & 4.55 & 7.23 & 3.23 & 1.05 & 1.038 \\
\hline Bitch. & 28 & 75.44 & 9.57 & 11.17 & 3.09 & .73 & 1.035 \\
\hline Elephant. & 3 & 79.30 & 9.10 & 2.51 & 8.59 & .50 & 1.0313 \\
\hline Hippopotamus. & 1 & 90.43 & 4.51 & $\ldots \ldots$ & 4.40 & .11 & \\
\hline Camel. . & 3 & 86.57 & 3.07 & 4 & 5.59 & .77 & 1.042 \\
\hline Llama. . & 3 & 86.55 & 3.15 & 3.90 & 5.60 & .80 & 1.034 \\
\hline
\end{tabular}


Variation of Total Solids.-As applied to milk, "Total Solids," is a term that includes fat, casein, albumen, sugar, and ash; in other words, all the milk constituents except the water. "Solids Not Fat" is a term often used, and includes the casein, albumen, sugar, and ash, or all the milk constituents except water and fat. "Serum" is a term used to designate all the milk constituents except the fat. The fat is the most valuable constituent of the total solids. The variation in the total solids of milk during the summer months is shown in the table quoted below from Dr. Van Slyke of Geneva, New York:

\begin{tabular}{|c|c|c|}
\hline Month. & $\begin{array}{l}\text { Per Cent } \\
\text { of Water. }\end{array}$ & $\begin{array}{l}\text { Per Cent of } \\
\text { Total Solids }\end{array}$ \\
\hline May. . . & 87.44 & 12.56 \\
\hline June....... & 87.31 & 12.69 \\
\hline July. . . . . . . & 87.52 & 12.48 \\
\hline August. . . . . & 87.37 & 12.63 \\
\hline September. . . . . . . & 87 & 13 \\
\hline October. .......... & 86.55 & 13.45 \\
\hline
\end{tabular}

Dr. Van Slyke also studied the effect of the lactation period upon the total solids in milk. A herd of fifty cows, calving in different months of the year, was used in the experiment. The per cent of total solids of this herd seems to average a little high all through the ten months. The total solids were found to be $14 \%$ during the first month, decreasing to $13.47 \%$ during the next two months, then gradually increasing with the advance of the lactation period. In the tenth month the average total solids was $14.83 \%$. Pingree, of Pennsylvania, reports having found normal millk from a cow, which contained $17.01 \%$ total solids. Sherman * reports a very high average total of the milk solids. He treated the milk from thirteen cows, and found it to contain on an average $18.03 \%$ of total solids. König reports a minimum of total solids of $9.31 \%$, a maximum of $19.68 \%$, and an average of $12.83 \%$. The average total solids quoted above from Richmond is $12.90 \%$, which agrees closely with König's results. 
The difference in total solids of milk from some of the leading breeds has also been studied by Dr. Van Slyke, and the results are as follows:

\begin{tabular}{|c|c|c|}
\hline Breed. & $\begin{array}{l}\text { Per Cent } \\
\text { of Water. }\end{array}$ & $\begin{array}{l}\text { Per Cent of } \\
\text { Total Solids. }\end{array}$ \\
\hline Holstein. & 88.20 & 11.80 \\
\hline Ayrshire. ........ & 87.25 & 12.75 . \\
\hline Shorthorn. . .. & 85.70 & 14.30 \\
\hline Devon.......... & 85.50 & 14.50 \\
\hline Guernsey......... & 85.10 & 14.90 \\
\hline Jersey. . . . . . . . & 84.60 & 15.40 \\
\hline
\end{tabular}

The maximum and minimum amounts of total solids mentioned above are abnormal cases. The normal variations of the solids in milk are within comparatively narrow limits. For this reason the minimum standard for total milk solids, in states where dairy laws are in force, is fixed by law. Usually $12 \%$ is the minimum.

Water.-From what has been said above concerning the total milk solids, it will be seen that water constitutes by far the largest portion of milk. It is quite uniform, and in milk from a mixed herd the water seldom falls below $86 \%$ and seldom exceeds $88 \%$. Variations ranging from a little less than $80 \%$ to a trifle over $90 \%$ are on record. But such variations must be looked upon as occurring in only a very few special cases.

It has often been asserted that cows in the spring of the year, when they are pasturing on new grass, or feeding on other succulent foods, yield milk which contains an excess of water. Under such conditions there is a tendency for cows to produce milk with a water content a trifle higher, as has already been shown by the figures quoted from Dr Van Slyke. As a rule this is much overestimated. It is even a common occurrence to hear creamery operators say that their "soft" or "slushy" butter, in the early spring, is due to the excess of the water present in the milk. This particular phase will be discussed further under the heading of "Fats in Milk."

The question has often been raised: Is the water in milk 
the same, or any more valuable than water obtained from other natural sources? The water in milk, so far as known, is transuded from the blood-vessels in the udder into the milk glands. It is so perfectly mixed with the other milk constituents, and holds the milk solids in such perfect emulsion and solution that it would seemingly be impossible to prepare milk so perfectly by artificial means. However, a substance is prepared by Jacob C. Van Marken, Neuweid, Germany, which, when added to water, produces a substance similar in appearance to watered skimmed milk. The preparation is named "Kalberrahm Vita." The first name literally means calf-cream. It has a syrupy consistency, and in appearance resembles light-brownish molasses. It is sold in tin cans, and recommended highly for calf-feeding when mixed with skimmed milk. When mixed with water, it is recommended highly for hog-feeding.

Water distilled from milk has the same appearance as ordinary distilled water. It is clear and colorless. The chenical reaction when phenolphthalein is used as an indicator, is neutral, the same as that of ordinary distilled water, even when distilled from milk in which acid las developed. But there is a considerable difference in the taste and smell. This indicates that some of the volatile substances are distilled over with the water. The probability is that these flavoring substances are so closely associated with water in milk that they are inseparable, and that the only place where this water can be prepared so as to assume these qualities is in the cow's udder. The conclusion would then be that the water in normal cow's milk cannot be distilled and substituted again by natural water and the product retain its normal good flavor.

\section{Fat in Milk.}

This is by far the most important constituent of milk, especially to creamery operators. It exists in the milk in suspension, in the form of globules so small as to be invisible to the naked eye. According to the best authorities, fat- 
globules, at ordinary living-room temperature, are present in milk in a liquid form. Cooling the milk to a very low tem-

o. Sklm milk.

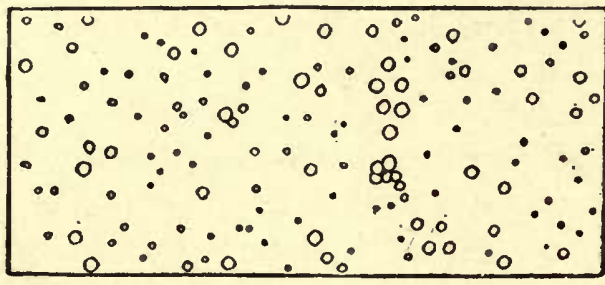

B. Milk.

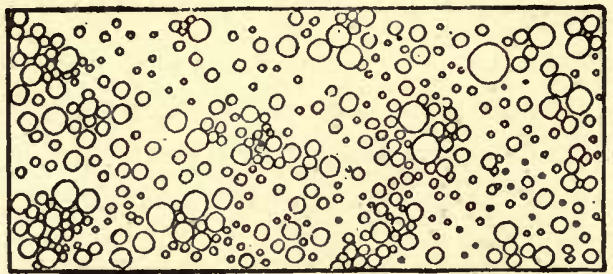

c. Cream.

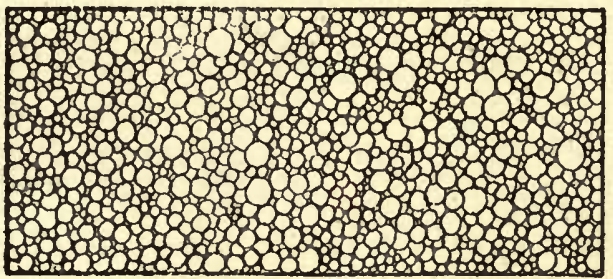

d. Colostrum.

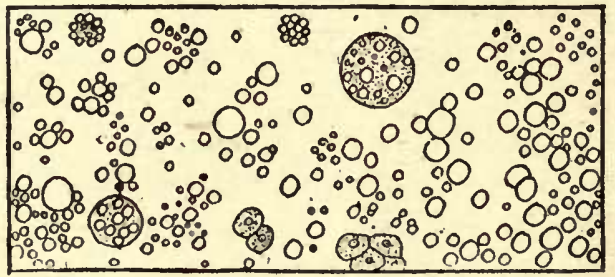

Fig. 1.-Microscopical appearance of different kinds of milk. Magnified 300 times. (U. S. Farmers' Bul. No. 42.)

perature (about $50^{\circ} \mathrm{F}$.) hardens them. When the globules are caused to unite, as in churning, they also solidify.

The size of the fat-globules is very minute, and varies con- 
siderably, according to breeds, individual cows, and the stage in the lactation period. The globules in the milk from the same cow also vary a great deal. Lloyd found that fat-globules in Jersey milk to be from 8 to 12 micro-millimeters in diameter. Very few were less than 4 micro-millimeters (a micro-millimeter is $\frac{1}{1000}$ millimeter, or $\frac{2}{2} \frac{1}{0} \bar{\sigma} \overline{0}$ of an inch). The majority of the fat-globules in milk from Shorthorn cows measured from 6 to 8 micro-millimeters in diameter. According to Fleischmann, the size of fat-globules varies between 1.6 micro-millimeters and 10 micro-millimeters in diameter. A Danish investigator maintains that the diameter of fat-globules is between .0063 and .00014 millimeters, and that 1 cubic centimeter of milk contains from 2.6 to 11.7 million globules. He also asserts that a reflection of the light renders it very difficult to get the proper size of the fat-globules, as the light tends to make the globules appear larger than they are in reality.

It has been maintained by some that the larger fat-globules contain fats which are different from those contained in the smaller globules. But this is by some investigators considered to be a matter of conjecture. Most authorities now believe that there is no difference in the kinds of fat of the differentsized globules, even though some experiments * show that fat composed of larger globules has a finer flavor, and a little more oily appearance.

From what has been said, it will be seen that the minuteness of the fat-globules is almost inconceivable. They were first discovered in 1697 by $\mathrm{A}$. von Leeuwenhock. The minute state of division, or the form of emulsion in which they exist in milk, renders it easy to digest when consumed as a food.

Properties of Fat.-The specific gravity of pure butter-fat at $15^{\circ}$ centigrade is .93002 . The refractive index of butterfat at $22^{\circ}$ centigrade is on an average 1.459. The meltingpoint of pure butter-fat, as now determined, varies between $32^{\circ}$ and $37^{\circ}$ centigrade. $\left(90^{\circ} \mathrm{F}\right.$. and $99^{\circ} \mathrm{F}$.

* Gembloux, Belgium, Creamery Jo., London, No. 8, Vol. I. 
When pure butter-fat is rapidly cooled, it solidifies into one solid mass; but if allowed to cool gradually, part of it solidifies, and part of it remains a liquid longer than other parts. This seems to indicate that some fats with a high melting-point separate out from the fats with a low melting-point. This behavior of pure butter-fat is not well understood, as it contradicts the now accepted theory that the different fats are in chemical combination with each other, rather than a mechanical mixture of different glycerides of fat.

Glycerides of Fat.-By this term we understand that the fatty acid radicals are in chemical combination with the glycerol (glycerine) radical, thus:

Fatty acid radicals.

$$
\begin{aligned}
& \text { Glycerol radical. } \mathrm{C}_{4} \mathrm{H}_{7} \mathrm{O}_{2} \text { (Butyric) } \\
& \mathrm{C}_{3} \mathrm{H}_{5} \quad \mathrm{C}_{18} \mathrm{H}_{33} \mathrm{O}_{2} \text { (Oleic) } \\
& \mathrm{C}_{18} \mathrm{H}_{33} \mathrm{O}_{2} \text { (Stearic) }
\end{aligned}
$$

The chemical formula for glycerine is:

Glycerol radical. $\mathrm{C}_{3} \mathrm{H}_{5}\left\{\begin{array}{c}\text { Hydroxyl groups. } \\ \mathrm{OH} \\ \mathrm{OH} \\ \mathrm{OH}\end{array}\right.$

Comparing these two formulas, their difference and similarity are easily observed, and the reason why the term "Glyceride of Fat" has been applied to such a compound is evident.

Condition of Fat.- Whether the fats in milk exist in chemical combination, or whether they exist as glyceride of butyrin, stearin, olein, etc., in the form of a mechanical mixture, is a question in dispute. If they exist in the latter form, the composition of the different fats must be thus:
Butyrin.
Olein.
$\mathrm{C}_{3} \mathrm{H}_{5}\left\{\begin{array}{l}\mathrm{C}_{4} \mathrm{H}_{7} \mathrm{O}_{2} \\ \mathrm{C}_{4} \mathrm{H}_{7} \mathrm{O}_{2} \\ \mathrm{C}_{4} \mathrm{H}_{7} \mathrm{O}_{2}\end{array}\right.$
$\mathrm{C}_{3} \mathrm{H}_{5}\left\{\begin{array}{l}\mathrm{C}_{18} \mathrm{H}_{33} \mathrm{O}_{2} \\ \mathrm{C}_{18} \mathrm{H}_{33} \mathrm{O}_{2} \\ \mathrm{C}_{18} \mathrm{H}_{33} \mathrm{O}_{2}\end{array}\right.$
Stearin.
$\mathrm{C}_{3} \mathrm{H}_{5}\left\{\begin{array}{l}\mathrm{C}_{18} \mathrm{H}_{35} \mathrm{O}_{2} \\ \mathrm{C}_{18} \mathrm{H}_{35} \mathrm{O}_{2} \\ \mathrm{C}_{18} \mathrm{H}_{35} \mathrm{O}_{2}\end{array}\right.$ etc. 
and the total fat made up of a mechanical mixture of these and the remainder of the fats in butter-fat.

Richmond and other authors believe that fat probably exists in milk chemically, as first mentioned and illustrated; because, if the fat were a mixture of glycerine tributyrate with other glycerides of fat, butyrin or glycerol tributyrate could be dissolved out by the use of alcohol. But this is not the case. Moreover, if butyrin existed separately in milk, it would be possible to distill it off under reduced pressure. This cannot be done.

Theory in Regard to Films Enveloping Fat-globules.-The extreme minuteness of the fat-globules in milk renders it almost impossible to determine by direct microscopical observation whether there is a membrane around each globule or not. Fleischmann and Lloyd assert that, so far as they were able to detect, there is no real membrane surrounding each globule.

The theory generally accepted in the past was that the only film surrounding the fat-globules was simply due to surface tension, or to the fact that the molecules of the fat have a greater attraction for themselves than they have for the molecules of the serum, in which they are held in suspension. In support of this two things are considered:

(1) The natural milk-fat may be removed from milk and artificial fat substituted in its place. The resultant milk has characteristics similar to milk containing normal fat; that is, the emulsion which milk forms with the artificial fat is apparently like that formed with the natural fat.

(2) If there were a special albuminous membrane around each fat-globule, cream should contain a higher percentage of albuminoids than milk. This, Richmond maintains, is not so.

Dr. Storch concludes from extensive researches that there is a gelatinous membrane enveloping the fat-globules. His conclusions are based mainly upon the first three reasons given below. The other facts mentioned also support his conclusions:

(1) When milk has been stained with ammoniacal picro- 
carmine, and the cream washed with water until it is free from milk-sugar, a stained layer is present around each globule.

(2) He has succeeded in isolating this gelatinous substance from cream and butter. Owing to its existence in these two substances, he assumes that it is also present in milk.

(3) When ether is added to milk, the fat globules dissolve with difficulty, unless some alkali is added to the milk first.

(4) Bichamp maintains that when ether is added to milk the fat-globules are enlarged due to the ether passing through the supposed membrane by the process of osmosis. He considers this fact sufficient to prove that there is a membrane encircling each globule.

(5) Butter containing 85 to $86 \%$ fat is asserted by Richmond to have the same consistency as cream containing about $72 \%$ fat at the same temperature. The solidity of butter is due to the close proximity of the fat-globules. Now, if cream with less fat has the same consistency as butter, the proximity of the fat-globules must be equal to that of the butter; this would indicate that there is a membrane and that this membrane increases the size of the fat-globules.

(6) The fact that cream separated by centrifugal force is more easily churned than crearn of same richness separated by gravity methods, would also be explained if the fat globules in milk had such a membrane surrounding them.

This membrane, or what is believed to be a membrane, Storch has isolated and analyzed. He finds it to consist of $94 \%$ of water and $6 \%$ of proteid.

The reasons deduced by Storch are strong; and the behavior of cream and butter renders it probable that there is such a membrane enveloping each globule of fat.

\section{Classes of Fats.}

There are two great classes or groups of fats present in the butter, namely:

(1) Volatile and Soluble,

(2) Non-volatile and Insoluble. 
It was previously stated that little is known concerning the way in which the fatty acids are combined with glycerine in the milk; but, for the sake of convenience, the fats will be referred to as if they exist as separate glycerides of fat.

The terms "Volatile" and "Non-volatile" are applied to the glycerides of fat, or to the fats as they exist in butter. Strictly speaking, this is not proper, as they do not assume the volatile characteristics until the glycerine separates from the fatty acids; it is only then that the latter becomes volatile.

Volatile Fats.-The first group, or the volatile fats, include butyrin, caproin, caprylin, caprin, and laurin. Butyrin is the one present in the largest proportion. Laurin and caprin are partially non-volatile. Butyrin is the most important fat belonging to the volatile group. It is the most important quantitatively, and also qualitatively. So far as is known, butyrin is the least stable of any of the butter-fats. Under normal conditions, so long as the fatty acid remains in combination with the glycerol, it is not volatile nor soluble in water but as soon as separation takes place, due to the action of micro-organisms, or to the effect of light and air, then it becomes volatile, and escapes in the form of gas. According to the mass of evidence, these factors are the chief causes of rancidity in butter.

It is also claimed that these volatile fats have the special properties of absorbing odors and gases to a greater extent than any of the other fats. This absorption takes place when fat comes into contact with the undesirable taints. For this reason it is essential that milk, cream, or butter be kept away from any foreign undesirable odors. These undesirable taints may also be imparted to the fat before the milk is drawn. If the cow is fed on undesirable food such as turnips, onions, garlic, etc., the milk from the cow assumes undesirable characteristic flavors, which can-easily be recognized in the finished product. On the other hand, such foods as well-cured sweetclover hay, and bran, seem to impart desirable flavors to milk and butter. 
The presence of these volatile fats in butter is quite uniform, and is a distinguishing feature of pure butter-fat. The detection of adulteration of butter with foreign fats is based chiefly upon the presence of these volatile fats. The characteristic desirable flavor of butter is also believed to be due to the presence of the volatile fats. The volatile fats vary but slightly during the different seasons of the year. They are present in the greatest proportion during the spring and early summer months, when cows are fed on grass, and also during the early stage of the period of lactation. They decrease gradualiy as the lactation period advances.

About $8 \%$ of the total fats in milk is volatile fats.

Non-volatile Fats.-This group constitutes about $92 \%$ of the total fats in butter. Chemists now agree that palmitin, stearin, olein, and myristin are the most important ones to be considered, as will be seen from the table quoted from Richmond.

These non-volatile fats are of special importance, as the relative amount of each of these fats largely causes the variation in the hardness and softness of the butter and butter-fat. The melting-point of these different fats varies according to the different investigators: olein is a liquid at ordinary temperature and melts at about $41^{\circ} \mathrm{F}$; stearin, on the other hand, has a melting-point of about $150^{\circ} \mathrm{F}$; p palmitin also has a high melting-point, namely, about $142^{\circ} \mathrm{F}$; myristin melts at about $129^{\circ} \mathrm{F}$.

Olein has been found to be present in the greatest proportion during the spring, when cows are fed on grass. When cows are fed on normal dry food, as in the winter time, it is present in a much less degree. This, together with the small increase of volatile fats, is the cause of the softer butter so frequent in the spring. The hardness of the butter in the fall or winter is due chiefly to the presence of a slightly increased amount of the fats, with a high melting-point, as mentioned above:

From what has been said above, one is led to believe that, 
by melting a sample of butter which contains these different fats, the fats with a low melting-point would melt first, and leave the remainder in an unmelted condition. Such is not the case. Butter-fat in this respect behaves a good deal like different metals with different fusing-points. When they are melted and mixed together, cooled and then remelted again, they assume a common melting-point. It is the same way with butter-fat. It melts at a temperature of $91^{\circ}$ to $96^{\circ} \mathrm{F}$.

As the body temperature of cows (about $101^{\circ} \mathrm{F}$.) is above this temperature, the fat globules are present in the milk in liquid form when milk is first drawn. A peculiarity about these fat-globules in milk is that the milk and fat may be cooled down below the melting-point of the fat of butter without the fat-globules in milk being solidified. It requires a temperature of between $60^{\circ}$ and $78^{\circ} \mathrm{F}$. before the fat-globules in milk begin to solidify. When these small fat-globules are caused to unite, as during the churning process, they solidify at higher temperature. This behavior of the fat in milk evidently must be due to a relative change in the position of the molecules of fat during the process of cooling and warming. No definite explanations, so far as is known, have been given for this condition of the fat.

The non-volatile fats found in butter-fat are practically the same as those found in other animal fats.

Composition of Butter-fat.-In his "Dairy Chemistry," Richmond gives the following composition of butter-fat, representing the mean results obtained by different observers:

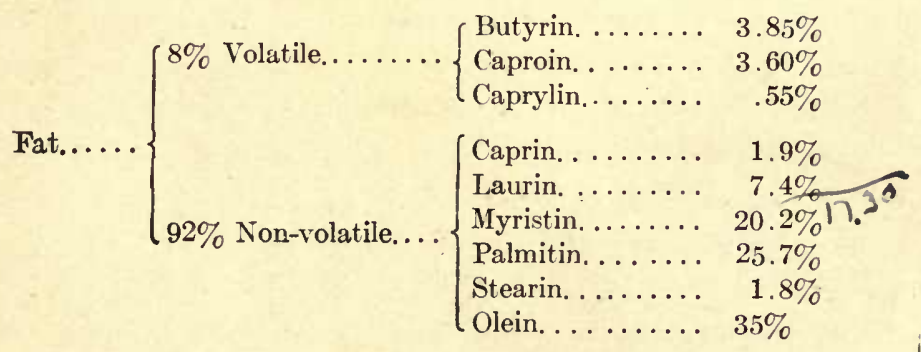


Richmond also gives the percentage of glycerine and fatty acids in each of the different fats, as follows:

\begin{tabular}{|c|c|c|c|c|c|c|c|c|}
\hline Butyrin. & $3.85 \%$ & yieldin & g $3.43 \%$ & fatty & acids & and & $1.17 \%$ & glycerine \\
\hline Caproin. . & 3.60 & . & 3.25 & " & $"$ & 1. & .86 & 16 \\
\hline Caprylin.. . & .55 & " & .51 & “" & 16 & " & .10 & "6 \\
\hline Caprin.... & 1.9 & $" 1$ & 1.77 & " & $" ،$ & " & .31 & "s \\
\hline Laurin. ... & 7.4 & "c & 6.94 & “ & " & 66 & 1.07 & "6 \\
\hline Myristin. . & 20.2 & $" 6$ & 19.14 & “" & "، & " & 2.53 & 66 \\
\hline Palmitin.. & 25.7 & 6 & 24.48 & " & "، & .' & 2.91 & "6 \\
\hline Stearin. ... & 1.8 & "6 & 1.72 & "6 & " & " & .19 & "6 \\
\hline Olein.... & 35 & $" 6$ & 33.60 & "6 & “ & “ & 3.39 & "6 \\
\hline & 100 & & $\overline{94.84}$ & & & & $\overrightarrow{2.53}$ & \\
\hline
\end{tabular}

Proteids (Albuminoids).

The proteids of milk are present partly in solution and partly in suspension. They are present in a very complex chemical form. Some of the chemists reckon as many as eight different albuminoids or proteids in milk. Duclaux claims that there are only two kinds of albuminoids, the coagulable, and non-coagulable casein. He has, by the use of a fine filter, been able to separate the fat and the coagulable from the rest of the serum. The amount of coagulable casein is claimed to vary considerably, and seems to depend upon the amount of lime phosphate present. The filtrate which Duclaux obtained from filtering the milk was clear and colorless, which proves that the removal of the casein was quite complete. In order to remove casein from milk, a special filter (Chamberland) is employed. Owing to this fact, we may consider the casein to be present in suspension or semi-solution. Noted chemists, such as Babcock, Van Slyke, Duclaux, Storch, Hammarsten, Ritthausen, and Richmond, disagree upon the number of albuminoid substances found in milk, and upon the chemical behavior of each.

For all practical purposes it is safe to mention two, namely, (1) casein, and (2) albumen. Those two substances, as all agree, are present in milk, and constitute practically all the 
albuminoids in milk. But after these two have been separated from milk a slight precipitation can be obtained by treating the filtrate with alcohol. This has been called albumose and also lactoglobulin. From this resultant filtrate can again be separated a very small amount of material containing nitrogen. Dr. Babcock has obtained a substance from milk called fibrin. These latter substances, however, are present in minute portions, and are believed by some of the best scientists to be the same as the albumen, and their presence in the filtrate is due to incomplete precipitation of the albumen in the first place.

Casein.-Casein is by far the most important of all of the albuminoids. It is the substance which forms the curd in cheese-making. In fresh milk, as is now understood, it is in chemical combination with lime salts. It is on this account that fresh milk shows the amphoteric reaction, which will be explained under the "Properties of Milk." The coagulation of casein by the addition of rennet or dilute acids is thought to be due to this union between the casein and lime. Fleischmann refers to this as the "caseous matter" of milk. The viscosity of normal milk is believed to be due in a large measure to this condition of casein in milk. It causes the casein to be present in a colloidal condition. When milk coagulates by natural or by artificial means, the union between the casein and lime phospliate is largely broken.

Casein and albumen differ in composition, in that the casein contains phosphorus and less sulphur than does albumen. Fleischmann maintains that a substance called nuclein is associated with casein, and is not found in albumen.

Casein is precipitated by the use of rennet and dilute acids, and coagulates spontaneously, due to the acid formed in the milk. The precipitates formed by the use of different precipitating agents are not alike. The curd coagulated by rennet contains more fat and calcium phosphate than the curd does which is precipitated by dilute acid or soured spontaneously. If milk stands at air temperature for any length 
of time after milking, the caseous matter (or the nitrogenous matter combined with lime) tends to separate. The caseous matter of milk is not completely precipitated by heat, although heat partially destroys the union between the casein and lime. This destroys the action of rennet. Instead of getting a smooth solid coagulum, a more flaky precipitate is obtained. For this reason milk for cheese-making should not be heated to a high temperature. By heating milk in a glass flask to a high temperature, and letting it stand for a time, it will be found that a mineral precipitate has settled to the bottom. This precipitate is believed to be a lime phosphate, which, previous to heating, was combined with the casein of the milk. By adding calcium chloride $\left(\mathrm{CaCl}_{2}\right)$ to milk which has been heated, its normal condition towards the action of rennet is again restored.

Albumen.-If the casein is removed from the milk by precipitation, and then filtered off, the filtrate will contain a 'substance which will precipitate when boiled. This is albumen, and is similar in character to albumen from the white of an egg. It differs from casein in that it is not precipitated by rennet or acids, but precipitates on heating. It does not contain any phosphates, but contains a comparatively large amount of sulphur.

As the albumen is soluble in rennet and dilute acids, it can readily be seen that it is retained in the whey obtained in cheese-making. When albumen is present in small quantities, as it is in normal milk, heating does not completely precipitate it, unless the casein or curd is first removed. If, on the other hand, albumen is present in excess, as is the case in colostrum, the major portion of the albumen is precipitated when heat is applied, without first removing the casein.

Sugar.-Milk-sugar occurs in milk to the extent of about $5 \%$. It varies very little in quantity, seldom falling below $3 \frac{1}{2} \%$ and seldom rising above $5 \frac{1}{2} \%$. It occurs in solution, and is found in no other place in nature.

Milk-sugar is the most unstable component of milk. It 
quickly and easily decomposes. This decomposition is caused by micro-organisms. If these could be entirely excluded from the milk, it would keep for an almost indefinite length of time. As it is impossible under practicable conditions to entirely exclude organisms from the milk, the only way in which the growth of germs can be retarded and prevented, and thereby prevent the changing of the sugar into other products, is to cool the milk to a low temperature $\left(50^{\circ} \mathrm{F}\right.$.), or to heat the milk to a sufficiently high temperature $\left(180^{\circ} \mathrm{F}\right.$.) to destroy most of the germs. According to Van Slyke and Hart, the decomposition of the caseous matter produces free casein. When about .5\% acid has developed in the milk, the free casein combines with the acid and forms casein lactate.

The chemical composition of milk-sugar is $\mathrm{C}_{12} \mathrm{H}_{22} \mathrm{O}_{11}+\mathrm{H}_{2} \mathrm{O}$. When a perfect decomposition of milk-sugar into lactic acid takes place, the following equation would represent the change:

$$
\begin{aligned}
& \text { (Milk-sugar) (Lactic acid) } \\
& \mathrm{C}_{12} \mathrm{H}_{24} \mathrm{O}_{12}=4 \mathrm{C}_{3} \mathrm{H}_{6} \mathrm{O}_{3} \text {. }
\end{aligned}
$$

Such an ideal change, however, never takes place. In such a case, one gram of milk-sugar should produce one gram of lactic acid. In a number of experiments carried on by one of the authors of "The Analysis of Cream During Different Ripening Stages," * the highest amount of acid produced from one gram of milk-sugar was .8 of a gram. This indicates that there are always accompanying by-products produced, besides lactic acid, when milk-sugar is being decomposed in cream or milk. The sourness of milk is due to this change. The by-products which accompany the production of lactic acid are many and various. The most important ones are gases of different kinds, such as carbonic acid gas $\left(\mathrm{CO}_{2}\right)$; marsh gas $\left(\mathrm{CH}_{4}\right)$; hydrogen $(\mathrm{H})$; and nitrogen $(\mathrm{N})$. A

$$
\text { * Thesis I. S. C., Ames, Ia. }
$$


small amount of alcohol, formic, acetic, and succinic acids are said to be normal accompanying by-products also. These by-products may also partially result from the breaking down of some of the other milk components.

As milk-sugar is in perfect solution, it follows the water of milk, and in cheese-making nearly all of it passes into the whey. Commercially and chemically it is prepared from whey. It is a white, not very sweet powder, and is used for medicinal purposes to dilute pure, powerful drugs. It is also used extensively in the preparation of modified milk.

Ash.-The ash of milk is present in very small quantities, and when viewed from such a standpoint it may first seem to be of small importance. On account of the effect of the mineral constituents upon the properties of milk, it is one of the most important components of the milk. It consists partly in solution, and partly in suspension. Babcock maintains that about one-third of the usual ash constituents is in suspension, and that they consist chiefly of lime phosphate.

All of the minerals in milk consist chiefly of potash, lime, soda, magnesia, and iron, combined with phosphoric, hydrochloric, sulphuric, and carbonic acid. Calcium phosphate constitutes about one-half of all the ash constituents. They are named above, in order, according to the extent in which they occur in milk.

Gases of Milk.-These do not normally exist in milk to such an extent as to enable chemists to determine them quantitatively, but they are of great importance, owing to the effect they have upon the quality of the milk, viewing it in the commercial sense.

Gases in milk may be divided into two classes according to their origin; namely, (1) those imparted to milk before milking and (2) those which are formed and absorbed in milk later.

(1) When freshly drawn milk has a characteristic cowy smell, which seems to be normal to all fresh milk. These gases are very volatile, and by cooling and aerating milk (differ- 
ent processes of which are now in use in this country) these gases can, to a large extent, be eliminated. The amount and kind of taints existing in milk, immediately after it has been drawn, largely depend upon the food which the cow has been fed. Turnips, onions, and garlic, when fed to cows a short time before milking, cause undesirable gases or taints to exist in the milk. Good sweet hay, bran, and good grass are said to produce milk of superior quality, and containing no bad taints, except the cowy or animal taste, which is natural to all milk when first drawn.

The milk yielded by cows pasturing in the Alps of Switzerland is said by tourists to possess a peculiar, not undesirable, spicy odor and flavor. It is maintained by the native people in Switzerland that the peculiar flavor of the Emmanthaler cheese cannot be developed anywhere else in the world. This flavor they believe to be due to the kind of vegetation the cows feed upon in the Alpine pastures. In Denmark, the poor people who do not own much land, graze their cows along the roads where weeds of different kinds grow. Milk from such cows has a peculiar characteristic odor or taint. In this country it is a common occurrence to find that milk delivered by patrons who keep their cows on timber-land pastures has a peculiar weedy odor. Especially is this true in the fall or late summer. These flavors are somewhat difficult to remove by the ordinary process of aeration. By heating such milk to $160^{\circ}$ or $180^{\circ} \mathrm{F}$, and stirring occasionally, most of these taints pass off. An addition of a small amount of saltpeter also improves it.

Too much emphasis cannot be placed upon the food that the cows receive. While it is true that much of the desirable aroma and flavor in butter are due to bacterial growth, the kind of food fed to cows is not without significance. It is a well known fact that districts such as Normandy and Denmark, which have become famous for their high quality of dairy products, have the best of pasture and winter feeds. 
Besides the kind of food, some physiological disturbances of the cow may cause abnormal taints in milk.

(2) Gases or taints which are formed in the milk or absorbed by the milk are due to fermentation and absorption respectively. The fermentation cause will be considered in a separate chapter, and the latter cause needs little explanation. It is a well known fact that milk, or any of its products, has the special property of absorbing odors which may be present in the surroundings of milk. For this reason, milk, as well as other dairy products, should at all times be kept in clean utensils and pure surroundings.

Abnormal taints appearing in milk immediately after - milking are due to absorption within the cow. Taints that develop on standing are due to bacterial growth in the milk, or to absorption from impure surroundings. In removing undesirable taints from milk the first step is to remove the inciting cause, and the second to cause as many of these taints as possible to escape by a process of aeration or pasteurization.

Coloring-matter. - It is not known of what the coloringmatter in milk consists. A substance named lactochrome has been found in milk. So far as known, this coloring-substance is closely associated with the fat called palmitin. The amount of coloring-matter varies during the different seasons of the year. It also varies according to the different breeds. During the spring of the year, when cows are first put on grass, the color of the butter-fat is always higher than it is during the latter portion of the summer. During the winter, the fat in milk is quite pale. By feeding the cows some succulent feed in the winter, such as silage, carrots, and beets, the color of the butter-fat becomes much higher.

From this it would seem that the change in the color of the fat with the different seasons, and the food fed, is closely associated with chlorophyl, the coloring-matter of grass.

Other Constituents of Milk. - It is said that constituents such as citric acid, urea, nuclein, lecithin, and galactase are present. Babcock maintains that he has discovered a sub- 
stance named fibrin. This seems to be similar to the nuclein mentioned by Fleischmann, if not the same. But as these substances are present to a very small extent, citric acid, urea, and fibrin being present to the extent of .12, .007, and $.0002 \%$ respectively (Fleischmann and Babcock), they are of little importance. 


\section{CHAPTER II.}

\section{MILK SECRETION.}

The Mammary Gland as a Secretory Organ. - The mammary gland of females belonging to the order of mammalia, secretes a fluid known as milk. This substance is strictly a secretory product. There are two kinds of glands present in the animal body; viz., the excretory and the secretory. Generally speaking, an excretory gland is one which receives or absorbs the waste matter of the body, and causes it to be carried off without causing any marked change to take place in the substance excreted. A secretory gland is one in which the raw material is obtained from the blood and then manufactured into a special different product within the gland itself. As an example of a secretory gland, the milk-gland of the cow's udder is an apt illustration. The glands in the mouth secreting saliva, and those in the walls of the stomach secreting the digestive fluids, are also secretory glands.

Internal Structure of Cow's Udder. - The cow's udder is composed of two separate glands, the right and left halves. These two glands are distinctly separated from each other by a fibrous tissue running longitudinally. This fibrous partition extends along the abdomen in front, and back to a point between the thighs of the cow. It also serves to hold the cow's udder in place. There is no connection at all between the right and left gland, and consequently milk cannot be drawn from the left side over to the right, and vice versa.

Each of these right and left halves is again divided into two parts, thus making the cow's udder appear in quarters. The cow's udder may then be said to consist of two glands 
on the right side, and two on the left side. The divisions between the two glands on the side are not entirely complete. That is, there is enough connection between the two glands on the same side to allow a portion of the milk to be drawn from the rear teat to the front teat on the same side, and from
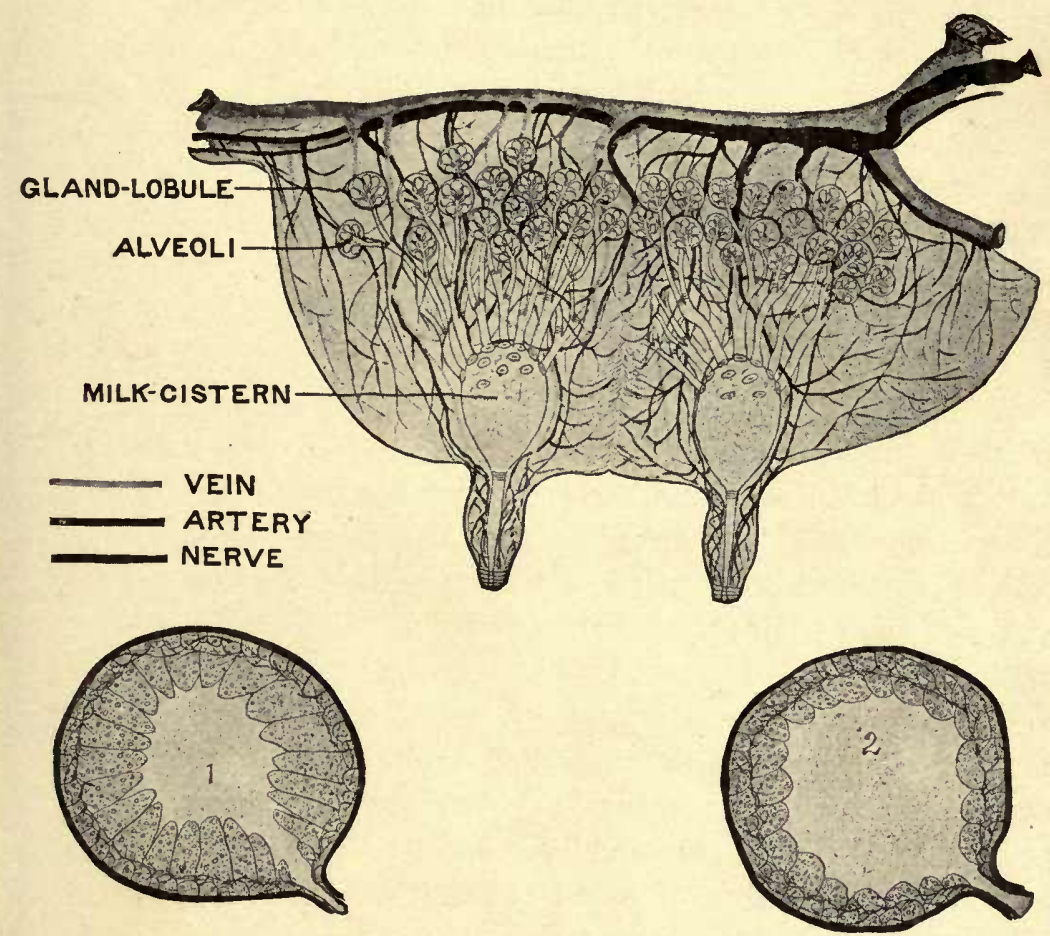

FIG. 2--Schematic figure showing cross-section of cow's udder; and also enlargement of epithelial cells in alveoli when cow is giving milk (1). Each alveolus is surrounded with a membrane called tunica propria. Cell nuclei not shown. When cow is in milk they are also enlarged. When not the epithelial'cells are flat and the nuclei small and spindle shaped (2).

the front teat to the rear teat. The milk-glands proper are located near the abdomen and extend downwards into the udder a trifle. The remainder of the udder is filled with ducts, fibrous and connective tissue, muscle, nerves, and blood-vessels, the whole udder assuming a sort of spongy and open condition. 
The teat is simply a cylindrical-shaped body, with a hollow tube extending down through the center of it. At the bottom of this opening, or at the end of the teat, there is a sphincter muscle. This muscle in some circumstances is drawn up very tight, while in other instances it is so loose that it will not.guard the milk from escaping. In case the muscle is so tight that the milk can be drawn only with difficulty, it may be relaxed a trifle by entering a small, smooth wooden plug. This will usually dilate the opening sufficiently, so that the milk may be drawn with comparative ease. In some instances this muscle is so tight that it is necessary to relax it by the use of a sharp knife. This, however, should be done with surgical skill; otherwise the whole muscle is likely to be so injured as to cause the milk to leak away at all times.

The upper part of this canal in the teat connects with what is called the milk-reservoir. The size of this reservoir varies in different cows. The average capacity of this milkcistern is about one pint. The opening from this reservoir into the teat is also guarded with a muscle. Over this muscle the cow has little control. Over the muscle at the lower end of the teat the cow has no control whatever.

Opening into the sides and top of this reservoir is a large number of tubes, which are called milk-ducts. These milkducts extend from the reservoir up into the milk-gland. They radiate in all directions, divide and subdivide, so as to form a very large number of small tubes. These milk-ducts are surrounded with fibrous muscular tissue, nerves, and bloodvessels. They are all guarded by a special muscle at the junction to the main milk-ducts, from which they radiate. These muscles are so intimately connected with the nerves and muscular system of the cow that she is able to open and close them at will. There are very few cows that are not able to hold up their milk during nervous and exciting periods. It is a common occurrence for a milker to get only a small part of the milk from a cow. This small amount is the portion which is present in the teat and milk-reservoir. Some cows 
are able to hold up this milk also, but the majority of cows cannot perfectly control the muscle which guards the entrance to the teat. The milk which is present in the milkducts and which has to pass through these junctions referred to above, can be held up by most cows at will.

All of these small milk-ducts end in small sack-like bodies. Each of these dilated portions is called the gland-lobule or ultimate follicle. These gland-lobules enclose numerous individual microscopical bodies called alveoli or acini. These alveoli constitute the organs which possess the proper secretory functions. These alveoli are lined on the outside with a membrane called the tunica propria. Next to this membrane is a layer of cell-tissue. The inside layer is composed of cells, which are named the epithelial cells. These epithelial cells within the alveoli are supplied with blood from the cow's system. During lactation they assume a different form. When the cow is yielding milk abundantly, these cells swell and extend into the cavity of the alveoli. When the cow is not in milk these alveolian cells become flat. A certain number of alveoli is tributary to one particular duct leading from the gland-lobule.into still larger milk-ducts.

Each aggregation of gland-lobules, tributary to one milkcistern, constitutes a lobe, and may be likened to a side branch of a bunch of grapes. Each separate grape may represent a gland-lobule. The seeds within the grape, if we imagine each seed to be hollowed out and lined with small column-like bodies, may be likened to the alveoli. These column-like bodies would then represent the epithelial cells. The stem leading from each individual grape may represent the small duct which carries the milk on to the larger ducts. The main stems of the bunch may represent the larger ducts that enter into the milk-reservoir. The air which everywhere fills the openings or interstices of the various parts of the bunch of grapes may be likened to the fibrous fatty tissue between the alveoli and the lobules of the gland.

Theories of Milk Secretion.-Although the theories of milk 
secretion have been studied considerably, many things in this connection are not well understood. Previous to the year 1840 it was thought that the only function of the milk-gland was to filter the milk as it transuded from the blood. It was supposed that the quality and quantity of milk depended entirely upon the food. The theory has also been advanced that the major portion of the milk constituents was a decomposition of the product of the lymph bodies of the blood. It was believed that the lymph bodies were a source of nourishment to the fœtus, and that the calf received its nourishment from the same source after it was born as it did previous to birth. It was supposed that after the birth of the calf the opening on the uterus through which the food was supplied was closed, and that a new opening was formed in the milkgland. These two theories have now been practically overthrown. It has been demonstrated that the major portion of the milk is formed within the milk-gland. The fat, casein, milk-sugar, and part of the albumen are supposed to be formed in the udder. This conclusion is substantiated by the fact that these substances do not appear in the blood, at least not to such an extent as to warrant the assumption that they are not manufactured in the cow's udder. The total amount of fat in the blood of the cow would not equal the fat in the milk from one milking.

By some it is maintained that the substances in milk which are found in solution may be transuded directly from the blood. Here again milk-sugar is found to be in perfect solution in the milk, but this substance can be found nowhere in nature besides in milk. It is not present in the blood of the animal, consequently it must be manufactured within the gland itself. The water of milk, and the ash constituents which are in solution, are probably transuded directly from the blood. No attempts have been made to determine definitely how casein and albumen are formed within the gland.

The theory advanced for the formation of fat is, that the epithelial cells break down and form fat. When the breaking- 
down process is completed, the transformed cells appear at the opening of the alveoli in the form of distinct fat-globules. This is supposed to be the origin and formation of fat-globules in milk; so it may be said that so far as known the fat is the result of a breaking down of degenerated epithelial cells.

Dr. Bitting asserts that the formation of milk solids in the cow's udder is probably due to a metabolic process rather than

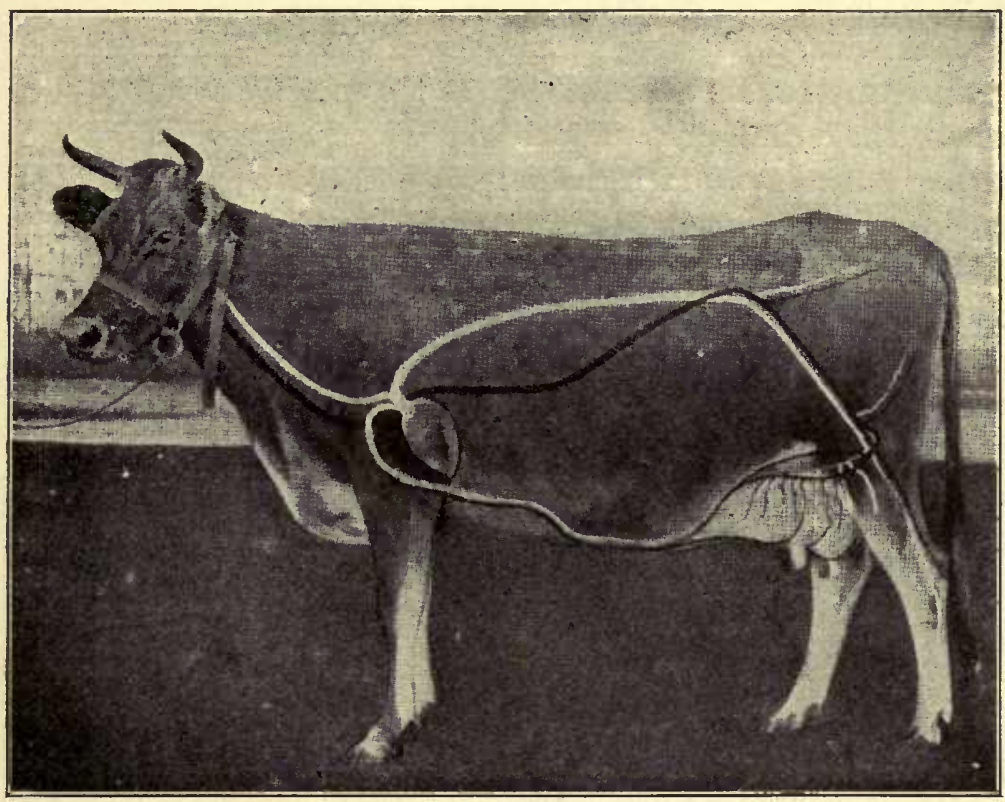

FIG. 3.-A schematic figure showing the course of the artery leading to the mammary gland and the veins returning to the heart. The light-colored lines represent arteries and the dark-colored lines the veins. (From Bitting, Twelfth An. Report, Indiana.)

to a degencrative. Collier found that a cow giving a normal amount of milk would secrete about 136,000,000 fat-globules per second. He also suggests that a cow secretes about 5 pounds of milk solids per day. As a cow's udder weighs only about $2 \frac{1}{2}$ pounds, the whole udder would have to be renewed twice daily. This is not consistent with our present knowledge of tissue building. 
The chief incentive to milk secretion is maternity. As soon as the young mammalia is born the blood which went to the uterus to supply the calf is turned towards the udder instead. As soon as this current of blood begins to flow, all of the bloodvessels and capillaries in the cow's udder swell. This causes the minute blood-vessels or capillaries which form a network in the walls of the alveoli to swell. This swelling stimulates the epithelial cells to activity.

Conditions Affecting Secretion of Milk. - There are a great many conditions which affect the milking capacity of a cow. These conditions may be conveniently grouped into two classes according to their causes: (1) conditions which are controlled largely by man, and (2) conditions which are inherent to the cow.

1. Some of the chief conditions which reduce the secretion of milk and are largely controlled by man are: improper care and treatment of the cow, lack of proper food, incomplete and improper milking, irregularity, and long periods between milkings. Pregnancy, nervousness, or excitement of any kind affect the proper working of the milk-glands considerably. These latter causes, however, are not always controlled by man.

2. Without denying the influence of those conditions mentioned above, the conditions which chiefly affect the milksecreting capacity are inherent. It does not matter how much good care and food a cow receives, if she does not possess these inherent necessary qualities. As was mentioned before, the milk-secreting capacity depends upon the number of glandlobules, upon the amount of blood which is supplied to these secretory parts, and upon the capacity of the cow to digest and assimilate food.

The number of gland-lobules is believed to increase until the cow is about seven years old. The milk-secreting glands are present only in a rudimentary form, until the cow has had her first calf, or is well advanced in the first stage of pregnancy. The gland-lobules then increase in number up to the age of about seven. The relative number of lobules in the cow's 
udder can only be approximately ascertained. The size of the udder in some measure indicates this. A cow with a large flexible udder is usually a good milker, due to the fact that a large udder usually contains a large number of gland-lobules.

The amount of blood which is turned through the cow's udder to supply the milk-secreting cells may approximately be ascertained by the size of the blood vessels. The blood enters the udder from the heart near the region of the hips. It then passes down through the udder, along the abdomen just beneath the skin, until it reaches about midway between the flank and the girth. At this place it penetrates the abdominal wall and enters the thorax. The place at which the blood penetrates the abdominal wall may be felt with the finger. It is supposed that the size of this hole is in some measure indicative of the milk-producing capacity of the cow. This opening in the abdominal wall is called the milk-hole or milkfountain. Large irregular veins are considered a much better indication of good milking properties than small straight veins.

The formation of gland-lobules is entirely inherent in the cow. The only way that these may be increased is through selection and breeding. The amount of blood which passes through the cow's udder is also largely inherent, although this may in a small measure be affected by the amount and quality of food given to the cow. It should at all times be remembered that a cow is not a mere receptacle into which so much food can be introduced, and so much milk drawn from the other end. After giving due credit for the influence of all other conditions, we must still recognize that the inherent conditions affecting the secretion of milk are the most important.

External Appearance of the Udder.-A cow's udder should be well and symmetrically formed. It should be square, wide, extend well along the abdomen of the cow, and back up between the thighs. When the udder is empty it should be soft and flexible. The teats should be medium large, should be placed well apart, and should point downwards.

There should be little or no depression in the udder between 
the teats; that is, each quarter should not appear distinct and separate when viewed from the exterior.

The cow's udder should be covered with fine soft, downy hair. A light golden yellow is said to be indicative of a good quality of milk.

A firm, fleshy udder is undesirable. In the first place, it is not indicative of good milking qualities, and, secondly, such an udder is predisposed to inflammatory diseases.

Milk-fever. - This is a common disease in fresh cows. It is due to a congested condition of the cow's udder. The decomposition products of the colostrum milk in the udder are absorbed by the blood, and produce the characteristic symptoms of milk-fever. Dr. Peters, of the Nebraska Experiment Station, says that a good and simple remedy for a diseased udder is to pump it full of air. This can be accomplished with an ordinary bicycle pump. After some air has been pumped in, then the cow's udder should be worked or massaged with the hand so as to cause the air to pass through the quarter. He claims that the udder can thus be restored to its normal condition very quickly, thereby preventing and even curing milk-fever. In case the udder is caked very badly, apply a hot poultice. Small five- or ten-pound bags filled with bran and kept hot is a good substance to use. A compress is also used. This consists simply of using a piece of heavy cloth. Put it on so that it lifts up the entire udder, and tie it over the back of the cow. Straw should be put underneath it on the back so that the cord does not injure the animal. 


\section{CHAPTER III.}

\section{PROPERTIES OF MILK.}

Color.-The color of normal milk ranges between bluish white and golden yellow, according to breeds, foods, and seasons of the year. The milk yielded by Jersey cows generally is more yellow, due chiefly to the larger amount of fat which it contains. Holstein cows yield milk of a whiter color. Foods such as grass and certain roots (mangles and carrots) have the power of giving to milk a higher color. As has been previously mentioned, the coloring substance in milk has been named lactochrome, and so far as known is associated with the palmitin fat.

Flavor.-Milk has a sweet flavor, and a faint odor. Fresh milk has a peculiar cowy taste and odor, which pass off when exposed to the air. The flavor is affected by foods and conditions of the cow, as mentioned under " Abnormal Milk."

Opacity of Milk.-Milk is opaque, except when seen in very thin layers; then it is slightly transparent. The opacity of milk is due to the presence of the fat and nitrogenous matter. When these substances are filtered away on a fine clay filter (the Chamberland), the filtrate which passes through is clear and transparent. It has been maintained that the fat in milk is the chief cause of its opacity, and that the percentage of fat could be determined according to the degree of opacity and transparency of milk with an instrument named pioscope; but it was soon found out that the size of the fat-globules, as well as the number, had considerable influence upon the degree of opacity of milk. For that reason, this method of determining the amount of fat in milk was not 
reliable. The fat-globules themselves are said to be almost transparent, yet the color and opacity of milk is largely due to their presence. This characteristic may perhaps be explained by assuming that the fat-globules in milk deflect the light instead of allowing it to pass through them.

The opacity of milk, after the fat has been removed, is due to the presence of nitrogeneous matter. After the fat has been removed from the milk, the milk still continues to be opaque. When the albuminoid matter has been removed and filtered off the filtrate becomes clear and transparent.

Chemical Reaction of Milk.-Milk when fresh shows an amphoteric reaction, which means that it exhibits both an alkaline and an acid reaction when tested with litmus paper. It turns blue litmus paper red, and red litmus paper blue. This peculiar behavior of milk is said to be due to the caseous matter in the milk, which itself has an acid reaction, but the remainder of the serum has a slight alkaline reaction. By testing the reaction of fresh milk with a tenth normal alkali solution, and using phenolphthalein as an indicator, it will be found to give an acid reaction. After standing, milk soon becomes distinctly acid, which is due to a change of the milk-sugar into acids, chiefly lactic acid, through the action of micro-organisms. Richmond maintains that the amphoteric reaction of milk has acquired a false importance, as he believes that the neutrality, as measured by the action of litmus paper, is not chemical neutrality.

Specific Gravity of Milk.-By specific gravity of milk we mean the weight of the milk as compared to that of an equal volume of water at the same temperature. If a certain volume of water weighs 1000 pounds, an equal volume of milk at the same temperature and under the same conditions, will weigh about 1032 pounds. Reducing the figure to a basis of 1 , as is always done, the comparison between the two equal volumes of water and milk will be 1 and 1.032. This latter figure represents the average specific gravity of normal milk.

It can be readily seen that the correct specific gravity can 
only be obtained at one given temperature, for, as the temperature of the substance becomes higher, the density of it grows less, and consequently the specific gravity will be less. The temperature at which the lactometers are standardized is $60^{\circ} \mathrm{F}$.

The variations in the specific gravity of milk will also vary according to the relative variation in amounts of the different components of milk. If a sample of milk is rich in solids not fat, as, for instance, skimmed milk, the specific gravity will be high and usually between 1.033 and 1.037. If the sample of milk is rich in fat, as, for instance, in cream, the specific gravity will be less.

By adding water to milk, the specific gravity of it is lessened. Owing to this fact it was first thought that adulteration of milk with water could be detected by testing its specific gravity. But this method was soon found to be erroneous, as it is possible to take cream away and add water in such a proportion as not to alter the specific gravity of the sample. A low specific gravity of milk may, however, cause the suspicion that the milk has been adulterated, and the test for water adulteration can be supplemented by testing it for fat.

As has been mentioned before, the lactometer reading should be taken at $60^{\circ} \mathrm{F}$. If the temperature of milk is above or below, corrections must be made. The amount of correction which will give approximate results is .1 of a degree added to the lactometer reading for every degree Fahrenheit of temperature the milk is above $60^{\circ} \mathrm{F}$., and also .1 of a degree subtracted from the lactometer reading for every degree of temperature the milk is below $60^{\circ} \mathrm{F}$. The temperature of milk when tested for lactometer reading should never go any lower than $10^{\circ}$ below $60^{\circ}$, nor any higher than $10^{\circ}$ above $60^{\circ}$. This would leave the range of temperature between $50^{\circ}$ and $70^{\circ} \mathrm{F}$.

In chemical laboratories, the specific gravity of milk is usually determined by the use of a picnometer.

In practice there are three instruments in general use for determination of lactometer reading, or specific gravity, viz.: Quevenne lactometer, New York Board of Health lactometer 
and the ordinary hydrometer. The Quevenne sactometer is the one that is used chiefly in creameries. The graduation of each one of them is given in the accompanying diagram. It may be

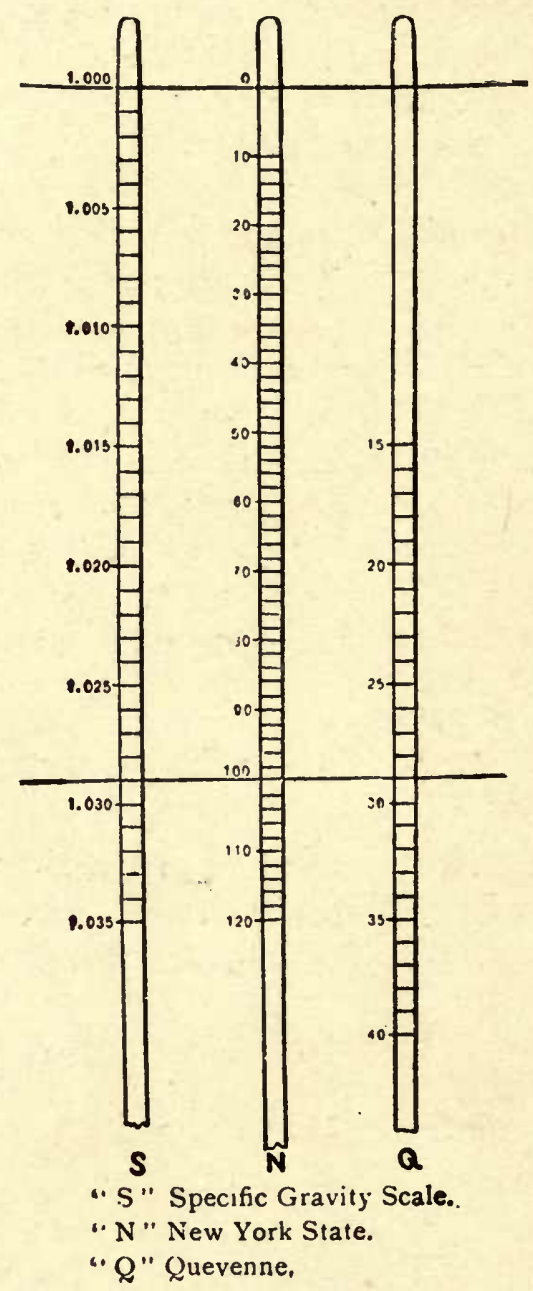

Frg, 4.-Comparative graduation of lactometer stems.

seen from the figures that in order to change the Quevenne lactometer reading into specific gravity, all that is necessary is to add 1000 and divide the sum by 1000 . In order to change the 
specific gravity into lactometer reading the reverse process will give correct results.

The hydrometer gives the specific gravity directly. The Board of Health lactometer has a special graduation. In devising this lactometer it was thought that 1.029 was the minimum specific gravity of unadulterated milk. The scale on this lactometer was made from zero to 120 ; zero marking the point which represents the specific gravity of water, namely, 1. 100 is the point which is assumed to represent the least specific gravity of milk 1.029. If the specific gravity of a certain sample of milk fell to 90 , it indicated that there was $10 \%$ of water present. If it fell to 80 , it indicated that there was $20 \%$ of water, etc.

In order to calculate the total solids, and solids not fat, of milk, it is necessary to know the lactometer reading, and the percentage of fat content. Knowing these factors, by the use of the following formula given by Farrington and Woll, and deduced from Fleischmann's work, the total solids, and solids not fat, can be found:

Solids not fat $=\frac{1}{4}$ lact reading +.2 times the fat.

Total solids $=$ fat + solids not fat.

Natural Separation of Milk and Cream.-When milk is allowed to stand quietly for a short time, a layer having a richyellow color comes to the surface. This is the cream, and contains most of the fat. This separation is due chiefly to the difference in weight, or specific gravity, of the fat-globules and the serum. The force which acts upon the globule of fat is the difference in weight between the fat-globule and the serum which it displaces, minus the resistance force with which it meets in its upward passage. In milk with a high degree of viscosity this force is great. In milk of a limp and liquid consistency this force is smaller. By adding water the viscosity of milk is reduced considerably, and the specific gravity of the serum is also decreased. But the effect of the added water upon the viscosity is greater than the effect the water has 
upon the specific gravity of the serum; hence, by adding water to milk, the resistant force is decreased to such an extent as to get a more rapid and more efficient separation of the fat. The water dilution separators are bassed upon this principle. In normal milk, the amount of fat left in the skimmed milk by natural creaming is about .4\%. The fat which is left in this skimmed milk is largely composed of very small globules. This is due to the fact that the resistant force of these small globules is equal to or greater than the buoyant force acting upon them.

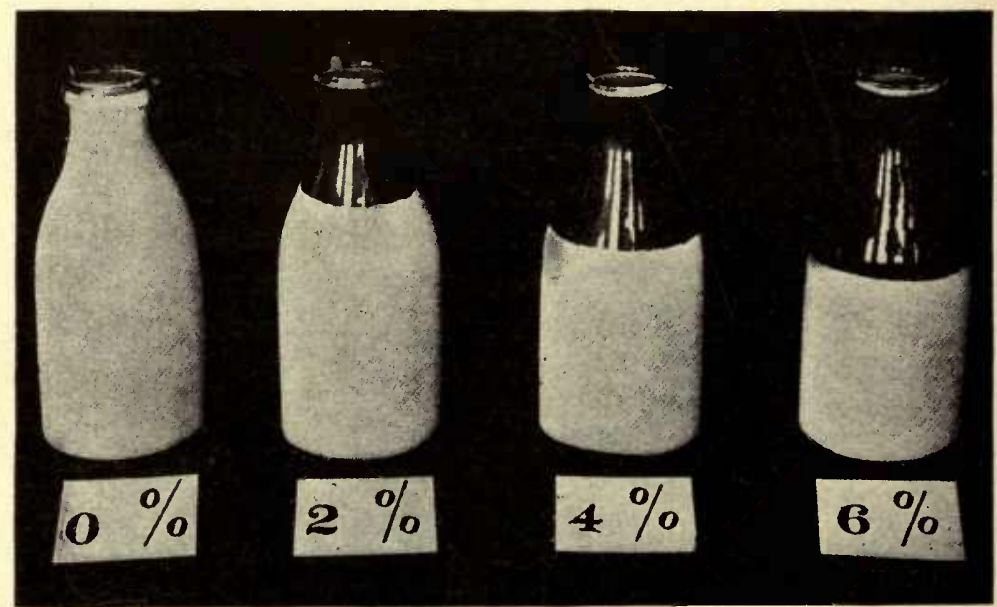

FIG. 5.-Standardized milk. Showing the amount of cream on milk containing the designated per cent of butter-fat. (From Bul. 92, Ill.)

This completeness of natural skimming is to a certain extent based upon the mathematical law which is stated as follows: "The surfaces of two spheres are to each other as the squares of their diameters, and their cubical contents are to each other as the cubes of their diameters." The larger the globules are, the greater the surface is, and the greater the resisting force to which they are subjected. From the law stated it can be seen that as the size of the globule increases, the cubical content increases more rapidly than the surface. If a fat-globule were split up into smaller ones, there would be more surface exposed 
to the serum than was the case while the fat was present in one globule.

For illustration, take two globules of fat having a diameter of 4 and 2 inches respectively. The squares would be 16 inches and 4 inches respectively; their cubes would be 64 inches and 8 inches respectively. It will thus be seen, according to the law quoted above, that the larger globule has a surface only four times as great as that of the smaller one; but the cubical content of the larger globule is eight times that of the smaller one. This illustrates why the large globules rise in cream quicker than the small ones. In this particular instance the upward force the larger globule is subjected to is eight times greater than that of the smaller one, while the resistance force is only four times as great as that of the small one.

Adhesion of Milk.-Normal sweet milk adheres to wood, glass, and metals to a greater extent than does water. Whole milk has greater adhesive properties than skimmed milk. A paper moistened with milk or cream makes a label that will stick to any dry object; the same paper moistened with skimmed milk has less adhesive power. The adhesive properties of milk are also due to the condition of the nitrogenous matter. This fact is made use of in painting and whitewashing. Slacked lime, when mixed with buttermilk, or milk of any kind, gives a whitewash which will remain on objects much longer than that made by mixing with water.

Viscosity of Milk.-Milk is more viscous than water. The degree of viscosity of fresh milk varies chiefly with the temperature and fat content. So far as understood, the lower the temperature, the greater the viscosity. Development of acid, and high temperature lessens the viseosity of milk. Pasteurized milk or cream is less viseous than the same milk or cream unpasteurized. This lack of body can again be restored by adding a little viscogen, as recommended by Babcock and Russell. It is advisable not to use it, however, as it does not add materially to the nutritive value of milk. It merely restores the body. 
The great viscosity of thick and cold cream has been encountered by most butter-makers when attempts have been made to churn cream under such conditions. It adheres to the inside of the churn and does not agitate. It simply rotates with the churn. Cream that is cold and thick whips more easily than thin and warm cream. The viscosity is so great that the air incorporated cannot escape so easily. In ice-cream making, a greater yield is obtained by using cold and thick cream. The air, when once incorporated, cannot easily escape, owing to the great viscosity of such cream.

Specific Heat of Milk.-The specific heat of milk is less than that of water; that is, it requires less heat to warm a definite amount of milk to a certain temperature than it does to heat the same quantity of water to the same temperature. It also takes less ice to cool the same volume of milk to a certain temperature than it does to cool the same quantity of water to the same temperature. The specific heat of milk is, according to Fjord, .94. The specific heat of cream is about .7. It varies according to the percentage of fat in the cream. The specific heat of butter is about .4. From these figures it will be seen that it takes less heat to warm milk, cream, and butter, and less cold to cool the same substances, than it does to heat and cool water; but it takes a longer time to heat or to cool milk, cream, and butter; that is, the milk, cream, and butter are not as rapid conductors of heat and cold as is water.

The maximum density of milk is not, like rater, at $4^{\circ} \mathrm{C}$. but at about $.3^{\circ} \mathrm{C}$. The boiling-point of milk is a trifle higher and the freezing-point a trifle lower than that of water.

Effect of High Heating ( $180^{\circ}$ and above) on Properties of Milk. - The chief effects of heat upon milk may be summarized in the following headings:

(1) It destroys nearly all germs present in the milk.

(2) It diminishes the viscosity, or body.

(3) It drives off gases. 
(4) It imparts a cooked taste (especially if not heated and cooled properly).

(5) It precipitates some of the albuminoids and ash constituents.

(6) It destroys the properties of enzymes present in milk.

(7) It divides or splits up the fat globules.

(8) It caramelizes some of the sugar.

r. Destroys Nearly All Germs.-Heating milk to a temperature of about $180^{\circ} \mathrm{F}$. for ten minutes destroys most of the germs present in milk. This is the temperature used chiefly in creameries for pasteurization. The details concerning the different effects of temperature upon growth of germs properly comes under the heading of bacteriology, and will be referred to more in detail in the chapter on "Bacteria in Milk."

2. Diminishes the Viscosity, or Body.-Heating milk or cream diminishes the viscosity of these substances; that is, the body or consistency is lessened; and in cities where milk or cream is sold directly to consumers, heated milk appears as if it had been adulterated. This diminution in the body is claimed to be due to a breaking up of the fat-globules and the caseous matter. The chemical union of some of the calcium salts and the casein is altered or destroyed.

The consistency of milk or cream can be restored by adding a substance named viscogen. Russell and Babcock* advise this method of overcoming the apparent defect caused by heating. It consists of making a strong solution of cane-sugar and mixing it with freshly slacked lime. This mixture is allowed to stand, and the clear solution coming to the top is the viscogen, which, when drawn off and used in the proportion of one part of viscogen to from 100 to 150 parts of cream, restores the body of cream or milk. This is due to the fact that viscogen causes the fat-globules to cluster together again, and the lime in the viscogen may combine with the

* Bulletin No. 54, Wisconsin. 
nitrogenous constituents in such a way as to aid in the restoration of the body of the cream or milk.

Nearly all dairy laws forbid the addition of any foreign substances to milk or cream. If viscogen is added, Babcock and Russell suggest to name it visco-milk, visco-cream, etc. When this modification is made, then no objection can be raised to its legitimate use.

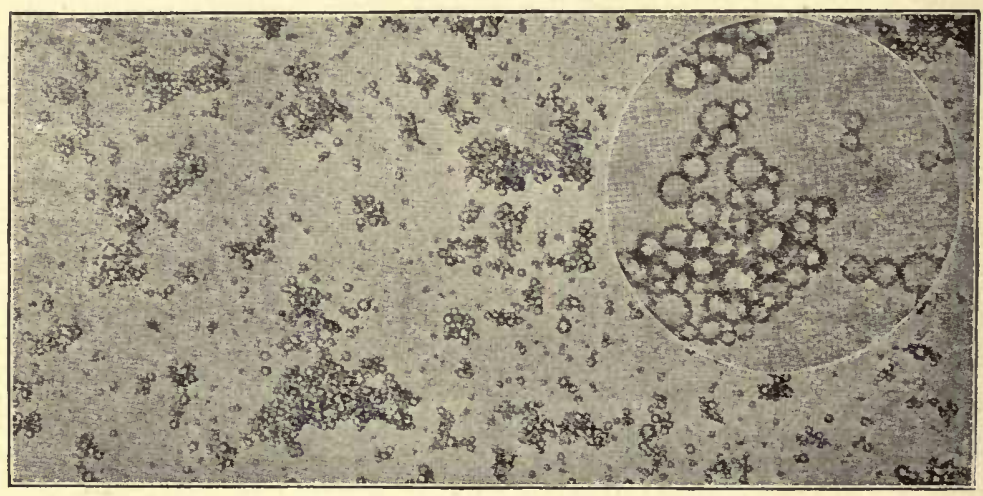

FIG. 6.-Microscopic appearance of milk, showing natural grouping of the fat-globules. Single group in circle, highly magnified. (From Bul. 64, Wis.)

3. Drives off Gases.-When milk is heated, taints, and gases of different kinds pass off to some extent. This is facilitated by heating and stirring in an open vessel. Many of these gases also escape when milk is aerated and cooled in a pure atmosphere.

4. Imparts a Cooked Taste.-When milk is heated to $160^{\circ} \mathrm{F}$. or above, it assumes a distinctly cooked taste, which makes it disagreeable as a food for many people. On this account, milk for city supply in America is generally not heated. In a few cities where milk is consumed directly, heating and cooling (pasteurization) has been generally introduced. It is said that people can become accustomed to this cooked flavor and acquire a liking for it. When milk is not heated higher than $180^{\circ} \mathrm{F}$., nor exposed to the heat very long, and 
cooled quickly, the cooked taste can be greatly reduced and almost entirely avoided. Where heating or pasteurization of cream has been adopted, as in some creameries, the prevention of this cooked flavor in the butter is of vital importance.

The reason why this cooked flavor forms in milk when heated is not well understood. It is supposed to be due to the effect which heat has upon the nitrogeneous constituents of milk.

5. Precipitates Albuminoid and Ash Constituents.-When milk is heated, there is a tendency for the soluble salts and a portion of the albuminoids to be thrown down, or changed into an insoluble form.

The higher the milk is heated, the greater is this tendency. By subjecting a sample of milk in a flask to intense heat, and then allowing it to stand, a fine white sediment will be deposited on the bottom. This is believed to be minerals precipitated from the milk.

When milk has been heated to about $170^{\circ} \mathrm{F}$., and cooled, rennet is unable to precipitate the curd in a normal way. The curd resulting from adding rennet to pasteurized milk is flocculent in nature. It does not assune that smooth and even texture that curd from raw milk has when precipitated with rennet. This abnormal behavior of pasteurized milk towards rennet can be reestablished by adding a small quantity of calciun chloride $(\mathrm{CaCl})$. Whether this would effect the quality of cheese materiaily has not yet been determined definitely. According to G. Fascetti,* if pasteurized milk is used for cheese-making, the cheese ripens more slowly than when made from raw milk. The same investigator also claims that a larger quantity of cheese is obtained per 100 parts of milk when pasteurized milk is used.

6. Destroys Properties of Enzymes.-As was mentioned in the composition of milk there is a substance normal to milk named galactase. This is an enzyme. By heating milk to

* Exper. Sta. Record, Vol. 15, No. 10, 1904. 
about $175^{\circ} \mathrm{F}$. the properties of the enzyme are destroyed Owing to this it is easy to detect whether a certain sample of milk has been pasteurized or not. Galactase is present in so small a quantity that it could not be determined in milk quantitatively. It must be detected in a qualitative way.

The test used and invented by Storch, of Copenhagen, Denmark, is to put a small quantity of milk in a test-tube, add to it a small quantity of a weak solution ( $2 \%$ ) of hydrogen peroxide $\left(\mathrm{H}_{2} \mathrm{O}_{2}\right)$, a small quantity of potassium iodide, and a little starch solution. The whole mixture is then shaken. If the mixture does not change in color, it has been heated to at least $170^{\circ} \mathrm{F}$. If it turns blue, it has not been heated to a sufficiently high temperature to destroy the properties of the enzyme present in the milk. Another test which can be used in distinguishing raw milk from scalded or boiled milk is to take 10 cubic centimeters of the milk to be tested, add $1 \%$ of recently prepared aqueous solution of "Ortol," and then one or two drops of hydrogen peroxide. If the milk has not been heated, a vivid red color is produced. Heated milk shows no effect.

7. Divides the Fat-globules. - The fat-globules in normal milk are grouped in minute clusters. When milk is heated, these clusters break up, and each globule exists more or less independently. When heated to an excessively high temperature, and exposed to this temperature very long, the fat-globules tend to run together. This can be proved by heating milk in an open vat for about half an hour. A small amount of yellow fat will then be seen floating on the top.

8. Caramelizes the Sugar.-The brownish color which the milk assumes when it is heated excessively is due to a change which the milk-sugar undergoes. Fleischmann claims that the sugar begins to change into a substance known as lacto-caramel at a temperature of $160^{\circ} \mathrm{F}$. This change, however, is not pronounced enough to be apparent in the color, unless the milk is heated a long time. The higher the temperature is, and the longer it is exposed to the heat, the more pronounced is the change. 
General Remarks. - While all of the above changes have been found by investigators to take place when milk is heated, they can, in a measure, be avoided, if special precautions are taken in the heating and cooling of milk with the special, recently improved forms of apparatus for heating and cooling milk. The heating to $160^{\circ} \mathrm{F}$. can be accomplished without changing materially the chemical or physical properties of milk.* Rapid heating and rapid cooling seem to be two essentials in order to prevent changes from occurring in the milk.

* Fjadon, Koshe, and Hertel in Exp. St. Record, Vol. 14, No. 5. 


\section{CHAPTER IV.}

\section{FERMENTS IN MILK.}

Definition.-The changes which milk undergoes by standing at a suitable temperature are called fermentations. The causal agents are called ferments. There are two kinds of ferments in milk; viz.: (1) the organized, and (2) the unorganized. The latter includes the enzymes. So far as known, only one pre-existing enzyme is found in milk. This one was discovered by Russell and Babcock. They named it galactase. It is a tryptic ferment. This galactase is present to such a small extent in milk that it exercises very little influence upon the characteristics of milk. If the milk were rendered entirely sterile or free from organized ferments, the fermentative changes would proceed at an unusually slow rate. The galactase has been suggested to be of some importance to the butter-making industry. The properties of galactase, like those of any other enzyme, are destroyed by heating to or above a temperature of about $175^{\circ} \mathrm{F}$.

The organized ferments are by far the most important to the dairy industry. It should be understood in this connection that the organized ferments may produce unorganized ferments, or enzymes, as products, but these produced enzymes do not exist in milk, like galactase, when it is first drawn from the cow. The organized ferments of milk consist chiefly of bacteria. There are present also some yeasts and molds.

It is a common impression that bacteria are animals, which is incorrect. Bacteria are minute microscopical plants, belonging to the lowest order of plants in the vegetable kingdom. Bacteria differ from the ordinary plants that we see, in that they are composed of a single cell containing protoplasm, 
while the plants that we see in every-day life are aggregations of cells. Some bacteria are motile, while others are not.

Size and Shape of Bacteria.-In size, bacteria are the smallest organisms that exist, so far as known. The size varies considerably. Russell * gives the average diameter as $\frac{1}{30000}$ of an inch. They are so inconceivably small and light that nine hundred billions of them would only weigh $\frac{1}{2} 8$ of an ounce. $\dagger$

Bacteria also vary considerably in shape. They are as a rule classed into three groups: (1) The bacillus or rod-shaped; (2) The coccus or ball-shaped; (3) The spirillum or spiralshaped (like a corkscrew). Some types of bacteria are classified according to the way in which they adhere to each other. For instance, when two cocci occur together and form a pair, they are called diplococci, when bacteria occur in chains, they are called streptococci, when bacteria appear in bunches they are called staphylococci, etc.

\section{Favorable Conditions for Bacteriat Growth.}

Food.-Bacteria are like other plants in nature,- they need food for their existence. However, they require their food in solution. Nitrogen, carbon, oxygen, and mineral matter are essentials for bacteria. These substances are furnished in abundance in milk from casein, albumen, milk-sugar, and the mineral salts. Butter-fat in milk is said to be of little value as a food for bacteria.

Some bacteria prefer a substance having an acid reaction in which to grow; others thrive best in an alkaline medium. Most bacteria, however, prefer a neutral or slightly alkaline substance. Darkness is essential to some bacteria, and is preferred by the majority of the different species. Bright sunlight is a very effective germicide. It is fatal to all species, so far as known. Some germs require air for their growth. These are called aerobic. Others again grow only in the 
absence of air. These are called anaerobic. Some grow under either or both conditions, and are called facultative aerobic or facultative anaerobic.

Temperature.-Favorable temperature is essential to bacterial growth. Temperature is, indeed, the most important means by which the growth and development of bacteria can be controlled. The range of temperature at which bacterial growth can occur may be p'aced between freezing-point and

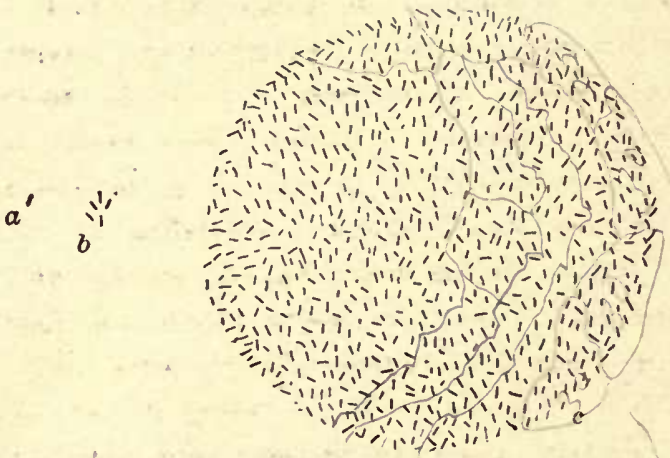

FIG. 7.- $a$, single bacterium; $b$, progeny resulting from the growth of a bacterium during 24 hours in milk at $50^{\circ} \mathrm{F}$; $c$, progeny of a bacterium during 24 hours growth in milk at $70^{\circ} \mathrm{F}$. At $50^{\circ} \mathrm{F}$. multiplication was 5 -fold. At $70^{\circ} \mathrm{F}$, the multiplication was 750 -fold. (Bul. 26, Storrs, Conn.)

a little above $110^{\circ} \mathrm{F}$. The growth of bacteria at these extreme temperatures is very slight. Even at $50^{\circ} \mathrm{F}$. the rate of growth is very slow. According to experiments conducted by Dr. Conn, the multiplication of bacteria at $50^{\circ} \mathrm{F}$. was 5 fold, while at $70^{\circ} \mathrm{F}$. the multiplication was 750 -fold. The following table shows the number of bacteria per cubic centimeter in milk kept at different temperatures:*

\begin{tabular}{|c|c|c|c|c|c|c|}
\hline $\begin{array}{l}\text { No. at } \\
\text { Outset. }\end{array}$ & $\begin{array}{l}\text { In } 12 \\
\text { Hours } \\
\text { at } 50^{\circ} .\end{array}$ & $\begin{array}{l}\text { In } 12 \\
\text { Hours } \\
\text { at } 70^{\circ} \text {. }\end{array}$ & $\begin{array}{l}\text { In } 50 \\
\text { Hours } \\
\text { at } 50^{\circ} .\end{array}$ & $\begin{array}{l}\text { In } 50 \text { Hours } \\
\text { or at Time of } \\
\text { Curdling } \\
\text { at } 70^{\circ} .\end{array}$ & $\begin{array}{l}\text { No. of } \\
\text { Hours be- } \\
\text { fore Curd- } \\
\text { ling at } 50^{\circ}\end{array}$ & $\begin{array}{l}\text { No. of } \\
\text { Hours be- } \\
\text { fore Curd- } \\
\text { ling at } 70^{\circ} \text {. }\end{array}$ \\
\hline 46,000 & 39,000 & 249,500 & $1,500,000$ & $512,000,000$ & 190 & 56 \\
\hline 47,000 & 44,800 & 360,000 & 127,500 & $792,000,000$ & 289 & 36 \\
\hline 50,000 & 35,000 & 800,000 & 160,000 & $\begin{array}{c}2,560,000,000 \\
42 \text { hours }\end{array}$ & 172 & 42 \\
\hline
\end{tabular}

* Bull. 26 Storr's Stn., Conn. 
All bacteria do not have the same optimum growing temperature. Some species develop most rapidly at one temperature, while other species prefer a different temperature for the greatest development. It is on this account that certain temperatures are employed in ripening of starters and cream. According to researches by Conn, Bacillus lactis aerogenes develops very rapidly in milk at $95^{\circ} \mathrm{F}$. It produces much gas and an unpleasant flavor in the milk. This particular species sours milk very rapidly. As a rule, milk which has been held at this high temperature, contains a preponderance of this undesirable species of bacteria. At $77^{\circ} \mathrm{F}$. results are more uncertain. The species of bacteria which will predominate in milk at this temperature depends in large measure upon the number of each kind present. According to Conn, Bacillus lactis acidi has the highest relative growth at about $70^{\circ} \mathrm{F}$. This particular species produces no gas, and is desirable to have present in cream for butter-1naking. Milk kept at this temperature will, in most cases, providing it has previously been properly treated, develop a pleasant acid taste, will curdle into a smooth uniform coagulum, and will contain a preponderance of the species of germ mentioned above.

At as low a temperature as $50^{\circ} \mathrm{F}$. acid-producing types of bacteria do not develop very well. But Conn maintains that at this temperature miscellaneous species of bacteria develop that produce unfavorable results. While milk does not easily sour at this temperature, it should be remembered that undesirable germs are constantly developing.

As it is practically impossible to exclude all of the bacteria from milk during milking and the handling of the milk, it is very essential that the multiplication of the germs present be checked, or at least retarded; and this can be done by controlling the temperature of the milk. As low temperature is effective in checking the multiplication of the bacteria, the sooner the milk can be cooled after it is drawn, the better it is for the keeping quality of the milk.

Moisture.-Moisture is one of the essentials for bacterial 
growth. As milk is composed largely of water, bacteria find in milk a good medium for growth. All the other required food elements are also found in abundance in milk. Damp utensils and rooms are always more conducive to the growth of germs than are utensils and rooms which are thoroughly dried and ventilated. This is well illustrated by a refrigerator. A very damp dark refrigerator is always more conducive to the growth of molds in butter than is a dry refrigerator.

Unfavorable Conditions for Bacterial Growth.-The reverse

- of the favorable conditions mentioned above would be unfavorable to the growth of bacteria. As it is practically impossible to make conditions unfavorable for the growth of bacteria by taking away food, other means must be used. Extremely high temperatures destroy bacteria. Low temperatures check their growth, but so far as known do not destroy them. Absence of moisture and presence of direct sunlight are conditions which are not conducive to bacterial growth. Certain chemical substances when added to milk, or to the medium in which the bacteria are present, are very unfavorable to their growth. Some of these chemicals entirely destroy all germ life when added in even very small quantities. These are called disinfectants (formaldehyde, corrosive sublimate, etc.). Other chemicals are more mild in their effect upon germ growth, and merely inhibit or retard the growth of microorganisms. The chemicals which have this milder effect upon germs are called antiseptics. Boracic and salicylic acids are examples. Practically all disinfectants are violent poisons, and should not be used in any quantity or in any form in milk or dairy products which are intended for human food. The milder preservatives, or the antiseptics, are, as a rule, not so poisonous or injurious to human health. In some countries they are allowed to a small extent. For instance, according to reports, the laws of England permit the use of boracic acid to the extent of 0.5 of one per cent. It is, however, safest not to use any of these chemicals, except for preserving samples for analytical or similar purposes. As low and high temperatures 
are so effective in producing unfavorable conditions, these should be chiefly employed in controlling the growth of microorganisms in the dairy industry.

Kind of Germs Found in Milk.-The number of species of germs found in milk has not yet been definitely established, due chiefly to the fact that it is in some instances difficult

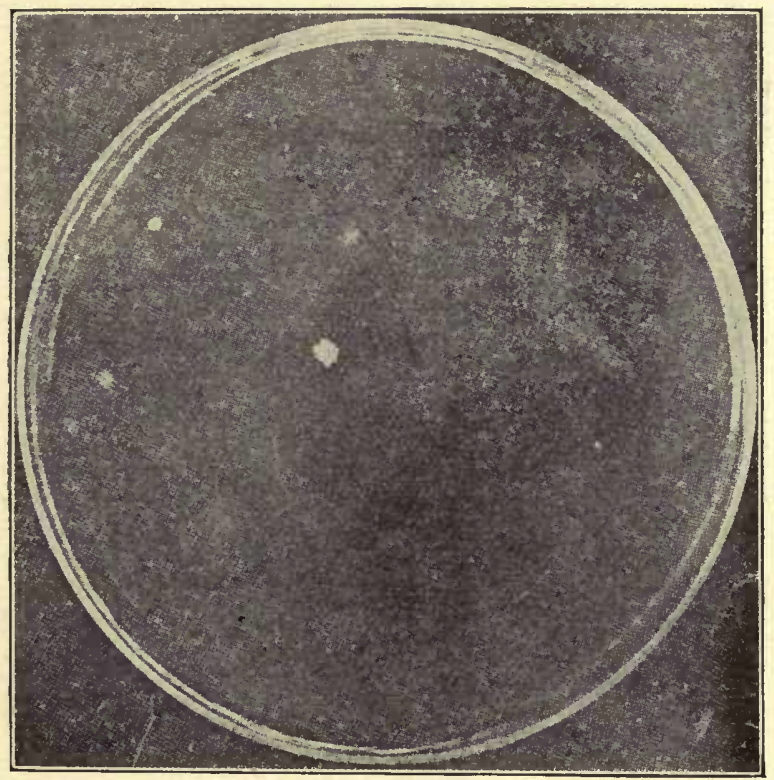

FIG. 8.-Shows a plate exposed in pasture where air must have been very pure and free from germs. (Bul. 87, Nebraska.)

for bacteriologists to differentiate one species from another. The description of one species of bacteria by two different bacteriologists may vary considerably, as the characteristics of the germs depend so much upon the conditions throughout the classification process. Over 200 different species have been described. It is possible, however, though all of these types may have different morphological and physiological characteristics as described by different bacteriologists, that some two or more of the 200 types may belong to one species. 
For this purpose, it is sufficient to classify the bacteria into three groups; viz., (1) those which are harmful to the buttermaking industry, (2) those which are beneficial, and (3) those which are indifferent, or produce neither good nor bad results.

From the farmer's or milk-producer's standpoint, none of these bacteria are desirable. Each milk-producer should

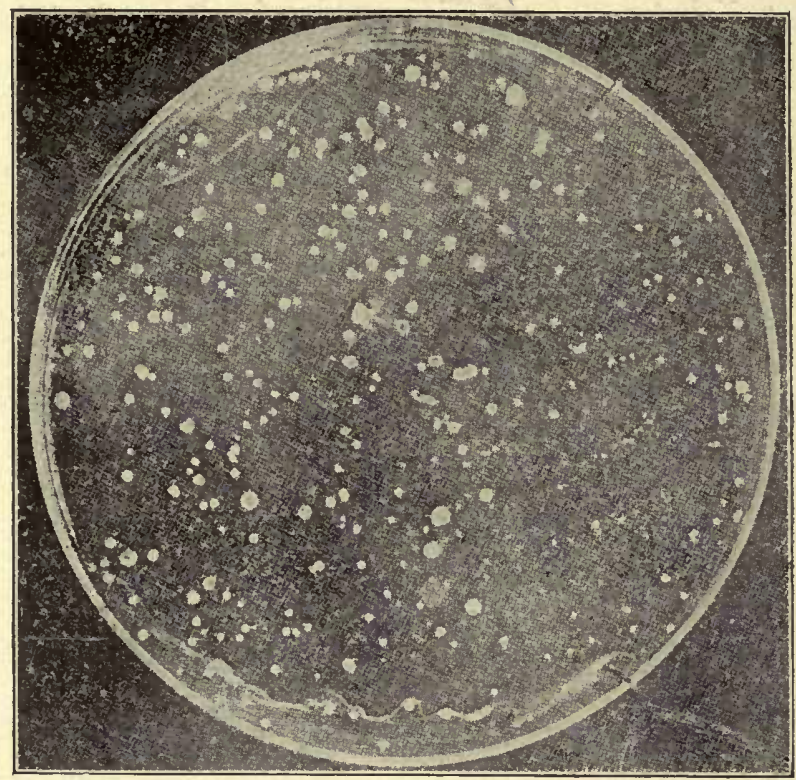

FIG. 9.-Shows a plate exposed one-half minute under a cow's udder treated with a $5 \%$ solution of carbolic acid. (Bul. 87, Nebraska.)

make it a point to prevent their entrance and suppress their development in milk and cream to as great an extent as possible. The creamery operator should endeavor to suppress all of the harmful germs, and foster the development of the desirable ones.

The germs which are desirable belong chiefly to the acidproducing types. They are often called lactic ferments.

The harmful bacteria include those which produce bitter milk, red milk, blue milk, yellow milk, slimy milk, etc. There 
is a number of species belonging to this group. The pathogenic germs, or disease-producing bacteria, must also be classed with the harmful bacteria. It is not the intention in this work to give an extended discussion of this subject. For such discussion see special works on Dairy Bacteriology.

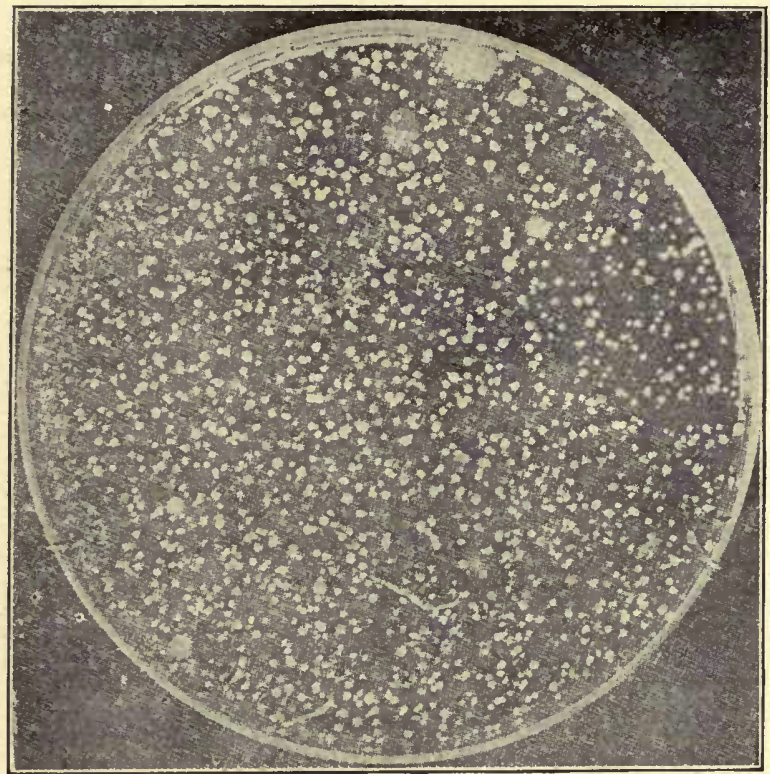

FIG. 10.- Shows plate exposed one-half minute under cow's udder treated by merely brushing with the hand; each little spot represents a colony of some kind of bacteria. (Bul. 87, Nebraska.)

Number of Bacteria in Milk.-The number of bacteria found in milk varies so much that it is practically impossible to state accurately the average number. The number of germs found varies according to several conditions, such as degree of cleanliness of cows, utensils, and milker; degree of purity of the atmosphere when the cows are nilked; and the temperature at which the milk is kept. When the milk is being produced under the best practical sanitary conditions, the number of germs need not exceed 10,000 per c.c. Such 
results cannot be obtained unless extreme precautions are taken. Milk produced under average farm conditions seldom contains less than 50,000 germs per c.c. shortly after the milking. Milk which is produced under filthy conditions, and which is several hours old, may contain several millions of bacteria per c.c.

Sources of Bacteria in Milk.-Except in the cow's udder where they are present to only a small extent, bacteria are present almost everywhere. They float in the atmosphere
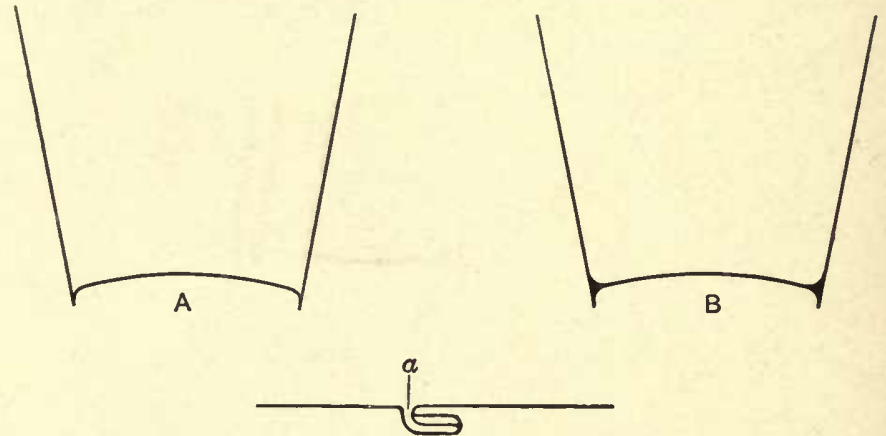

FIG. 11.-The wrong and the right kind of a milk-pail. $a$, the ordinary type of pail showing sharp angle between sides and bottom; $B$, the same properly flushed with solder so as to facilitate thorough cleaning. The lower figure represents a joint as ordinarily made in tinware. The depression $a$ affords a place of refuge for bacteria from which they are not readily dislodged. This open joint should be filled completely with solder. (From Bul. 62, Wis.)

and adhere to particles of dust. Especially is this so in the dusty cow-stable. They are present in all well water to a greater or less extent. They are very abundant in streams and rivers. They are present in the soil to a depth of several feet, the number decreasing with the depth. As these germs are practically present everywhere, the source of germs in milk may be said to be all around us. The principal sources of germs in milk are, however, unclean dairy utensils, unclean cows, and unclean surroundings. As these germs multiply chiefly by fission, or by one cell dividing into two, it is plain that the number of germs will increase very rapidly under favorable conditions. Under the most favorable conditions it requires 
approximately twenty minutes for this process of fission to take place.

Some germs develop small bodies within the cell, called spores. It is not difficult to destroy the sporeless cell by heat, but the spores are very resistant to unfavorable conditions. The spore-bearing bacteria eannot be destroyed by boiling. The heating destroys the vegetative cell, but the spores still remain. In order to destroy the germ in the spore form, it is essential that the milk be cooled to a temperature favorable to growth, and then allow the spore to develop into a vegetative cell. If heat is again applied, the milk ean be rendered entirely sterile. Usually three or four suceessive heatings and coolings are necessary in order to render the milk completely sterile. A single heating under pressure (15 minutes at 15 pounds) kills them at onee.

It has been demonstrated by several investigators that freshly drawn milk is not a good medium for bacteria to develop in. In fact, several experiments seem to indicate that milk acts as a germicide to certain varieties of bacteria. For instance, the cholera germ is to some extent destroyed in fresh milk, but it is not known to what extent. Organisms producing lactic acid eheck the multiplications of these pathogenie baeteria. This germicidal property is said to be common, to a greater or less extent, to all the animal secretions.

Effect of Thunder-storms on Souring of Milk.-It is a common impression that thunder-storms hasten the souring of milk. This was attributed to the electricity in the air accompanying the storm. Experiments by several investigators have proved that electricity does not have any effect on hastening the fermentative ehanges of milk. The reason why milk sours quicker when an electrical storm is approaching, is that the air temperature is usually higher then than at any other time. This higher temperature warms the milk and creates more favor. able conditions for the rapid multiplication of the germs present in the milk. It is for this reason that milk sours quicker during or previous to a thunder storm than at any other time. 


\section{CHAPTER V.}

\section{ABNORMAL MILK.}

Colostrum Milk.-Colostrum is the milk yielded immediately after calving. As the time of calving approaches, a cow usually diminishes in her milk-producing capacity. Most cows become dry about two months previous to parturition. If they do not naiurally stop giving milk, they should be dried up so as to have a seven week's rest before calving. When the rest has been given, the cows yield, immediately after calving, milk which has a composition and characteristics different from those of normal milk. If the cow continues to give a copious flow of milk up to the time of calving and is not allowed any rest, the difference in the milk yielded before calving and after calving is comparatively slight.

The composition of colostrum varies considerably during the first three days after calving. According to Engling, as reported by Richmond, the composition is a follows:

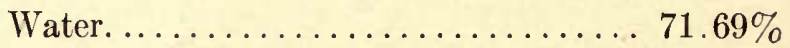

Fat. .................... 3.37

Albuminoids $\left\{\begin{array}{l}\text { Casein } \ldots \ldots \ldots \ldots \ldots \ldots \\ \text { Albumen . . } \ldots \ldots \ldots \ldots\end{array}\right.$

Sugar. ................. 2.48

Ash..................... 1.78

Colostrum greatly changes in composition and appearance as it gradually assumes the characteristics of normal milk. It is at first reddish yellow in color, and has a viscous and slimy 
consistency. It is a food which the newly born calf should not be deprived of, as it seems to be specially suited for the digestive tract of the young calf.

It will be seen from the above table that the water content of colostrum is less than that of normal milk. The fat content is a ittle lower than that of normal milk. The most striking characteristics of colostrum, however, are the low content of sugar, and the large amount of albumen. Of the latter substance very little is present in normal milk. The mineral constituents of colostrum also run quite high. The specific gravity of colostrum varies from 1.046 and 1.079. When boiled, the nitrogenous matter coagulates. The colostrum is not considered to be suitable for food until about four days after parturition. Whenever it can be boiled without coagulating, it is claimed to be safe to use. At times a cow's udder becomes inflamed after calving. In such cases the abnormal qualities of the cow's milk will extend over a greater period of time than that mentioned above.

Salty Milk.-The average chemical analysis of salty milk as calculated from results obtained by the analysis of such milk from four cows given by Böggild,* is as follows:

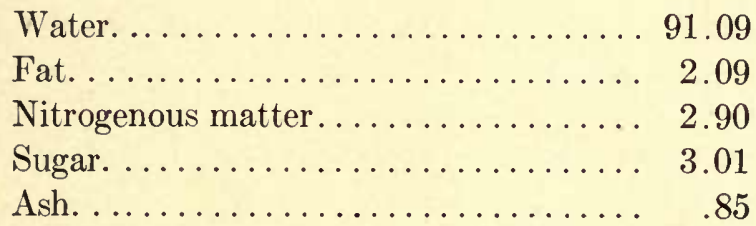

It has an average specific gravity of 1.0244 .

Salty milk does not occur very often, but whenever it does occur, it is difficult, and, so far as known, impossible to cure without drying up the cow. Two samples of such milk have recently come within the author's notice. It had the appearance of normal milk, had a foul smell, and very salty taste. 
The two samples contained $1.7 \%$ and $1.9 \%$ of fat respectively. They soured and curdled in a normal way at living-room temperature in about thirty hours. At this stage they were very foul in smell, and unpleasant in taste.

The cows which had produced this milk had both calved about three months previously. It occurred in the month of July, when pastures were quite good. The udders of the cows were in an apparently normal condition. At first it was thought that some conditions in the pasture caused this abnormal milk. The cows were taken into the barn, and fed on dry food for two weeks, but without any change in the quality of the milk. Gradually they dried up.

The reason for the secretion of this salty milk was laid to the long time which the cows had been yielding milk without any rest. They had been given no rest previous to the last calving. It is also believed that this quality of milk will occur more frequently when the cows are near the close of their lactation period.

While the above two causes are perhaps the most common, they are not the only ones. Salty milk has been obtained from cows to which these reasons could not be ascribed. Böggild has found that salty milk has been secreted by cows with abnormal udders. He has also demonstrated that it was the diseased part of the udder from which the salty milk was yielded. The healthy portion of the udder yielded normal milk. It is possible that an obscure, diseased condition of the udder may be the entire cause.

Salty milk is of course undesirable in the dairy or creamery. It is very disagreeable to the taste, and in a fermented stage becomes very foul.

Bloody or Red Milk.-Bloody, or red milk is caused, first, by an abnormal condition of the cow's udder, which may or may not be apparent; and second, a red color may be developed in milk after standing, through the action of bacteria.

The bloody milk, caused by an inflamed udder, often assumes a reddish-yellow appearance, and may, if not examined care- 
fully, be mistaken for colostrum. Bloody milk produced by an inflamed udder, may be distinguished by noticing small blood particles, which will settle to the bottom, and can be noticed if the sample is placed in a glass test-tube. Bloody milk caused by bacterial growth does not show the blood at the bottom, but instead, previous to stirring the milk or cream, it appears on the surface in small red dots. The red color which commonly occurs in milk is due chiefly to a species of germ called Micrococcus prodigiosus. Colostrum will show reddish cream on the surface, but no blood-like material will separate out.

Blue Milk.-Blue milk is quite commonly found. Formerly it was thought that this color was due to the condition of the casein in the milk, but since more has been discovered in regard to the effect of germ life upon conditions and properties of milk, it has been proved that blue milk is caused by bacteria* (Bacillus cyanogenus). This particular germ produces the blue color in the milk only when the milk has an acid reaction. When sterile milk is inoculated with this particular germ, the blue color is not produced, but by the addition of a little acid, or by inoculating the milk with the bacteria that produce lactic acid, the blue color is produced. This seems to be one of the instances of symbiotic action of bacteria in milk. There are probably other causes, but they are not known. This germ, according to Aikman, is killed by heating the milk to about $176^{\circ} \mathrm{F}$. The germ ceases to work as soon as milk is coagulated.

Yellow Milk.-According to Aikman,* yellow milk is caused chiefly by one species of bacteria, named Bacillus synxanthus. This micro-organism belongs to the group of ferments that act upon the fat of milk. There are different shades of yellow produced in milk, caused by different species of bacteria, but the above-mentioned one is considered to be the principal cause. Some produce a brilliant yellow color, while other species first 'curdle the casein, and then digest or dissolve it into a yellow or amber-colored liquid.

* C. M. Aikman, in "Milk, Its Nature and Composition." 
Ropy Milk.-The slimy or ropy condition of milk is not common. It is sometimes found in milk handled by milk-

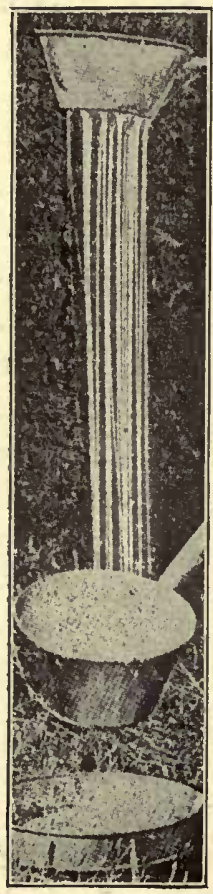
FIG 12 - Slimy ency over the germs causing sliminess, and mould "string in that way the trouble may be eradicated. out" in fine threads several feet in length. (From Bul. cies which produces sliminess in milk. This 62 , Wis.) organisms. Aikman mentions the fact that no less than eighteen different distinct organisms have been identified as associated with this slimy fermentation. Most of the investigators agree that two organisms are chiefly responsible for this slimy condition. One of these is Bacillus lactis viscosus.* This germ has been found to be frequently present in surface waters. The very fact that milkdealers in cities are occasionally troubled with this sliminess in milk indicates that precautions are essential in order to avoid the presence of this ferment in milk. This germ, when it once gains entrance to a milk establishment, is very difficult to eradicate. In order to overcome this trouble it may be necessary to cover the whole inside of the milk-store, and all of the vessels used for handling the milk, with sour coagulated milk. The lactic acid germs present in this milk gains ascendStreptococcus hollandicus $\dagger$ is another spedealers and is caused by certain microparticular organism is used in Holland as a starter. The starter containing this particular germ is added to the milk used in the manufacture of Edam cheese, in order to control or check the gassy fermentation which may be present in it.

Bitter Milk.-This is one of the most common kinds of abnormal milk, and like some of the others, may have more

* Adametz Landw. Jhr., 1891, p. 185.

$\dagger$ Milch Zeit., 1889, p. 982. 


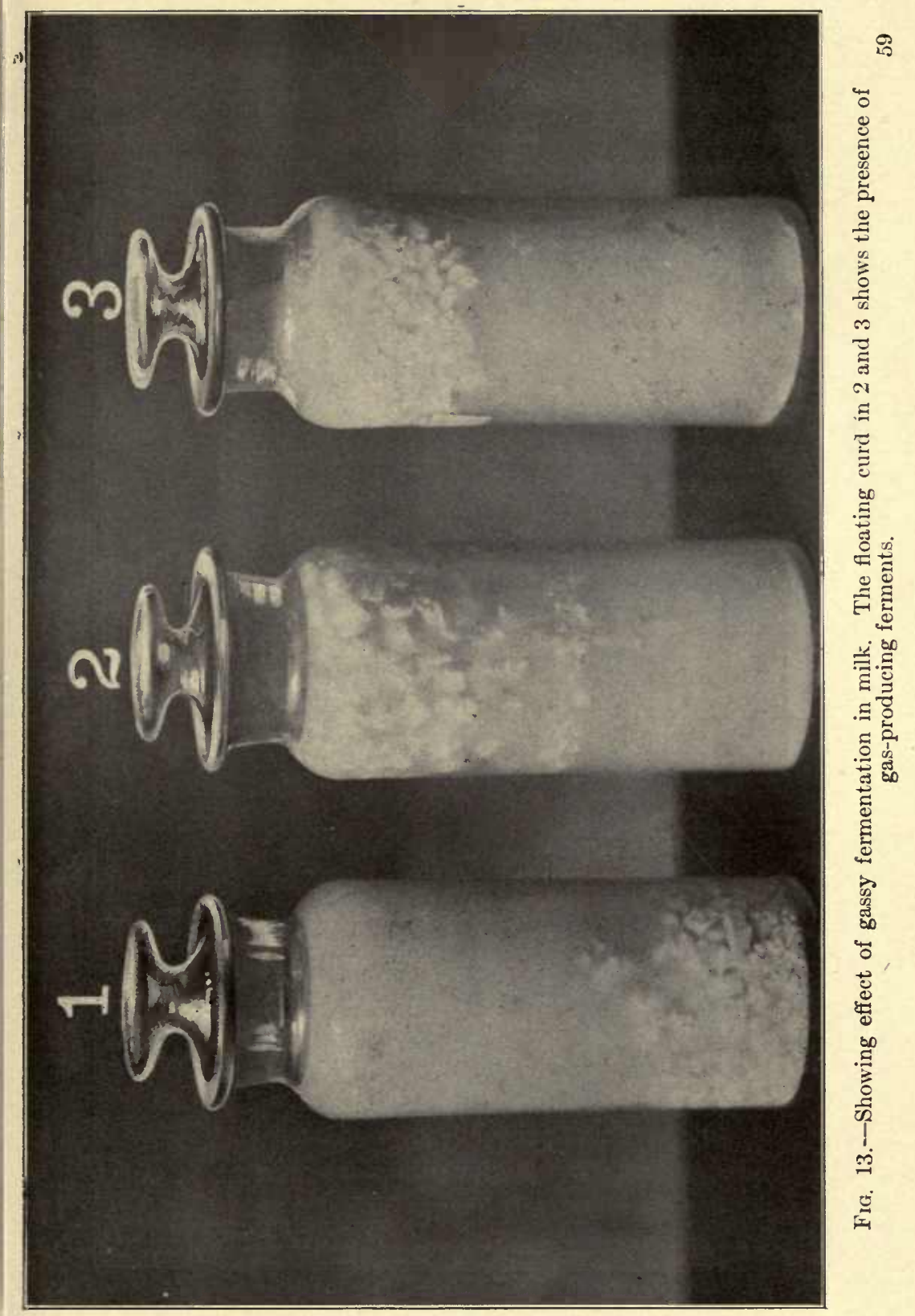


than one cause. It may be due to some undesirable food that the cow has eaten, or to the development of certain germs in the milk. If caused by the food eaten by the cow, the bitter taste is recognizable immediately after the milk has been drawn. If it develops on letting the milk stand, it is caused by bacterial growth.

Several germs have been found to be associated with the production of this bitter flavor in milk. Conn has described a micrococcus which produces a bitter flavor in milk. Weigmann has described a bacillus which also produces bitter flavors. Nearly all of the investigators agree that the germs causing the bitter flavors in milk belong to the group which acts upon the casein in milk. The bitter flavor is most commonly found in milk that has been heated, and then cooled to a low temperature. The heat destroys the bacteria that produce lactic acid, but does not kill those that produce the bitter flavor, owing to the fact that they are spore-producing.

The germs that produce a bitter flavor do not develop in milk that is partly soured, because an acid reaction is unfavorable to their growth.

It was formerly thought that the organisms that cause the bitter flavor in milk produced butyric acid. This theory, however, has been largely overthrown, as it has been found that the germs causing bitter flavor are chiefly of the kind which peptonize the casein and produce gas.

Milk from Cows which have Been in Milk for a Long Period. -The difference in the composition of the fat yielded by cows in different stages of the lactation period seemingly does not affect the quality of the milk to a noticeable extent. If the cows have been giving milk an unusually long time, then the milk may become abnormal.

The impurities in the small amount of milk yielded by cows almost dried up are quite apparent, and the causes of the presence of these impurities are readily understood. The small amount of milk drawn from such a cow would contain a proportionately larger amount of dirt and germs than would 
a larger amount of milk drawn from a cow yielding more milk, providing the cleanliness of the udder and manner of milking were the same. Cows giving a good quantity of milk always seem to have a cleaner udder. This has been laid to the more vigorous circulation of the blood in the udder of the cow that yieldls a larger portion of milk.

When cows calve once a year, and have rest of about seven weeks previous to parturition, if proper precautions are taken concerning cleanliness, they seldom yield milk from which a first-class quality of butter cannot be produced. In practice this regularity of calving does not always exist. Several instances have come within the author's notice where cows have been in milk for two years or more without coming in fresh. Such a condition happens quite frequently on small farms, where the cows kept are so few that it is deemed impracticable to keep a bull. As a consequence cows are not served at the proper time, and great irregularities in calving are introduced.

At times it also happens that cows become barren. In such a case they are usually milked as long as they will produce even a very small quantity of milk. Milk produced under such conditions is likely to become abnormal in character. It may remain normal with a slight increase in the fat-content. The abnormal milk, so often complained of, is usually brought about by similar circumstances. It is a common belief that milk yielded from such animals always contains a high fatcontent, but it may contain very little fat. It may be salty. It may also appear normal, and the cream when separated appear viscous and dead. Böggild states that the milk at the creamery from one barren cow has more than once produced difficult churning.

Milk from Spayed Cows.-H. Lennat has given this kind of milk considerable study. He finds that milk from spayed cows may vary in quality to the same extent as milk from normal cows. The solids of milk, as a rule, increase as the spayed cow advances in the milk-giving period. Especially was this 
noticeable in the fat, sugar, and casein. Such milk is considered to be of extra good quality, and is recommended as being especially suitable for infant-feeding.

Milk from Sick Cows. - Too much cannot be said against the use of milk from sick cows. As soon as the cows decline in health, the quantity will be noticeably decreased, and the quality is usually abnormal. The kind of milk yielded varies with different cows and different diseases, but it is interesting to note from the study of this subject, by several men, that the milk-secreting glands are quickly affected by disease and are unable to perform their proper functions. Even a slight derangement of the digestive organs is said to have a marked influence upon the flavor of the milk and butter. When cows do not clean well after calving, the milk secreted by them always has an undesirable taste. During the time of sexual excitement of the cow, milk is usually decreased in quantity, and in a great many instances assumes a very disagreeable flavor.

When a cow's udder is inflamed, the milk usually assumes an abnormal condition. It usually contains large, white, slimy lumps. According to Bang, * this is caused by a snall round bacterium, and is contagious. When this germ is inoculated into the udder, the cow gets feverish and the milk becomes slimy.

When cows become infected with tuberculosis to such an extent that the udder shows lesions and nodules, then the composition and appearance of the milk is altered considerably. Milk from such cows contains tubercle germs, appears yellowish brown in color, and has an alkaline reaction. The composition of such milk has been studied in Denmark and reported by Böggild to be as follows:

Water........................ 88.79

Fat......................... 3.55

Albuminoids. ................. 5.69

Sugar. ...................... 1.25

Ash. ....................... .94

* Maelkeribruget i Danmark, by Böggild. 


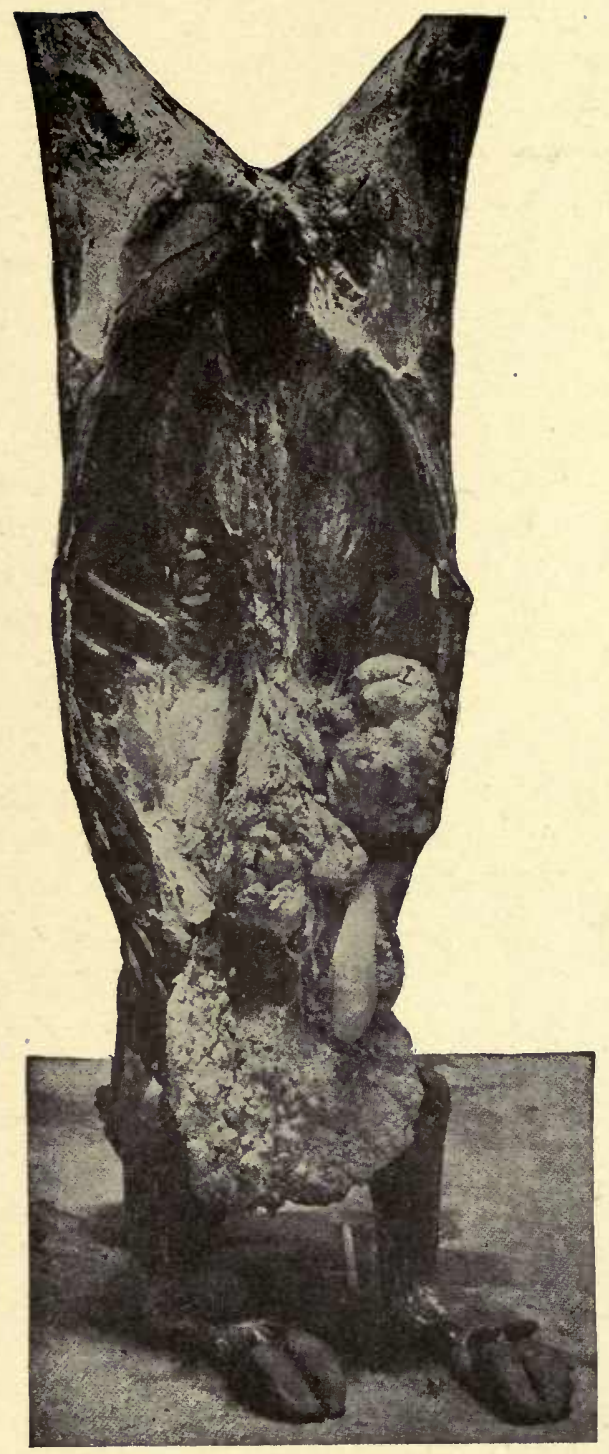

FIG. 14. - The carcass of an animal killed for beef, showing tuberculosis of the liver, omentum, and lungs. Generalized tuberculosis. (Bul, 229, Cornell, N. Y.) 
These results represent the average of four samples taken from the diseased part of the udder. It will be seen that the greatest variation from normal milk exists in the small amount of sugar it contains and the high per cent of ash and nitrogenous matter. 


\section{CHAPTER VI.}

\section{VARIATION OF FAT IN MILK.}

The percentage of fat in normal milk varies a great deal more than any other of the constituents of milk. Dr. Richmond reports that the fat of milk may go as low as $1.04 \%$ and as high as $12.52 \%$. Such extreme variations are, of course, abnormal. The fat-content seldom falls below $2 \frac{1}{2} \%$ or rises above $7 \%$. The fat-content of milk from a whole herd of cows, varies only within comparatively narrow limits. The following are the chief factors which cause the fat-content of milk to vary:

(1) Individuality of cows.

(2) Breed of cows.

(3) Time between milkings.

(4) Manner of milking.

(5) Whether the milk is fore or after milk.

(6) Age of cow.

(7) Lactation period.

(8) Feed of cows.

(9) Environmental conditions.

I. Individuality of Cows.- That the quantity of milk from individual cows varies is a fact that is well known to everyone who keeps cows, but the average cow-keeper does not very well apprehend that the percentage of fat is as variable a factor as it really is. As a rule, when a cow yields only a small quantity of milk she is in many instances condemned without taking the quality into consideration. If the fat content were taken 
into consideration, such a cow might prove more profitable to keep than another that yields a larger quantity of milk. For this reason the yield of fat is a better standard by which to judge the value of a cow than the quantity of milk. Since the general introduction of the Babcock test for the determination of fat in milk, the fat-content of milk can be easily determined, even on the farm. The importance of testing the milk of each cow in a herd is sufficient to warrant every cow owner to have a complete Babcock testing outfit on the farm.

Unprofitable cows are, and have been, a serious drawback to dairy progress. According to Dairy Commissioner Wright's reports, the average yield of butter per cow, in the State of Iowa, is less than 140 pounds per year. Some of the cows from which these statistics were calculated evidently gave good returns to the owners, while others again would run their owners in debt. Cases are on record where single cows have produced more than eight hundred pounds of butter annually. Such a yield is the result of a great many years of attention to the selection and breeding, and can be obtained only in special cases. A yield of 400 pounds of fat per cow annually might be a good standard for which to strive. Even if the average annual butter yield per cow could be brought up to 300 pounds, the dairy industry would be put on a sounder and more profitable basis. The average price of butter is about twenty cents per pound. At this rate 300 pounds of butter would be worth $\$ 60.00$. The average cost of keeping a cow in the State of Iowa is about $\$ 35.00$, including care and feed. This would leave a net profit of $\$ 25.00$ per cow. If a cow yielded only 140 pounds per year, which at 20 cents would be worth $\$ 28.00$, the owner of that cow would suffer a loss of $\$ 7.00$. It must not be forgotten that the above calculation is based only upon the butter-fat. The calf and the skimmed milk are not taken into consideration. The skimmed milk is worth 25 cents per hundred pounds for feeding purposes, and the calf is worth about $\$ 3.00$. 


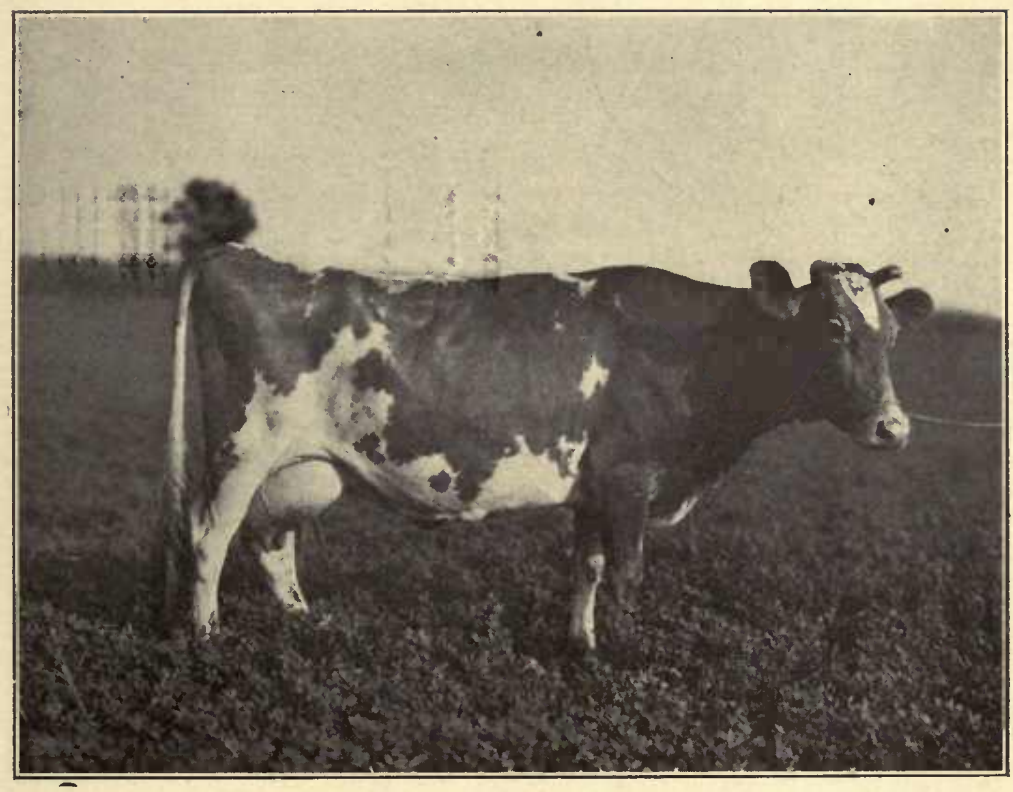

Guernsey Cow (Custer's Belle, 9514).

Owned and bred by W. D. Hoard, Fort Atkinson, Wis. Calved when two years old. She produced that year 423 pounds of butter-fat. Periodical weighing of milk every seventh week and testing showed that she had produced 6649 pounds of milk containing 314 pounds of fat in eight months ending Sept. 14, 1905. She calved again Jan. 15, 1905. The above records we e made under ordinary feeding and management such as the whole herd received. 

Table by Gurler, Showing Records of Individual Cows.

\begin{tabular}{|c|c|c|c|c|c|c|c|c|c|c|}
\hline 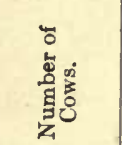 & 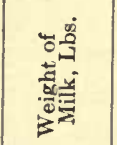 & 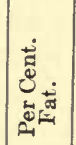 & 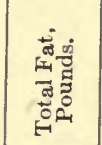 & 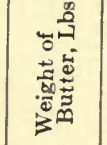 & 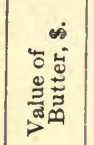 & 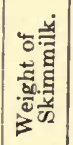 & 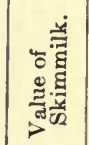 & 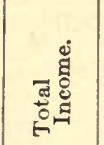 & 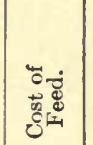 & $\begin{array}{c}+1 \\
+11 \\
11 \\
0 \\
0 \\
0 \\
0 \\
0 \\
0 \\
0\end{array}$ \\
\hline $\begin{array}{c}\text { Av. of } \\
50 \text { cows } \\
244 \\
154 \\
44 \\
72 \\
308 \\
184 \\
262 \\
283 \\
129 \\
\text { Av. of } 4 \\
\text { best } \\
\text { Av. of } 4 \\
\text { poorest } \\
\text { Av. of } 9 \\
\text { cows }\end{array}$ & \begin{tabular}{|c|}
5708 \\
2382.5 \\
3619 \\
3399 \\
2661 \\
4617 \\
7997 \\
9297 \\
10151 \\
8449 \\
9098 \\
\\
3020 \\
5897
\end{tabular} & $\begin{array}{l}4.47 \\
4.87 \\
4.51 \\
4.58 \\
5.06 \\
3.83 \\
4.77 \\
5.03 \\
3.68 \\
4.52 \\
4.25 \\
4.75 \\
4.43\end{array}$ & \begin{tabular}{|l|}
255.2 \\
116.13 \\
163.4 \\
155.94 \\
134.97 \\
177.16 \\
382.04 \\
372.56 \\
374.76 \\
406.73 \\
384.00 \\
142.60 \\
253.5
\end{tabular} & $\begin{array}{l}297.7 \\
135.48 \\
190.63 \\
181.93 \\
157.46 \\
206.68 \\
445.71 \\
434.65 \\
436.75 \\
472.18 \\
447.32 \\
160.40 \\
295.7\end{array}$ & $\mid \begin{array}{l}59.54 \\
27.09 \\
38.12 \\
36.86 \\
31.49 \\
41.43 \\
89.14 \\
86.93 \\
87.35 \\
94.43 \\
89.46 \\
33.28 \\
59.14\end{array}$ & $\begin{array}{l}5453 \\
2266 \\
3494 \\
3243 \\
2526 \\
4440 \\
7615 \\
8900 \\
9777 \\
8545 \\
8709\end{array}$ & $\begin{array}{r}14.00 \\
5.66 \\
8.64 \\
8.10 \\
6.31 \\
11.03 \\
19.14 \\
22.00 \\
24.44 \\
21.36 \\
21.76 \\
7.20 \\
1.1 .11\end{array}$ & $\begin{array}{r}73.57 \\
32.75 \\
46.76 \\
44.48 \\
37.80 \\
52.36 \\
108.28 \\
109.02 \\
111.79 \\
115.80 \\
111.22 \\
40.48 \\
73.25\end{array}$ & $\begin{array}{l}41.06 \\
31.23 \\
41.06 \\
37.32 \\
26.45 \\
39.32 \\
44.32 \\
44.72 \\
44.72 \\
46.06 \\
44.95 \\
33.96 \\
39.46\end{array}$ & $\begin{array}{r}+19.98 \\
-11.00 \\
-\quad 6.80 \\
-5.34 \\
-1.15 \\
+\quad 0.44 \\
+51.46 \\
+51.80 \\
+54.57 \\
+57.24 \\
+53.77 \\
-5.98 \\
+21.25\end{array}$ \\
\hline
\end{tabular}

In making the calculations in the above table the price of butter per pound was taken as 20 cents, the skimmed milk was considered to be worth 25 cents per hundred pounds, and the cost of iabor was taken at $\$ 12.50$ per cow.

Breed of Cows.-There is a marked difference in the milk secreted by different breeds of cows. The most striking difference is, perhaps, between the Holstein and the Jersey breeds. The former, as a rule, yields a large quantity of milk, with a comparatively low fat-content; the latter, as a rule, yields a comparatively small quantity of milk, with a high percentage of fat. The influence of individuality of cows must not be overlooked in this connection.

It is said that the color of the skin, and of the fine hairs on the exterior of the cow's udder may be taken as a guide in selecting cows for breeding purposes. A fine soft skin, darkish golden yellow in color, enveloping the milk-glands, and covered with fine soft hair, are considered indications of rich milk. While the Jersey cows perhaps yield milk with a higher fat- 
content than any other breed, a high percentage of fat is characteristic of the milk from all the Channel Island breeds. On account of the great variation in the composition of milk from different cows, it is difficult to get results from experiments where the number of cows involved in each breed and trial have been so numerous as to overcome the individuality of the cow. We quote the following table, which shows the average results from the breed tests conducted at the Annual Dairy Shows of the British Dairy Farmers' Association between the years 1879 and 1893, inclusive:

\begin{tabular}{|c|c|c|c|c|c|c|c|c|}
\hline \multirow{2}{*}{$\begin{array}{l}\text { Total } \\
\text { No. of } \\
\text { Ani- } \\
\text { mols. }\end{array}$} & \multirow{2}{*}{ Breed. } & \multirow{2}{*}{$\begin{array}{c}\text { Average } \\
\text { Milk } \\
\text { Yield. } \\
\text { Lbs. } \\
\text { Daily. }\end{array}$} & \multicolumn{2}{|c|}{ Total Solids. } & \multicolumn{2}{|c|}{ Fat. } & \multirow{2}{*}{$\begin{array}{l}\text { Soljds. } \\
\text { Not } \\
\text { Fat, } \\
\text { Per } \\
\text { Cent. }\end{array}$} & \multirow{2}{*}{$\begin{array}{l}\text { Live } \\
\text { Weight. }\end{array}$} \\
\hline & & & $\begin{array}{l}\text { Per } \\
\text { Day, } \\
\text { Lbs. }\end{array}$ & $\begin{array}{c}\text { Per } \\
\text { Cent. }\end{array}$ & $\begin{array}{l}\text { Per } \\
\text { Day, } \\
\text { Lbs. }\end{array}$ & $\begin{array}{l}\text { Per } \\
\text { Cent. }\end{array}$ & & \\
\hline 147 & Shorthor & 43.86 & 5.64 & 12.86 & 1.65 & 3.77 & 9.09 & 1403 \\
\hline $1: 9$ & rsey & 27.36 & 3.98 & 14.54 & 1.33 & 4.85 & 9.69 & 832 \\
\hline 63 & Guernsey. & 28.95 & 4.07 & 14.05 & 1.38 & 4.78 & 9.28 & 1033 \\
\hline 10 & Holstein. & 45.19 & 5.53 & 12.25 & 1.54 & 3.41 & 8.84 & 1383 \\
\hline 18 & Ayrshire. & 37.82 & 5.09 & 13.45 & 1.60 & 4.22 & 9.23 & 1060 \\
\hline 2 & sons & 30.12 & 4.32 & 14.34 & 1.48 & 4.90 & 9.44 & \\
\hline 8 & Red Polls..... & 35.10 & 4.55 & 12.96 & 1.38 & 3.92 & 9.04 & 1201 \\
\hline 1 & Welsh. . & 46.00 & 5.86 & 12.74 & 1.91 & 4.16 & 8.58 & \\
\hline 1 & Aberdeen-Ang. & 60.30 & 8.29 & 13.74 & 3.01 & 4.99 & 8.75 & \\
\hline 12 & $\begin{array}{c}\text { Fierries } \\
\text { Dexters. . . . . }\end{array}$ & 26.59 & 3.56 & 13. & 1.11 & 4.18 & 9.19 & 749 \\
\hline 30 & Crosses. . . & 42.05 & 5.41 & 12.87 & 1.56 & 3.70 & 9.17 & 1362 \\
\hline
\end{tabular}

These results agree very closely with tests carried on in the United States, with the exception of the two breeds, Welsh and Aberdeen Angus. The former breed is rare in this country. The latter breed is considered to be quite inferior as a milkproducing breed, but one of the best beef types known. The results obtained in the test above, where only one cow was involved, are abnormal and cannot represent the average of Angus cows' milk.

Time Between Milkings. - The common practice in the United States is to milk twice during twenty-four hours, every morning and evening. The intervals between these milkings are not always of the same length. Under the average farm 


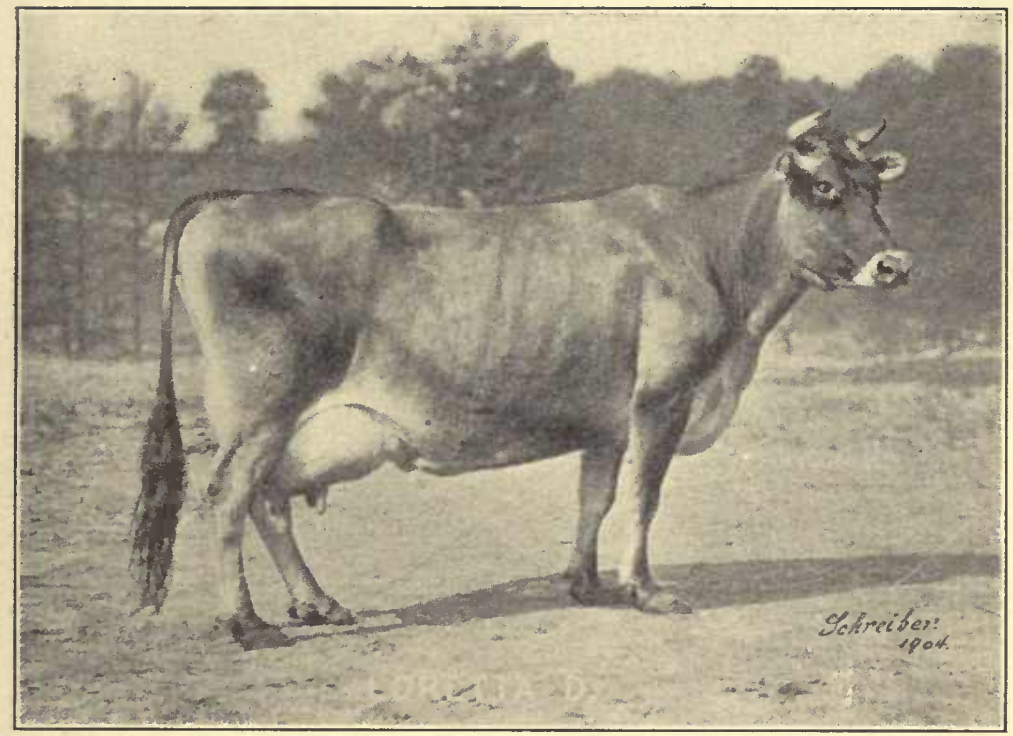

Jersey Cow (Loretta D, 141,708, A. J. C. C.).

Owned by W. S. Tadd, Portland, Oregon. Record at St. Louis Exposition from June 16 to Oct. 13,1974 , (120 days, 5802.7 pounds of milk containing 280.16 pounds of fat. Value of feed consumed \$31.99. Dropped Oct. 13,189 ). Weight 1075 poinds 


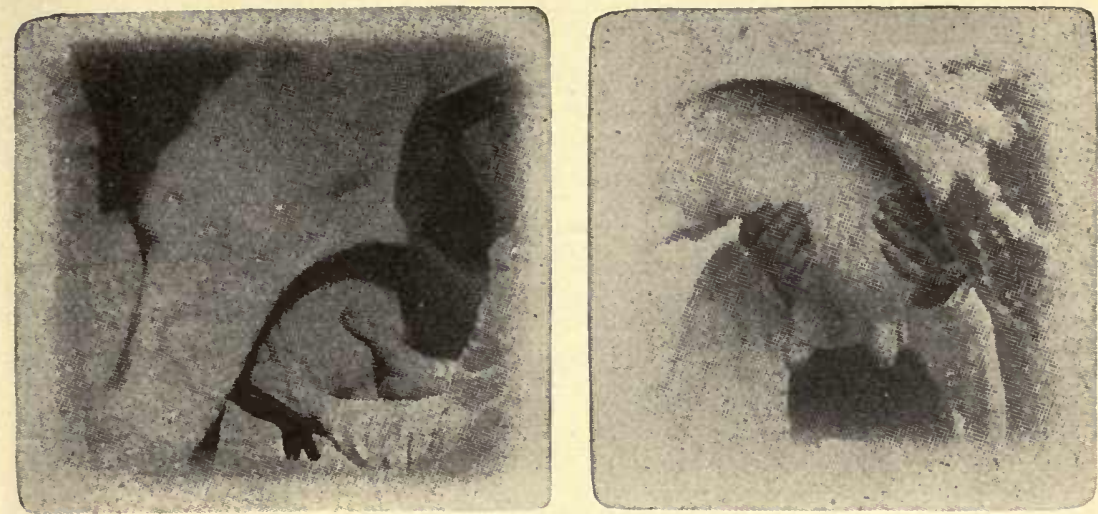

FIG. 16.-First manipulation of udder, right Fig. 17.-First manipulation, left quarters. quarters.

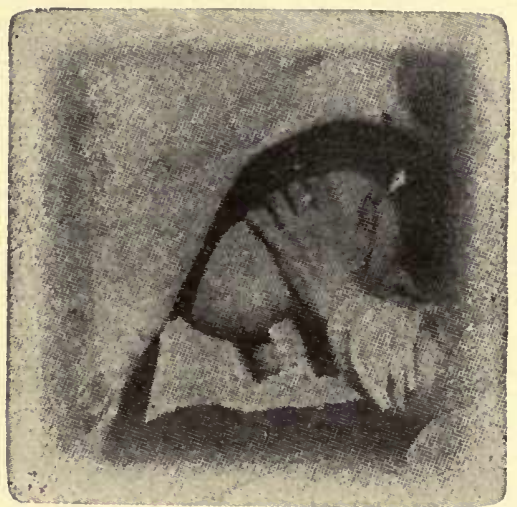

FIG. 18.-Second manipulation, right fore-quarter.

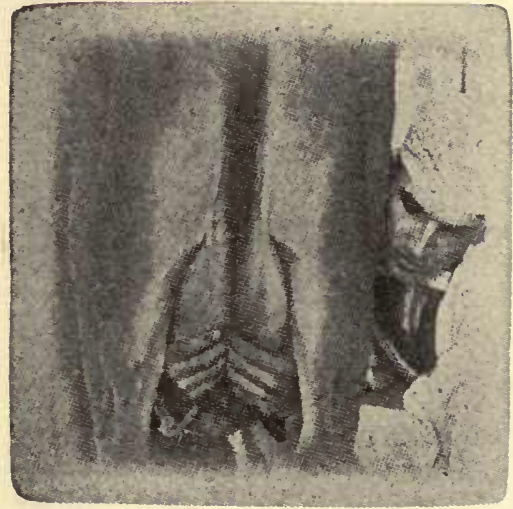

Fig. 19.- Second manipulation, right hindquarter, rear view.

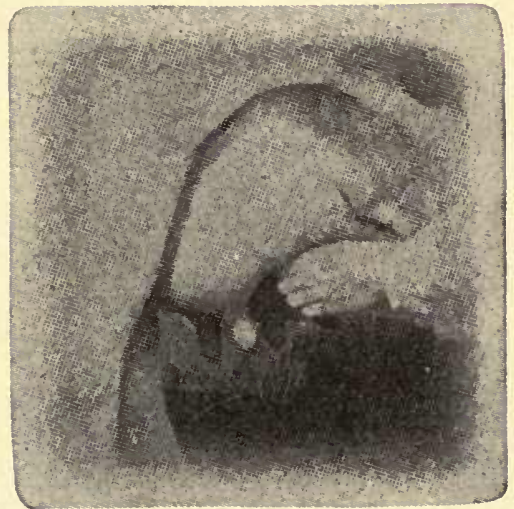

FIG. 20.-Third manipulation.

Illudstrating Hegelund Method of Milking. (From Report of Kansas State Board of Agriculture, No. 87, 1903.) 
Milking-machines.*-For a long time successful milkingmachines have been expected by dairy enthusiasts. Seemingly these expectations have been fulfilled. Many large dairy farmers are now operating such machines. The Burrell-Lawrence-Kenedy milking-machine and the Globe are two of the machines which under proper conditions and

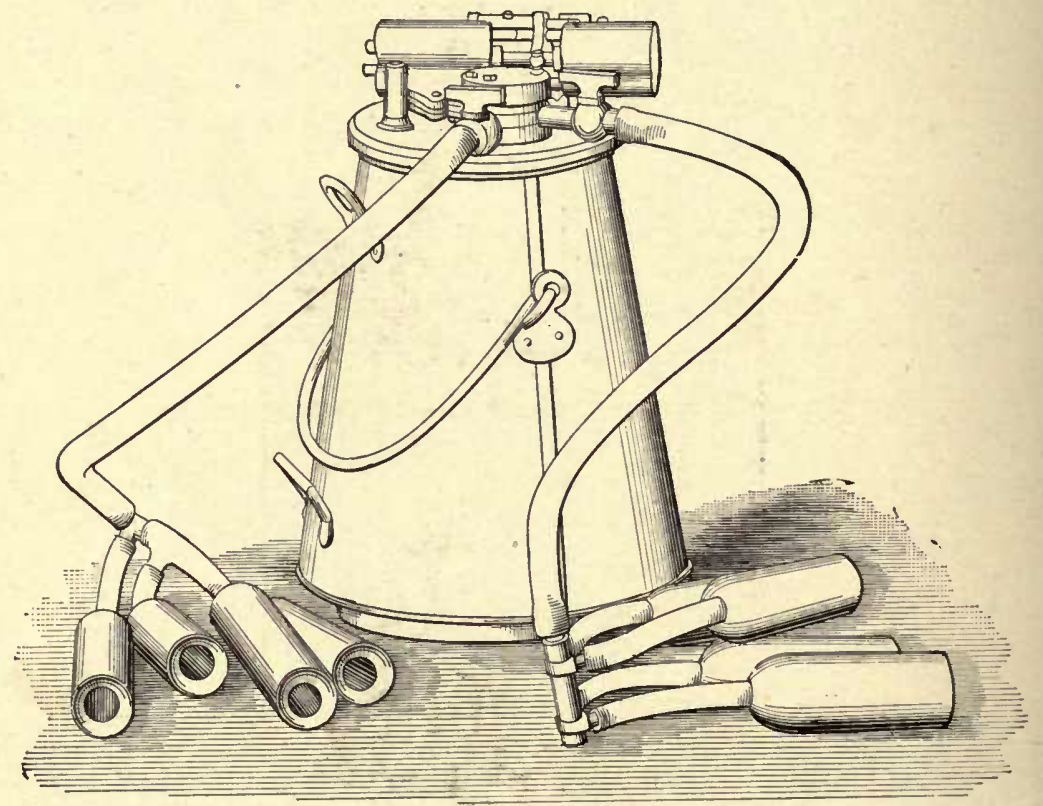

Fig, 20a.-The Globe milking-machine.

care have been found to operate successfully in the United States.

The cost of installation, and eare and skill necessary in -conomic operations, are factors which retard their use on the

* Bulletin No. 92, Bureau of Animal Industry, U. 3. Dept. of Agr. Bulletin No. 47, Storr's Experiment Station, Conn. Bulletin No. 140, Manhattan, Kans. 


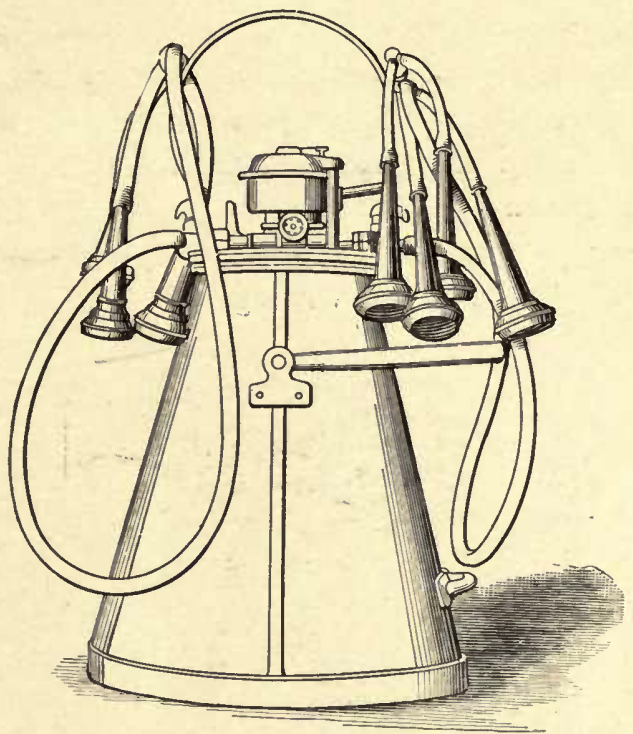

FIG. 20b.-The Burrell-Lawrence-Kenedy milking-machine.

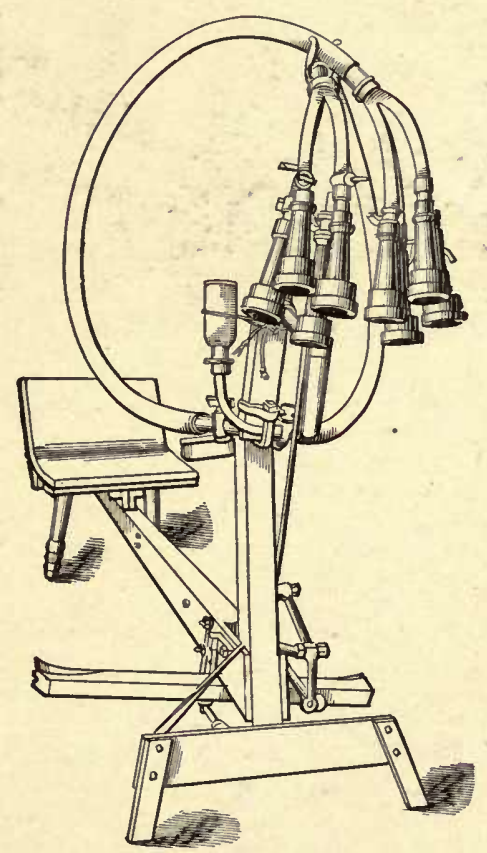

FIG. 20c.-A foot-power cow-milker with attachments. (Mehring.) 
average sized dairy farms. If a man keeps at least twenty good cows in milk at the time, and makes dairying a business, not a side issue, and is willing and able to care for the machine as it should be cared for, then the milking-machine can apparently be economically and successfully operated. The milkingmachine question is still in a transitional period and shall not be considered in detail at this writing.

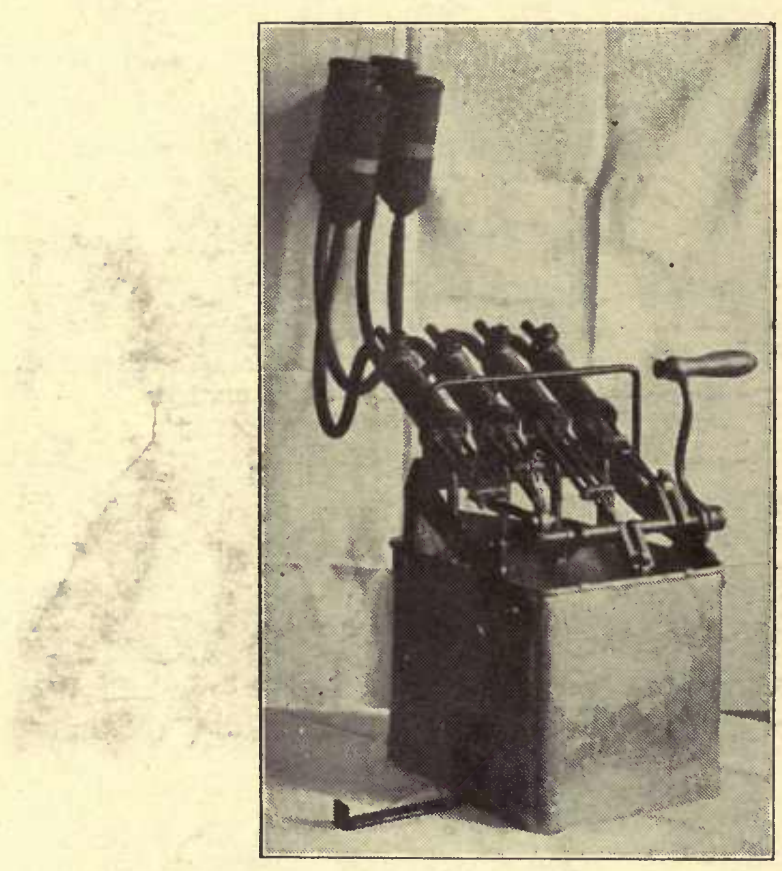

FIG. 21.-De Schmidt milking-machine.

All of the above machines are represented by their respective inventors and manufacturers to do successful work. Whether a milking-machine will ever be perfected which can imitaté nature's methods as closely as the human hands, is a question which has yet to be solved. 


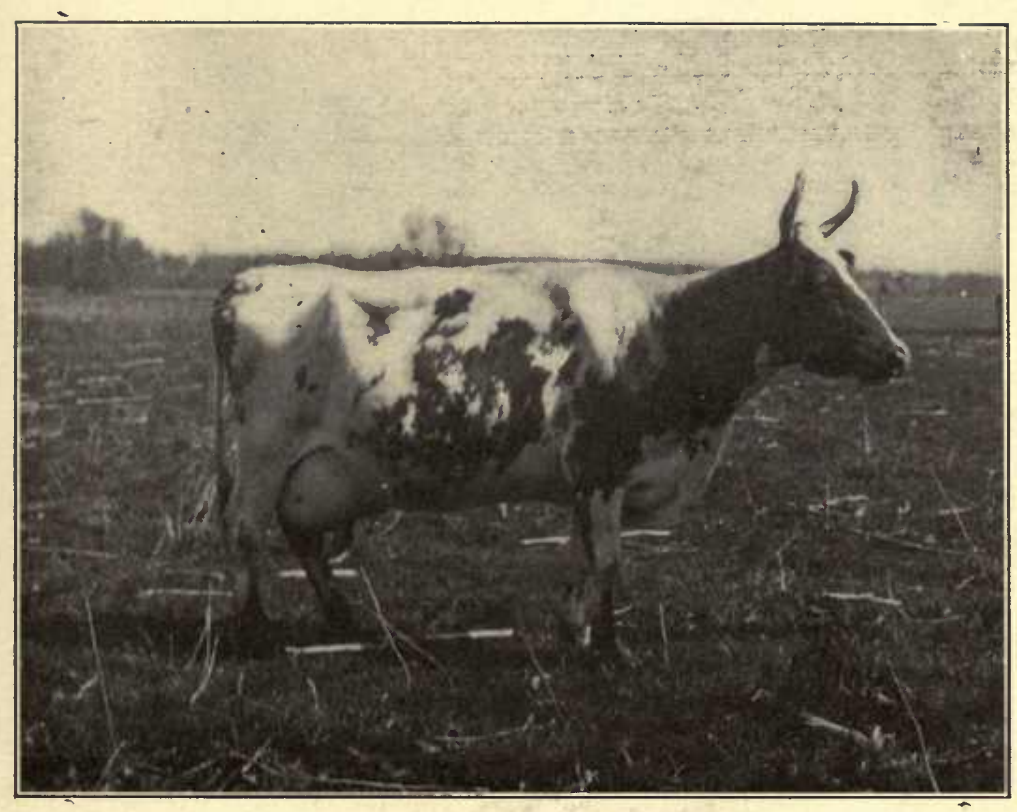

An Unregistered but Pure-bred Ayrshire Cow.

Owned by C. C. Burr, St. Charles, Ill. In the year 1902-3, under ordinary farm conditions and feeding, she gave 8467 pounds of milk which contained 342 pounds of butter-fat. 

According to experimental evidence, milk drawn with a machine contains more bacteria than milk drawn by hand. This is claimed to be due to the suction on the exterior of the teat, and to the tubes through which the milk must pass after it is drawn.

Fore-milk and After-milk. - The fore-milk, or the milk drawn from the cow's udder first, contains much less fat than does the milk drawn subsequently. The very first milk drawn

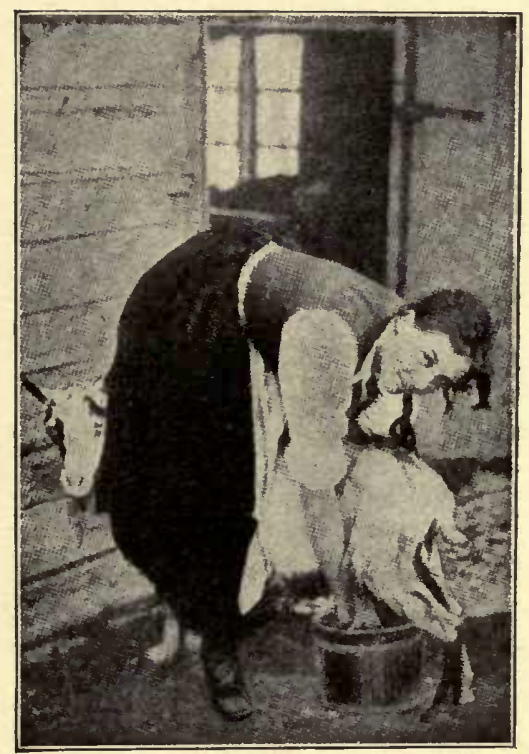

Fig. 22.-Milking goats in Norway.

appears watery and contains as little as $0.1 \%$ of fat, while the very last milk in the udder may contain as high as $12 \%$.

The reasons assigned for this variation are (1) the milk in the canal of the teat, and lower portion of the milk-reservoir is present under such conditions as to allow creaming to proceed. (2) The larger fat-globules are about as large as the smaller milk-dusts in the cow's udder; consequently the downward passage of these fat-globules meets with some obstruction 
and they are drawn out only when the last milk is removed. (3) The fore-milk has been subjected to a re-absorption process of the lymphatics. The third factor perhaps plays only a small part in reducing the fat-content of the fore-milk. As the fore-milk contains so very little fat, and a great many micro-organisms, it is often advantageous to reject the first few streams of milk. Especially is this important when sanitary milk is desired.

It is in many instances customary, in order to apportion the calf a certain amount of milk, to first partly milk the cow by hand, and send this milk to the creamery, and then allow the calf to suck the remainder. The results of such procedure are plain, yet it is practiced to a large extent. When discovered, it has in many instances explained why a certain creamery patron's milk has been testing low at the creamery.

Age of Cow.-There is a time during the life of a cow when she is most vigorous and most productive. At the time she first calves (about three years old) the cow or heifer is still growing, and her milk-producing capacity is not so great then as it is later on, when she becomes matured. After this increase in quantity there is also a slight increase in quality. At the age of about seven years the cow is usually at her best. As the cow advances in age, usually the quantity and quality diminish. However, the individuality of cows prevents drawing any definite line. In some cows age has considerable effect, while in others age has but little effect.

Lactation Period.-By lactation period we understand the milking period, from the time of calving until the cow is dried up. The first few days after calving, the cow yields milk which is rich in solids, not fat. The fat-content in milk from most cows usually increases a trifle during the first two weeks after parturition. Then, when conditions are normal and uniform, the percentage of fat is nearly constant for about three months. After this time the quantity decreases and the quality gradually increases a trifle. This applies more fully if the cow is pregnant. Most cows calve in the spring of the 


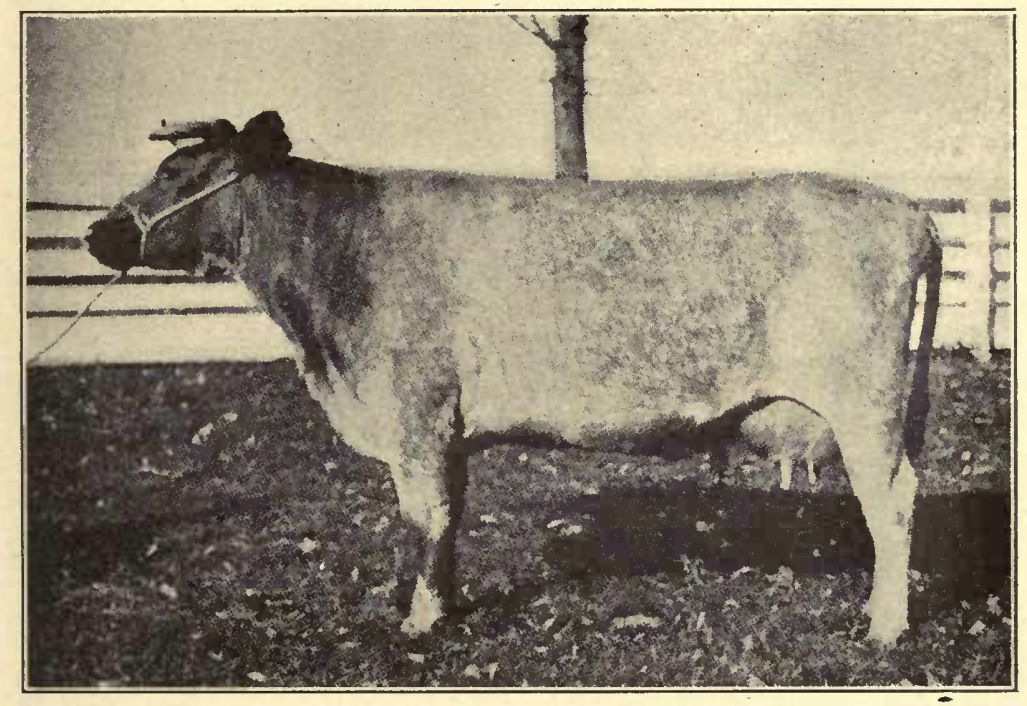

Short-horn Cow (College Moore).

Owned by Iowa State College, Ames, Ia. She produced 9896.5 pounds of milk containing 406.8 pounds of fat during one milking period extending over 393 days beginning Oct. 4, 1899. Weight 1695.8 pounds. 

year, and as a consequence milk usually tests a little higher in the fall.

Food of Cows.-For a long time it was thought that the kind of food had considerable influence upon the fat-content of milk, but later experiments in this country, as well as in foreign countries, have almost completely demonstrated that food has practically no effect upon the quality of milk. Investigators agree that foods may affect the fat-content of milk by increasing the quantity of milk, without reducing the per cent of fat, thus increasing the total amount of fat. Extensive experiments were carried on in Denmark, where more than one hundred and fifty cows were involved in each experiment, on ten different estates, in order to determine the effect of food upon the percentage of fat in the milk. Roots of different kinds, which are very succulent, were fed with out reducing the per cent of fat. Different concentrated feeds (oil-cake, wheat, bran, ground barley, and oats) were also fed with a view of increasing the percentage of fat, but without any noticeable effect. The New York Station found, through carefully conducted experiments, that feeding tallow to cows did not increase the percentage of fat in the milk.

Soxhlet found that by feeding tallow, in the form of an emulsion, for a consiclerable time, he was able to increase the percentage of fat in the milk. The Iowa Experiment Station also reported that the percentage of fat could be increased by feeding oil meal. Dr. Lindsey, at the Hatch Experiment Station, Massachusetts, recently found that fat can be slightly increased by the use of certain foods rich in oil.

But on the whole, the results reached so far show that different foods have little influence on the percentage of fat in the milk. Especially is this so under practical conditions.

On the other hand, different kinds of foods affect the composition of the fat itself. Gluten meal, in fact all gluten products, produce butter containing a high per cent of olein, and usually an increase in the volatile fats. Cottonseed-oil produces a 
decrease in the volatile fats, and makes butter noticeably harder and more tallowy in appearance.

Environment.-Unfavorable environmental conditions imposed upon a cow, such as sudden changes in temperature, storms, impure surroundings, and ill-ventilated barns, are certain to decrease the flow of milk; and if they are continued a few days, the percentage of fat in the milk will decrease also. In a general way it might be said that any unfavorable condition which causes a decrease in the quantity of milk will cause a slight increase in the percentage of fat during the first few days. But if the cow is surrounded with these unfavorable conditions for any length of time, the percentage of fat will again decrease. It is possible, however, by ill treatment, to diminish the fatcontent greatly.

Exercise, also, affects the yield of milk, as well as the quality. Uninterrupted, long confinement in a stall is detrimental to a cow's health. For a time it shows no effect upon the quantity and quality of the milk, but eventually it will decrease both. However, many Danish dairy farmers keep their cows in the barn all winter, without letting them out for exercise, and it is said that this confinement has apparently no effect upon the quantity and quality of milk. But a proportionately large number of their cows are infested with tuberculosis. Whether this is due to lack of fresh air and exercise, the authors cannot say.

Too much exercise is adverse to producing the most and best milk. If a cow is kept in the barn every day, half an hour's exercise, preferably out of doors, when weather permits, seems to give good results. A small box-stall for each cow, or a well-bedded shed for them to stand or lie down in after feeding, are favorable conditions for getting the proper amount of exercise, especially during cold weather.

Change of location, fright, sudden shocks, and nervousness are conditions from which the cow must be kept, in order to do her best as a milk-producing animal. 


\section{CHAPTER VII.}

RECEIVING, SAMPLING, AND GRADING MILK AND CREAM.

Receiving and Grading of Milk and Cream. - The man who receives and samples milk at a creamery should be accurate and quick with figures, have ability to grade and select milk, and to stimulate interest in the production of good milk. He should also be able to reconcile and satisfy patrons. The method employed in some creameries of allowing a boy with immature judgment to weigh and sample milk should not be tolerated. The person who weighs and samples milk and cream comes in direct contact with the patrons. Therefore, he is a strong factor in preserving the best interests of the creamery. In many of the best butter and cheese factories in the country the head maker or manager in charge is usually found at the weighing can. This gives him the opportunity of studying the raw material from which he is expected to make a high grade of butter or cheese. Some of our large central plants pay the highest salary to the man who has the ability to properly grade the cream and prepare the starters. This requires a fine sense of smell and taste, which is not possessed by every one.

The first step in the receiving of milk is to ascertain the quality of the milk delivered by the patrons. It is now a recognized fact that the best butter cannot be produced from defective or abnormal milk or cream, no matter how many improved methods are employed in the manufacture. In view of this, and the knowledge we now have of the transmission of undesirable germs from one sample of milk to another, and also the probability that some of the patrons will deliver poor 


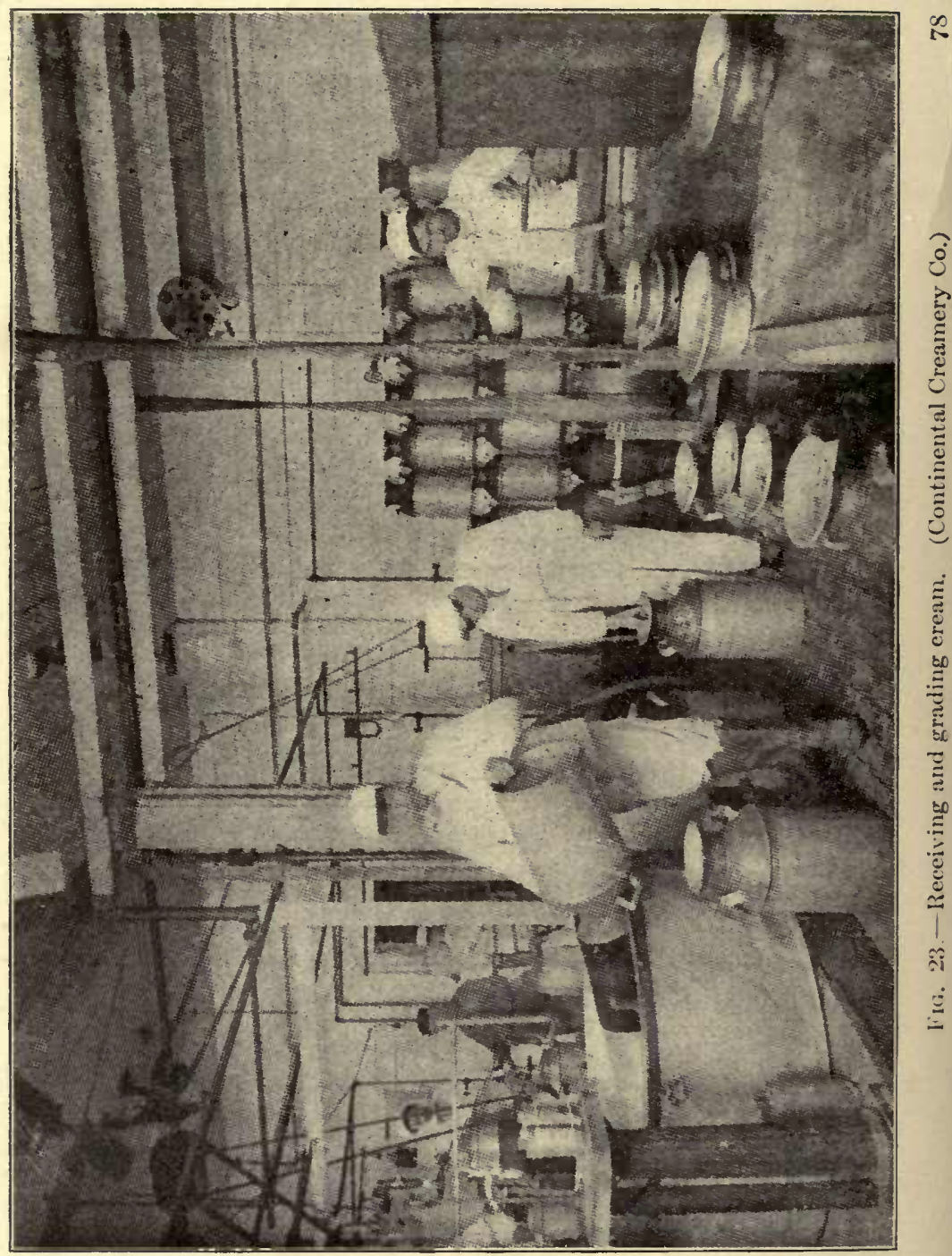


milk, it is essential that the milk or cream be graded when it is delivered at the creamery.

In the grading of milk or cream, different methods can be used for detecting abnormal milk: (1) through the senses, taste, sight, and smell; (2) by the acid tests; (3) by the fermentation test; (4) by heating; (5) by the Babcock test and the lactometer.

I. Detection of Abnormal Milk through the Senses.-In order to detect the different kinds of defective milk, one must be

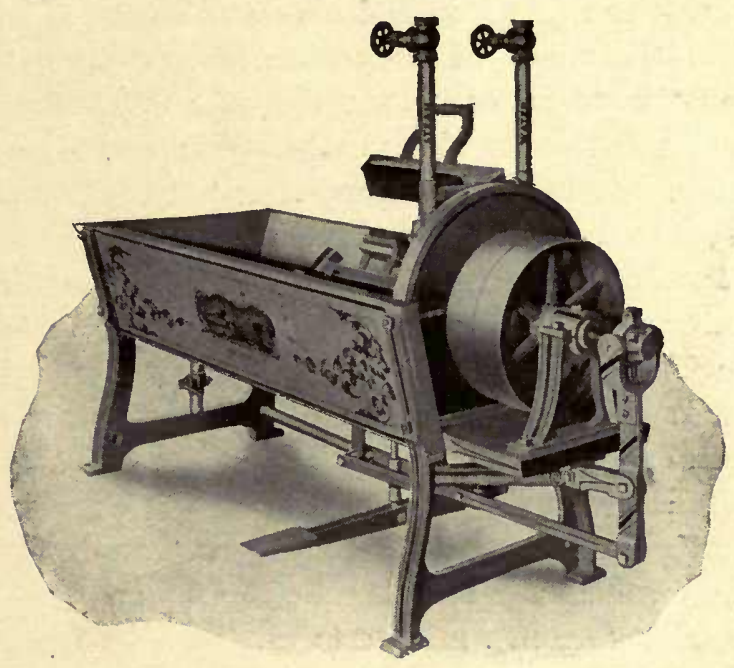

FIg. 24.-The Twentieth-century can-washer.

endowed with acute senses of smell, taste, and sight. When the milk is in a good condition, it has a pleasant smell and sweet taste, and appears normal. If it has a disagreeable smell and taste it cannot produce good butter or cheese. As a rule, the quantity of defective milk brought into the average creamery is much in excess of that of really perfect milk. As a consequence it would not be practical to separate all the defective milk into one class and the perfect into another. The question as to where the line should be drawn between the good, medium, and very bad milk or cream, must depend 
upon the judgment of the receiver, and in a great measure upon the local conditions. Some of the creameries have no facilities for handling different grades of milk, and some sell butter on a market where no sharp distinction is made between good and poor butter. Others have, through experience, satisfied themselves that under American creamery conditions it does not pay to make too many grades, nor does it pay to grade too closely. Two, or at the most three, grades of butter can at times be manufactured in one creamery profitably. It is advisable to reject sour and abnormal milk. If accepted, it should not be mixed with the remainder of the milk, as it might contaminate all of it; or, the sour milk might cause coagulation, and thereby clog up the separators. If a can of milk is sour, but otherwise clean, it is not necessarily unfit for the production of first-class butter. If retained until after the sweet milk has been skimmed, it may be run through the separator successfully.

2. The Use of Acid Tests.-Some creameries, especially the larger central cream plants, are now grading the milk or cream according to the amount of acid it contains. For instance, cream or milk containing $.2 \%$ acid or less is classed as first grade; that containing from .2 to $.4 \%$ as second grade, and the cream containing more than $.4 \%$ acid as third grade. Mann's and Farrington's acid tests can both be used, but a more rapid and convenient way is to use a solution prepared from Farrington's tablets. The solution is prepared by taking one tablet for each ounce of warm water and allowing the tablets to dissolve. When one part of this alkaline solution and one part of milk are put together in a cup and mixed and the solution still retains a pink color, it shows that there is less than $.1 \%$ acid in the sample tested. If two parts of alkali and one part of milk are mixed and the mixture remains pink, then there is less than $.2 \%$ of acid. If the mixture turns colorless, it shows there is more than $.2 \%$ acid in the sample. If three measures of alkali to one measure of milk are taken, and the mixture remains pink, that indicates that there is 
less than $.3 \%$ of acid, etc. By means of such a test the acidity can quickly be determined.

The sample cups should be numbered to correspond with the number of each patron. The results of the tests should be noticed at once, as the action of the atmosphere affects the color.

The acid tests are of value in grading cream, as a sour sample of milk or cream is either old or has been improperly kept and handled. The number of grades of cream and milk and the maximum limit of acid each grade can contain, are factors which must be decided according to local conditions, by the operator.

3. Use of the Fermentation Tests.-Curdled, ropy, red and blue milk can, as a rule, readily be detected without the application of a special test, but there are cases when a person's senses are not sufficiently acute to detect samples of milk containing undesirable fermentations. Several instances haye recently come within the authors' notice. A neighboring creamery was infested with a peculiar fermentation that caused a very rank flavor in the butter. The milk that came to the creamery was carefully examined, but without locating the source of the trouble. The cause could not be ascertained without the use of the fermentation test.

It is in such instances that a fermentation test is of special value. As a rule, at least when the trouble first begins, it is milk from one particular patron that causes the trouble. This milk may appear to be normal, and yet contain germs which are very undesirable for the manufacture of the best quality of butter.

Fermentation Te-ts.-There are two tests which may be of general use; namely, the "Wisconsin Curd Test" and the "Gerber Fermentation Test." The former is used in cheese factories, but the latter is to be recommended in testing milk for butter-making.

Gerber Test.-This test consists of properly made glass tubes which fit into a rack. This rack, containing the bottles, 
fits into a small round tin tank, which is kept about two-thirds full of water. The temperature of this water can be controlled by means of a lamp kept burning underneath, or by the use of steam. The milk from the different patrons is put into the glass tubes, and these tubes numbered so as to indicate to which patron each belongs. The temperature should be kept at about 104 to $106^{\circ} \mathrm{F}$. for about six hours. Then the tubes are taken out, the milk shaken, and the appearance, smell, and taste of the milk noted. The tubes are warmed again for about another six hours, when they are again examined. If any samples contain a preponderance of abnormal ferments, the fact will usually appear in less than eighteen hours. If milk does not coagulate in twelve hours, or become abnormal in some way, it is supposed to be good.

The special apparatus mentioned above is not absolutely essential, nor is the temperature employed considered by the authors to be the most suitable to give reliable results. Ordinary sample jars can be used, instead of specially prepared tubes. After the milk has been placed in the jars they can be kept in any convenient place, at a temperature of about $98^{\circ} \mathrm{F}$. The best place to keep them is in a vessel containing water, the temperature of which can be controlled.

Wisconsin Curd Test.-This test consists of taking some milk in a jar and adding about ten drops of rennet, which coagulates the milk. The sample is allowed to stand until the curd hardens, then it is cut into small pieces with a case knife; the whey is drawn off, and the curd allowed to stand at a temperature of $98^{\circ} \mathrm{F}$. If there are any undesirable forms of bacteria present, they will reveal themselves by developing small holes in the curd, usually accompanied by a bad odor.

This test is a very ingenious one for cheese-making. In butter-making the Gerber Fermentation Test, or a similar one, is more convenient.

4. Grading Milk by Heating.- This test is not used very much in creameries; but in cheese factories the heating of milk in order to ascertain its suitability for cheese-making is 
practised to a considerable extent. This test is in common use in Canada. It consists of heating a small sample of the milk to be tested to $120^{\circ} \mathrm{F}$. If it will stand this temperature without coagulating, it is considered to be good milk. If it

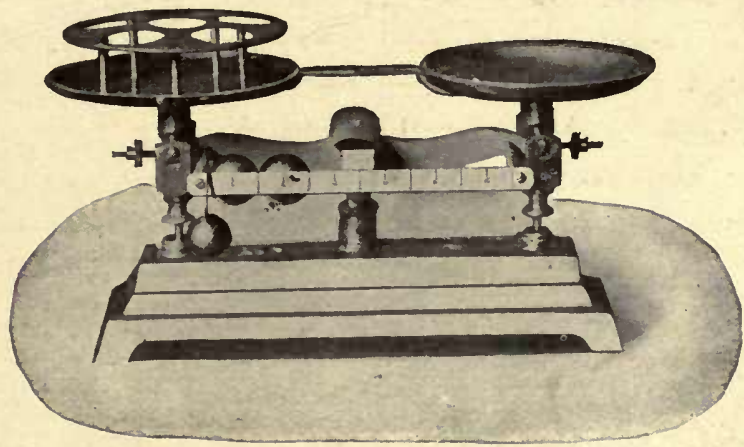

FIG. 25.-Troemner's Babcock cream-testing scales,

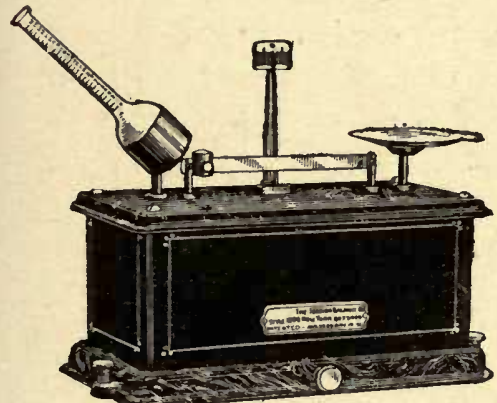

FIG, 26. - Tortion cream testing sca'es.

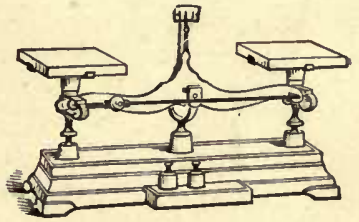

FIG. 27.-Troemner's Bal;cock cream-testing scales.

coagulates when heated to this temperature, it is too sour to be used for cheese.

This heating may be considered an acid test. When nilk contains about $.3 \%$ acid, it usually coagulates when heated. It should be borne in mind in this connection that different samples of milk do not coagulate when containing exactly the same amount of acid, and at the same temperature. Some samples will coagulate upon heating when containing little 
less than $.3 \%$ acid, while others will not coagulate until more than $.3 \%$ acid has developed.

In practice the temperature $\left(120^{\circ} \mathrm{F}\right.$.) is not always considered. A small portion of the sample to be tested is put into a tin cup. The cup containing the milk is put into hot water or over a jet of steam. When hot its characteristics are noticed.

5. Use of Babcock Test and Lactometer.-These tests are of special value in detecting watered or skimmed milk. When-

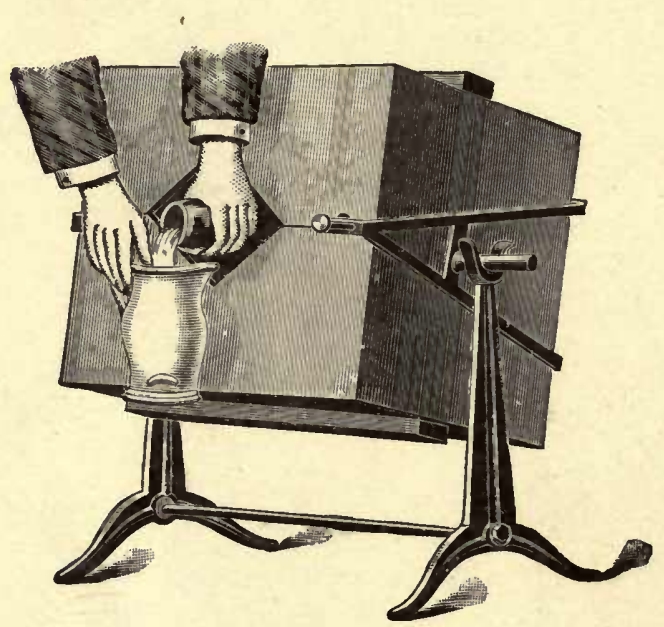

FIG. 28.-Acid carboy trunnion.

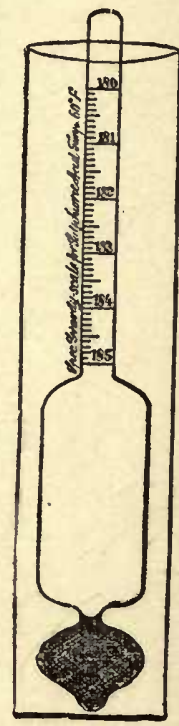

Fig. 29.-Acid hydrometer.

ever a sample of milk appears watery or blue, it is fair to presume that water has been added. The test for specific gravity and the test for fat can then be applied to such samples of milk. As a rule composite samples are taken daily at creameries, and the patrons paid according to the fat delivered. For this reason water adulteration is not very common at creameries, but is practiced to a greater extent in the milk-supplies of cities. The use of the lactometer in connection with the Babcock test has already been referred to under the heading of "Specific Gravity of Milk." 
There are two tests commonly used for determining fat in milk, viz., the Babcock and Oil-test Churn. The latter method is rapidly giving way to the former. The Babcock test. is undoubtedly superior, though many still prefer the Oil-test.

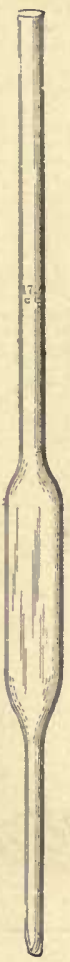

FIG. 30.-17.6 c.c. milk FIG. 31.-Automatic pipette.

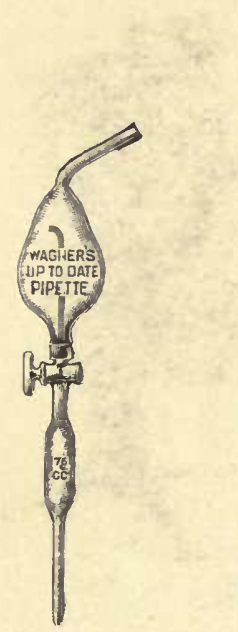

17.6 c.c. pipette.

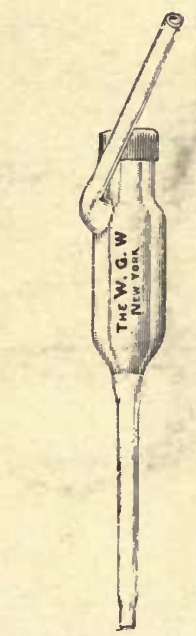

Frg. 32-Automatic Russian pipette.

The Babcock method of testing consists of taking 18 grams of the substance to be tested into a special graduated bottle as shown in illustration. Milk is measured out with a pipette holding 17.6 c.c. Cream, butter, and cheese, or any other substance which cannot be measured accurately, should be weighed. The measured quantity of milk in the bottle is then digested by adding 17.5 c.c. of commercial sulphuric acid having a specific gravity of about 1.82. The acid digests all proteids and sets 
free the fat. The contents of the bottle should be well shaken at once after the acid has been added.

The bottle with its contents is then whirled about five minutes in a centrifugal machine at a rate depending upon the diameter of the machine, usually about 850 to 1000 revolutions

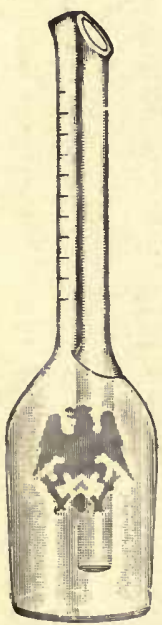

FIG. 33.

Skim-milk test-bottle.

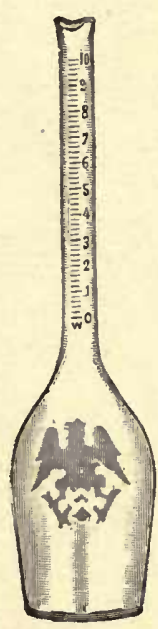

FIG. 34. Whole-milk test-bottle.

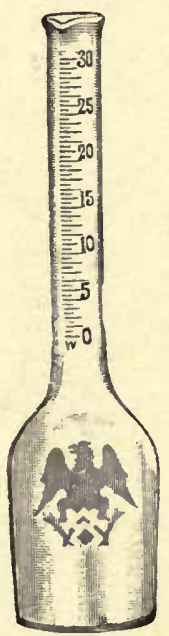

FIG. 35.

Cream testbottle

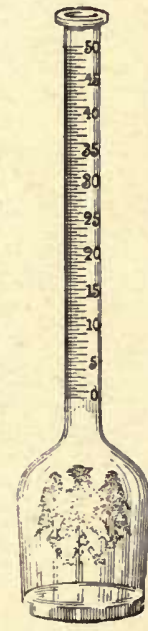

Fig. 36.

9-gram cream test-bottle.

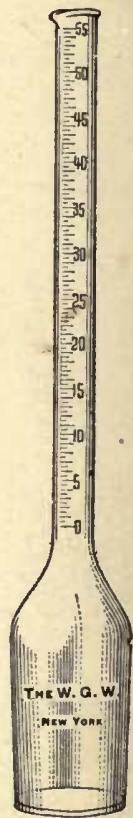

FIG. 37.

Cream test-bottle.

BABCOCK TEST-BOTTLES.

per rinute. The machine is then stopped and filled to the neck of the bottle with pure hot water. Distilled water is preferred. The bottles are then whirled two minutes, and hot water added again until the fat rises in the neck where it can be read. The bottles are then whirled again for about one minute. The machine is then stopped and the fat read in percentage direct from the bottle. By using a pair of dividers 
the reading may be facilitated. The temperature at the time of reading should be between $120^{\circ}$ and $140^{\circ} \mathrm{F}$.

There are three very common defects in the clearness of fat reading: (1) The fat contains black, charred, flocculent matter at the bottom of the fat column. This is commonly caused by

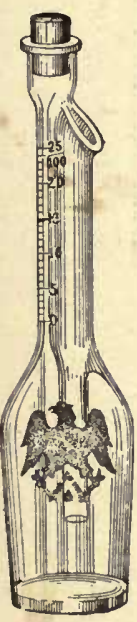

FIG. 38.

agner's skim milk bottle.

(Both with pneumatic fatindicator (pat.).)

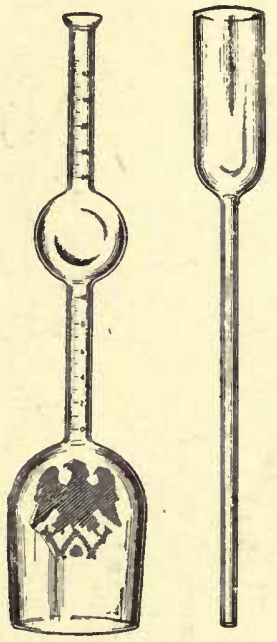

Fig. 40.

Butter test-bottle, and Russian Babcock funnel which holds about 9 grams of butter.

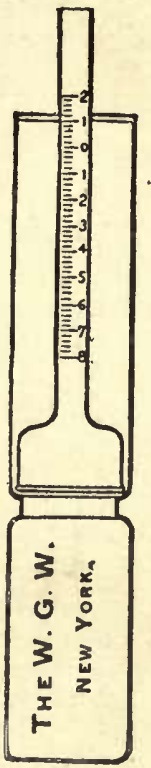

FIG, 41. test-bottle and reading-tube.

using too much or too strong acid or mixing milk and acid at too high a temperature. The remedy is to use less acid or to cool milk and acid before mixing. The llack charred matter may also be due to allowing the acid to stand in contact with the milk too long a time before mixing or by pouring acid through the center of the milk. (2) There may be a layer of white flocculent matter at the bottom of the fat column. This is due to not having used enough acid or to the temperature of milk and acid being too low or to not mixing the acid and milk 

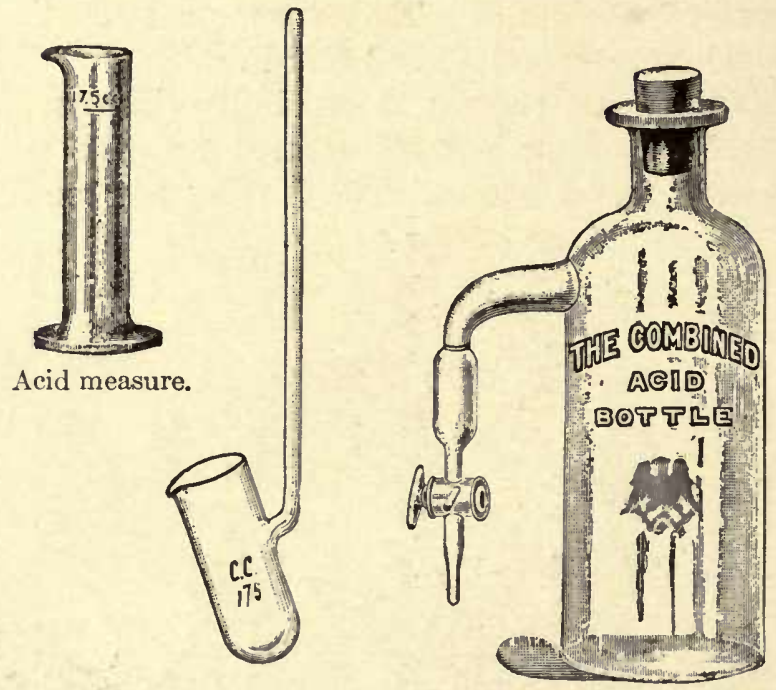

FIG. 42.-Acid dipper. FIG. 43.-Combined acid bottle.
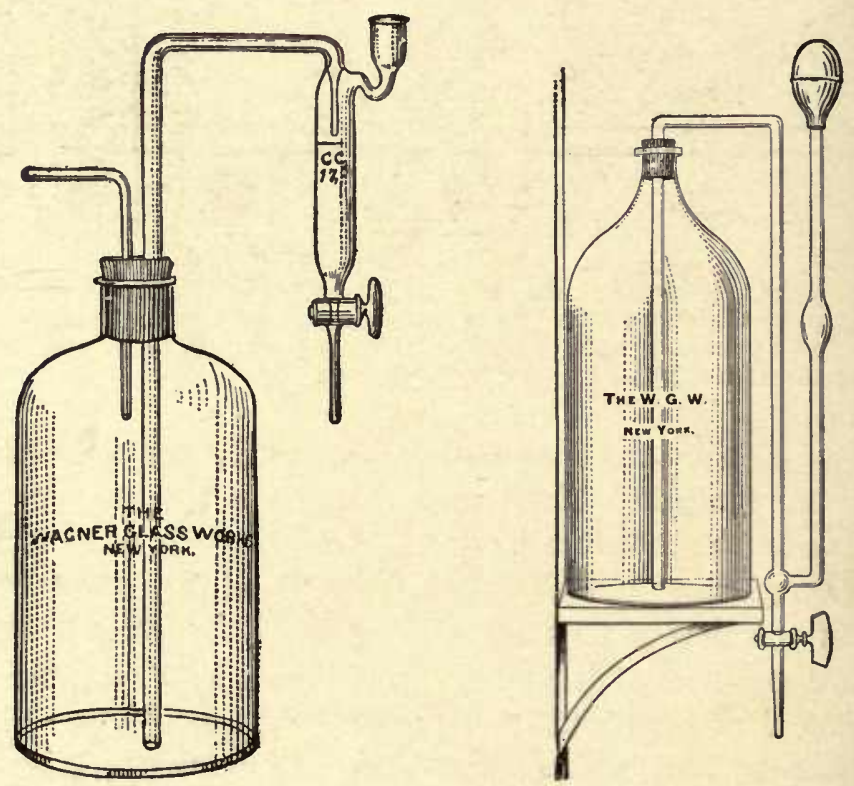

FIG. 44.-Automatic acid pipette. FIG. 45.-Wagner's acid siphon. 
thoroughly. The remedy is to use more acid, or to warm milk and acid before mixing, or to shake the mixture thoroughly before whirling. (3) Occasionally there is a layer of impure foam at the top of the fat column. This is generally due

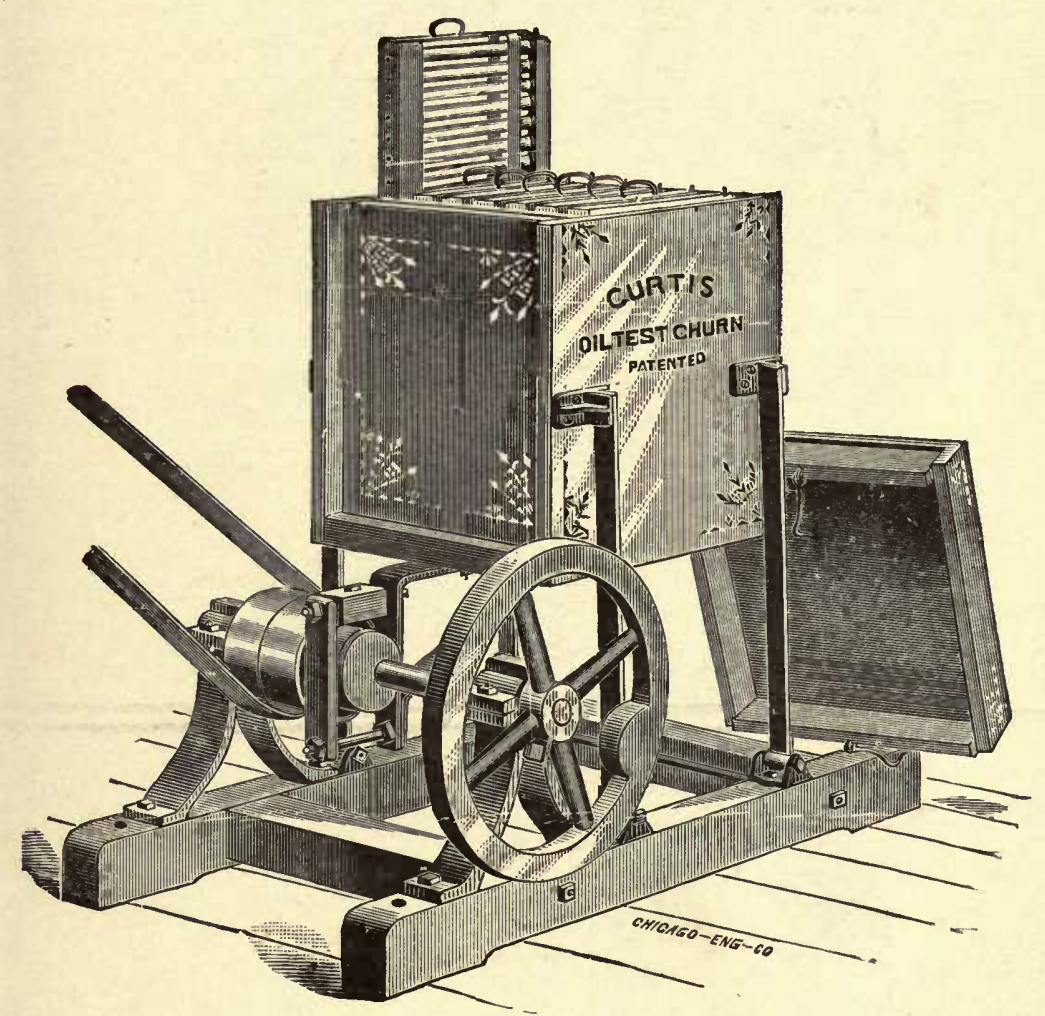

FIG. 46.-The oil-test churn.

to the use of hard and impure water. The remedy is to use pure distilled hot water. For more detailed information on this subject see "Testing Milk and its Products," by Farrington and Woll.

Necessity of Good Milk.-All authorities agree that the best grade of butter and cheese cannot be made from sour or tainted milk. The two countries renowned for the excellence of their 
dairy products-Denmark and Canada-owe their success largely to the purity of the milk furnished by their patrons. Makers who have won for themselves national reputation in cheese- and butter-making have almost invariably been men who insisted on getting first-class milk." Badly tainted milk

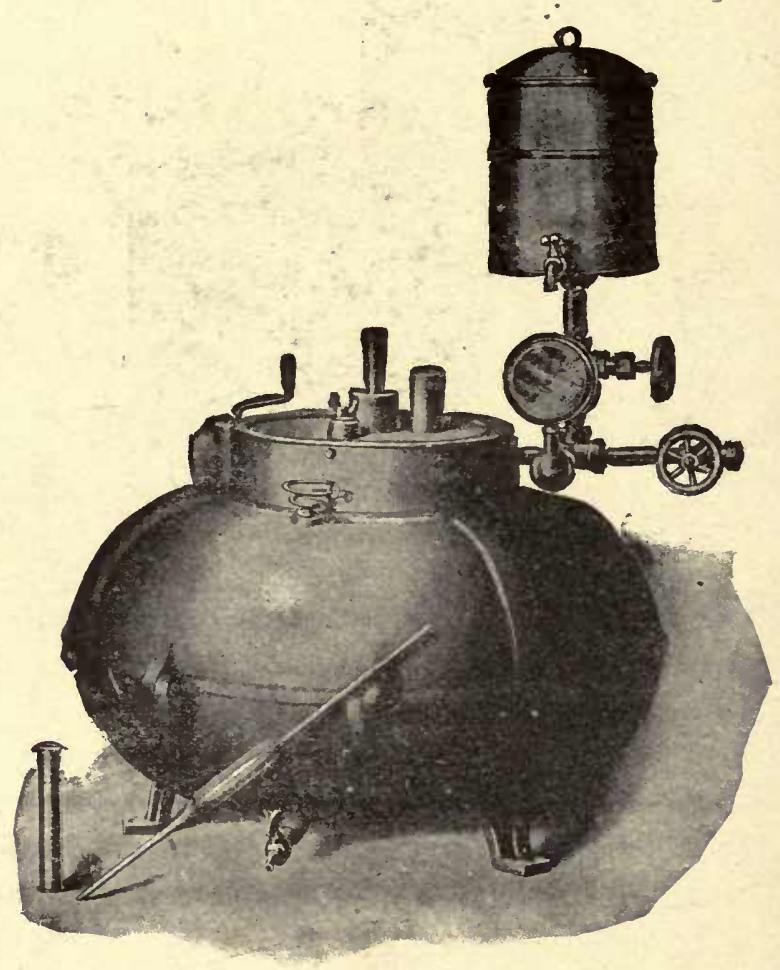

FIG. 47.-Wizard tester.

should not be manufactured into food. The method of classifying milk and cream and paying for each according to quality has been adopted by some creameries, especially by some of the large central plants. The object of this is to induce those patrons who are sending poor milk or cream to furnish a better grade. It seems more practical with milk than with cream, because the average maker dislikes to reject a can of cream, 
owing to the loss the patrons would sustain. If such cream is received, it should be churned separately, and the butter marked and sold on its merits. The practice of taking in poor milk and cream should be discouraged. One of the authors has come in contact with many patrons in different parts of the
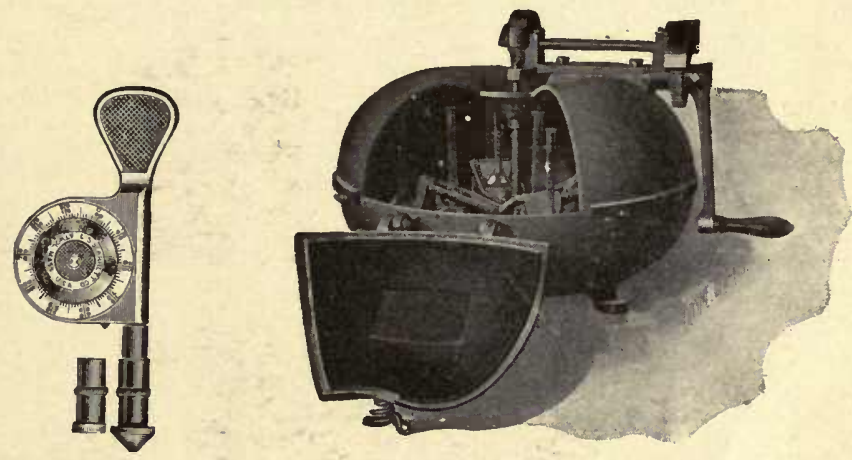

FIG. 48.- Speed indicator. FIG. 49.-Twentieth-century hand tester.

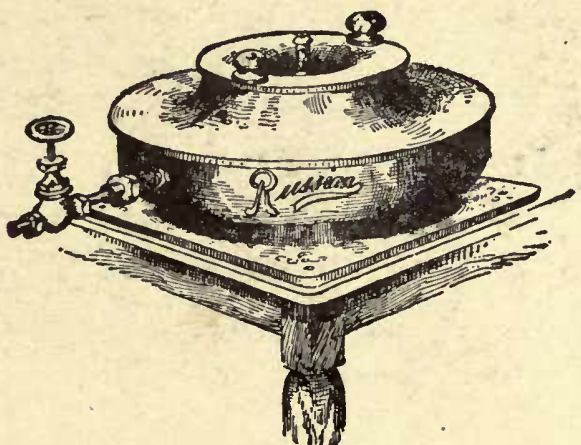

Fig. 50.-Russian Babcock tester.

country and has yet to find the first patron who seriously objected to taking his milk back home when he was thoroughly convinced that it was not in good condition. Patrons as a rule respect the maker who keeps his creamery in a good sanitary condition and insists on getting good milk. It should be the aim of every creameryman to make the highest grade of butter possible. 


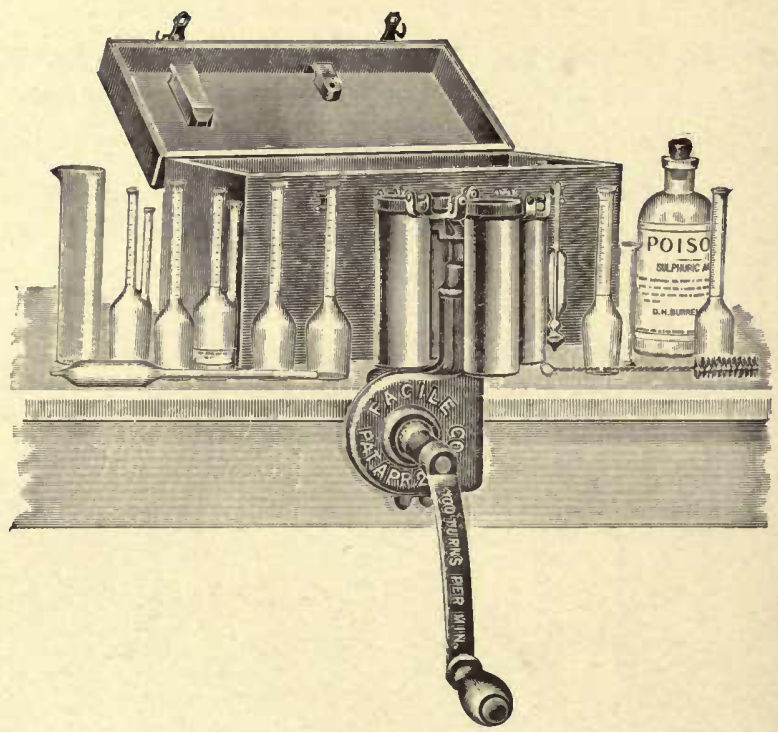

FIG. 51.-Babcock test traveling outfit.

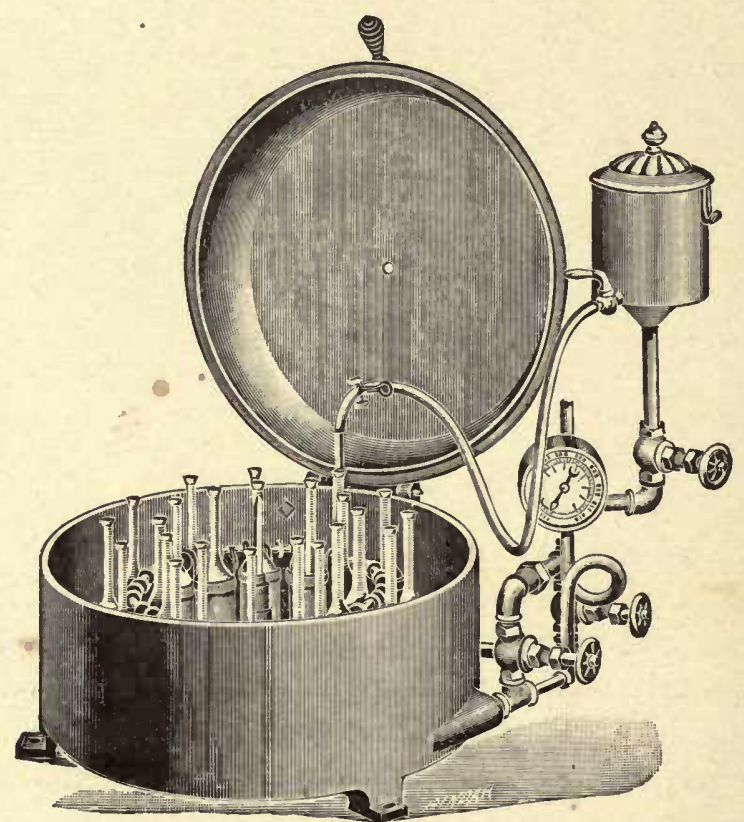

FIG. 52.-The Agos steam tester. 
Sampling of Milk.-The sampling of milk and cream for fat tests is one of the most delicate problems with which the creamery operator has to deal. If a proper sample is not obtained, the ultimate test will not be correct, no matter how carefully the succeeding steps may be carried out. There are two methods of sampling in use: First, sampling with a small dipper, and second, sampling with a sample-tube, or milk-

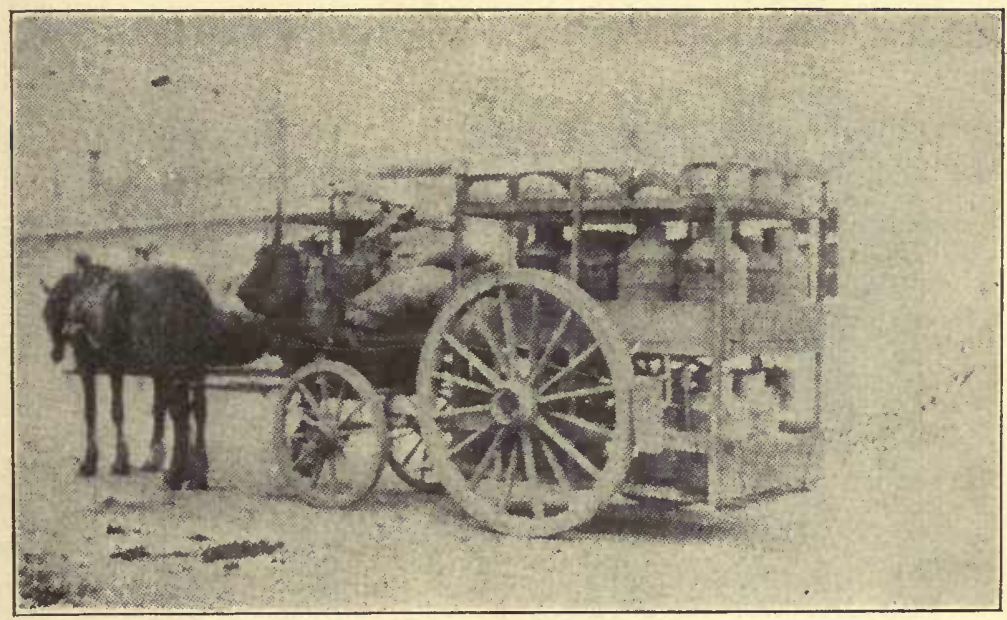

FIG. 53.-Danish milk-wagon. (N. Y. Produce Review.)

thief. The sampling of milk for composite samples should be done every day, and the samples taken.should represent the average quality and form a certain proportionate part of the milk or cream delivered.

In order to get a sample which represents the average quality, the milk or cream delivered must be thoroughly stirred, so as to get an even distribution of the fat.

- In order to get a proportionate part of the milk or cream delivered from day to day, it is necessary to use a samplingtube.

The sampling of milk or cream with a dipper for composite samples has been in use so long that this method has become 
very general. If composite samples are not kept, and the testing of each patron's milk is done every day, the dipper method of sampling answers the purpose. If thick cream is being delivered, the dipper may be found to work better than the sampling-tube, as the cream in some cases may be so viscous that it will adhere to the sides and ends of the tube, and in that way prevent the cream from entering. The samplingtube may also retain some of the thick cream on the inside and if not rinsed out properly each time, the adhering cream

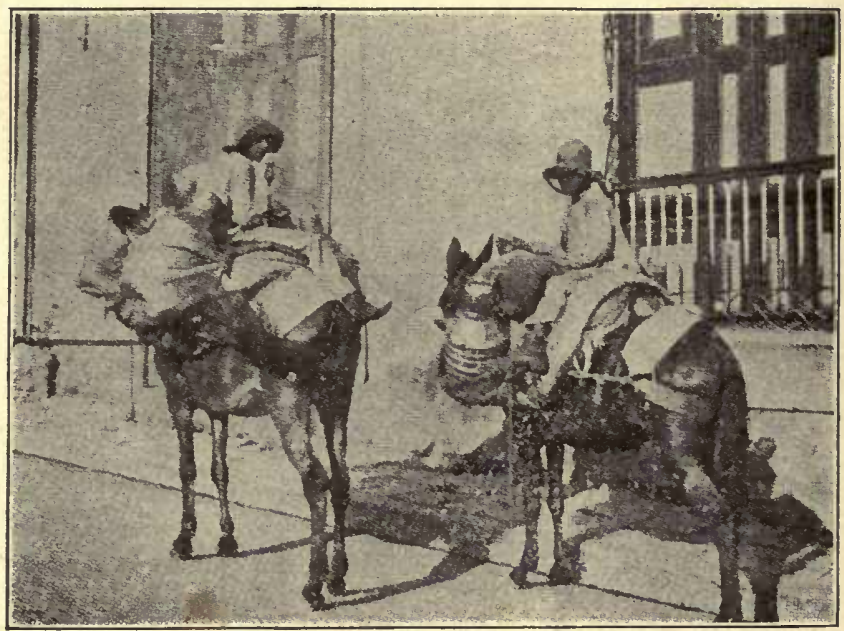

Fra. 54.-Delivering milk in Santiago. (Farmers' Bulleti: )

is likely to interfere with getting a fair sample of the succeeding lot. If the sampling-tube is rinsed in hot water each time, this probable mistake will be obviated.

Sampling-tube. - At creameries where milk is received, the sampling-tube, or milk-thief, gives the best results and satisfaction. It is very difficult in practice to get a proportionate sample with a dipper, from day to day. To illustrate: A patron who delivers 200 pounds of milk testing $3 \%$ fat one day may on another day deliver 100 pounds of milk testing $5 \%$ fat. If a dipperful is taken from each for a composite 
sample, the test of that composite sample will be $3+5 \div 2$, or $4 \%$. According to this test, these 300 pounds of milk delivered will contain 12 pounds of butter-fat. In reality 6 pounds of fat were delivered in the 200 pounds, and 5 pounds of fat in the 100 pounds, making a total of 11 pounds of fat. Thus we see that the dipper method is not reliable, and in this

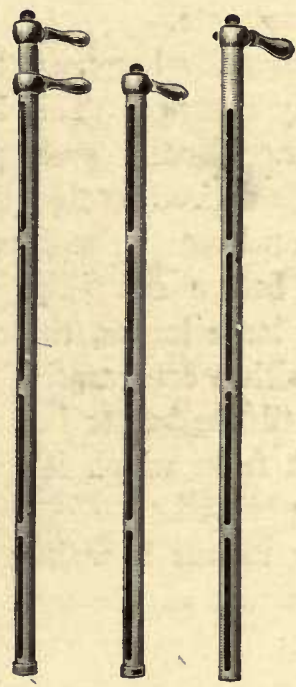

FIG. 55.-The McKay cream and milik sampler.

case the patron was paid for 1 pound of butter-fat too much for the two days' delivery. If the sample taken from the 200 pounds of milk had been twice as great as that taken from the 100 pounds of milk, then the composite test would have been perfect, no matter whether it had been taken with a dipper or with a sampling-tube. If the same weighing-can is used every day, then an exact proportion for a sample can be 
maintained, if the sampling-tube is put down perpendicularly into the milk every day at the same place in the weighing-can and otherwise carefully taken.

In case the cream is being collected from different patrons by a hauler, a milk-thief often works unsatisfactorily. This is especially true during cold weather. A cream tube similar to the one shown in the accompanying illustration is more effective. The way in which the tube is used is apparent from the figure. If a certain patron has 40 pounds of cream, the cream is filled to the 40 mark on the scale of the tube. If he has 30 pounds, it is filled to the 30 mark, etc.

Sampling Churned Milk.-It occasionally happens that the milk arrives at the creamery slightly churned. This is especially the case during the summer. Usually such milk is sampled in this condition, but if it is desired to find the percentage of fat in such milk in its unchurned condition, it is essential to melt the churned fat before sampling. If the butter has been churned into a few large lumps, these lumps can be taken out in a pan, or pail, with a comparatively small amount of milk, and this heated until the butter has melted. Then this is remixed with the milk from which it was first taken, and sampled while it is being stirred.

The churning of the milk during transit is mainly due to two things: First, to a high temperature of the milk $\left(65^{\circ}\right.$ to $85^{\circ} \mathrm{F}$.), and secondly, to hauling partly filled cans a long distance over rough roads. If the temperature of the milk is low (about $50^{\circ} \mathrm{F}$.), when it leaves the producer, then there is seldom any danger of having churned milk at the creamery.

Frozen Milk. -When milk is cooled to $31^{\circ} \mathrm{F}$., or below, the milk freezes. Ice forms near the sides and bottom of the can, until a funnel-shaped cavity filled with milk is left in the center. According to both Richmond and Fleischmann, the icy portion contains more water than the unfrozen milk, and the unfrozen portion is rich in solicls. According to Farrington, when $25 \%$ of the sample of milk was frozen, the icy portion contained about $1 \%$ less fat than the original portion. When 
about half of it was frozen there was no great difference in the fat-content of the frozen and unfrozen parts.

In practice, however, it seems to be different. When a can full of partly frozen milk is sampled at the creamery, the unfrozen milk nearly always contains less fat than the original sample. This ean be accounted for by opening the can of milk and noting the amount of frozen cream on the sides near the top. Whether the unfrozen portion contains less or more fat than the original depends, therefore, upon conditions. At any rate, frozen milk has a composition different from that of the original sample. On this account an accurate sample cannot be had, unless the frozen portion be first completely melted and well mixed with the remainder.

Sour and Coagulated Milk.-In order to get a fair sample from a can of sour and coagulated milk, it must be stirred very thoroughly, so as to bring the coagulated milk into a uniform emulsion. A better sample can usually be obtained with a dipper. If the milk is not too thick, a fair sample can be obtained by the use of the sampling-tube. In order to reduce a can of coagulated milk to a thoroughly uniform quality, it is best to pour it from one can into another. This mixes it much more completely than if the sample were simply stirred with a dipper or any other kind of an agitator.

Apportioning Skimmed Milk.-The amount of skimmed milk to be received by the patron depends largely upon the thickness of cream skimmed, and upon the amount of skimmed milk retained at the creamery for various purposes. The amount of skimmed milk generally returned by creameries varies between 80 and $90 \%$ of the whole milk delivered.

Most up-to-date creameries now make use of skimmedmilk weighers. Where such are employed the man, who receives the milk, hands each patron a check for the amount of milk delivered. This check is put into the skimmed-milk weigher, and it allows an amount of skim-milk to flow out, corresponding to the number of pounds indicated on the check.

In case a skimmed-milk weigher is not employed, it is 
essential to have a man at the skim-milk tank to weigh out the proper amount of skimmed milk to each patron. If

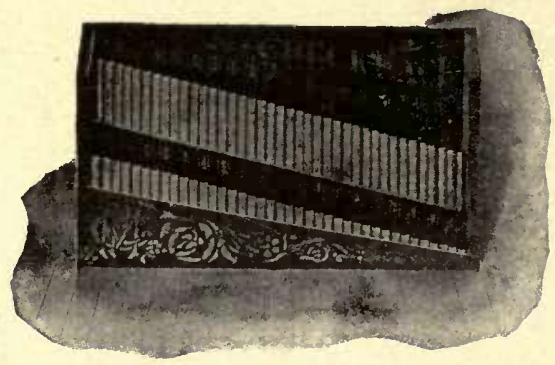

FIG. 57.-Check-rack.

the patrons are allowed to weigh out their own skimmed milk, mistakes are frequently made, which result in more or less dissatisfaction. It is quite customary for butter-makers to

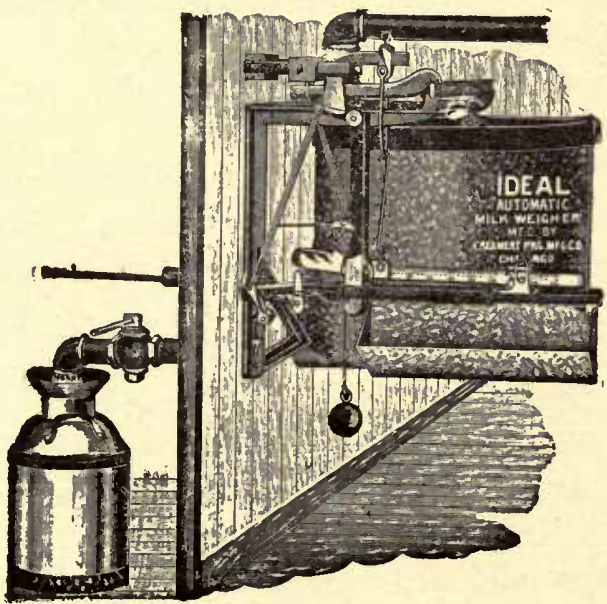

FIG. 58.-The Ideal skim-milk weigher.

draw a chalk line on the outside of the can some distance below the surface of the milk. This indicates the point to which the can may be filled with skimmed milk. 


\section{CHAPTER - VIII.}

\section{COMPOSITE SAMPI,ES.}

Definition.-In order to avoid testing each patron's milk or cream every day for fat, a small sample, which represents the average quality and a proportionate part of the whole, is taken from each patron's milk every day and placed in a jar. A preservative of some kind is pieviously added, which keeps it from spoiling. This is called a composite sample.

When to Sample.-Some makers prefer to sample the milk or cream delivered every day; others prefer to sample every other day. Some creamery operators, again, sample four or five times in succession at intervals, the patrons being unaware of the time when the sampling is to take place. The most reliable and practical method, however, is to take a sample every lay, and test it for fat at the end of every two weeks. When cream is received it is not reliable to take composite samples.

Kind of Preservative to Add.-A number of different preservatives are now in use, and different ones are being recommended for creameries and cheese factories by various authorities. Even a few of the best authorities differ as to which one of the preservatives gives the best results.

Among the most common of the milk preservatives, and less poisonous than certain others, are salicylic acid, borax, boracic acid, and bicarbonate of soda. Among the more violent poisons and strong preservatives are formaldehyde and its compounds, chloroform, corrosive sublimate, and bichromate of potash. Bichromate of potash and corrosive sublimate are the two most commonly used in preserving composite samples. The former is recommended highly by Farrington \& Woll on 
account of its relative harmlessness, its cheapness, and efficiency.

While bichromate of potash is relatively efficient in its preservative effect, and not so poisonous as some of the others, it does not give as general satisfaction as does corrosive sublimate (mercuric chloride), unless relatively greater precautions are taken. If the composite samples preserved with bichromate of potash are left standing in the light very long, a leathery scum forms on the top, which is very difficult to dissolve in the sulphuric acid. This is claimed to be due to the reducing influence of light on chromate solutions. If too

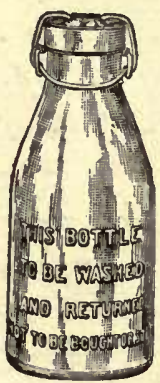

FIG. 59.-Composite sample bottle.

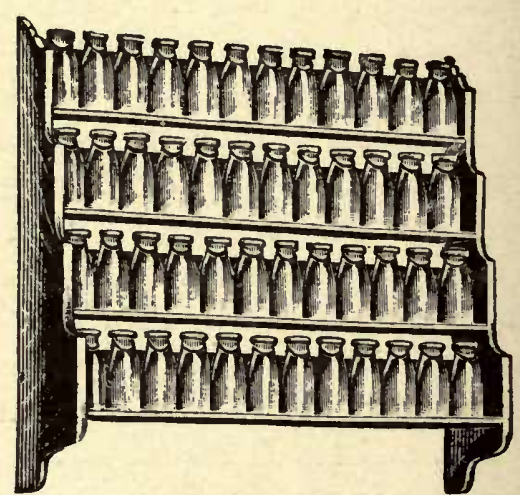

FIG. 60 -Composite samples and rack to hold sample jars.

much bichromate of potash is added, the sulphuric acid added digests the curd with difficulty. When the sulphuric acid is added the curd is precipitated into a heavy, gray-colored coagulum, which dissolves with difficulty in the acid.

According to the authors' experience, corrosive sublimate tablets can be highly recommended. The tablets contain a color, which, when dissolved, colors milk, so that it can readily be distinguished as not being fit for human food. The tablets are very poisonous, but are more efficient in their preservative effect than bichromate of potash. They can be obtained from any creamery-supply house.

During the winter, when the samples are kept comparatively cold, less preservative is needed than in the summer. One 


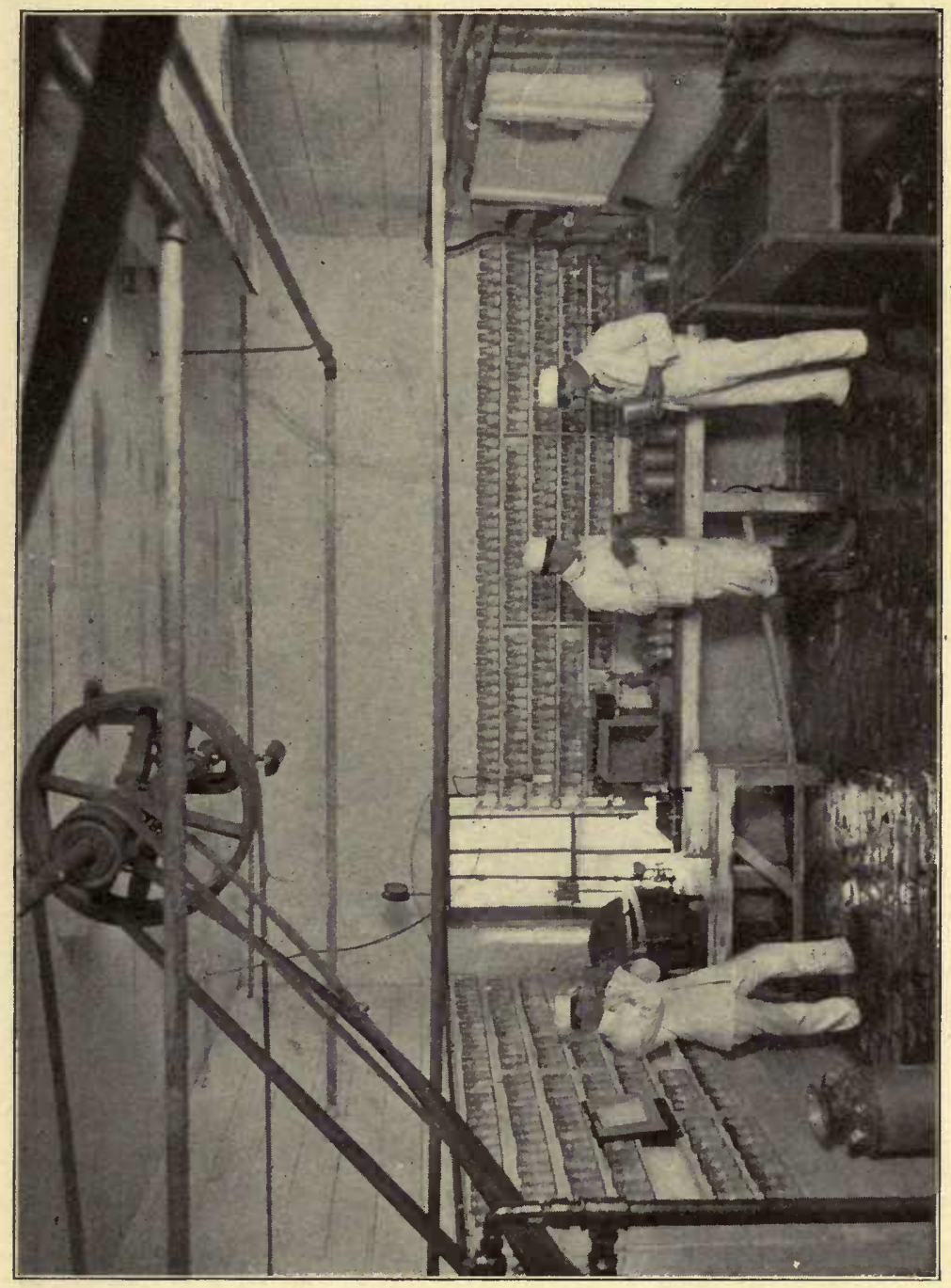



递

ह

苟

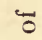

है

ఏ్

ह

.

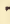

ह

(7)

है

5

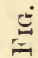

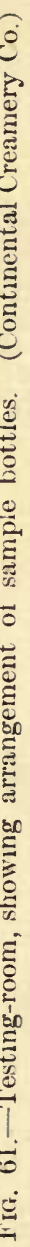


corrosive sublimate tablet will keep a half-pint to a pint of milk or cream in good condition for about two weeks in summer, and about three weeks in winter, providing the sample is properly cared for. Some makers are practicing testing at the end of every month during the winter, and every two weeks during the summer. Testing at the end of every month saves labor, but it is not a reliable method to follow under all conditions, as some of the samples are likely to be somewhat impaired after standing so long.

Arrangement of Composite Samples.-Pint glass jars with covers are, so far as known, the most convenient vessels to use for composite samples. Shelves should be arranged in the weighing-room on which to keep the bottles. If possible, it is best to have them in a case closed with glass sliding doors. This is neat, and, if the glass doors fit well, the samples are in some measure protected in case of quick, unexpected changes in temperature. These sliding doors should be locked when the creamery operator is absent from the creamery, in order to prevent any tampering with the composite samples.

The best method of arranging the sample jars is to have all the jars belonging to the patrons of each route standing in one group, or on one shelf together, if possible. The bottles are numbered to correspond with the number given each patron on the milk sheet. The name of the hauler, or the number of the route, can be put on each shelf. The samples belonging to those who haul their owr milk can be put on another shelf. These can be designated as individual haulers. Such a classification, when the bottles are plainly numbered, will of ten prevent the mistakes that are likely to occur if the bottles are simply numbered and put into a rack together.

Care of Composite Samples. - In the first place the jars should be kept scrupulously clean. It makes the test unreliable if the jars are left covered with milk and molds round the neck from one month to another. When the samples have been tested the jars should be thoroughly cleaned, and, if necessary, scalded, before they are used again. Care should be taken to 
spill as little milk as possible around the neck, inside as well as outside, of the bottle when the sample is put in. If the milk is spilled there, it makes an unattractive appearance. Very often it becomes moldy, and, as more milk is added and the sample shaken every day, this mold gradually extends down the sides of the bottle. This causes the composite sample to be infested with undesirable growth, and to spoil sooner than

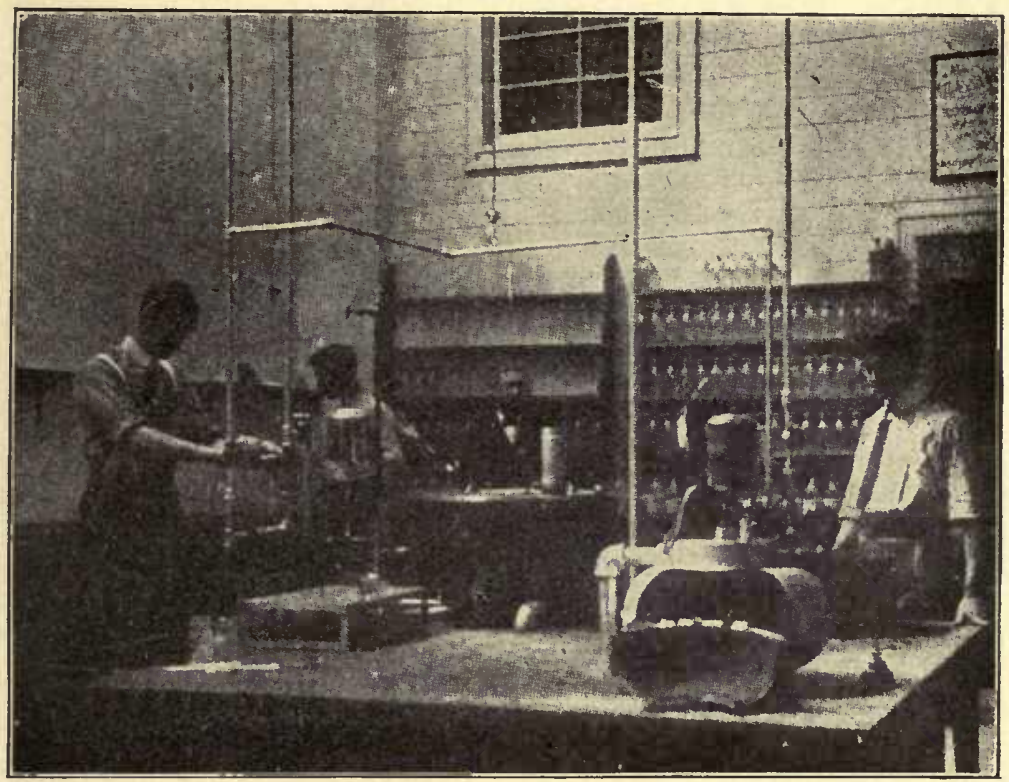

FIG. 62.-Testing-room in Model Dairy, St. Louis Exposition. (Chicago Dairy Produce.)

it would if greater care were taken in keeping the milk from coming in contact with the sides of the bottle, before coming in contact with the preservative.

It is important also that the sample jars be well covered, otherwise the moisture evaporates and causes the milk or cream to dry up. It also makes the test unreliable by increasing the per cent of butter-fat. A gentle rotary motion should be given each jar when a sample is added to it to mix the cream, which rises to some extent after the milk has stood a while. 
Average Sample.-It is sometimes desirable to obtain an average test of the milk from a whole day's delivery. This can be obtained in two ways: First, by taking a sample from each patron's milk with a sampling-tube, and putting it all together in one jar. The result represents an average test, providing the samples have been correctly taken. Second, an average test can be had by boring a small hole in the conductor-head. When the milk passes over this hole, a small portion of it drops through. A vessel of some kind can be put underneath to eatch the drops. Such a drip-sample will represent very: accurately the average quality of the milk received at the creamery. If it is desirable to keep this sample, a preservative can be added to it.

Composite Sampling without the Use of Preservatives.Pipettes can be obtained holding 5.87 c.c. of milk. These are one-third the size of the ordinary 17.6 c.c. pipette used for the Babcock test. With this small pipette a sample may be taken every day from each patron's milk, during three successive days, and emptied into the same test-bottle each day. At the end of three days the samples may be tested and the bottles cleaned, ready for use again.

Accurate composite samples may be obtained in this way, providing the sample in the pipette is correctly taken each day. No preservative is needed. The preservatives are added to the composite samples to prevent curdling. The test-bottles may be placed on a shelf, or preferably in a rack made to hold them. They should be marked in such a way as to identify them. A good way is to mark them the same as the composite jars, the number on the jar corresponding to the number on the milk-sheet for each patron. 


\section{CHAPTER IX.}

\section{CREAMERT CALCUIAATION}

Find the Average Per Cent of Fat.-In calculating the average per cent of fat from a number of cows, or the milk furnished by the different patrons, the mistake of adding the tests of all the samples together and dividing the sum by the total number of samples tested is often made. Milk from different patrons, or from different cows, will always vary, some in quality and some in quantity, and in order to get a correct average test, both quantity and quality must be taken into consideration. The wrong way of calculating the average percentage may be illustrated as follows:

$\begin{array}{ccc}\text { Sample. } & \text { Milk Delivered. } & \text { Per cent Fat. } \\ 1 & 50 \mathrm{lbs} & 5.0 \\ 2 & 100 \text { “6 } & 4.5 \\ 3 & 500 \text { “ } & 3.0 \\ 4 & 300 \text { “ } & \frac{3.5}{4} \overline{16 \%}\end{array}$

The average test, according to the wrong method, $=4 \%$.

The correct way of calculating the average percentage may be illustrated as follows:

$\begin{array}{cc}\text { Sample. } & \text { Milk Delivered. } \\ 1 & 50 \mathrm{lbs} . \\ 2 & 100 \text { “6 } \\ 3 & 500 \text { “6 } \\ 4 & \frac{300}{4} \\ & \overline{950} \mathrm{lbs} .\end{array}$

Per cent Fat.

$5.0=2.5 \mathrm{lbs}$. fat

$4.5=4.5$ " “

$3.0=15.0$ " “

$3.5=10.5$ " "

950)32.5 lbs. fat

3.42 
The average test, according to the correct method, is $3.42 \%$.

It will be seen from the example quoted that there is a difference of more than $.5 \%$. If the percentage of fat or the number of pounds of milk is uniform, then it does not matter which of the two ways illustrated above is used. But as uniformity in either of these respects scarcely ever exists in practice, the only correct way of calculating the pereentage is to find the total number of pounds of fat and divide it by the total number of pounds of milk; the result is .0342 , which may be written $3.42 \%$.

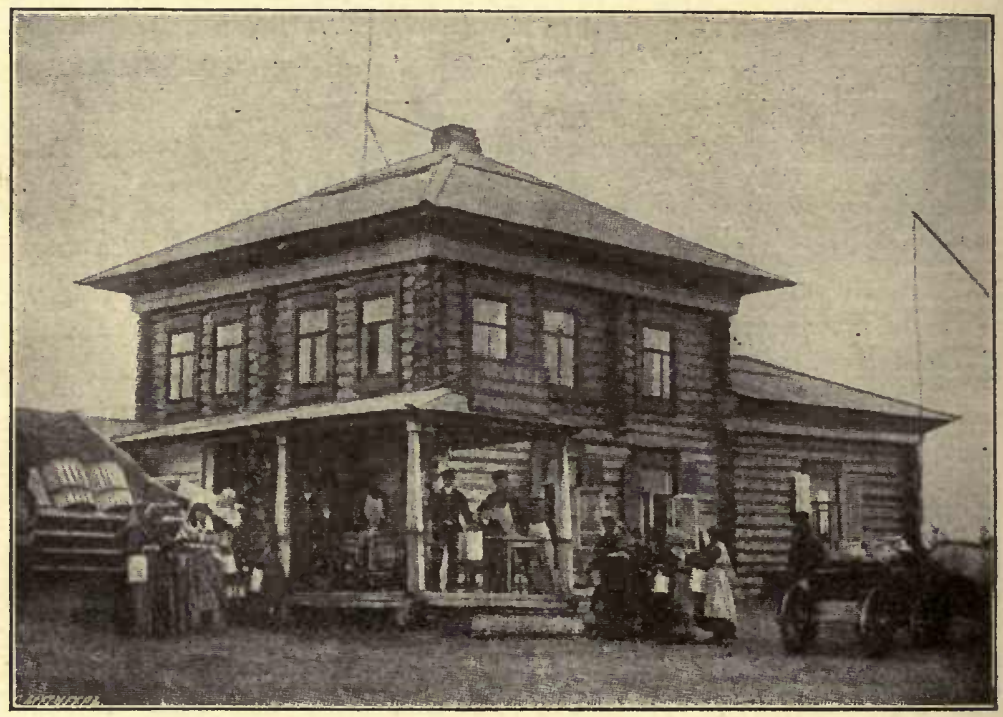

Fig. 63.-A Russian co-operative creamery in Siberia. (U. S. Government Bulletin.)

It is very common for creamery patrons to test the milk from each of their cows, then add the tests together and divide by the total number of cows tested. The result they will call the average test, and frequently such tests are made use of as evidence against a creamery operator to prove that his tests at the creamery were not correct. The fallacy is evident from what has been said above. 
The same mistake is also likely to be nade in finding the average test from several creamery-plants and skimmingstations.

Calculation of Overrun.-The amount of overrun is the difference between the amount of pure butter-fat, and the amount of butter manufactured from that given amount of fat. This difference, divided by the amount of fat and multiplied by 100 will give the percentage of overrun. The calculation of the overrun in the creamery should always be made

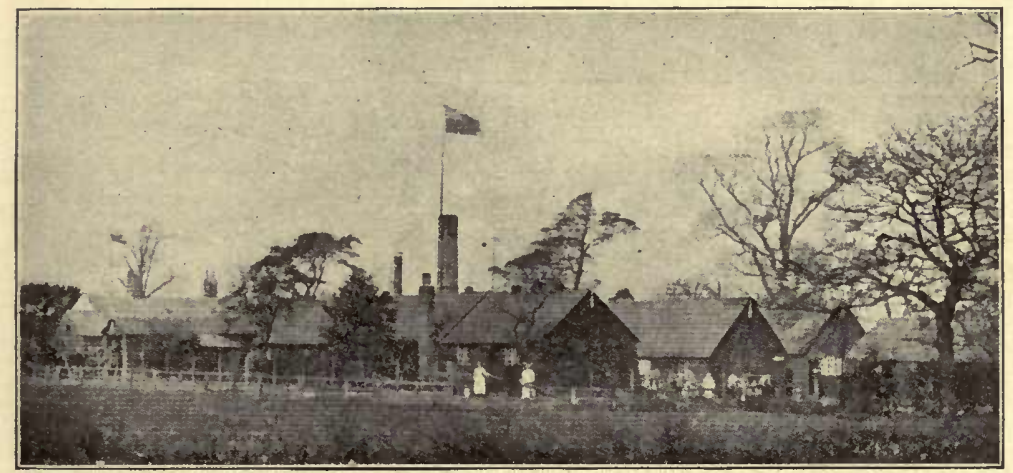

FIG. 64.-A Cheshire creamery, England. (London Creamery Journal.)

from the fat-basis on which the patrons are being paid. If the fat is delivered in the cream, the overrun should be calculated from the fat in the cream. The overrun calculated from the composition of the butter manufactured would not be an indication of the correct overrun, as there might be serious losses of fat sustained during the different steps in the manufacture, such as from inefficient skimming, incomplete churning, and general losses in the creamery. It is possible that butter might show a high content of the substances not fat, and yet not show a good overrun on account of losses; while butter containing only a medium high moisture-content might show as great or greater overrun on account of thorough and efficient work during the different steps of manufacture. 
The amount of overrun depends upon:

1. Thoroughness of skimming.

2. Completeness of churning.

3 . General losses in the creamery.

4. Composition of the butter manufactured.

The theoretical overrun, however, may be quite accurately calculated from the composition of the butter manufactured in a well regulated creamery. In creameries where the conditions of separation and churning are almost perfect, the amount of fat lost in the buttermilk and the skimmed milk is quite constant from day to day, and should not exceed $.1 \%$ in the skimmed milk and $.2 \%$ in the butternilk, according to the Babcock test. Basing the calculations upon the above figures, the theoretical overrun may be calculated from the composition of the butter as follows:

If, for instance, we start with 1000 pounds of milk-testing $4 \%$ fat, there will be a total of 40 pounds of fat. If we skim $32 \%$ cream from $4 \%$ milk, we should have $\frac{4}{32}$, or $\frac{1}{8}$, of it cream, and the remainder skim-milk, or 125 pounds of creanı and 875 pounds of skimmed milk. If there were $1 \%$ of fat in the skimmed milk, there would be a loss of .875 pounds of fat during skimming. There would then be 39.125 pounds of fat in the 125 pounds of cream $(40-.875=39.125)$. If $10 \%$ of starter were added to the cream we should get 137.5 pounds of cream testing $28.4 \%$. ( 125 pounds cream $\times 1.10=137.5$ pounds cream; $39.125 \div 137.5=28.4 \%$ fat.) By churning this cream we should obtain about 100 pounds of buttermilk. If it tested $.2 \%$ fat there would be a loss of about .2 pounds of fat, making a total loss of fat in skim-milk and buttermilk of 1.075 pounds. Subtracting this total loss of 1.075 from 40 pounds we would have 38.925 pounds of fat left to be made into butter $(40-1.075=38.925$ pounds of fat $)$. If the butter on analysis proves to contain $82 \%$ fat, the total number of pounds manufactured will be $38.925 \div 82=47.47$ pounds of butter. $47.47-$ $40=7.47$ pounds theoretical overrun, and $7.47 \div 40 \times 100=18.7 \%$ overrun (theoretical). 
It is evident that the losses of fat will vary according to the different conditions. The richer the cream, and the less fat in the whole milk to be skimmed, the more skim-milk there will be; the thinner the cream, and the more fat there is in the milk to be skimmed, the less skimmed milk there will be, and consequently with the same skimming efficiency less fat will be lost in the skim-milk. The thinner the cream is the more buttermilk there will be. These conditions must be left for the operator to govern according to the conditions present.

The actual amount and per cent of overrun as determined in creameries is calculated as described previously. The formula is as follows:

$$
\frac{\text { Butter-fat }}{\text { fat }} \times 100=\text { per cent of actual overrun. }
$$

Calculation of Churn-yield.-Instead of expressing the increase of butter over that of fat in the percentage overrun, as above, it is often customary among creamerymen to speak of the "churn-yield." For instance, they say that their test was 3.90 , and their churn-yield was 5 , meaning that on the average each 100 pounds of milk contained 3.9 pounds of fat and yielded 5 pounds of butter. The churn-yield is always expressed in percentage, and is obtained by dividing the total pounds of butter obtained by the total pounds of milk from which the butter was made, according to the following formula:

$$
\frac{\text { Pounds of butter }}{\text { Pounds of milk }} \times 100=\text { churn-yield. }
$$

In case cream is handled instead of milk, the same may be obtained by substituting "pounds of cream" for "pounds of milk" in the formula.

Calculation of Dividends. - The method of calculating dividends will vary according to the agreements between the manufacturer of the butter and the milk and cream producers. 
Some manufacturers agree to make the butter for so many cents per pound of butter (usually 3 or 4 cents). Occasionaliy the creamery proprietor agrees to pay a final fixed sum for milk delivered containing a definite amount of fat (usually $4 \%$ ). These two methods are not in use much at the present time, although in the eastern part of the United States the method of paying the operator so much per pound of butter-fat manufactured is quite common.

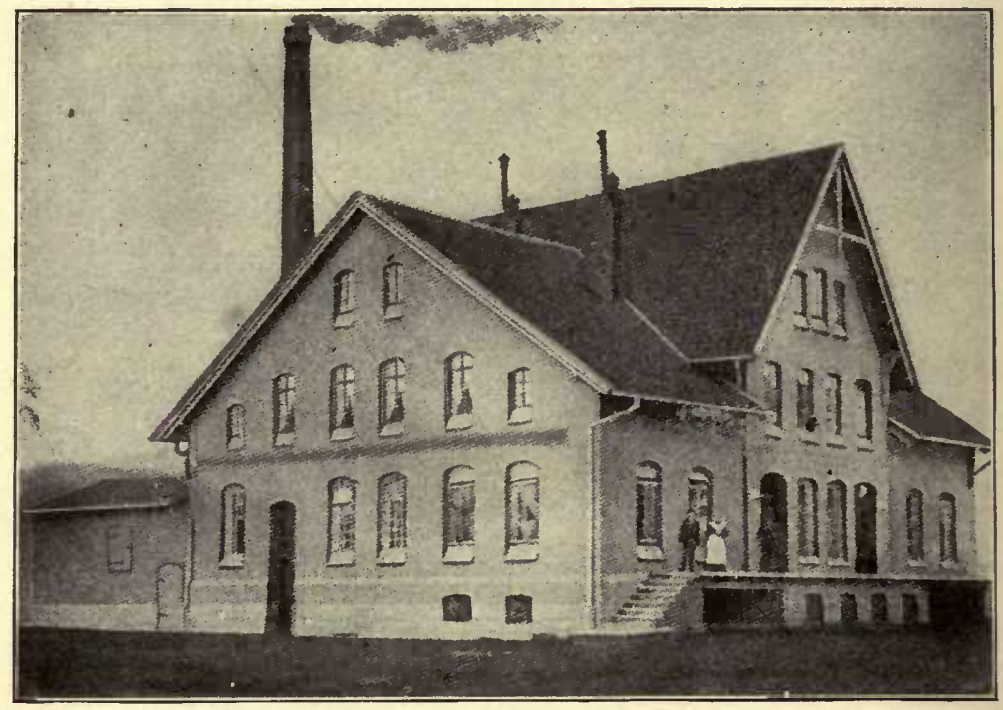

FIG. 65.-Jeinsen creamery, Barnten Province, Hamburg, Germany. (Creamery Journal.)

The two methods most commonly used, especially in the central West, are as follows:

(1) Pay so much per pound of butter-fat based upon some standard market price, such as Elgin or New York. The amount paid now by the central plants for butter-fat is usually 2 or 3 cents per pound below "New York Extras," and the company pays all freight or express charges.

(2) Pay per pound of fat based upon the net income of the creamery. 
1. The former method of paying for butter-fat has become quite common. Nearly all the hand-separator or central plants are paying for butter according to this method. Payments are usually made every two weeks. Although this causes more work, it is much more satisfactory to the patrons than to pay only at the end of each month.

In order to calculate dividends when paid at the end of two weeks or at the end of each month, the first step is to find how many pounds of butter-fat have been delivered by each patron. If composite samples are taken, and these tested for fat at intervals of one week, which would make about four tests during the month, and two during half a month, the results of the several tests may be added, and the sum divided by the number of samples tested. This may give the average test, but it must be borne in mind that this method is also likely to give wrong results. Especially is this so when cream is delivered which varies in quantity as well as quality during the different parts of the month.

If cream only is being received, it is a good plan to test each patron's cream every day, as it is more or less difficult to get absolutely accurate composite samples from creams of different richness. Besides this, the patrons can get the test as well as the weight of the cream of each previous day's delivery, and thus know how their account stands from day to day. A little more labor is involved in doing this, but in the long run it keeps the patrons better satisfied.

2. If the price of butter-fat per pound is being based upon the net income, as is the case in nearly all co-operative creameries, and also in many proprietary creameries, the first step is to find out how much butter-fat each patron delivered during the specified time, - two weeks or a month, whichever may be the case. When this has been obtained, the total pounds of fat delivered by all the patrons are found. From the gross income the total expenses of running the creamery are subtracted. The remainder represents the net income. This is then divided by the total pounds of fat delivered to the cream- 


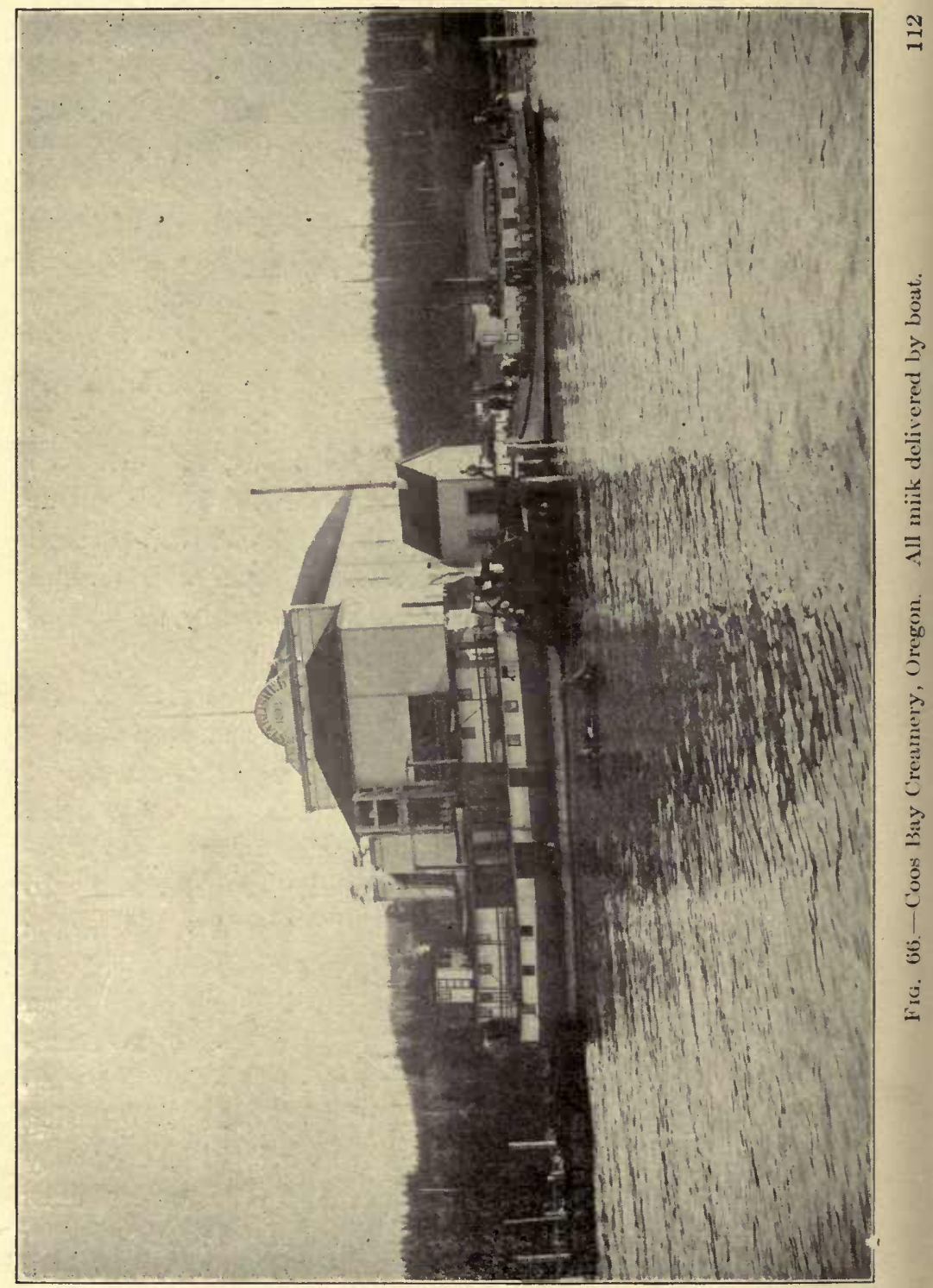


ery, and the quotient represents the price per pound of butterfat to the patrons.

Knowing the price of one pound of fat to be paid to the patrons, the sum due to each patron is found by multiplying the price per pound by the total number of pounds of fat each patron delivered during the specified time.

In some instances provisions are made for a "sinking fund." This is a name given to a fund raised by deducting so much per pound of fat, or per 100 pounds of milk, from each patron's delivery at the end of each month. This fund is for the purpose of paying off a debt gradually, or for raising a fund for new equipment, or other improvements in the creamery. In case such money is to be withheld, it is deducted previous to making the final calculation.

Cream-raising Coefficient.-By the term cream-raising coefficient we understand the percentage of fat removed from the milk during the process of separation. The calculation of the cream-raising coefficient may be illustrated as follows:

Suppose we have 100 pounds of milk containing $4 \%$ fat, and yielding 85 pounds of skim-milk and 15 pounds of cream, the skim-milk containing $.2 \%$ fat.

Total fat in whole milk $=100 \mathrm{lbs} . \times 4 \%=4 \mathrm{lbs}$.

Total fat in skim-milk $=85 \mathrm{lbs} . \times .2,0,0.17 \mathrm{lbs}$.

Total fat in cream $=4 \mathrm{lbs} .-.17 \mathrm{lbs} .=3.83 \mathrm{lbs}$.

$\frac{3.83 \times 100}{4}=95.75 \%$ of the total 4 pounds of fat, or the cream-raising coefficient.

Statement to Patrons.-A complete statement should be made each time a settlement is made, and accompanied with the check. A statement similar to the following one may serve as an example:*

* Creamery Butter-making, by Michels. 
IN ACCOUNT WITH

Mr.

For the month of 190

No. pounds milk delivered

Cr.

Dr.

by you

Average test

No. pounds butter-fat .

Price per pound

$\$ \ldots \ldots$

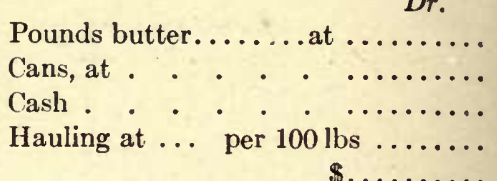

Balance due you

Total pounds milk delivered at creamery .

Average test at creamery

Total pounds butter-fat at creamery

Sales of butter \{

lbs, at

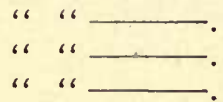

Less cts. for making.

$\$$.

Balance due patrons

Per cent overrun

Testing witnessed by

Prest.

Secy.

At the end of the year a final statement should be made by the respective officers, similar to the following one:

\section{ANNUAL REPORT.}

Incorporated. .......190.. Commenced Operations, .190 ........... Annual Report, 190... of the CREAMERY COMPANY

CAPITAL Stock $\$ \ldots \ldots \ldots \ldots \ldots$ Butter-maker;, Asst. Butter-maker)
OFFICERS AND DIRECTORS. 


\section{SECRETARY'S REPORT.}

To the Stockholders: Your Secretary herewith submits the following report for the year ending December $31,190 \ldots$

Total pounds of milk received

Total pounds butter-fat contained in same ${ }^{*} \cdot v^{-}, \ldots \ldots \ldots$

Total pounds butter manufactured

Average test of butter-fat per hundred pounds of milk

Average yield of butter per hundred pounds of milk.

Average price paid per hundred pounds of milk

Average price paid per hundred pounds of butter-fat

Average per cent increase of churn over test (overrun)

Average price received per pound of butter

Average monthly expenses of running creamery

Average cost of manufacturing butter per pound.

Following is a Monthly Statement for the year $190 \ldots$

January

February

March

April

May

June

July

August .

September

October

November

December

Totals

\section{STATEMENT OF CASH RECEIVED AND DISBURSED.}

RECEIPTS.

Received for butter

Total amount of cash received and paid to Treasurer

Cash balance in hands of Treasurer, Jan. 190.. Total
Disbursements.

Paid to patrons for milk

Running expenses of creamery and supplies on hand

Paid for machinery, material, repairs, etc. (out of percentage fund)

Paid dividend on stock for 190 . . (out of percentage fund)

Paid dividend on stock for 190 . . (out of percentage fund)

Total amount of orders drawn on Treasurer

Cash balance in hands of Treasurer, Jan. 190. .

Total 
TREASURER'S REPORT.

To the Stockholders of the Treasurer herewith submits the following report:

Statement of Cash Received and Disbursed.

RECEIPTS.

Total
DISBURSEMENTS.

Total

Creamery Company: Your

Respectfully submitted, Treasurer. Cashier of Bank.

\section{REPORT OF AUDITING COMMITTEE.}

To the Stockholders of the Creamery Company:

We, the undersigned, appointed by your Board of Directors to examine and audit the Books, Accounts, and Vouchers of the Secretary and Treasurer of the Creamery Company for the year $190 \ldots$, hereby certify that we have carefully examined the same and compared them with the above reports of said officers, and find them correct.

In witness whereof we have hereunto set our hands at Iowa, this .... day of ..... A.D., $190 \ldots$

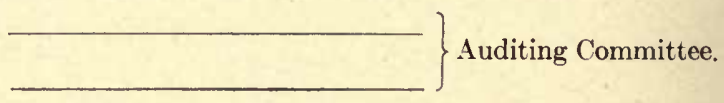

Paying for Fat in Craam Compared with Paying for Fat in Milk. - It is evident that when patrons deliver fat in the form of milk the creamery operator sustains a loss in the skimmed milk, while if the fat is delivered in the form of cream, no fat is lost in the skim-milk at the creamery, and consequently the cream patron should receive more per pound of fat delivered than the whole-milk patron, providing the quality of the fat in the cream is as good as that in the form of milk. The buttermaker should obtain a larger overrun from the fat of the cream than he does from the fat of the milk. The amount which the patrons should be paid for fat, delivered in the form of cream, depends upon the thoroughness of skimming. If 1000 pounds of milk testing $4 \%$ fat were bought and skimmed, there would be a loss of about .9 of a pound of fat during the skimming, which would make about 1 pound of butter, worth about 20 cents. If bought in the form of cream this loss would not be sustained. The above loss, during skimming, according to the figures mentioned, would amount to about half a cent 
per pound of butter manufactured. The fat lost during the skimming process would amount to about $2 \%$ of the total fat. If the cream fat be increased by $2 \%$, an approximate basis for paying milk and cream patrons is obtained.

\section{Degree of Justice in Paying Cream Patrons More per Pound} of Fat than the Milk Patrons.-There is another side to this question of reaching an equity of payment between the cream patrons and milk patrons. A cream patron should not receive more pay than a milk patron, unless the quality of the fat is as good as that delivered by the milk patron. It is a wellknown fact that the fat delivered in the form of cream is, as a rule, and has been, much inferior to that delivered in the form of whole milk. This is evidently due to the fact that cream is not delivered daily to the creamery, and that it is improperly handled on the farm, and during transportation. According to the results obtained in the Iowa Educational Contest, and other scorings, butter from hand-separator cream on an average seldom scores above 90 , on a scale of 100 . It is safe to come to the conclusion that there is at least a difference of three points in quality in favor of creamery butter made from milk-fat. Mr. Healy, one of the best known butter judges, claims that in the near future butter will be sold more according to quality than it is now. He asserts that a fair basis of paying for butter according to scores would be to deduct a quarter of a cent for every point that the butter scores below 91 , and an addition of a quarter of a cent for every point it scores above. This would make a difference of three-quarters of a cent per pound in the selling price of butter made from whole milk and that made from hand-separator cream. It was figured above that the loss from skimming would amount to about half a cent per pound of butter, thus leaving a margin of one-quarter of a cent in favor of the whole-milk patron per pound of butter, rather than being in favor of the cream patron. 


\section{CHAPTER X.}

\section{HEATING MILK PREVIOUS TO SKIMMING.}

Reasons for Heating.-Owing to the fact that all separators will skim closer and not clog so easily when milk is heated, nearly all creameries heat or warm the milk previous to skimming. By thus heating and stirring the milk in a pure atmosphere, many undesirable odors or taints escape. With an increase of temperature, the viscosity of the milk is lessened, due chiefly to the softening and separation of the fat-globules. Such an increased fluidity of the milk lessens the resistant force of the fat-globules when exposed to the centrifugal force of the separator. The higher the temperature the more fluid the milk becomes, and consequently the easier the fat can be separated.

By warming the milk to a high temperature and leaving it for some time, and then cooling quickly again to skimming temperature $\left(90^{\circ} \mathrm{F}\right.$.) and separating, the skimming efficiency of the separator is increased materially. If the milk has been standing at a very low temperature for at least three hours, and then is quickly warmed up to the usual skimming temperature, and skimmed, the warming of the milk has comparatively little effect in bringing it into a good condition for skimming. It will thus be seen that it is possible to skim milk at the same temperature, and yet get different results, due to previous temperature conditions. Duration of temperature should be considered as well as the temperature itself.

The temperature to which milk should be heated previous to skimming varies according to different investigators. The temperature that has been mostly employed in the past in 
this country, and perhaps at the present time, is about $90^{\circ} \mathrm{F}$. This comparatively low temperature was fixed owing to the supposedly bad effect high skimming temperature had upon the body of the finished butter. Exposing milk, at high temperatures, to the centrifugal force in a separator was said to producea greasy body in butter. According to some experiments conducted at the Iowa Experiment Station by the authors during the year 1902 , milk can be skimmed at $175^{\circ} \mathrm{F}$. without any injury to the quality of the butter, providing the cream is cooled to ripening temperature, or below, as soon as it has been skimmed. After the ripening has been completed the cream should be exposed at least three hours to a low temperature $\left(50^{\circ} \mathrm{F}\right.$.) previous to churning.

If the milk is heated in any of the best modern heaters, no injurious results to the quality of the butter will be obtained. Prof. Dean, at the Ontario Agricultural College, has also found it practical to heat to pasteurization temperature previous to skimming. In many creameries in Denmark this method of heating milk is also followed. The Danes, as a rule, however, have the heated milk pass over a cooler before it goes into the separator.

The chief difficulty encountered by the authors in heating milk to such a high temperature previous to skimming, was that the upper bearing in the separator got so hot that it was deemed injurious to the separator, although the bearing did not heat to such an extent as to cause the running of the machine to be abnormal in any way.

Advantages of Warming Milk to High Heat Previous to Skimming.- The advantages of heating milk to a high temperature $\left(175^{\circ} \mathrm{F}\right.$.) previous to skimming, may be summarized as follows:

(1) Undesirable taints are eliminated from the milk to a greater extent than can be accomplished in any other way, without applying chemicals.

(2) The heating of whole milk destroys the germs in the resultant skimmed milk and cream practically as efficiently 


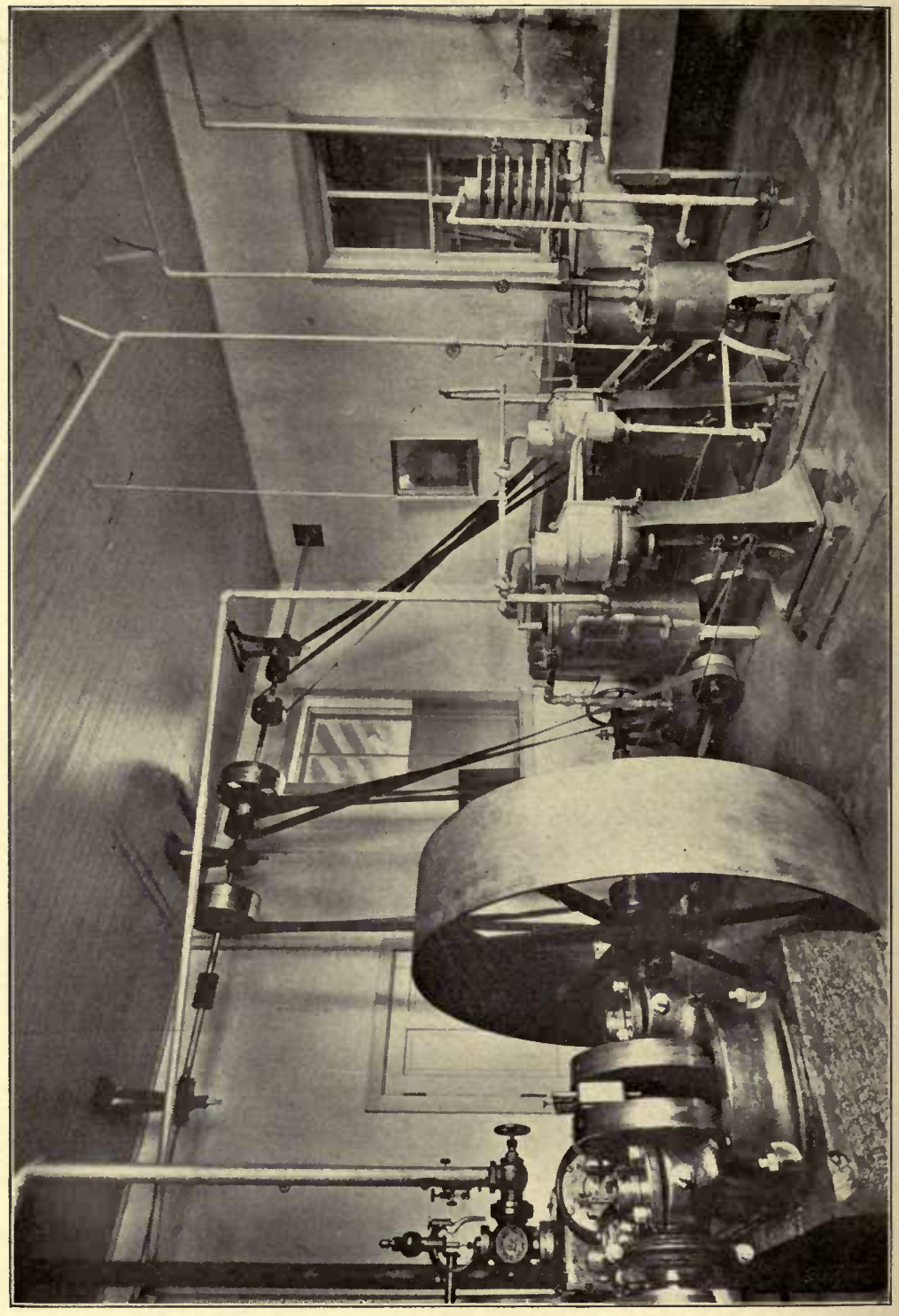

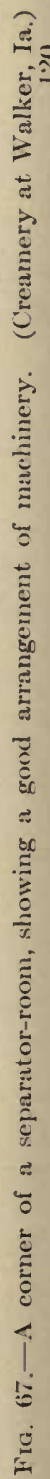


as when heated after the skimming process has been completed.

(3) Less heating and cooling apparatus is necessary.

(4) Closer skimming.

How Heated.-There are two methods by which milk is heated previous to skimming. First, by the use of direct live steam; second, by the use of heaters which heat with steam or hot water indirectly.

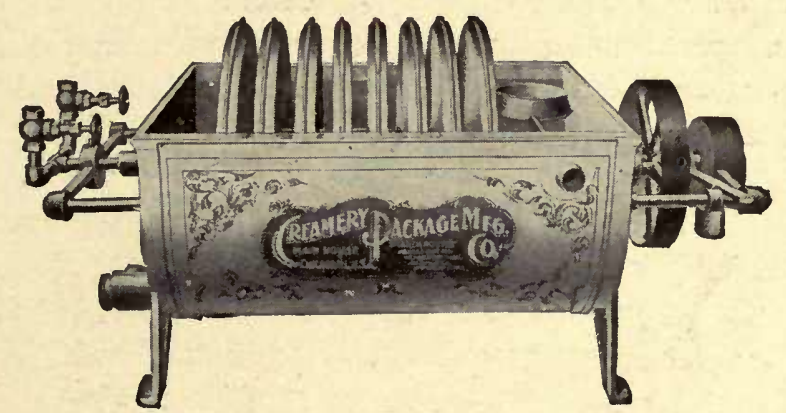

FIG. 68.-The Twentieth-century milk-heater.

Heating of milk with direct live steam is accomplished in two ways: first, by entering a steam hose into the vat full of milk; and, second, by making use of special heaters, which allow steam to come in direct contact with the milk as the milk passes through.

The method of heating milk with direct live steam cannot be too strongly condemned, because it leaves bal effects upon the flavor of the butter. At the Milwaukee National Butter contest in 1903, where over eight hundred exhibitors were represented, the authors noticed that where the criticism "burnt, oily flavor" was made on the score card, the milk from which the butter was made had in most cases been heated with live steam. The burnt flavor may possibly be due to the sudden excessive heat to which the milk will be exposed when coming in contact with live steam. The greatest danger, however, in heating milk with live steam is, that impurities from the pipes and boiler are likely to be transmitted to the 
milk, and cause bad flavors. In most of the creameries the exhaust-steam from the engine is used to heat the water for the boiler. This steam is likely to carry with it cylinder-oil, which will impart undesirable flavors to the butter. Some creameries are also using boiler compounds for the removal of scales. These, when subjected to high heat and pressure, are likely to be transmitted to the steam-pipes, and from there with the steam into the milk. The scale and rust of steam-pipes are also likely to be transferred to the milk.

The right way to heat milk previous to skimming is to make use of one of the special heaters on the market, which heat by the use of steam or hot water indirectly. 


\section{CHAPTER XI.}

\section{SEPARATION OF CREAM.}

In the process of the manufacture of butter it is essential that the fat of the milk shall be concentrated into a comparatively small portion of the milk-serum. This concentration of fat carries with it a portion of all the other milk constituents, and the product is called cream. It is possible to churn milk without any separation, but a much greater loss is attendant, if the fat is not brought together by the process called separation.

The different kinds of cream may be classified according to the different methods of cream-separating:

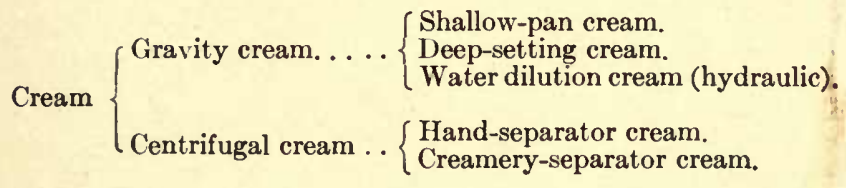

\section{Gravity Creaming.}

Shallow-pan System.-This method of creaming is used mostly on farms which are situated unfavorably in relation to a creamery, or for some other reasons do not send their milk to the creamery. It consists in placing the milk in shallow pans, from 2 to 4 inches in depth, as soon after milking as possible. The milk is then placed where it can be quickly cooled to a temperature of at least $60^{\circ} \mathrm{F}$. A lower temperature than this is desirable if conditions permit. The atmosphere in the room in which the milk is standing must be pure, free from dust, 
draught, and any undesirable taints or odors, since it takes about thirty-six hours of quiet standing for the cream to rise. If there is a constant current of air in the room, a leathery cream is likely to form. At the end of this time the cream is removed by the use of a skimmer, made especially for this purpose. It is difficult, however, to remove all the cream by this means.

If the conditions are such that cool water can be constantly circulated around the pans containing the milk, the temperature can easily be made to go below $60^{\circ} \mathrm{F}$., and the creaming process is facilitated. When such conditions are present, the depth of the milk in the pans can safely be increased to about 6 inches. Under the most favorable conditions about $.5 \%$ fat will remain in the skimmed milk.

Deep-setting System.-This system is undoubtedly the best method of gravity creaming When properly carried on the

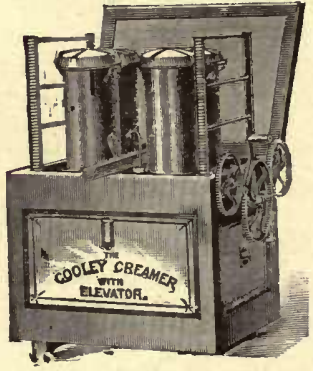

Fig. 69.-Cooley creamer and elevator. fat can be removed so completely that no more than $.2 \%$ of fat remains in the skimmed milk. It consists of putting milk into deep cans (ordinary fourgallon shotgun cans are usually employed) immediately after the milk has been drawn from the cow. Then it is put into cold water, and generally cooled down to, and maintained at, a temperature of about $55^{\circ} \mathrm{F}$. The creain will rise in about twenty-four hours. Better results can be obtained if the water is cooled down to about $40^{\circ}$ with the use of ice-water.

One reason why this system is in use so much, even in creamery localities is that the cream obtained is nearly always of a good quality. The farmer knows that unless the milk be cooled quickly, and maintained at a low temperature, the cream will not rise freely. For this reason the milk is systematically and thoroughly cooled, which is one of the great essentials in order to check the growth of the ferments in milk 
and keep the milk in good condition. In many parts of the eastern United States, the deep-setting system is in general use. A special form of can is used. The can is simply an ordinary four-gallon can, about 8 inches in diameter and 20 inches deep. It has a glass on one side near the bottom or near the top, which allows the reading of the thickness of the layer of cream. On each side of the glass is a graduated scale, which gives the reading in inches. In case the cream is being sold to a creamery, the hauler comes along, notes the depth of the layer of cream, and records the number of inches of cream opposite the patron's name. At the end of the month, or whenever the time for payment comes, the money is apportioned according to the number of inches of cream delivered by each of the patrons. No test for fat is made. This is what is known as the "Cooley system," and is used quite extensively in the East, especially in Massachusetts.

While cream usually arrives at the creamery in a fair condition, there is the objection that the cream is always thin. It seldom contains any more than 18 or $20 \%$ of fat.

No good explanation has yet been given why cream in a deep layer of milk at $40^{\circ} \mathrm{F}$. should rise more quickly and more completely than in a thin layer at a higher temperature. * Arnold seeks to explain it by saying: "Water is a better conductor of heat than fat; hence when the temperature of the milk varies either up or down, the water in the milk feels the effect of the heat or cold sooner than the fat in the cream does. Therefore the cream is always a little behind the water in swelling with heat or shrinking with cold, thus diminishing the difference between the specific gravity of the milk and cream when the temperature is rising, and increasing it when the temperature is falling."

This explanation is, according to Babcock, $\nmid$ not satisfactory. He says: "Though it is true that water is a better conductor of heat than fat, the small size of the fat-globules renders it

* American Dairying, p. 210.

† Wisconsin Experiment Station, Bull. 18, p. 24. 
impossible that under any circumstances there can be more than a small fraction of a degree of difference between the temperature of the fat and that of the milk serum. Moreover, with the limits of temperature practical for a creamery, $\left(90^{\circ}\right.$ to $40^{\circ} \mathrm{F}$.), the coefficient of expansion of butter-fat is more than three times as great as that of water, so that in order to maintain the same relative difference in their specific gravities when the temperature is falling, the milk serum must cool nearly three times as quickly as the fat. In other words, when the milk serum has cooled from $90^{\circ}$ to $40^{\circ}$, or $50^{\circ} \mathrm{F}$., the fat-glabules should have lost less than $17^{\circ}$, and should still have a temperature of over $70^{\circ} \mathrm{F}$., a difference between the temperature of milk serum and fat of more than $33^{\circ}$. Such a condition is manifestly impossible, but no less difference than this would cause the fat to become relatively heavier than at first, and would operate against the creaming."

A low temperature increases the viscosity of the milk, and consequently it would seem that the resistant force of the fat-globules in their upward passage through the milk serum would be increased, and thus retard the creaming. Babcock maintains that fibrin is partially precipitated when milk is allowed to stand at a medium high temperature. The fibrin, when precipitated, forms a fine network of threads permeating the milk in all directions, similar to the network of fibrin in coagulated blood. It is possible to conceive that such a network would interfere with the rising of the fat-globules, at comparatively high temperatures. The reason that fat-globules will rise more quickly and more completely in the deep-setting system than in the shallow-pan system, might be explained on this fibrin theory were it not for the fact that experiments conducted at the Cornell Experiment Station show that the setting and cooling of milk may be delayed long enough for this fibrin to form, without any effect upon the separation when set and cooled.

Probable Explanation.- It is a well known fact in physics that most liquids, when present in the form of drops, increase 
their surface tension when the temperature is lowered. Owing to this increase in surface tension, the liquid drops unite together at a low temperature much more rapidly than they do at a high temperature. For instance, two drops of molten iron unite much more readily just previous to solidifying than they do while the temperature is higher, and the liquid more fluid. As the fat in milk is present in the form of small liquid globules, as mentioned previously, it seems probable that these fat-globules might have properties similar to those of the liquid mentioned above, and behave similarly in the milk, when set at low temperatures, in accordance with the deep setting method. If the fat-globules act in accordance with this theory, it seems probable that there is no real membrane, other than that resulting from surface, tension, enveloping each fat-globule. If there were such a membrane, composed of albuminoid chiefly, then undoubtedly the fat-globules would not assume this property.

With such a deep layer of milk the lower most fat-globules must evidently encounter a great many other globules as they rise. If the physical force mentioned does not facilitate the process of uniting the globules, they would partly unite without it. The more they unite in small bunches, or masses, the greater would be the tendency for them to rise, as explained previously, and more of the smaller fat-globules would be carried along. The bottom globules would tend to partly unite and form a filter, which passes up through the milk by the buoyant force, or force of levity.

If this latter explanation holds true, then more of the milk constituents would be present in the cream from the deepsetting system than in the cream from the shallow-pan system. By comparing the cream raised by the shallow-pan system with that raised by the deep-setting system, before the cream has been removed from the milk, it will be noticed that the cream raised by the shallow-pan system appears to be much yellower than is that raised by the deep-setting system. This condition can only be due to the fact that the surface cream, 
raised by the shallow-pan system, contains more pure fat. The fat, as it rises, does not have the same opportunity of uniting with so many other globules, owing to the comparatively shallow layer it has to pass through, and the temperature is not low enough to facilitate the uniting of the globules; that is, providing the fat-globules act the same as most other liquids at lower temperatures.

Water-dilution Cream (Hydraulic).-When milk is diluted with water, the fat or crean rises much more rapidly and completely to the surface than it would in its undiluted form. A creaming-can is based upon this principle, and it was expected to combine quickness, efficiency, and simplicity. The separator consists simply of a tin can into which the milk is poured and then diluted with cold water. In a few hours the cream rises to the surface. Arrangements are usually made so that the skim-milk can be drawn off from the bottom of the can. While the diluted form of the milk apparently causes the creaming to be more efficiently and quickly done, it can readily be seen that in order to have a skimming efficiency equal to other methods of skimming, it must leave only about half as much fat, because the milk is diluted with about an equal volume of water. If the water-diluted skimmed milk contains $.2 \%$ fat, then the same skim-milk in the undiluted form would contain .4 per cent fat.

The water-dilution method of skimming practically spoils skimmed milk for feeding purposes. Skimmed milk which contains a fourth or a half of water, has been robbed of its essential relish to the calf, and it becomes necessary for the calf to consume too much volume in order to get the required amount of nourishment.

This water-dilution system also gives more volume to handle. If farm dairying were conducted on a large scale, the method would not be practicable.

Another objection is that the cream which results from this dilution method is seldom of good quality. Most wellwater contains a multitude of micro-organisms which, when 
added to the milk, produce putrefactive and undesirable results. Much well-water also is tainted to a greater or lesser degree. Especially is this so with water from shallow wells. Butter made from cream which has been diluted with water usually has a flattish poor flavor.

The efficiency of separation of diluted and undiluted milk is reported by Wing * to be as follows:

Diluted with $25 \%$ warm water set at $60^{\circ} \mathrm{F}$. (39 trials), $0.77 \%$ fat in skim-milk;

Undiluted, set at $60^{\circ} \mathrm{F} . . .$. (30 trials), $1.00 \%$ fat in skim-milk Undiluted, set at $40^{\circ} \mathrm{F} \ldots \ldots$ (26 trials), $0.29 \%$ " " 6

\section{Centrifugal Creaning.}

In the separation of cream by centrifugal machines, the same principle is used as in the gravity system of separation. The only' difference is 'that in the centrifugal method the force which separates the cream from the milk is generated by artificial methods, and acts in a horizontal direction; in the gravity system the force which separates the cream from the milk is only that which results from the difference in the specific gravity of the cream and the skimmed milk, and the force acts in a vertical direction. The force generated in the separator is several hundred times greater than the natural force in the gravity method. For this reason the cream separates almost instantaneously after the milk has entered the separator and is exposed to the centrifugal force.

Advantages. - The centrifugal separator has several advantages over the gravity method, which are apparent without detailed elaboration. In the first place, the range of temperature and condition of the milk at which the cream can be successfully separated is much greater than that for successful separation by the gravity method. Second, a much better quality of cream can be obtained by the centrifugal system,

* Milk and Its Products, p. 105. 
as the separation can be done before the milk gets old, while by the gravity method the time required for.efficient separation is so long that the cream deteriorates more or less before it is removed from the milk. Third, by the centrifugal method the thickness of the cream can be regulated to suit requirements, while by the gravity method the thickest cream that can be obtained is about $20 \%$. Fourth, by the centrifugal method many impurities and undesirable germs are removed, while in the gravity method the exposure to open air more or less impure is likely to contaminate the milk with taints, and also allows the germs to fall into it. Fifth, by the centrifugal method the skimmed milk is left in an unadulterated condition. The milk can be skimmed soon after milking, or after it has been delivered to the creamery, and thus be in the best possible condition for feeding purposes. Sixth, the centrifugal method permits of a more thorough separation of the fat. Butter-fat, as a rule, is too expensive to feed, when good and much cheaper substitutes can be had.

History of Centrifugal Separators.-The first centrifugal separator was a very simple one. It consisted of buckets hanging on the ends of arms, or on the periphery of a rotating horizontal flat wheel which swung on a central axis. The milk was placed in the buckets and whirled for a time, and then the machine (if we may call it such) was stopped, and the cream removed in the same way as in the gravity system. This method of separation, according to J. H. Monrad,* had its origin in 1864. As early as 1859 Professor Fuchs of Carlsruhe, Germany, suggested testing the richness of milk by swinging tubes holding the samples of milk. In 1864 Prandtl, a brewer of Munich, separated milk by such a device. In 1870 Rev. F. H. Bond, of Northport, Massachusetts, worked out a method of separation which consisted of two small glass jars attached to a spincle making 200 revolutions per minute. By one hour's whirling the cream came to the top.

* Dairy Messenger, Oct., 1892, p. 109. 
In 1875 Prandtl exhibited at Frankfort-on-the-Main a continuous separator, which did not at the time attract much attention, due chiefly to the excessive amount of power needed to overcome the resistant force of the air. In 1876 a Danish engineer named Winstrup succeeded in improving the old bucket method. In 1877 Lefeldt and Lentch offered for sale four continuous separators with different capacities (from 110 to 600 pounds of milk per hour). During that year also the first practical centrifugal creamery was established at Kiel, Germany. In 1877 Houston and Thompson of Philadelphia filed a patent for the continuous method of separation of cream

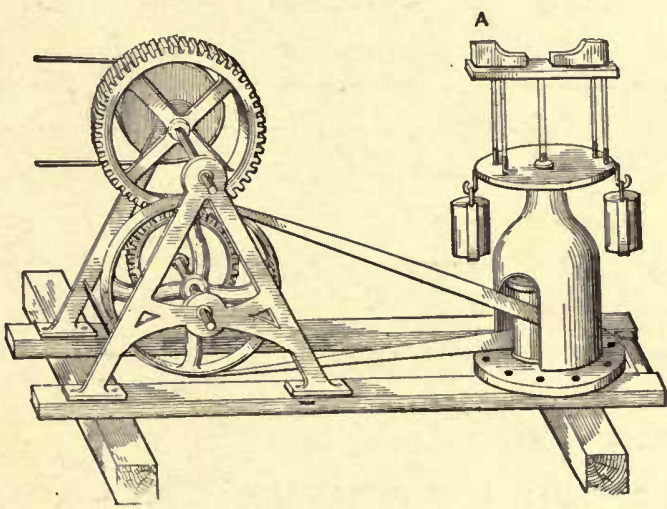

Fig. 70.-First centrifugal separator. (From Dairy Messenger.)

from milk. The patent was allowed in 1891. In March, 1877, Lefeldt and Lentch invented a separator similar in construction to the hollow bowl-a more recent type. This machine did not revolve at so rapid a rate as our modern machines do, nor did it have arrangements for continuous inflow and discharge. It was intermittent in its work, and it was necessary to stop at intervals to remove the cream and skimmed milk. 1879 was the year which marked the greatest advancement toward the perfection of modern separators. The appearance of the Danish Weston, invented in Denmark, and the De Laval, invented in Sweden during that year, marked a great advance- 
ment in the separation of cream from milk. This led to continuous milk and cream discharges, and consequently also to the continuous inflow of whole milk. These machines were of the hollow-bowl construction.

Modern Separators.- Since the year when the Danish Weston and the De Laval machines were invented, many different types of separators with different contrivances within the bowl have been put upon the market. Baron Bechtelsheim, of Munich, is given the credit of having discovered that certain

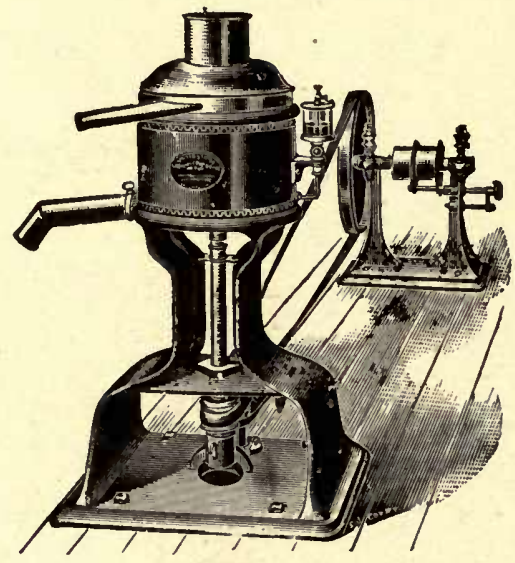

FIG. 71.-The United States separator.

contrivances on the inside of the machine increase the efficiency and capacity of skimming. This discovery was made, according to J. H. Monrad,* in 1890. This invention was bought by the De Laval Company.

The principal part of practically all the separators is a bowl rotating in a vertical position, with or without contrivances inside the bowl. Machines having a bowl rotating in a horizontal position are, so far as the authors know, not in use at the present time. Such a machine was once manufactured at Hamburg, Germany, and was called "Peterson's Centrifugal

* Dairy Messenger, Jan. 1892, p. 9. 
Machine." Another German machine, called "The Page," was also manufactured in the horizontal bowl style.

From the above it will be noticed that four separate steps are recognizable in the evolution and improvement of separators:

1. Revolving Bucket Centrifuge;

2. Intermittent Hollow Bowl;

3. Continuous Hollow Bowl;

4. Continuous Separator with contrivances within the Bowl.

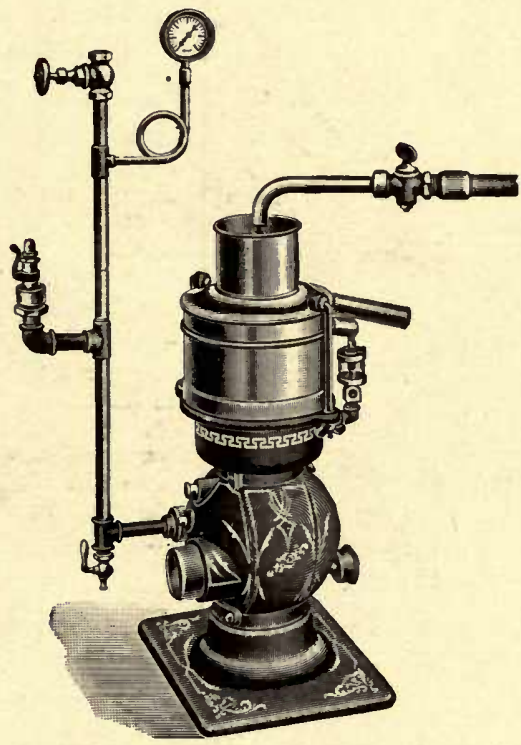

Fig. 72.-The Simplex separator.

The science and practice of separation of milk and cream have seemingly reached a high state of efficiency. It seems almost improbable, considering the many new improved separators on the market that any other great improvement could be made which would add a separate stage to the improvement of our best centrifugal milk separators of to-day.

Classification of Separators.-Owing to the many different standard types of separators now on the market, it is impossible to describe each one in detail. For this reason the classifi- 
cation appearing below has been made. There are undoubtedly many other types, especially in foreign countries, with which the writers are not familiar, and which are not mentioned here. The following elassification will, in some measure, illustrate the different makes of separators on the market to-day:

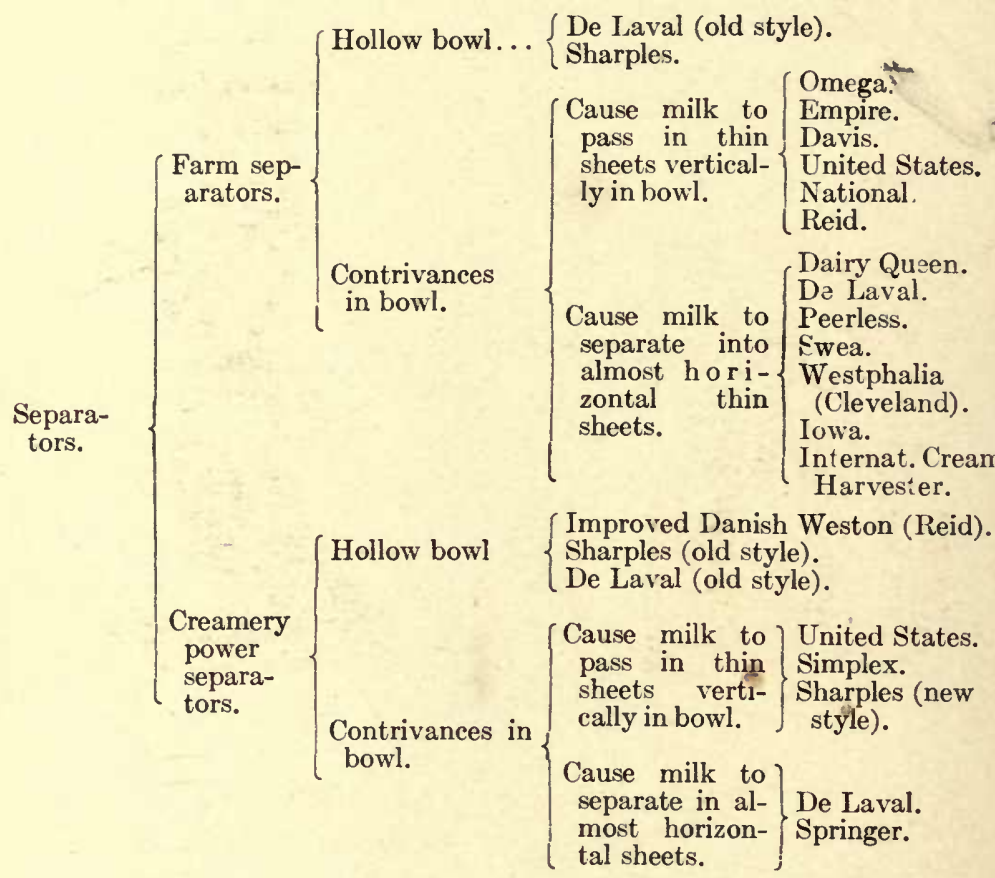

Many of these separators which cause the milk to pass up and down in vertical sheets have the bowl contrivances corrugated, and perforated with holes so that the skim-milk and cream assume also a partly horizontal direction.

Process of Separation.-From the illustrations, the structure of the more common types of separator bowls is readily understood. The whole milk may be made to enter at the bottom or top of the bowl when revolving. In the Sharples, the milk enters at the bottom. The more common way is to have the whole milk enter at the top. As the milk enters the bowl and is exposed to the centrifugal force, 
it immediately begins to separate into three distinct layers. The centrifugal force acting in a horizontal direction forces the heaviest portions of the milk and the precipitated albuminoids, ash, filth, and a multitude of germs over next to

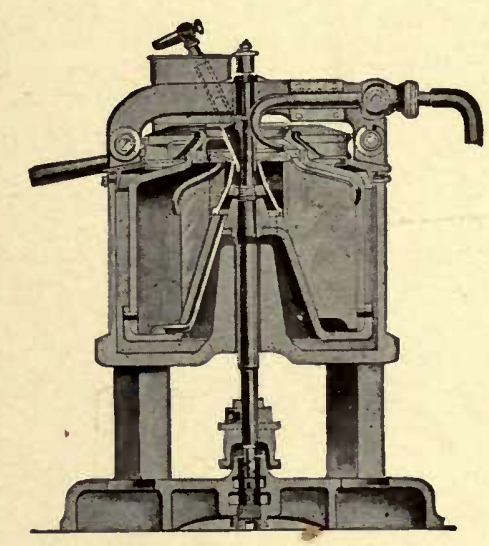

FIG. 73.-The Reid separator.

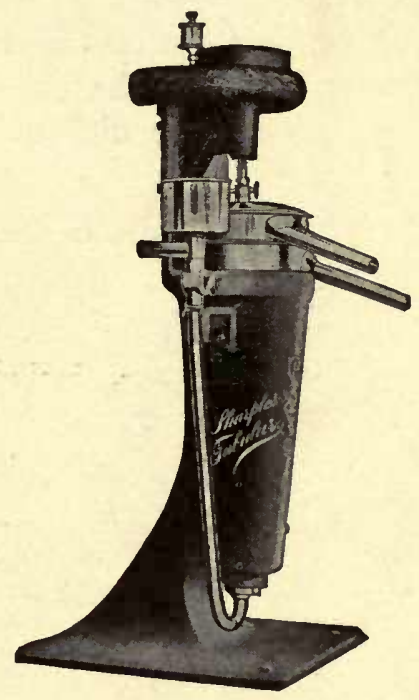

FIG. 74.-The Sharples separator.

the wall of the separator bowl, and into a solid and more or less gelatinous layer, which is known as the "separator slime." In very impure milk this substance is so plentiful that it is likely to clog the separator in a very short time, and before much separation is accomplished it is necessary to clean out the bowl. The second layer is the skim-milk, while the cream, being the lightest, is forced to the center of the bowl and forms the third portion mentioned. There is no distinct line of demarcation between the layers of skimmed milk and cream. They overlap each other and form a sort of zone, rather than a sharp separation. The richest cream is nearest the center of the bowl, and gets thinner toward the outer portion of the bowl; consequently, by turning the outlet for the cream, or cream-screw, nearer the center of the bowl, the cream is increased 
in richness. Turning it away from the center causes the cream to be thinner. The skimmed milk that is forced clear to the circumference of the bowl contains the least fat, and consequently the skimmed milk is always first removed from this portion of the bowl. Usually the skim milk outlet is brought in towards the center of the bowl at one end through tubes extending from the circumference of the bowl. If this were not done, some difficulty would be involved in arranging a

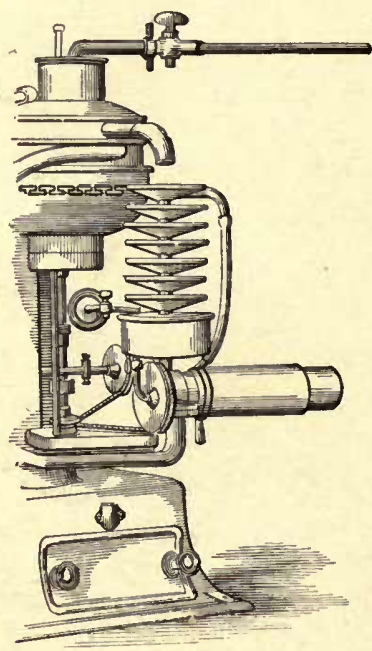

FIG. 75.-Showing "butter extractor" attached to De Laval separator. The butter extractor is not known to be in use now.

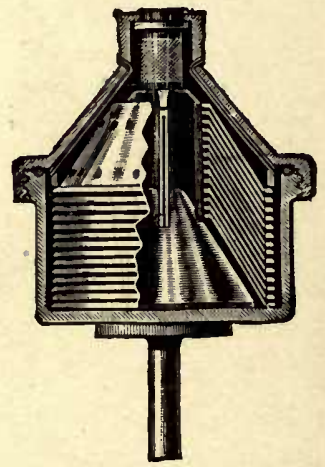

FIG. 76.-Showing cross-section of De Laval separator bowl.

receiving-pan for the discharged skim-milk. If the skimmilk were discharged near the circumference of the bowl, it would come out with a heavy force. Also, if the outlet for the skimmed milk were near the circumference of the bowl, a great deal more power would be required to run the machine. As the skimmed milk passes through the tubes towards the center it gives up its force. The nearer the skimmed-milk outlet can be brought to the center of the bowl, the easier will the machine run. 
The size of the skimmed-milk outlet is usually made so that it bears a certain relation to the size of inlet, size of bowl, and to the speed of the machine. Most skimmed-milk outlets are made so as to discharge from .4 to about .9 or a little more, of the whole milk that enters the bowl. The remainder is the crean, which is forced to the center of the bowl and discharged through the cream outlet.

\section{Relative Amount and Richness of Milk and Cream OBTAINED.}

The conditions which affect the relative amount of cream may be said to be as follows:

1. Regulation of the cream or skimmed-milk screw.

2. Rate of inflow to the bowl.

3. Speed of the machine.

4. Temperature of the milk.

I. Regulation of the Cream or Skimmed-milk Screw.-All modern machines, so far as known, have a device by which the relative amount of skimmed milk and cream can be controlled, and consequently the richness of the cream. Some machines have this device in the form of a cream-screw, and others as a skim-milk screw. The cream-screw in most of the machines has a hole on one side of it through which the cream is discharged. If this screw is turned so as to make the hole nearer the center, then the cream will be richer and less in quantity. If turned away from the center, then more and thinner cream will be discharged. In some machines there is a skim-milk screw which serves the same purpose. The method then of regulating the relative amount of cream and skimmed milk works in just the opposite direction; that is, when thicker cream and less of it is wanted, then the milk-screw is turned so as to bring the skimmed-milk outlet nearer the circumference of the bowl. This gives more skimmed milk and consequently less cream. If thinner and more cream is wanted, then the screw is turned in. This causes more milk to flow out through the cream outlet. The Reid hand separator 
is an example of this latter class. These two methods of regulating the thickness and amount of cream are the most common. It cannot be done while the machine is in motion. By some this is considered a drawback.

Other separators have a device whereby the amount of cream can be regulated while the machine is in motion. For instance, on the improved Danish Weston, there is a screw attached to the skim-milk discharge-tube, by turning which the end or point of the tube can be made to be closer or farther away from the center, thus regulating the relative-amount of cream and skimmed milk, and the thickness of the cream.

2. Rate of Inflow.-The rate of inflow of milk to the separator has a large influence on the relative amount of cream and skimmed milk. The greater the inflow to the separator, the more and thinner cream will be obtained, and with a diminished inflow the less and thicker cream is obtained. This is due to the fact that at a given velocity of the machine the skim-milk discharge remains practically constant. So, if more milk is turned on, the only place where the discharge can increase is through the cream outlet; and if the inlet is diminished, the cream will diminish until a certain time, when the amount of milk, which runs into the machine, equals the amount discharged through the skim-milk outlet, and then there will be little or no cream. This is aptly illustrated by Wing: "If the milk is turned into the bowl at such a rate that .8 escapes through the skim-milk outlet, we shall have .8 skim-milk and .2 cream. If, now, we reduce the rate of inflow by .1, we shall get just as much skimmed milk as before, but only half as much cream; or, if the inflow is increased .1 , we shall get the same amount of skimmed milk and one and a half times as much cream." The completeness of separation will be the same so long as the separator is run within the range of its capacity.

3. Speed.-The speed of the separator influences the relative amount of the cream and skimmed milk only in so far as an increase in the speed of the bowl increases the capacity 
of the skim-milk outlet, due to a more rapid discharge through the skim-milk outlet. The slower the bowl revolves the less skimmed milk will be discharged, and consequently, if the inlet is constant, more and thinner cream will be the result. It should be stated in connection with this that the efficiency of skimming depends to a large extent upon the speed, and if attempts are made to increase the amount of cream and decrease the percentage of fat in it, by lowering the speed, an abnormal amount of fat will be left in the skimmed milk.

4. Temperature.-The temperature of milk usually does not influence the relative amount of milk and cream very much. The higher the temperature the more fluid the milk becomes, and consequently, all other conditions being the same, slightly more milk will run through at a high temperature than is the case with a lower temperature. This increase will show itself chiefly in the amount of cream, as the higher temperature has a greater relative effect upon the cream than it has upon the milk. By increasing the temperature of the milk, slightly more and thinner cream is obtained.

\section{Conditions Affecting Efficiency of Separators.}

I. Manner of Heating Milk.-Owing to the fact that fatglobules rapidly change their shape and property by exposing them to heat and excessive agitation, it is essential that care should be taken in heating milk previous to skimming. When fat-globules are heated they become more liquid, and if stirred very much the clusters of fat-globules break up more rapidly. The individual globules, if stirred violently, will break or subdivide into several small ones. The higher the temperature of the milk, the more fluid the milk becomes, and the easier the separation. If milk is stirred violently, the individual fatglobules break up into smaller ones, which are separated from milk with difficulty. The following table* illustrates what

* Hoard's Dairyman, Fort Atkinson, Wis. 
effect the different degrees of agitation of milk has upon the efficiency of separation:

Milk heated in vat, not pumped................ $10 \quad \begin{aligned} & { }^{2} \\ & \text { milk. }\end{aligned}$

Milk heated in Pasteurizer, 200 revolutions of agitator per minute $\quad 8 \quad \begin{array}{ll}115\end{array}$

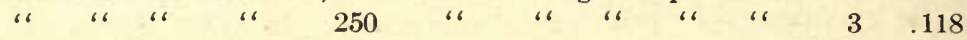

" " " $"$ "

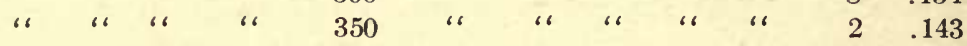

" 6 "

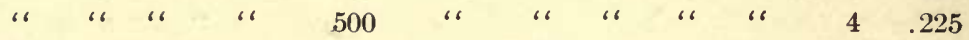

Milk pumped by the turbine pump at $122^{\circ} \mathrm{F} \ldots \ldots \ldots \ldots \ldots \ldots, 3 \quad .129$

" " " " " " $" 64^{\circ}$ F...........

" " with the pump, effective at $122^{\circ} \ldots \ldots \ldots \ldots \ldots \ldots .3 .117$

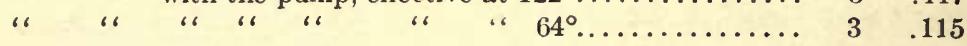

In the above experiments the diameter of the agitator in the Pasteurizer was 14 inches. The speed at the periphery, at 250 revolutions per minute, was 5 feet per second.

It will be seen from the above table that the higher the speed of the agitator, the greater the difficulty in getting a complete separation. Besides the speed of the agitator in the heating apparatus, undoubtedly the shape of the Pasteurizer is a factor in determining the efficiency of the subsequent separation. For instance, the milk in most horizontal Pasteurizers is, even at low speed, exposed to considerable agitation.

If the milk is suddenly heated from a low temperature to about $80^{\circ}$ or $90^{\circ} \mathrm{F}$. and then skimmed, the heating does not facilitate the skimming process very much. It is essential that the milk should be exposed to this temperature for a considerable time. The fat-globules do not warm as rapidly as the milk-serum. This diminishes the difference between the specific gravity of the two substances, consequently completeness of separation becomes more difficult. If milk is heated to a high temperature, say, for instance, $170^{\circ} \mathrm{F}$., then the separation will be sufficiently complete without exposing the milk for any length of time to that temperature. 
Machines are now made, and are on the market, which will bring the milk, or the fat-globules in the milk, into such a condition that they cannot be separated from the milk. The process is called "homogenization." It consists of bringing the milk under certain pressure, and then forcing it out through a special valve. This relief, through this special valve, causes the fat-globules to divide up into very minute ones. They divide up to such an extent that they cannot be separated from the milk by gravity methods, and it is impossible to get a complete separation by centrifugal methods. Homogenization of milk is carried on to some extent in Europe. The process practically insures uniform quality to the milk patrons in the distribution of milk in cities, and secures a more uniform consistency of the product.

2. Condition of the Milk.-In order to get complete separation, and keep the separator in good running order, it is essential that the milk should be in as good physical condition as possible. Coagulated, slimy, or otherwise viscous milk separates with difficulty. When such milk is on hand it should not be mixed with the milk that is in good condition, as it might tend to coagulate more of the good milk, and the coagulated or slimy lumps are likely to $\operatorname{clog}$ the separator. Such milk should be left until all the good milk has been separated. Then, if the coagulated or slimy milk is thoroughly stirred so as to reduce the lumpiness of it, it may be run through the separator successfully. It is a good plan not to feed the separator quite so heavily when this quality of milk is being run through. By shutting off the inlet a little, it will usually run through without clogging. Milk containing impurities in suspension should be thoroughly strained previous to separation.

Overfeeding the Separator.-When a separator is being overfed with milk there is a tendency for the machine to do less complete work. This is due to the fact that the more milk is being fed into the separator the less time it will be exposed to the centrifugal force. It is possible to underfeed the separator as well. As has been mentioned before, the 
inlet can be closed to such an extent as to cause nearly all the discharge to take place through the skim-milk tube.

As a rule when the machine has been set so as to allow the milk to flow in at a certain rate, it will continue to admit practically the same amount of milk all through the skimming period. Among the conditions which may alter the rate of inflow to some extent, are the amount of heat and the change of pressure, due to different amounts of milk in the receivingvat. Temperature will slightly affect the rate of inflow. The higher the temperature, all other conditions being the same, the more milk will pass through the inlet.

3. Speed.-All modern machines have a device by which their speed can be determined. Most speed indicators consist of a little wheel, which, when pushed up against the spindle of the separator while running, turns around and permits the calculation of the speed of the separator. - If the wheel on the speedindicator turns 10 revolutions during ten seconds, the machine would turn 1000 times during the same time. During one minute the separator will run six times as many revolutions, or 6000 , as ten seconds is one-sixth of a minute. Most speedindicators are so adjusted as to turn one revolution for every 100 revolutions of the machine. The higher the speed, the more thorough is the separation. Nearly all machines are balanced to do the best work at a certain definite speed, varying with different machines, and indicated in the directions for operating. It is essential that the machine should be brought up to speed gradually, and no milk be allowed to flow through it until after it has acquired its full speed.

During the run, all machines are likely to vary more or less in speed, owing to different causes. Pulleys are likely to slip on the shaft, and belts are likely to become loose, and thus cause variations in the speed. The steam pressure is likely to get low, and cause all of the machinery in the creamery to run more slowly. This cause, however, is not a very common one where belt separators are used. If the engine has an auto- 
matic governor on it, the speed is usually quite uniform. Where steam-turbine machines are used, the speed of the machine is more likely to vary with the different amounts of steam pressure on the boiler. With turbine separators it is very essential to keep an even steam pressure. Some turbine separators have a safety-valve attached to prevent too high speed.

The reason why the prevention of a variation in speed is so essential is that a slight variation in the speed has a comparatively large effect upon reducing or increasing the centrifugal force. The centrifugal force generated in a machine varies according to the diameter of the bowl, and according to the speed of the machine. The greater the diameter of the bowl, the less speed of velocity is required in order to get a certain force. The centrifugal force varies in direct proportion to the diameter of the bowl; that is, if the diameter of the bowl be doubled, then at the same speed, the centrifugal force has been doubled. The centrifugal force varies in quadratic proportion to the speed of the machine; that is, if the speed of the separator is doubled, the centrifugal force is increased four times. From this it will be seen that speed is a great factor in determining the centrifugal force generated. It is not a good plan to have the diameter of the bowl too large, for the following reasons: A large bowl is more likely to be thrown out of balance; it is harder to keep on the bearings; and it is heavier and more unhandy to handle. For these reasons it is better to lessen the diameter of the bowl and increase the speed. This, of course, is true only to a certain limit.

Steadiness in Running.- Smooth running of a separator is one of the first essentials. If a machine runs roughly, there will not be good separation, and it is dangerous to run it. The bowl itself is likely to jump out, or burst. The causes for unsteadiness in running are many. It may be due to a bent or sprung spindle; the machine not standing level; changing covers to bowls; using clamps which do not fit the bowl cover; unclean, worn-out bearings; condition of the bowl, and contrivances inside the bowl; and dented and rusty bowls. Occa- 
sionally it happens that a machine is run backwards. This is likely to cause the cover of the bowl to run off.

Thickness of Cream.--The efficiency of skimming depends to some extent upon the thickness of the cream skimmed. Most separators, however, will skim within quite a wide range as to thickness. The richness of cream usually skimmed by separators is about from $25 \%$ to $50 \%$. Most separators, however, will do good skimming even if the cream contains as high as $60 \%$ fat. This, however, should be considered to be about the maximum, in order to get the best results from a separator.

Slush in Bowl.-As has been mentioned before, there is always a thick, slimy substance which adheres to the bowlwall. The composition of separator-slime is, according to Fleischmann, as follows:

Water....................... 67.3

Fat........................ 1.1

Caseous matter. ................ 25.9

Other organic substances. ........... 2.1

Ash. .................... 3.6

100.0

At the center of the bowl, or along the axis which runs perpendicular in the bowl, there is always considerable cream. It is practically impossible to get all the cream out of the bowl, even if it is flushed with much water. The amount of slush varies somewhat with the different kinds of separators. For this reason, it is essential that it should be taken into consideration when the comparative efficiency of skimming of different separators is considered. When the test extends over a comparatively long period, and the milk skimmed amounts to several thousand pounds, then the bowl-slush does not affect the conditions for comparative results very much; but when the test is short, and only a hundred pounds of milk, or a similar amount, is skimmed, then the amount of fat left in the bowlslush will have considerable influence upon deciding which one is the most efficient machine. 
General Remarks. - In order to keep the separator in good running order, it must receive care. The belt should not be too tight, nor too loose. If too tight it is likely to bind, heat, and set the bearings of the separator. If too loose it is likely to slip, and to wear out more quickly. The machine should be well oiled. It is better to use a trifle too much oil than not enough. If a bearing is once heated, the machine will never run as well again.

The bowl should be handled with great care. Bowls, or parts belonging to the bowl, can be kept from rusting by boiling them in water, or by steaming them thoroughly after they have been cleaned. If scalding-hot water is used before the milky portion has been washed off, the albuminoids will be scalded on to such a degree that it is difficult to get them off. This applies to all dairy and creamery utensils. Hot water is said to be best in which to dip tin or iron-ware after washing in order to keep them from rusting. If the bowl, pail, or whatever utensil it may be, is turned over to drain after being dipped in hot water, the heat taken up by the utensil will in a short time perfectly dry the apparatus. If the bowl is steamed, it should be heated thoroughly to make it dry quickly.

If the milk supply gets short during the run, and it is necessary to run the machine without feeding milk, then the machine should always be flushed with luke-warm water. This will, in a measure, prevent clogging. Scalding-hot water should never be used for flushing the separator. The cream and skimmedmilk tubes should be carefully cleaned, with the special wire provided for that purpose, each time the machine is washed. The contrivances on the inside of the bowl should also be handled with care so as not to injure them in any way. They should be treated with hot water, as mentioned above, in order to keep them from rusting.

When the bowl is not to be used for some time, it should be oiled well so as to prevent it from rusting. It is easier to oil a separator bowl than it is to scour the rust off later on. 


\section{CHAPTER XII.}

\section{FARM SEPARATORS.}

THE conditions affecting the efficiency of skimming and the relative amount of cream and skim-milk described under "Creamery Separation" apply to farm separators as well. The conditions under which the farm separators are operated warrant a few separate remarks on this subject.

Introduction of Farm Separators.-Small, or hand, separators, have been manufactured for a good many years. It is, however, not until comparatively recent years that they have been numerous enough to be of commercial importance. The people in the Central West (Iowa, Kansas, Nebraska, Missouri, Minnesota, and Illinois) have been most prominent in introducing farm separators. In the year 1894 hand separators were introduced in Iowa, but it was not until 1898 that they gained sufficient foothold to be of commercial importance. According to the Iowa Dairy Commissioner's report of 1898, there were then only 904 farm separators in the state of Iowa. Now, in 1904, there are more than 17,000 separators. Glancing over the statistics it will be seen that the rate of increase in hand separators during the years intervening between 1898 and 1904 has been uniform and rapid. This proves that the dairy business is still in a transitional period; and the introduction of hand separators still on the increase. Such a time in any industry is always accompanied by more or less inconvenience, difficulty, and dissatisfaction. To receive a part of the butter-fat in the form of cream, and the other part in the form of milk, is undesirable. Under such a system it is always difficult to get milk or cream routes organized; proper sampling 
becomes more or less difficult, and the quality of butter is harder to control.

Reasons for Introducing Farm Separators.-It requires an investment of about $\$ 100$ to purchase a hand separator.

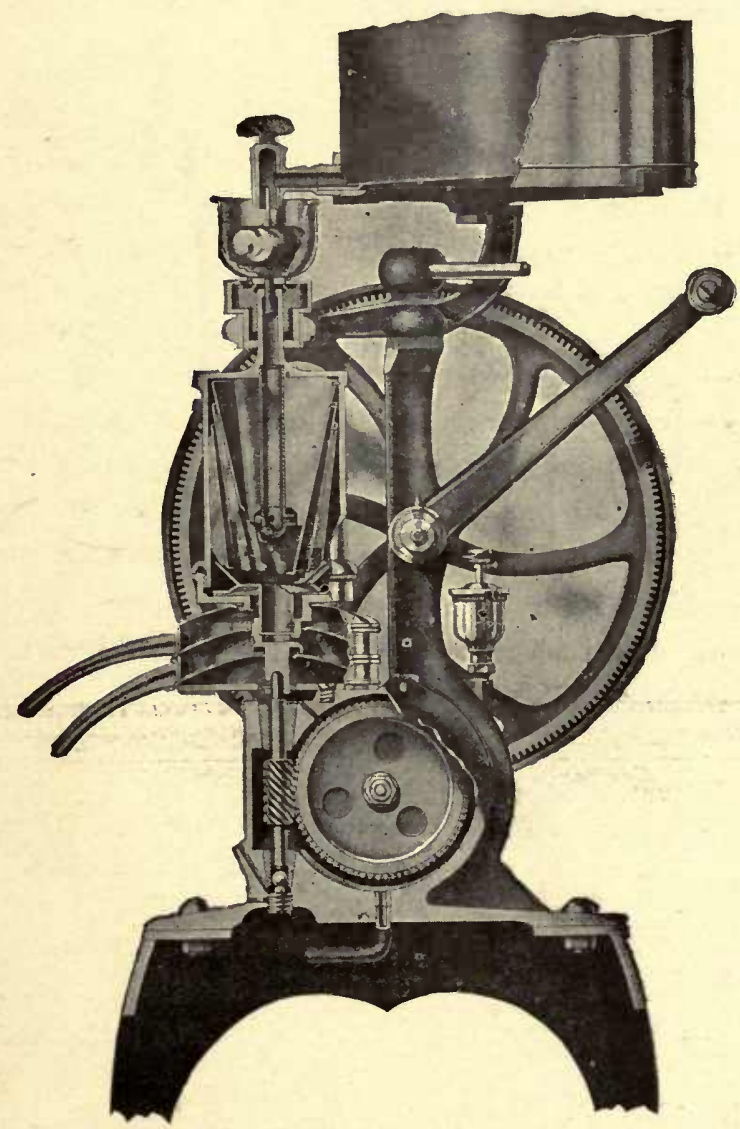

FIG. 77.- The Omega hand separator.

Most of the butter made from hand-separator cream is of poor quality. Still, in the face of this, separators have rapidly -iu creased. It may be concluded that there must be some good reasons why farmers are continuing to invest in farm separators. There are undoubtedly many reasons why farmers prefer hand 
separators; reasons which are, to a large extent, confined to local conditions. Only a few of the chief and general reasons can be given here:

(1) The farmer is able to skim the milk at once after it has been drawn, thereby enabling him to feed the milk while

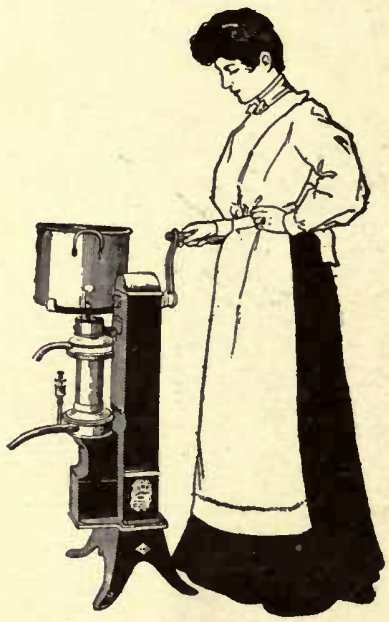

FIG. 78.-The Iowa hand separator. FIG. 79.-The De Laval hand separator (Baby No. 1).

it is in a warm, sweet, unadulterated condition. If he hauled the milk to the creamery, the skimmed milk would be likely to come back in a sour and curdled condition, and at times watery. (In a well-conducted creamery these latter conditions do not exist.)

(2) The high cost of hauling in many instances makes it almost impossible to get the milk to the creamery. Even if the roads are good, the distance to the creamery is frequently so great that it is impossible to get haulers, nor is it practical for every farmer to haul his own milk every day. Especially is this so during the busy season of the year. In the fall, when milk is scarce, it is almost impossible for the hauler to 
get enough milk to make it profitable. In many cases it is necessary to pay an excessive price for hauling milk.

When cream routes are established instead of milk routes, one hauler can usually cover as much territory as three could
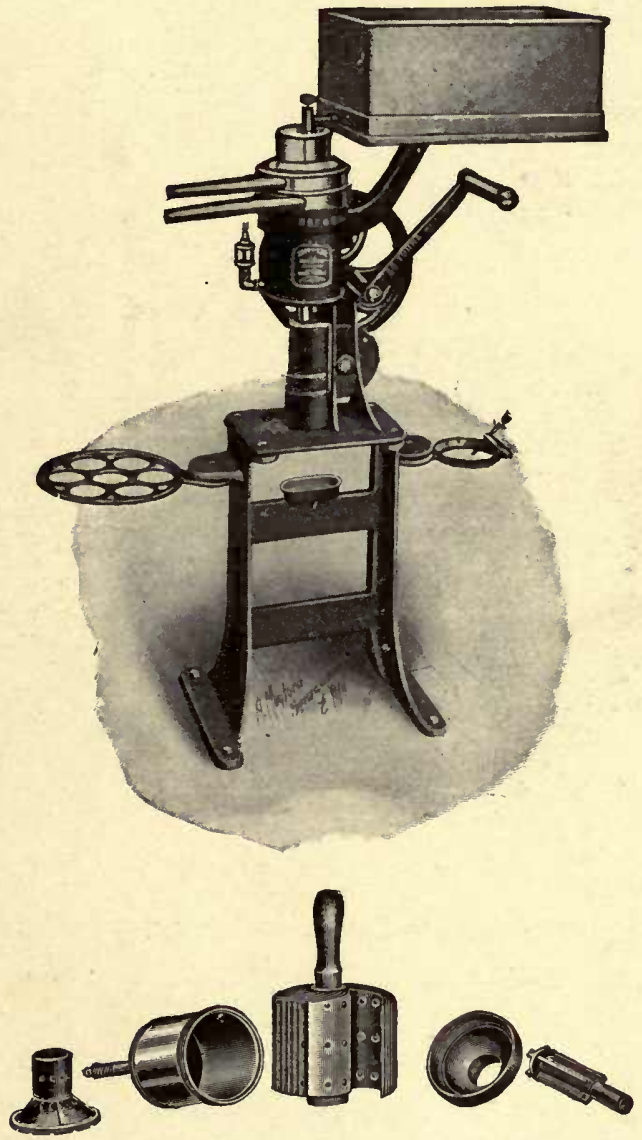

FIG. 80.-Simplex hand separator and the different parts of bowl.

under the milk system. Two thousand pounds of milk, testing $4 \%$ and containing 80 pounds of fat, would represent approximately a load of milk. At 12 cents per 100 pounds, this would mean a cost of $\$ 2.40$ for getting that much milk 
hauled. If the same amount of butter-fat were hauled in the form of cream, it could be gathered for about $1 \frac{1}{2}$ cents per pound of fat, or the cost of hauling in this particular case would be $\$ 1.20$. Under the milk system it would be necessary to haul the milk to the creamery every day, while under the cream system it is usually gathered every other day in the summer, and every three days in the winter. It is usually considered that there is a saving of about $1 \frac{1}{2}$ to 2

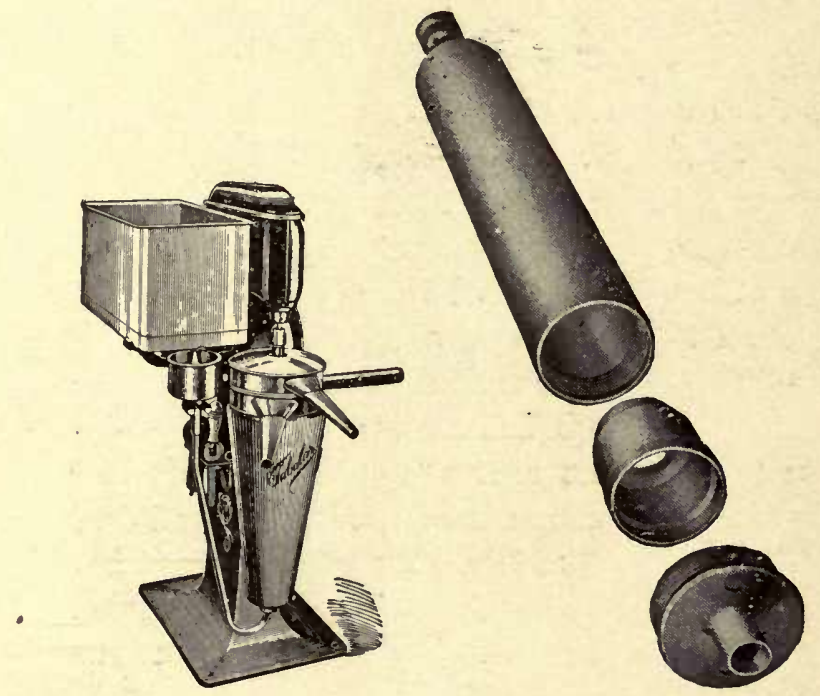

FIG, 81.-Sharples separator and parts of bowl.

cents per pound of butter-fat in hauling, by making use of the cream system instead of the milk system. This, of course, would vary according to local conditions.

3 . The use of hand-separators makes farmers more independent than they are under the whole-milk system. They are not compelled to support their local creamery unless they deem it advisable. They can ship their cream to any place that they may choose. If the butter from the hand-separator cream is going to be of as good quality as that made by the wholemilk system, the cream should be delivered as often as possible. Every day is preferable to every other day. In case frequent 
delivery is made, then it becomes quite essential for the farmer to patronize the local creamery, as very few farmers keep sufficient cows to get enough cream to pay them to ship by rail
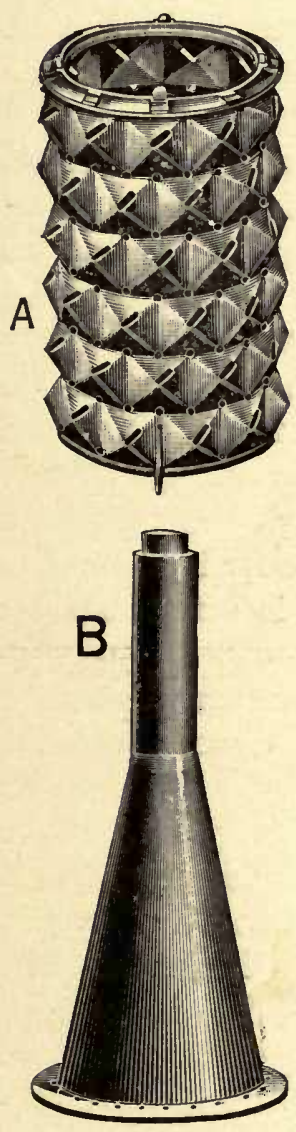
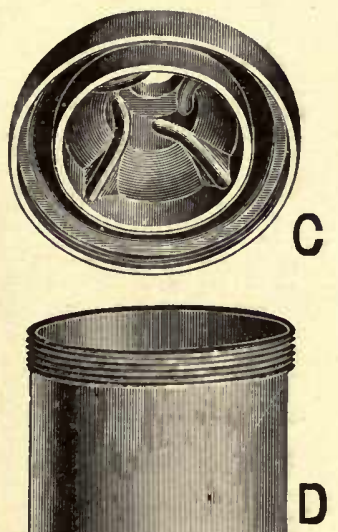

FIG. 82.-The National hand separator and parts of bowl.

every day. Usually it does not cost much more to ship a can full of cream than it does to ship it half or three-quarters full. 
Objections to Farm Separators.-Under the present manner of carrying on the hand-separator system, the quality of butter manufactured from the cream shipped into the central plants is much poorer than that made from whole milk. This is not due to any fault of the system, but to the poor care which

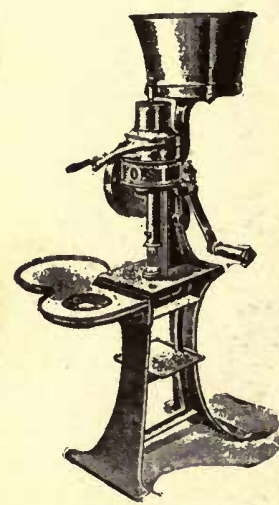

Fig. 83.-De Laval hand separator. the separator and cream receive. The separator on the farm is frequently kept in an unsuitable place. Often it is located in the barn. If the milk is separated in such a place it will absorb odors and undesirable taints. The cream is seldom taken care of properly after it is separated. The separators often are not cleaned well. A separator cannot be kept in good condition by simply flushing out the bowl with cold water at the end of each separation. It must be taken apart at the close of each skimming; have all the parts washed thoroughly in luke-warm water, and then scalded. The time and power it requires to skim the milk and to care for the milk is in many instances considered objectionable to the system.

Thickness of Cream.-The thickness of cream which most butter-makers at central plants prefer is cream containing about 30 to $40 \%$ of fat. Such cream is not thick enough to cause any inconvenience in sampling and weighing. It can be diluted with a good starter and ripened without getting it so thin as to produce unfavorable conditions for churning. By some it is deemed advisable to skim even thicker than this, up to $50 \%$. Cream containing this much fat, however, is difficult to handle especially in winter, during cold weather. It gets so stiff that it is difficult to pour, and there is also danger of losing more or less cream through its adhering to the sides of the cans.

A thick cream is advisable from the farmer's standpoint. The thicker the cream is, the more skim-milk he will retain on the farm for feeding purposes. It can also readily be seen 
that if thin cream is skimmed greater can capacity is necessary, and the express charges will be heavier than if the thicker cream were skimmed. Rich cream does not sour so rapidly as does thin cream.
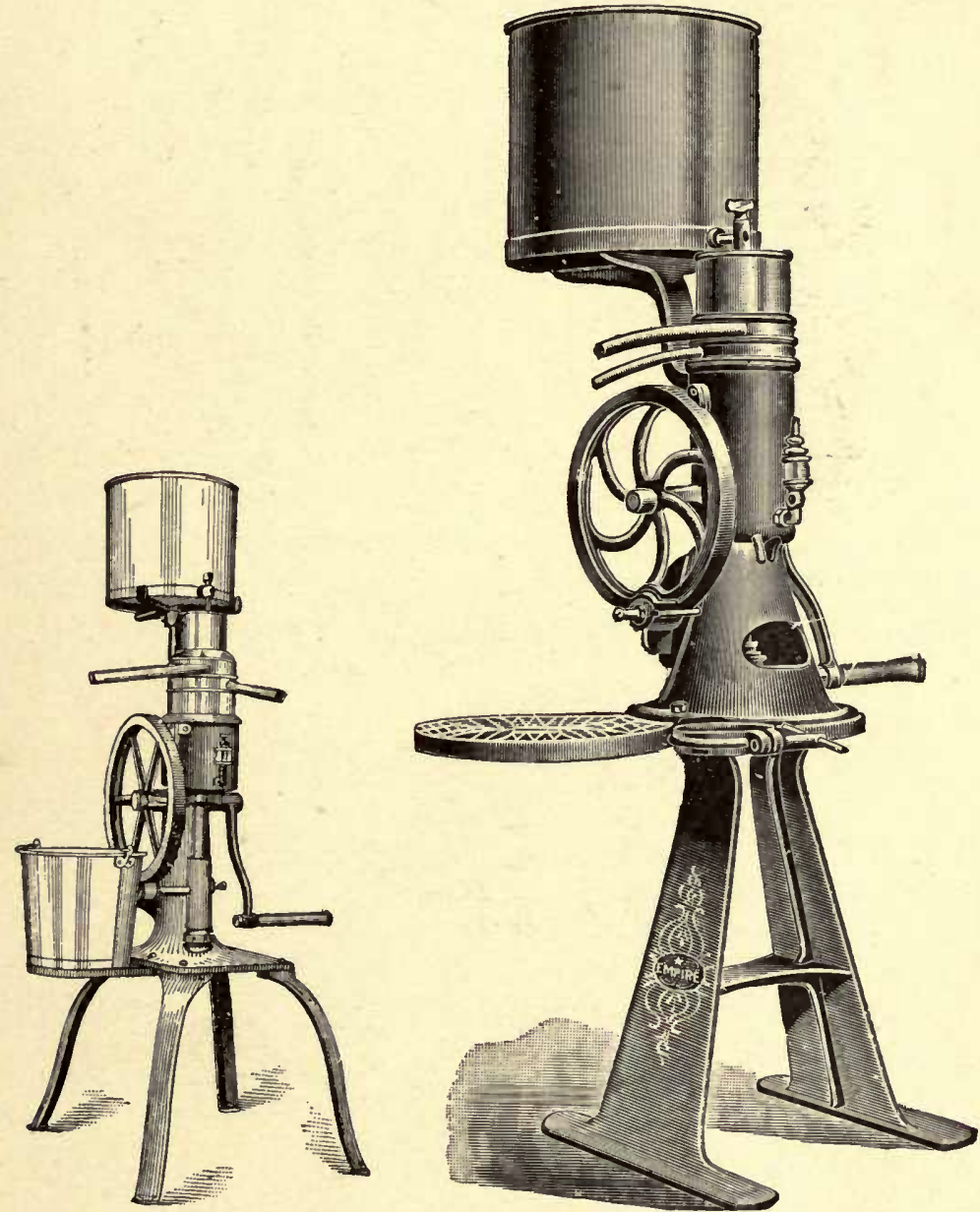

FIG. 84.-The Reid hand separator. FIG. 85.-Empire hand separator.

The thickness of cream can be readily ascertained by the use of a Babcock test, which every farmer should have in his possession. A whole outfit for testing fat in cream or milk 
can be had for about $\$ 8.00$ from any creamery supply-house. By the use of such a test, the farmer can test his crcam and
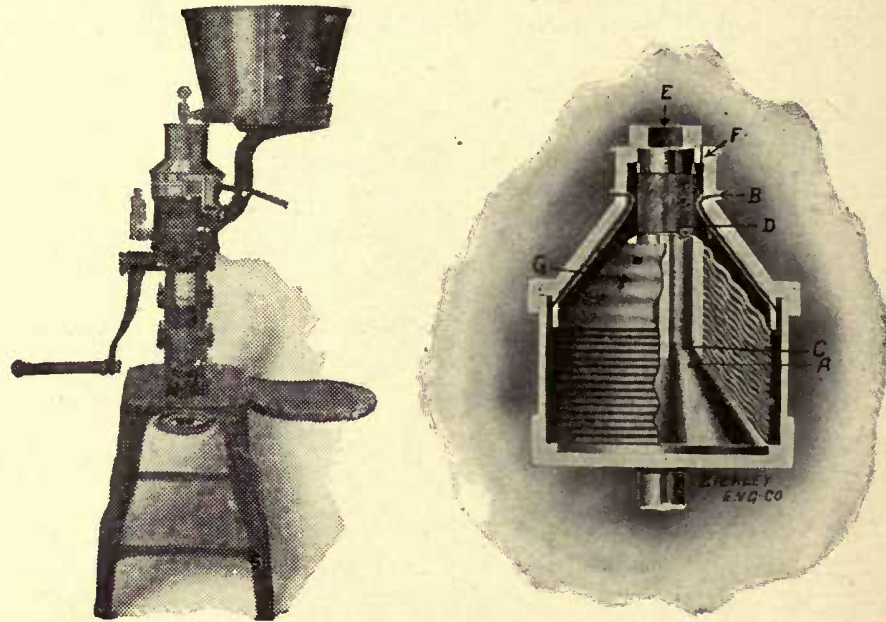

FIG. 86.-Peerless hand separator and cross-section of bowl.

skimmed milk. He can also test the milk of each individual cow in the herd, thereby ascertaining which ones are profitable.

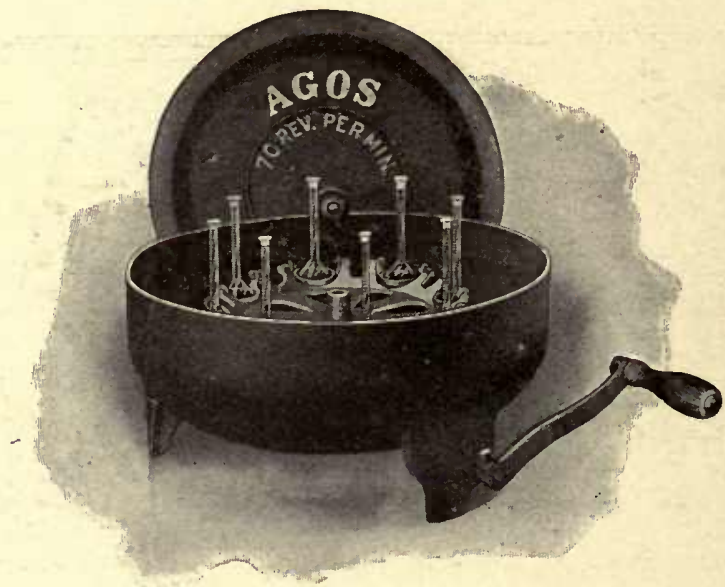

FIG. 87.-Agos hand tester.

By the use of such a test on the farm, the farmer can test his cream daily, and compare results with those from the creamery, 
thereby enabling him to detect any mistake which may happen at the creamery.

Power for Farm Separators.-Hand-power is often men-

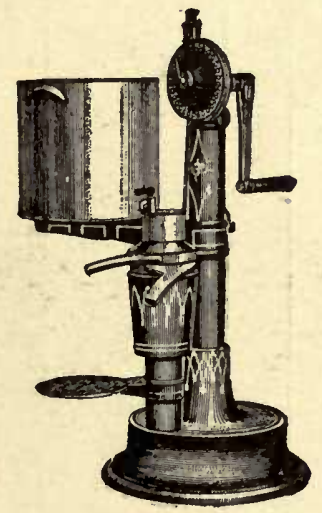

Fig. 88.-The Dairy Queen hand separator.

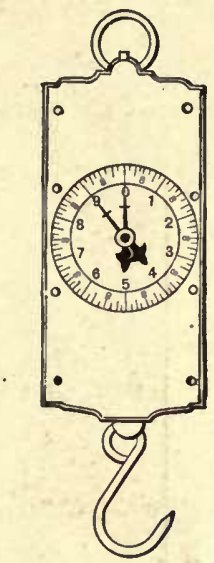

Fig. 89.-Scales.

tioned as an objection to farm separators. When a considerable quantity of milk is to be skimmed, it is certainly hard work to skim with hand-power. Windmills could not well be used

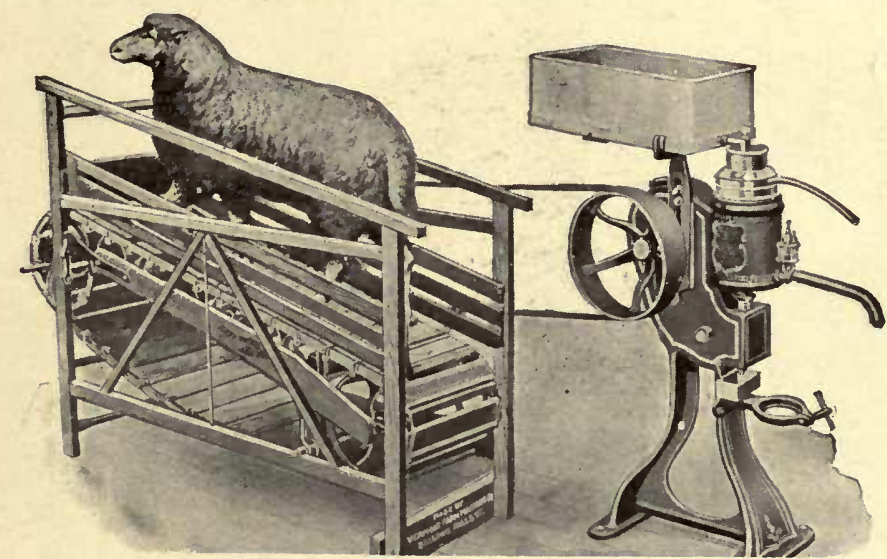

FIG. 90.-Tread-power attached to United States hand separator.

as they do not give uniform speed. The power must be steady and uniform. Farm separators are often run with treadpower. This kind of power is very applicable, and does not cost 


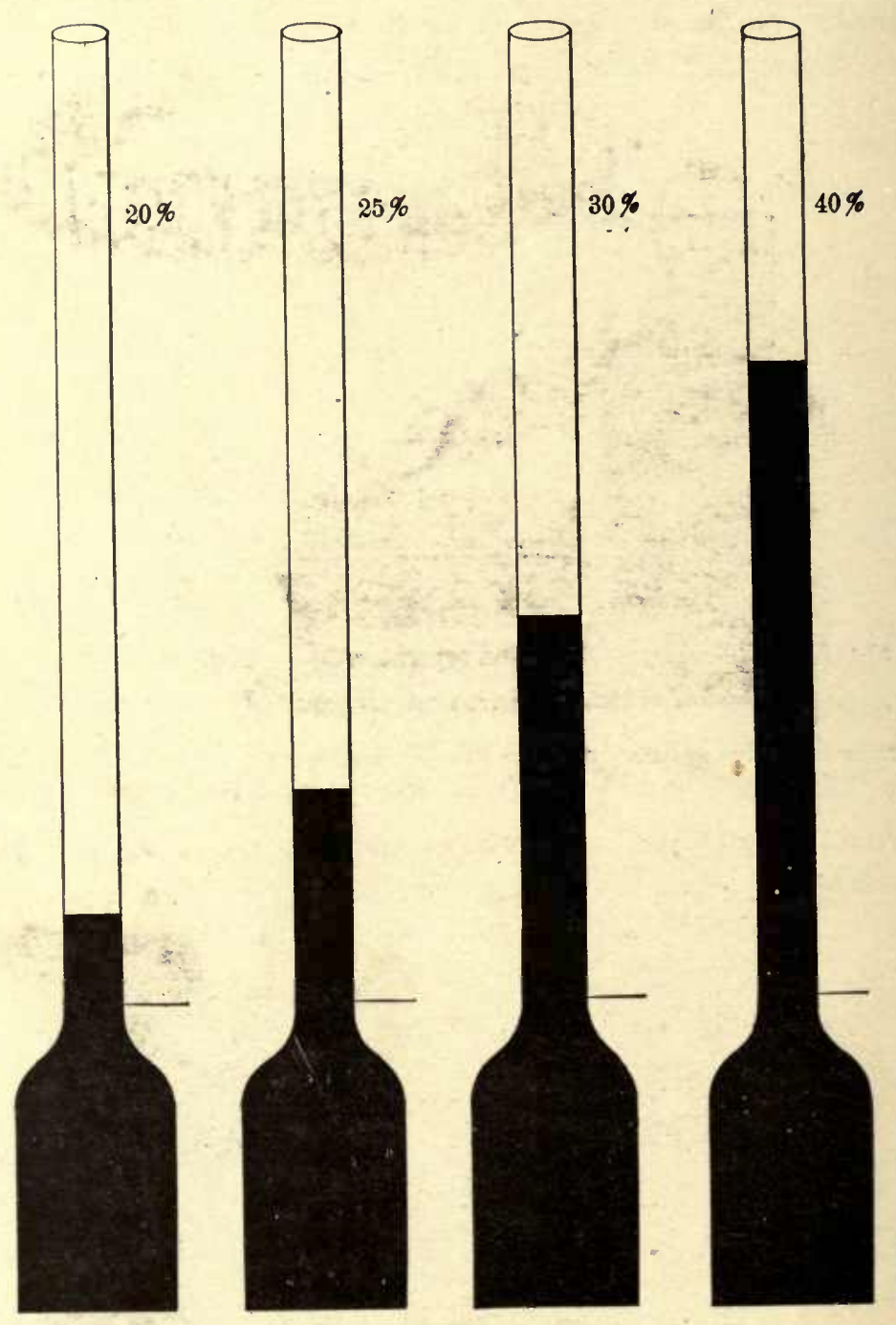

FIG. 91. - Showing the height to which cream free from air-bubbles must be raised in a pipette to get 18 grams of cream. It shows that to measure cream in a pipette is inaccurate in cream testing. (lowa State Dairy Com. Report, 1903.) 
anything after the tread-power has once been purchased. The power can be supplied by using different kinds of animals.

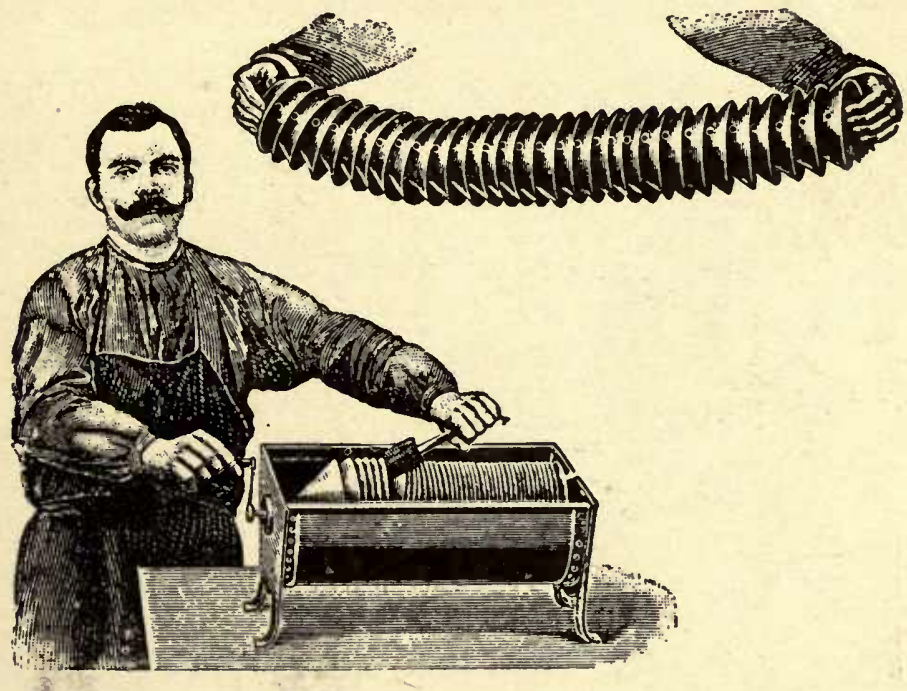

FIG. 92.-Showing how the internal bowl devices of Westphalia hand separator are washed. (N. Y. Produce Review and American Creamery.)

Sheep, goats, dogs, and bulls are used for this purpose. The process usually does not last very long, and it is not considered heavy work. Steam is good power, but it is hardly ever obtainable on the farm. Small gasoline-engines are also used very successfully.

The machine should always run smoothly in order to get efficient skimming. It should never be stopped and started with a jerk. Start it slowly and there will be less danger of breaking any of the gearing parts. The bowl and inside parts should be kept from rusting as described previously on page 145. The bearings should be well oiled. It is a good plan to have an extra

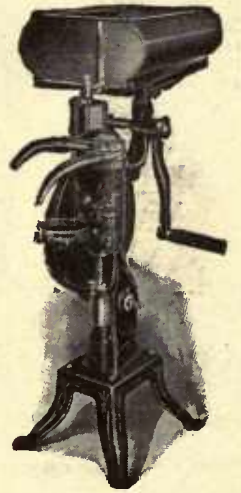

FIG. 93.-Davis hand separator. bearing or two on hand, so that if one happens to wear 
out another one can be put in. The bearings should be cleaned at intervals. When kerosene is occasionally used on the hearings they do not need to be cleaned so often, because

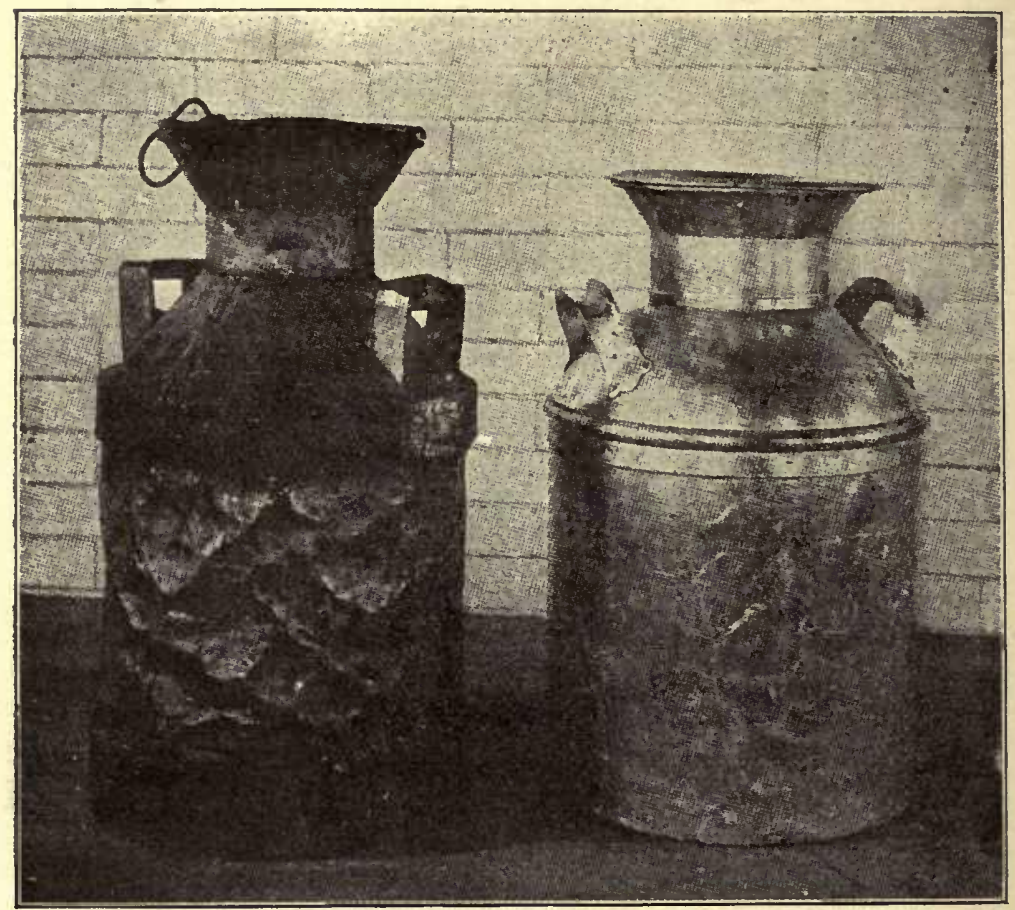

FIG. 94.-Dairy utensils in the battered condition of the can on left and with tin off in many places inside, cannot be kept clean and should be discarded. (Kiansas State Board of Agriculture Report No. 87, 1903.)

it keeps them from gumming. The machine should be turned at the proper speed, as indicated in the directions. A thicker cream will result from rapid turning; consequently more skimmed milk will be obtained. Slow turning causes inefficient skimming and thinner cream.

Care of Cream on the Farm.-The first step in the production of good cream is clean milking. This can only be accomplished when barn, cows, and utensils are clean. It is a good 
plan to dampen a cloth, and wipe off the cow's udder and sides each time previous to milking. The milker should never wet his hands while milking. Dust should not be stirred up in the barn during milking, as the dust particles carry with them a large number of undesirable germs. When these settle in milk they are likely to produce taints. If cloth strainers are used they should be kept scrupulously clean. It is advisable not to use them at all, as good sanitary wire-gauze strainers are inexpensive.

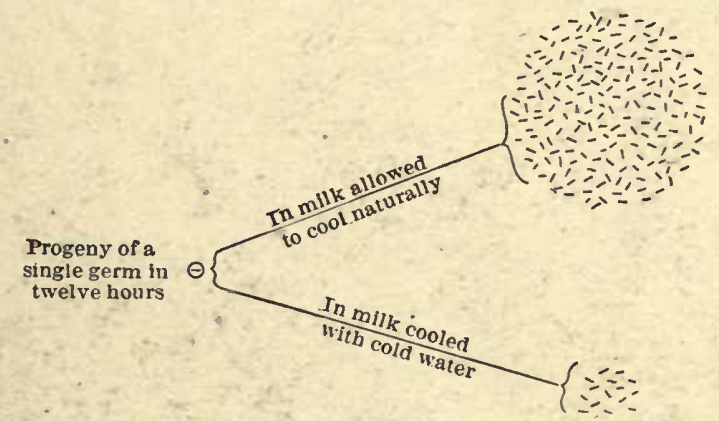

FIG. 93.-Showing the effect of cooling milk on the growth of bacteria. The beneficial results of early chilling are readily apparent. (From Bul. 62, Wis.)

If these conditions are complied with, and the separator is kept in a good clean condition, the milk will have comparatively few germs in it. Some germs, however, will enter the milk, and in order to keep thern from developing, it is essential to cool the cream or milk immediately. Low temperature retards and practically prevents the development of germ life. It is a well-known fact that when milk is kept cool, it will remain sweet much longer than if kept at a high temperature. Never mix two milkings or skimmings unless both are well cooled first. In order to cool cream quickly, it should be stirred during cooling. The ordinary four-gallon shot-gun cans are good and suitable for keeping milk and cream. They have a large cooling surface in proportion to their cubical content. 


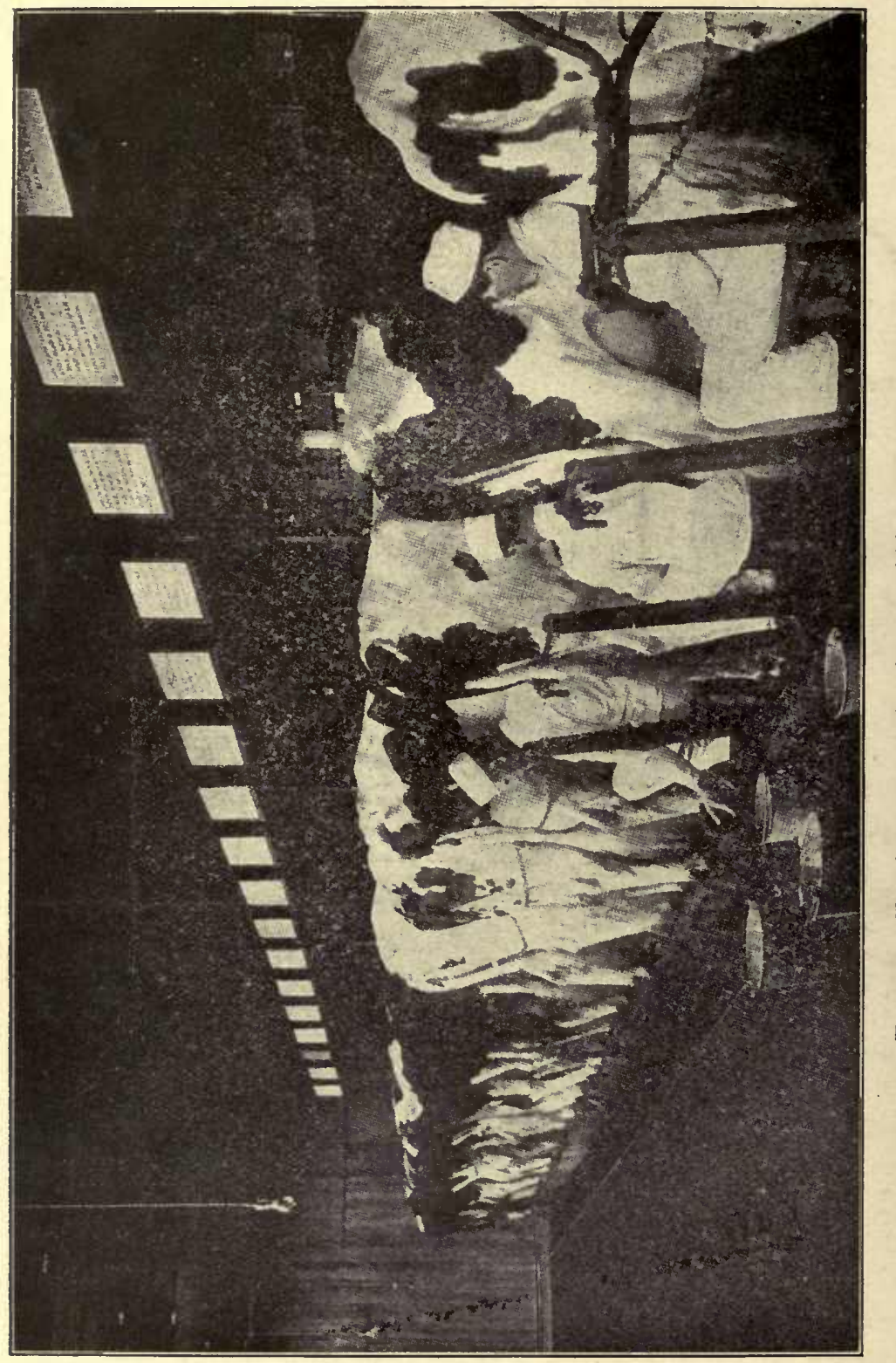

욕

है

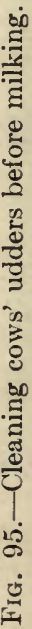


The milk or cream should be cooled as low as the water will cool it. It is well to cool it even lower than this if ice is obtainable. In keeping milk, the temperature should never go

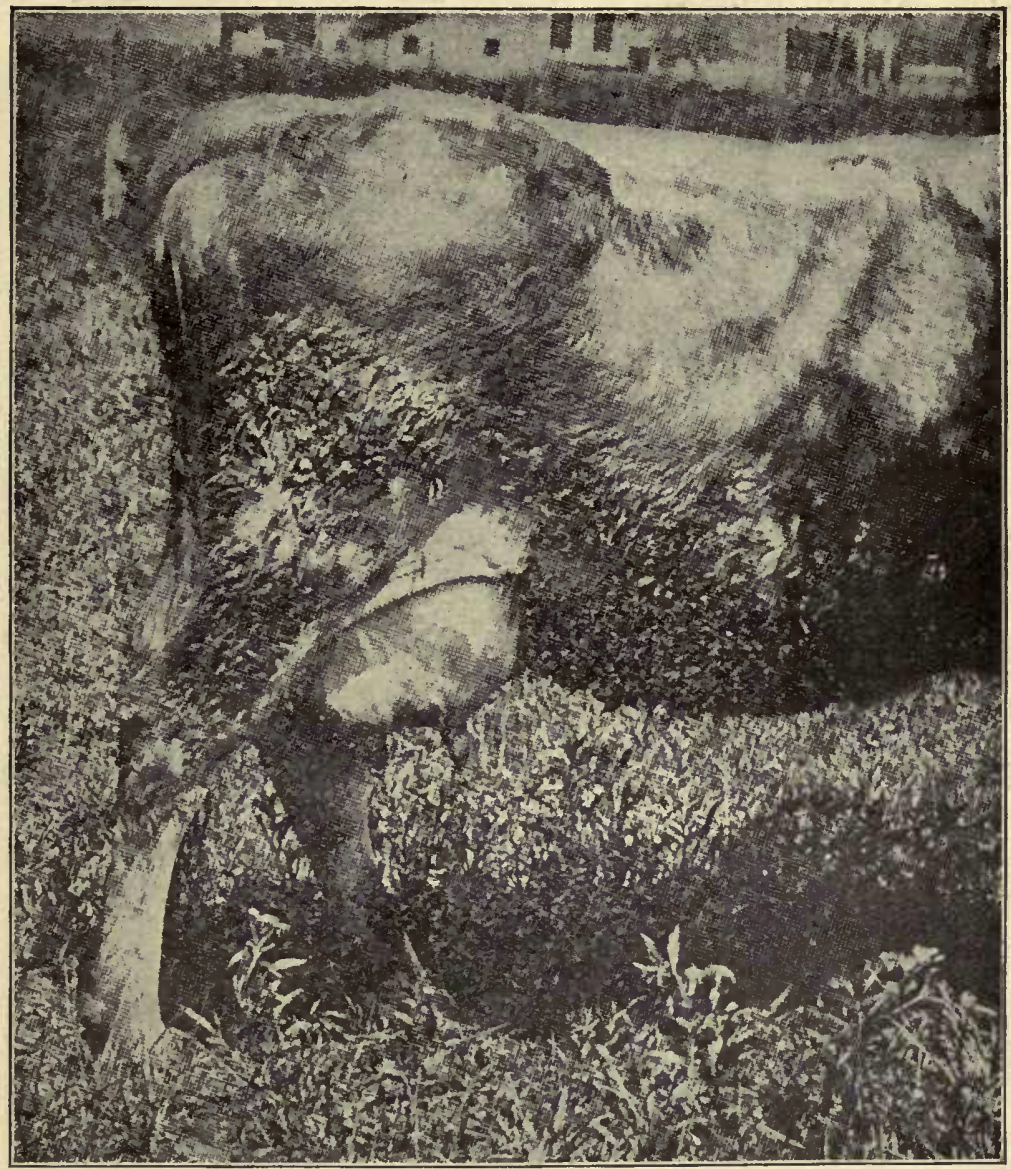

FIg. 97.-The condition of the cow shown in this cut is favorable for the accumulation of loose dirt. (Bul. 84, Ill.)

above $60^{\circ} \mathrm{F}$. Cooling to $50^{\circ} \mathrm{F}$., if it can be accomplished, is much more desirable for keeping milk or cream in good condition. 
If considerable milk is handled, it is well to provide a milkhouse. it should be built large enough to contain the separator, water-tank, and other utensils necessary for home butter-

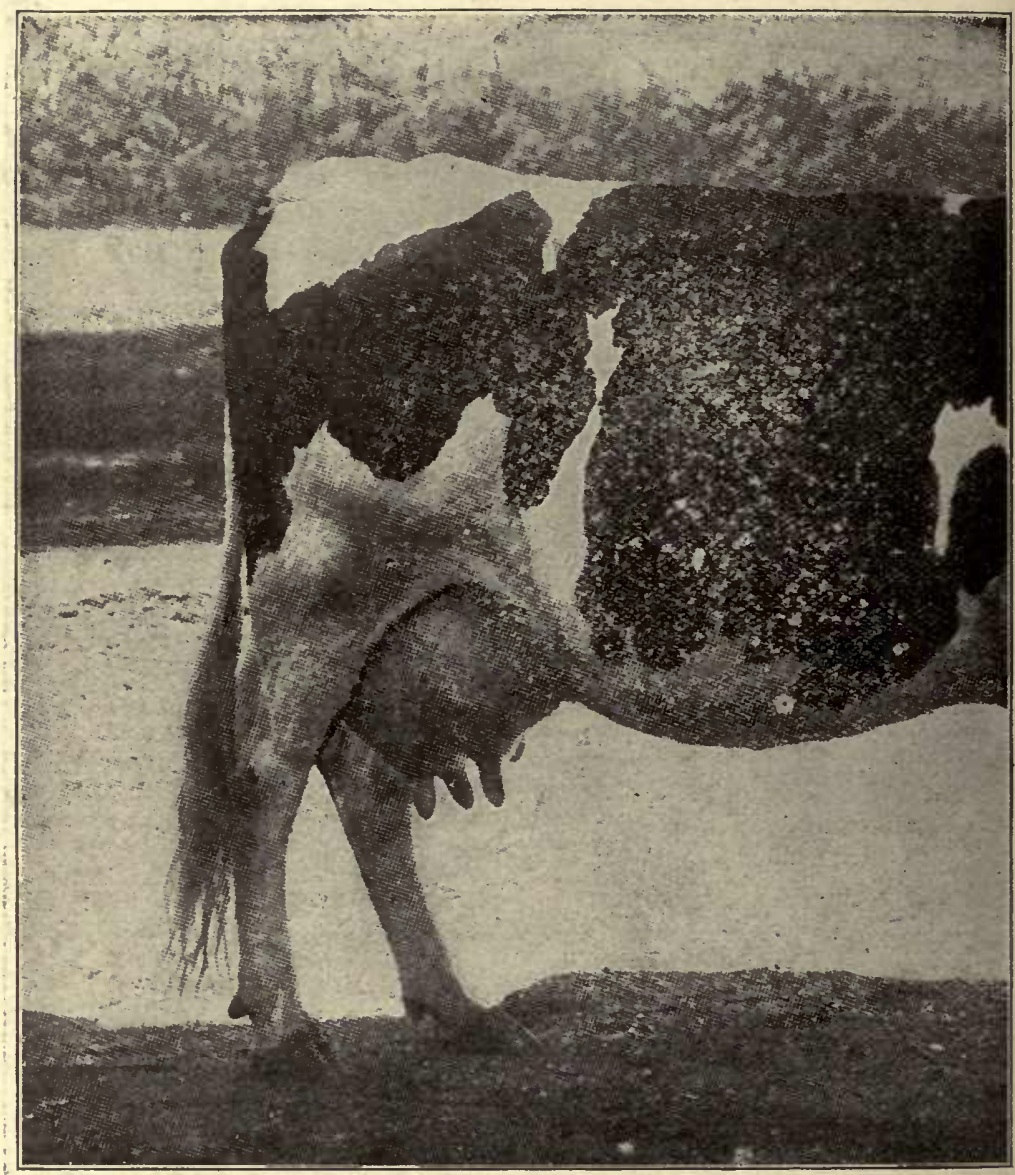

Fig. 98.-A clean cow. The dirt cannot adhere to this cow to so great an extent as to the one shown in Fig. 97. (Bul. 84, Ill.)

making, such as a churn and butter-worker. There should be plenty of windows on all sides to give good ventilation. The water-tank should be connected directly with the well, so that 

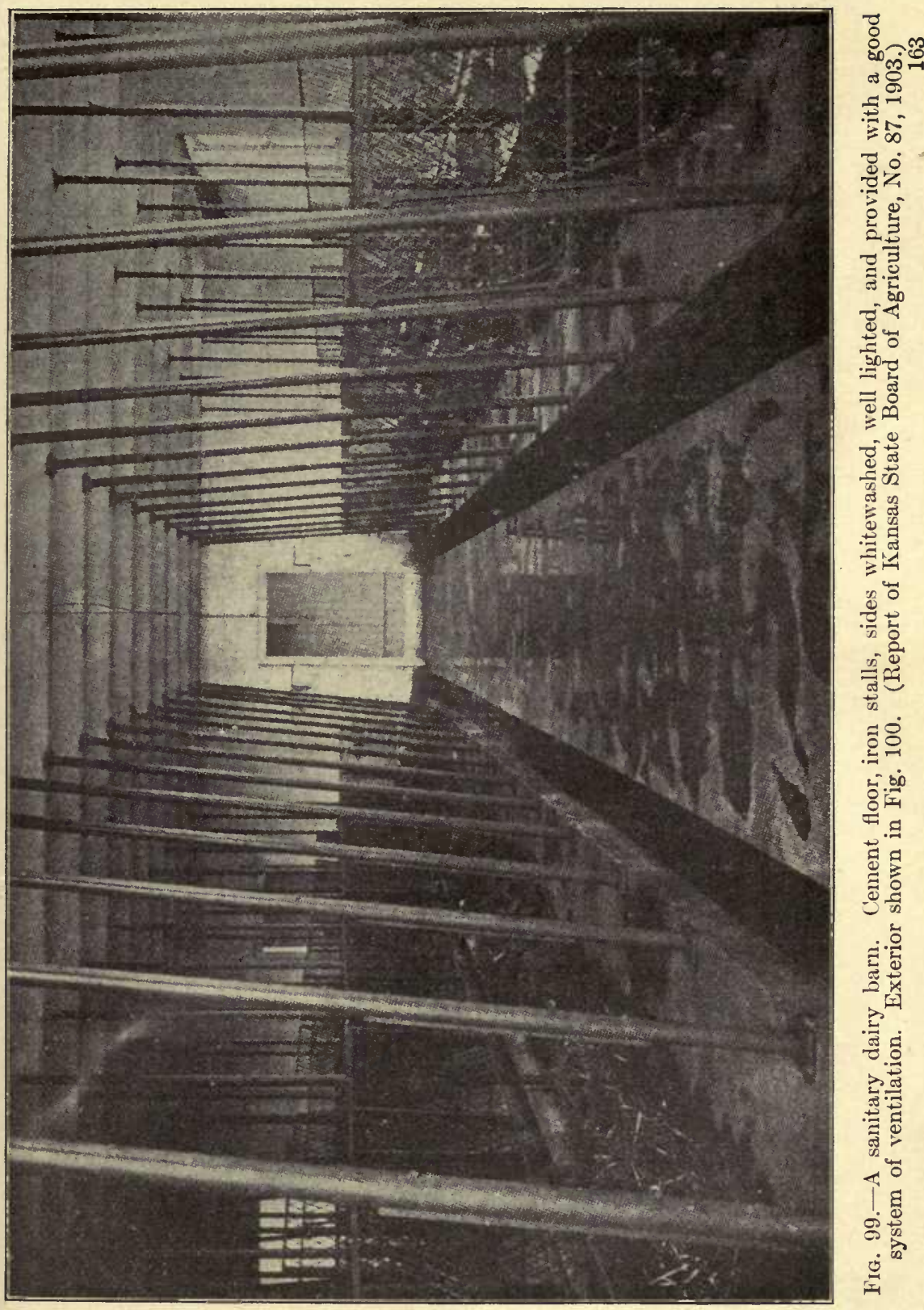


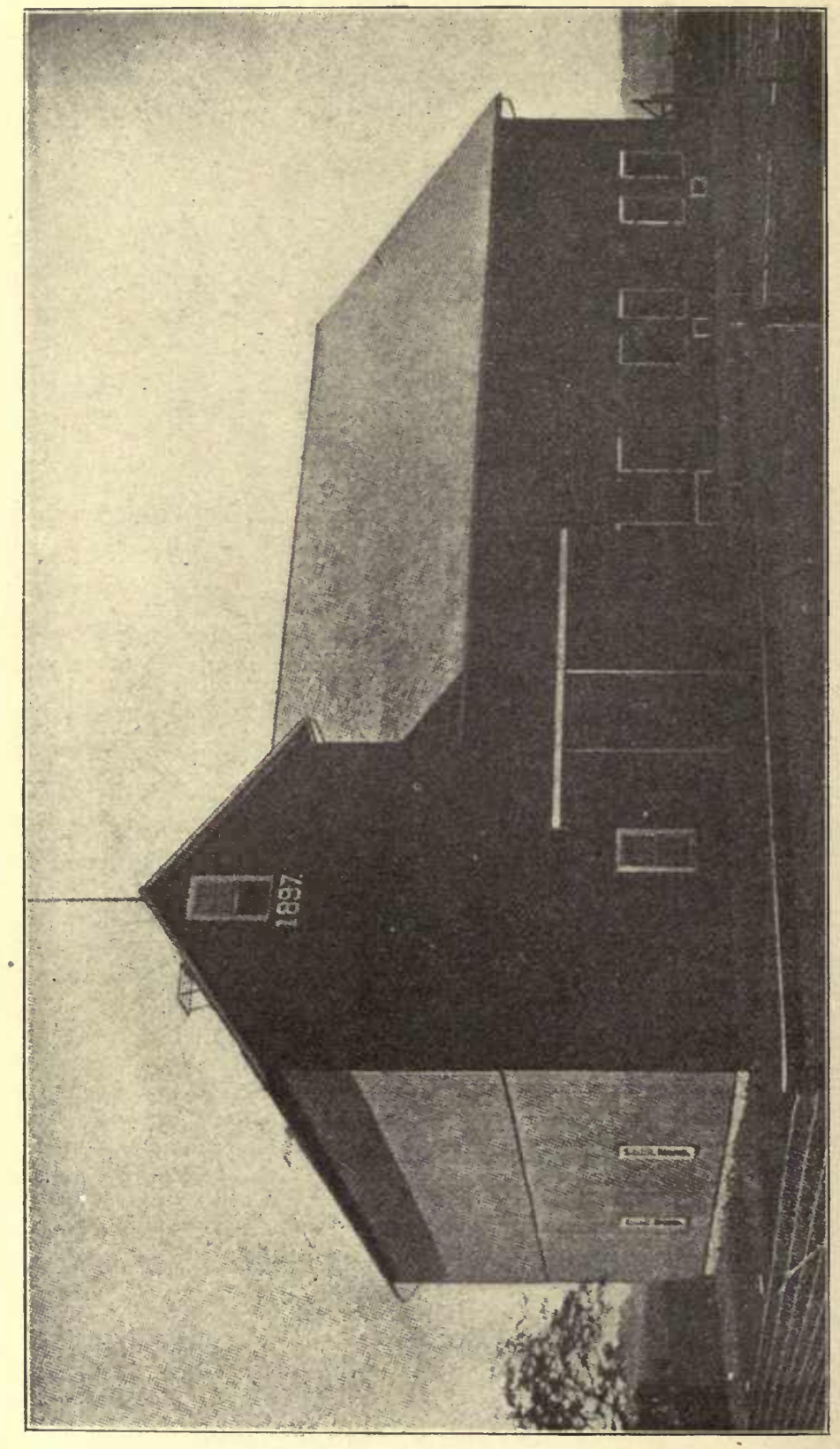

$\frac{1}{0}$

$\stackrel{\frac{3}{30}}{\frac{30}{2}}$

हี

.

क्षे

\%

ङ

ㅎ.

든

늘

$\Xi$ ํำ

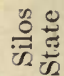

ล

0

可

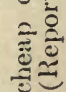

78

.

苟

ฏ.

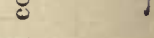

تृّ

$<$

$\stackrel{8}{8}$

Eే 


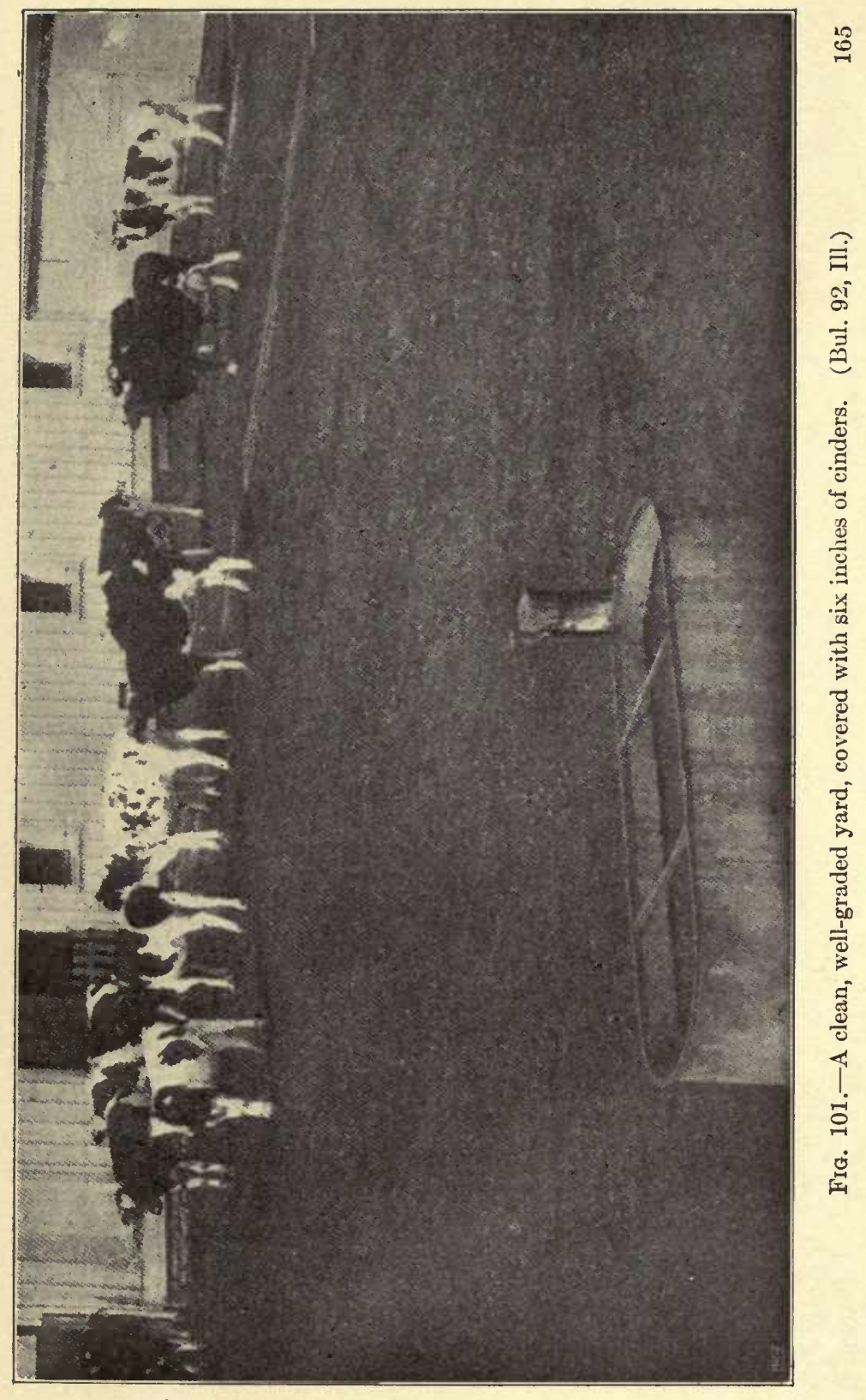




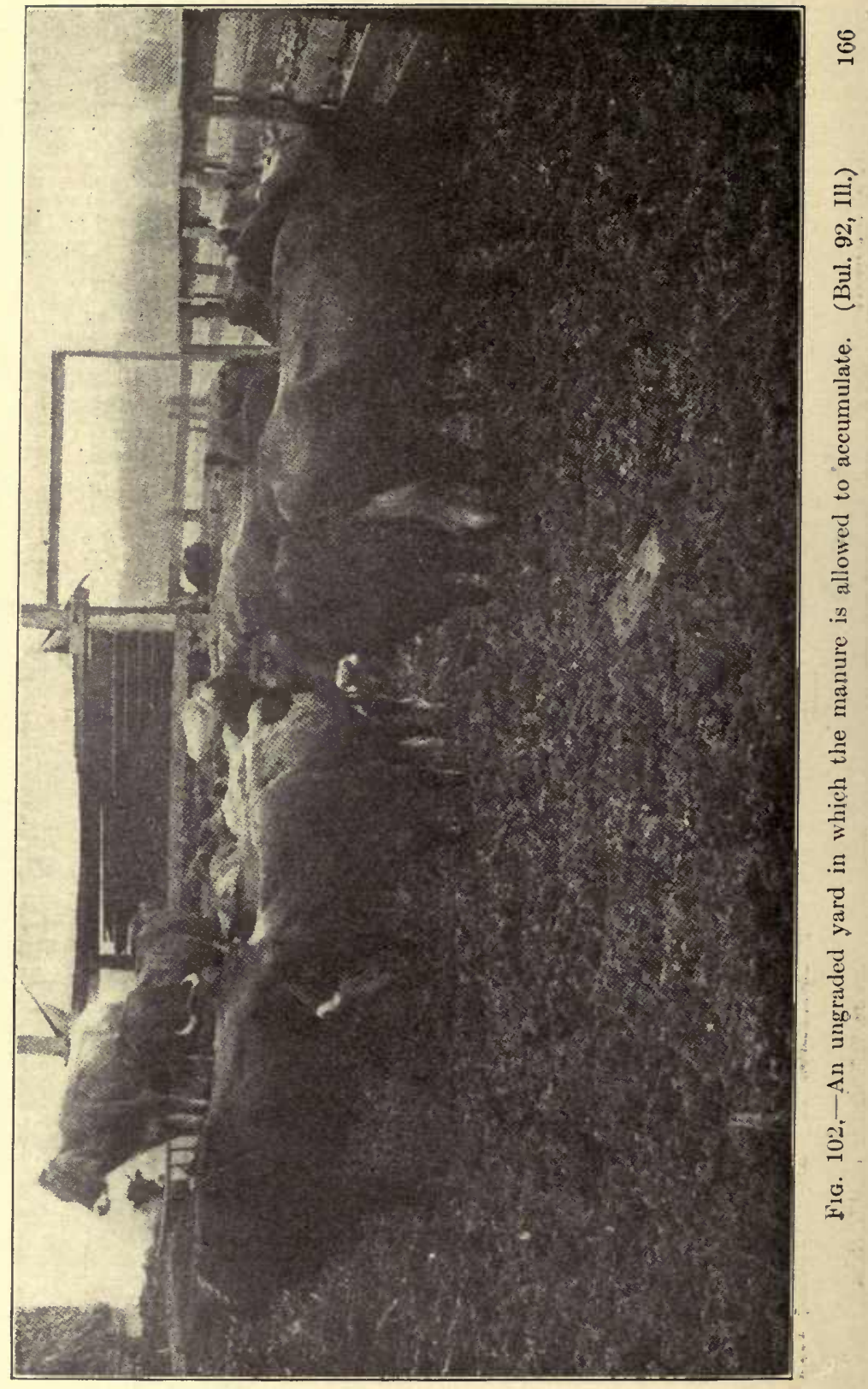


the water can be pumped directly to the tank holding the milk and cream. From this place the water can be run out into the stock-tank. This arrangement allows the milk to be kept at the lowest possible temperature.

It is just as essential to cool the milk during the winter as it is during the summer. By pumping water through this tank practically all the time, the water in the tank will be kept from freezing. It is well to keep the surface of the water higher

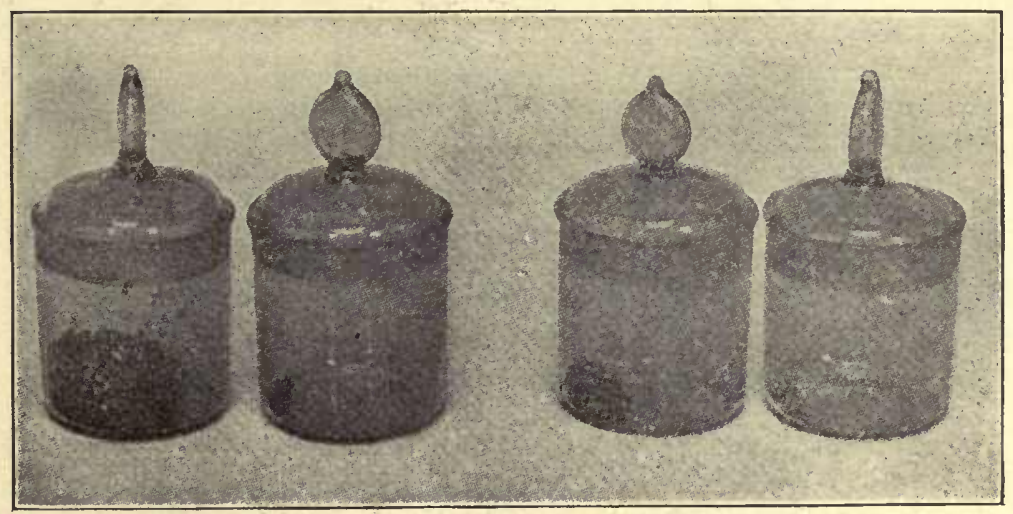

FIG. 103.-The average weight of dirt which falls from muddy udders during milking is ninety times as great as that which falls from the same udder after washing, and when udders are slightly soiled it is tmentytwo times as great. (Bul. 81, Ill.)

than the surface of the milk in the can. This will prevent the milk from freezing so easily. If the cold is too severe, a tankheater can easily be secured which will moderate the temperature a trifle.

Disposition of the Cream.-There are two ways of disposing of cream on the farm: (1) selling it to creameries or other parties, and (2) making it into butter on the farm. The former method is usually the most advantageous. Creameries, as a rule, are better equipped to control the quality of butter. The price per pound of butter-fat is usually about 2 cents below "New York Extras." A few of the best co-operative creameries are able to pay more than that. 


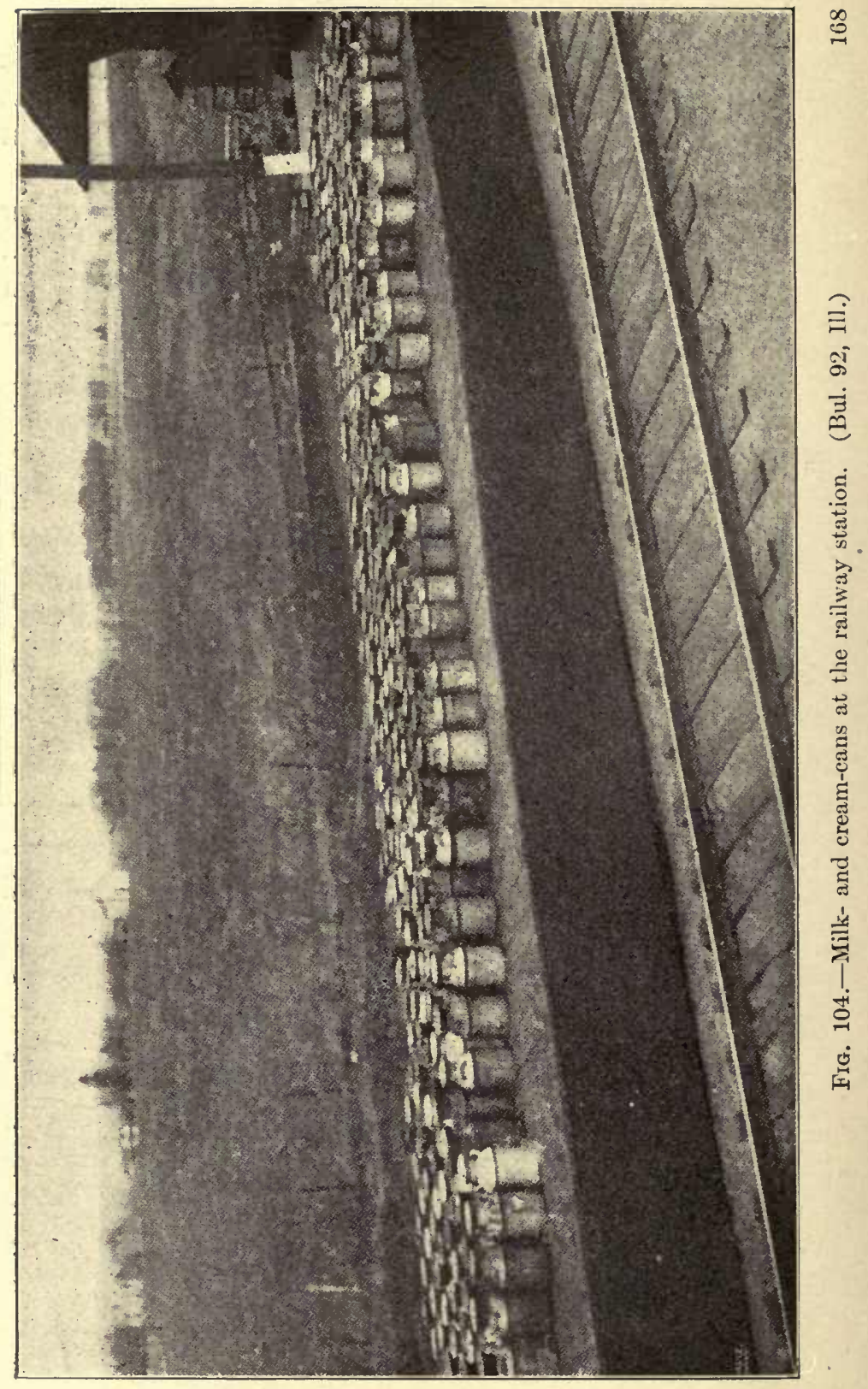


Shipping of Cream.-If cream is sent or shipped to creaineries and central plants, it is essential that it be delivered as frequently as possible, and that it be delivered in cans which will help keep it in good condition. If cream is to be shipped any great distance and be exposed to the sun, it is advisable to use special jacketed cans, which retard the transmission of heat. It is a good plan to cover the cans with a wet sack r. cloth during the summer, and the use of a dry sack an
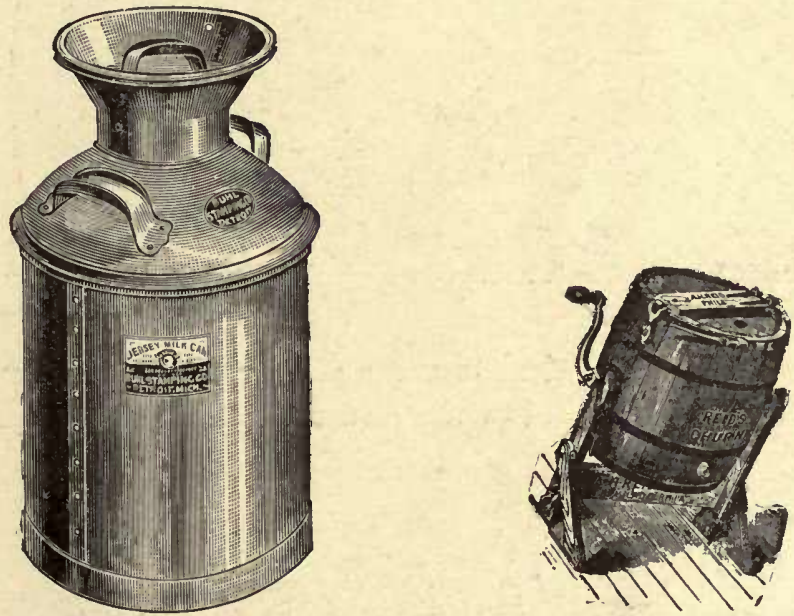

Fig. 105.-The Buhl milk and cream can. FIG. 106.-A barrel churn.

the outside in the winter often prevents the cream from freezing.

Making Butter on the Farm.-If cream is kept in good condition and proper skill is applied, the best of butter can be made on the farm. Theoretically, better butter can be made on the farm than at the creamery, because all conditions can be controlled better. This is not so in creameries. One can of bad cream mixed with a quantity of good cream is likely to contaminate and injure the whole lot. The cream which is to be made into butter on the farm should be ripened, or soured, properly before it is churned. In creameries, starters 
are used to set up a quick and desirable fermentation in the cream. Conditions are usually such on the farm that it is not

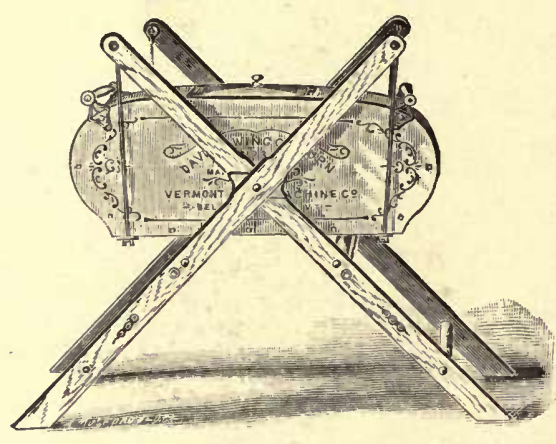

FlG. 107.-The Davis swing-churn.

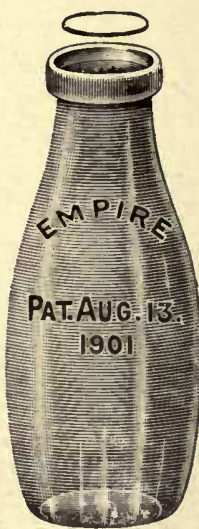

Fig. 108.-Sanitary glass milkbottle and cap for same.

convenient and practical to use a starter. In the summer the eream can be lifted out of the cold water the morning previous

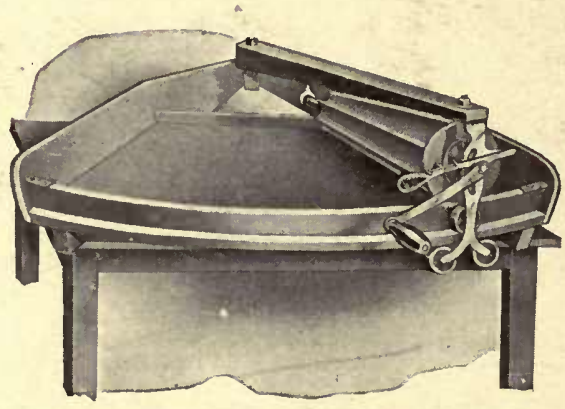

Fig. 109.-Skinner butter-worker.

to churning, and it will sour during the day. In the evening, or when it has soured, it can be set back into the water to cool. The next morning it is ready for churning. In the winter the cream can be soured by warming it up or keeping it in a warm place. If some good sour milk is on hand, it might be added, 
and the cream will sour much quicker. It is very essential that the cream can be cooled to a low temperature $\left(50^{\circ} \mathrm{F}\right.$.) and left

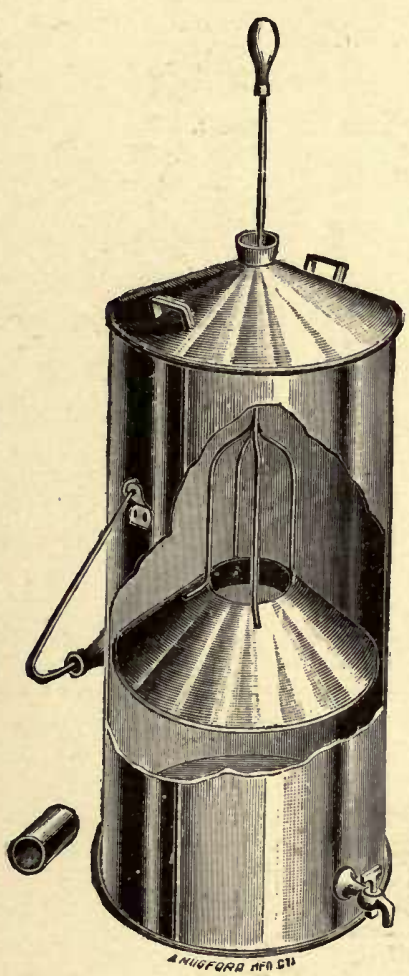

FIG. 110.-Milk or cream can with agitator.

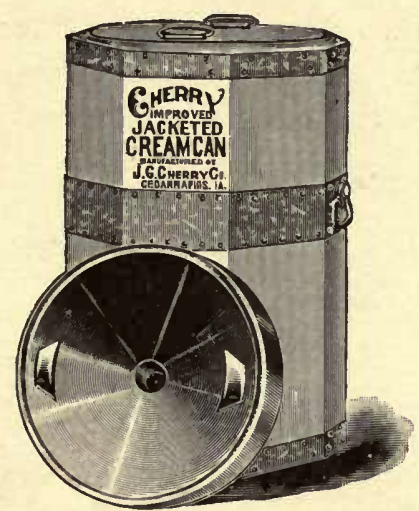

Fig. 111.-The Cherry jacketed cream can.

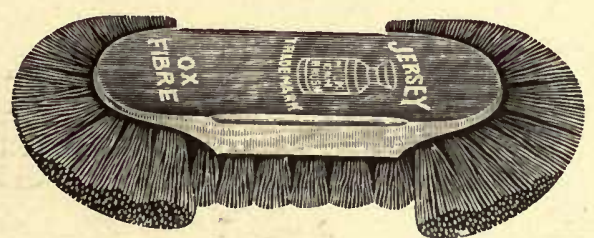

Fig. 112.-The Jersey can-brush.

at this temperature for at least two hours before it is churned; otherwise the butter is likely to be greasy and salvy. Color and salt to suit the market and season. About three-fourths to one ounce of salt to one pound of butter usually gives good results.

If a local trade can be secured, it is not necessary to pack it into tubs. Tarthen jars are good to keep butter in. If no local trade can be secured, and it is essential to ship the butter, 20- or 30-pound tubs should be used. If a good quality and. 
constant supply of butter can be secured throughout the whole year, it is an easy matter to find an excellent market for butter at hotels or good restaurants. (For a more detailed discussion of butter-making, see Chaps. XVI and XVII.) Putting up butter in prints and wrapping them in parchment paper which bears the maker's name usually increases its value. 


\section{CHAPTER XIII.}

\section{PASTEURIZATION.}

Definition.-The word pasteurization has its derivation from Pasteur, a French scientist. Pasteurization consists in heating milk somewhere between $140^{\circ} \mathrm{F}$. and $212^{\circ} \mathrm{F}$. This kills practically all germs in a vegetative state. Since most of them are in a vegetative condition, the process kills almost all the organisms. The heating is followed by rapid cooling. "Sterilization" is a word which is some times used incorrectly in connection with pasteurization. Sterilization means that milk or any other substance has been heated so of ten or to such a high temperature as to entirely destroy every living micro-organism present. In order to get a substance thoroughly sterilized without heating under pressure, it is essential that it be heated about thirty minutes on each of three or more successive days. Pasteurization in the dairy industry was introduced by Professor Storch of the Royal Experiment Station, Copenhagen, Denmark.

\section{Methods of Pasteurization.-}

(1) Intermittent.

(2) Continuous.

1. Intermittent pasteurization is usually accomplished in vats or cans. It is used nearly exclusively when pasteurization is practiced on a small scale, such as preparation of starters in creameries, pasteurizing cream and milk on the farm, etc. Intermittent pasteurization is as efficient, and undoubtedly more so, than the continuous method. The substance pasteurized is usually exposed to the high temperature a longer time than it would be by the intermittent system. In the continuous 
method of pasteurization the substance pasteurized is exposed only to a sudden temporary heat.

The intermittent process of pasteurization tends to drive off more of the undesirable taints present in the milk or cream. This is especially true when stirred occasionally. If heated too long the cooked flavor is likely to be more pronounced than when the intermittent system is used. If exposed very long

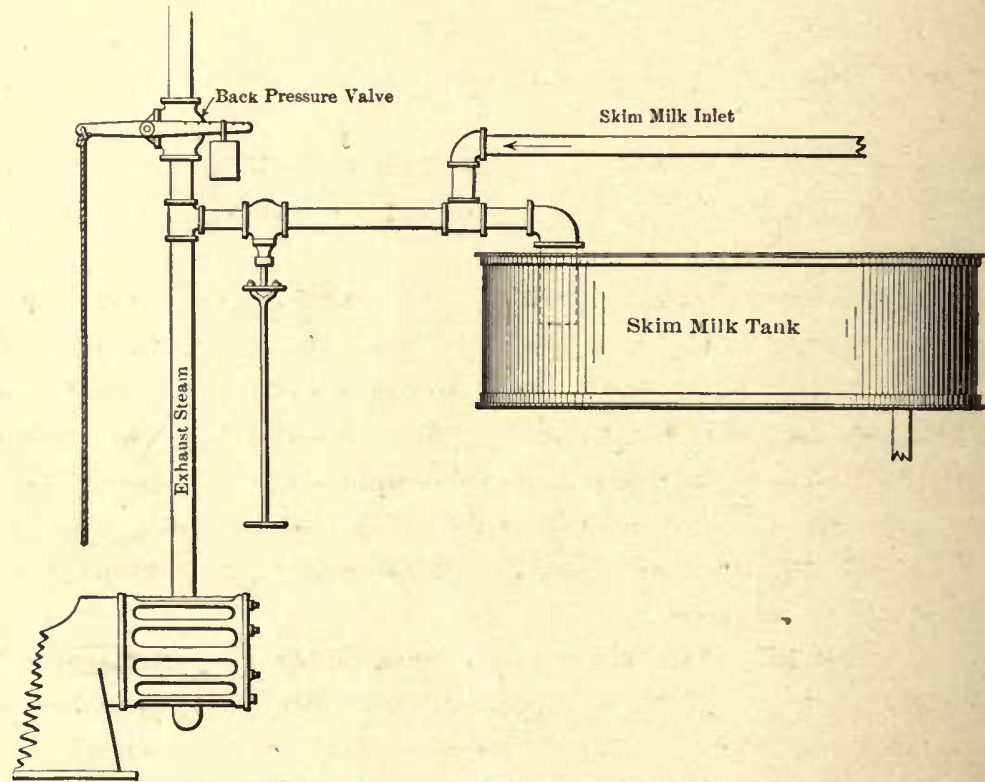

FIG. 115. - Scheme for pasteurizing skim-milk by the use of exhaust-steam direct. (Creamery Journal, by W. P. McConnell, Minn.)

to the high temperature and stirred excessively during the intermittent pasteurization, the butter-fat tends to melt and run together, and show itself on the top of the cream in the form of an oily layer.

2. The continuous method of pasteurization is more practical for large amounts of milk or cream. It is used almost without exception in pasteurizing cream, whole milk, and skinı-milk at creameries. Neither one of the two systems destroys spores. The intermittent system is the most effective because both 
time and temperature are under control. Various pasteurizing machines are in use, and it is not within the province of this work to recommend any machine. A few words in regard to the principles which affect proper pasteurization will serve a better purpose.

\section{Selection of Pasteurizers.}

Improper pasteurization is worse than none at all. If pasteurization is done at all, it is essential that it be properly accomplished.

There are two things to be sought when purchasing a pasteurizer; viz., (1) durability and capacity, and (2) economic efficiency.

1. Durability and Capacity.-The structure of most pasteurizing machines is simple and substantial. They do not wear out like a complex piece of machinery. It is essential that the machine be strongly made. Heating-walls and other portions should be made heavy enough to be consistent with its use, and of a substance which will conduct heat rapidly. Nearly all the types of pasteurizers are made in different sizes to suit the demands.

2. Economic Efficiency.-Obtaining efficient pasteurization economically is the most important question. It is important in this connection because it depends upon so many conditions which the operator has under control. The degree of conductivity of heating-surface during operation, may in one sense include most of the essential factors which affect pasteurization. This in turn depends upon a number of conditions which are as follows:

(1) Kind of material from which the heating-surface is manufactured.

(2) Degree of adhesiveness of milk or cream on heatingsurface.

(3) Thickness of layer of condensed steam, on steam side of heating-surface.

(4) Difference in temperature on each side of heating-surface. 
(5) Proper utilization of steam turned into the pasteurizer.

(1) Heating-surface.-It is a well known fact that some metals will conduct heat better than others. The relative heat conductivity of the two substances used chiefly for pasteurizers viz., copper and tin, is .918 and .145 respectively. This means that copper will conduct heat nearly seven times faster than tin of the same thickness.

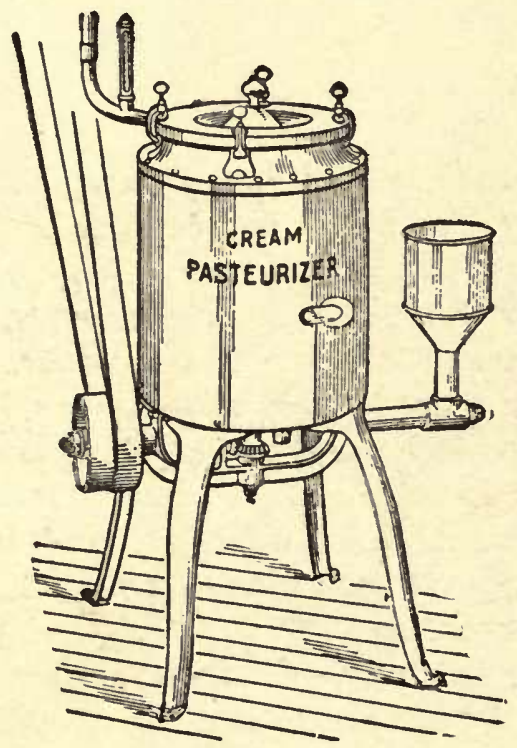

FIG. 116.-The Reid pasteurizer.

In connection with this it should be mentioned that stability and durability of the substance must also be taken into consideration. A heating-surface made from copper may be nearly seven times as thick as that made from tin, and still transmit as much heat as the tin surface. From this it can be seen that a heating wall made from copper can be increased slightly in thickness, and thus aid in stability, without affecting the degree of heat conductivity of the wall very much. The heatingsurface must be strong enough to withstand a slight steam pressure, otherwise the heating wall is likely to collapse or cave in in case of slight variation in the steam pressure. It is not 
an uncommon c scurrence to have the heating wall of a pasteurizer burst. This could be prevented by connecting a safety, or pressure, valve, to the pasteurizer.

(2) Degree of Adhesiveness. - Roughness, due to either defects in the metal itself, or to milk or cream being burned on the heating-surface, is a scrious defect. Such a condition

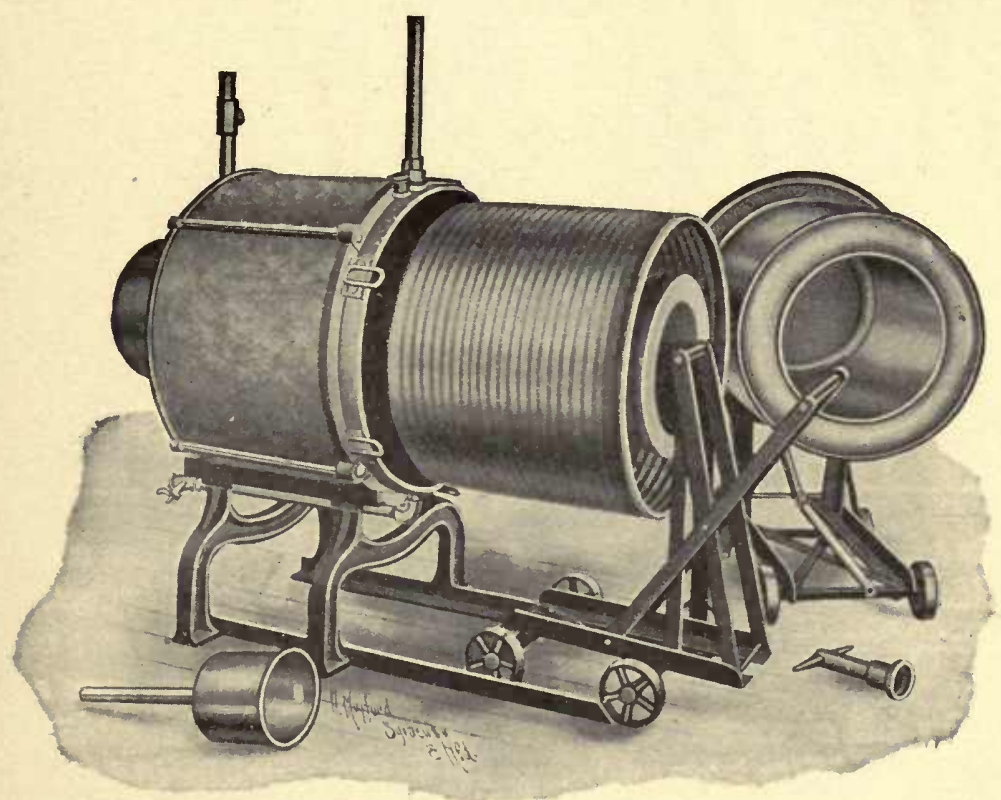

FIG. 117.-The Simplex regenerative pasteurizer (apart).

causes particles of milk or cream to move very slowly over the heating-surface; it tends to roll in much the same way as drops of liquids do when caused to flow over a slanting dry rough surface. As a consequence more and more casein will adhere. The thicker the layer of foreign matter is on the heating-surface, the greater the difficulty in getting the greatest efficiency from the pasteurizer.

It is important that the milk or cream be forced over the heating-surface with greater rapidity than could result from its own gravity. On heaters or pasteurizers, where milk flows 
over the heating-surface only by force of its own gravity, a heavy layer of curd usually adheres. This is due to the fact that certain portions of the milk are exposed to the excessive heating too long, while if caused to move rapidly it does not remain in contact with one portion of the heating-surface long enough to cause it to adhere to so great an extent.

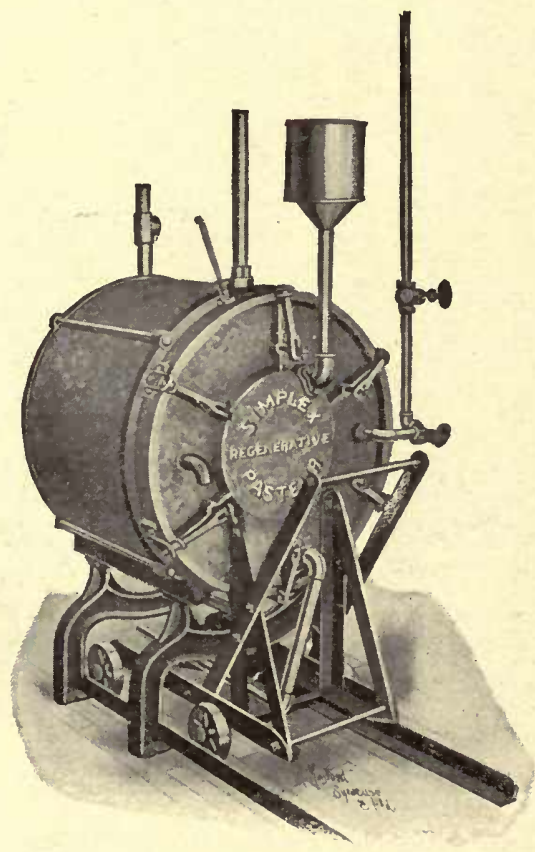

FIG. 118.-The Simplex regenerative pasteurizer (assembled).

The condition of the milk or cream has some influence upon the degree of adhesiveness of curd on the heating-surface. Sour and coagulated milk adheres or burns on to a greater extent than does milk or cream in good condition. This is evidently due to the lesser fluidity of the sour milk, and, as a consequence, it does not move over the heating-surface so rapidly, and therefore burns on. Milk which contains a great deal of air or scum also adheres to the heating-surface much 
more readily than milk containing less air. If pumps are used for pumping the milk, it is well to admit as little air into the milk as possible. This can be accomplished by keeping plenty of milk in the tank which feeds the pump, or by having a float which will close the inlet to the pasteurizer as soon as the tank is emptied. If the speed of the agitator in the pasteurizer is great enough, the scum is forced towards the center. For

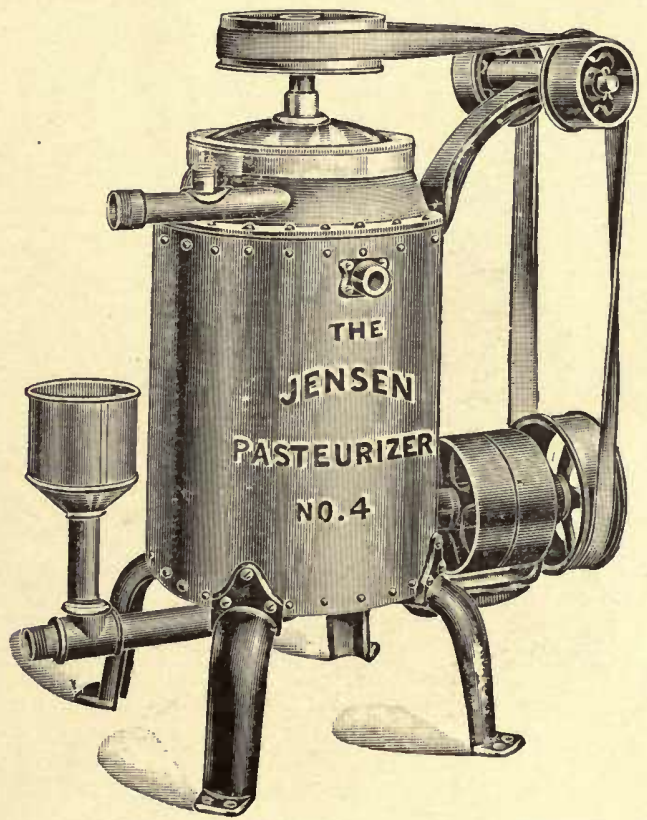

FIG. 119.-The Jensen pasteurizer.

some time it was thought that only the best sweet milk could be pasteurized by the intermittent process of pasteurization. It is well known that when a sample of milk reaches a certain degree of acidity it coagulates upon heating. It was thought that by the continuous method of pasteurization this would interfere with getting proper results. Experiment, however, shows that the coagulated sour cream and milk can be successfully pasteurized, but it is still a fact that the better condition the milk or cream is in, the easier it can be pasteurized 
and the better the results are. If pasteurization is not properly conducted, often the sour milk and cream coagulate and get very lumpy. This takes place chiefly when pasteurization is attempted at a comparatively low temperature, at a slow rate of speed of the agitator in the pasteurizer, and when there is about from $.3 \%$ to $.4 \%$ acidity in the cream or milk. Sour thin cream-less than $23 \%$ fat-does not pasteurize successfully.

In case there is any danger of sliminess taking place during pasteurization, the heat should be applied as quickly as possible.

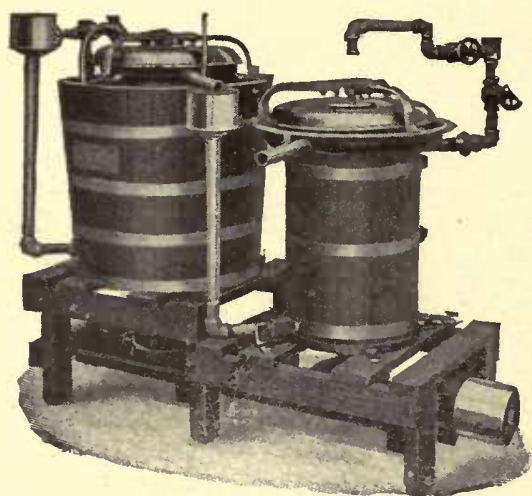

FIG. 120.-The Miller pasteurizer.

Only a thin layer of cream should be exposed to the heating-surface at one time. Flashy, quick heat tends to prevent this slimy condition. The speed of the stirrer should be increased, if possible, when such cream is being pasteurized.

By greasing the inside of the pasteurizer, or the heating-surface, a trifle previous to pasteurization, the burningon can be prevented in part. The casein that adheres can be more easily removed than if no grease were used.

(3) Thickness of Layer of Condensed Steam.-At first glance one might come to the corclusion that the small amount of steam which is constantly being condensed upon and adhering to the steam side of the heating-surface is not sufficient to cause any difference in the efficiency of the pasteurizer. Experiments conducted by Dr. Storch of the Royal Experiment Station, Copenhagen, Denmark, show that this condensed steam greatly resists the transmittance of heat. The comparative heat conductivity of water and copper is .0016 and .9 respectively, as found by Dr. Storch. It will thus be seen that copper is 600 times as good a conductor of heat as water is. This would mean that a quiet layer of water 3 millimeters in thickness 
would have the same resistance to heat as a layer of copper 2 meters in thickness. Consequently a very thin layer of water or condensed steam on the sides of the heating-wall would greatly interfere with the economic efficiency of a pasteurizer.

In order to overcome this difficulty drip-rings were circled round the drum of the pasteurizer at intervals on the steam side of the heating-surface. The first rings put around the pasteurizer were narrow smooth bands. These did not give entire satisfaction, as the condensed water from the top rings would drip on the edge of the lower ones, and cause the water to splatter over the side of the heating-wall. Another kind of ring was then invented, which was thin, narrow, and sawteeth-like in shape. These rings were fastened to the heating-wall at prcper intervals at an angle of $45^{\circ}$. The rings were so arranged that

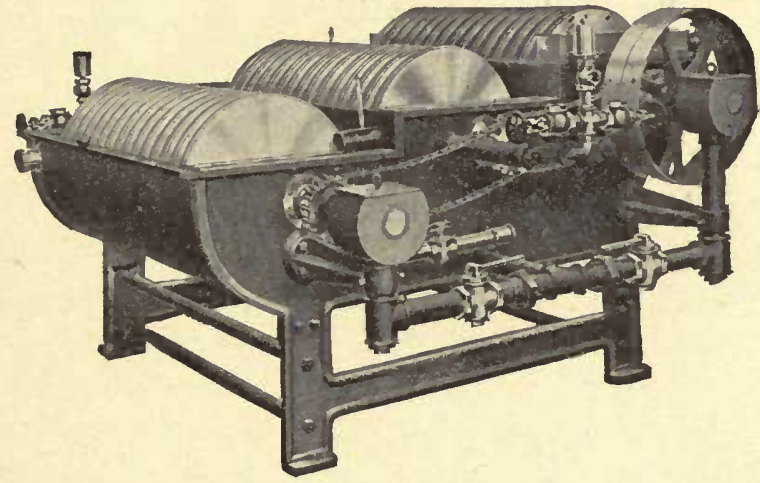

The Farrington pasteurizer.

the drops of condensed water escaping from the end of each saw tooth would fall in the hollow between the teeth in the lower rings and thus prevent any splattering of the water against the heatingwall. These contrivances greatly increased the efficiency - as high as $48 \%$ - and the capacity of the pasteurizer experimented upon.

(4) Difference in Temperature on Each Side of the Heatingsurface.-The difference in the temperature on each sidle of the heating-surface has a great effect upon the rapidity with which the heat passes through the wall. The lower the temperature is on the milk side the more rapidly does the heat pass through; and the higher the temperature of the milk is, the pressure on the steam side being the same, the more slowly the heat passes through the heating-wall. This would at first lead us to be- 
lieve that the last few degrees the milk is being heated are the most expensive; but if the steam is properly guarded from being condensed, or wasted, it does not cost any more to heat the milk the last few degrees than it does to heat the first degrees. While the temperature on the milk side is low, much more steam is consumed, and it is also used more rapidly. During the last heating of the milk or cream less steam is being condensed and the condensing proceeds more slowly.

When the temperature on the steam side is $220^{\circ} \mathrm{F}$. and on the milk side is $40^{\circ} \mathrm{F}$. during the same time, twice as much heat will pass through the heating wall as if the temperature of the milk side were $130^{\circ} \mathrm{F}$. In the first case the difference in temperature on both sides would be: $220-40=180^{\circ} \mathrm{F}$. In the second instance it would be: $220=130=90^{\circ} . \mathrm{F}$.

(5) Proper Utilization of Steam Turned into the Pasteurizer. - The cost of pasteurization will evidently vary under different conditions and with different kinds of pasteurizers. In order to reduce the cost of pasteurization to the minimum, it is essential that all steam turned into the pasteurizer be properly utilized. The pasteurizer, as well as the steam-pipes, should be properly insulated in order to prevent unnecessary condensation of steam. According to experiments carried on by Dr. Storch, all steam contains more or less air. By making a device on the pasteurizer for the escape of this air better results were obtained. By the use of such a vent it was made possible to heat 1890 pounds of water from $52^{\circ} \mathrm{F}$. to $185^{\circ} \mathrm{F}$, while without this air device, and with the same amount of heat, only 1467 pounds of water were heated. That is, by this device he made a gain of $30 \%$ in the heating efficiency of the pasteurizer. The contrivance used was simply a pipe attached to the bottom of the pasteurizer and extending down below the pasteurizer about 2 feet, then turned or bent, and brought up vertically a few inches above the bottom of the pasteurizer. The mouth of the pipe was then turned over. This pipe accomplishes two purposes. It removes condensed water from the pasteurizer, and also the accumulated air. It 
is also essential that the pasteurizer should not leak. All the steam turned into the pasteurizer should be condensed before it is allowed to escape.

The Cost of Pasteurization.-Dr. Storch in his 43rd report of the Royal Agricultural Experiment Station, at Copenhagen, Denmark, reports that it requires 80 pounds of steam to heat 1000 Danish pounds of milk from $40^{\circ} \mathrm{C}$. to $85^{\circ} \mathrm{C}$. This would be equivalent under American conditions to about 90 pounds of steam to pasteurize 1000 pounds of milk from $90^{\circ} \mathrm{F}$. to $185^{\circ} \mathrm{F}$.

According to good authority it takes 1 pound of lump coal to produce 6 pounds of steam. Calculating from this, it will take 15 pounds of coal to produce 90 pounds of steam. If coal costs $\$ 4.00$ per ton, the cost of 15 pounds of coal would be 3 cents. If the milk tests $3.6 \%$ fat, and calculated on one-sixth overrun, the 1000 pounds of milk would produce about 42 pounds of butter. The cost of pasteurizing the milk producing 42 pounds of butter is then 3 cents, and the cost of pasteurization per pound of butter would be .07 of a cent.

Taking into consideration the cost of cooling, and counting on about .03 of a cent for leaks involved during the process, the cost of pasteurizing per pound of butter would be about .1 of a cent. As a rule, the major portion of the cooling is done with water, which at most creameries costs little or nothing. For this reason the cost of cooling has been omitted.

Advancement of Pasteurization.-During the last few years pasteurization has gained favor with the American creamery operators. It has been thoroughly demonstrated that if the best product is to be manufactured it is absolutely essential that the operator liave complete control of the fermentations in the cream or milk. This control of the fermentation can best be accomplished by the process of pasteurization. Pasteurization has been gaining favor with the creamery operators owing to its own merits. The Danish Government compelled the pasteurization of milk or cream as a safeguard against tuberculosis. It was found not only that the system was efficient in this respect, but also that it produced a more uniform product, with 
better keeping qualities. At the present time nearly all of the central plants are pasteurizing their cream to a greater or less extent.

Advantages of Pasteurization.-The advantages of pasteurization are many, but the chief ones are as follows:

(1) It enables the butter-maker to produce a uniform quality of butter. If most of the germs are destroyed by pasteurization, and a pure culture added to the cream, the ferments added will be in full control. If nothing but a desirable kind of germ is added, it follows that the product will be uniform in quality In this way practically the same results can be obtained from day to day.

(2) It eliminates many of the undesirable taints in the milk. Especially is this effeet noticeable during the fall, when cows are liable to eat weeds that taint the milk. No matter how well milk has been taken care of, it usually contains taints which, when pasteurized will be partially eliminated from the milk.

(3) It destroys most of the germs. This is important for two reasons. It destroys most of the germs which effect the quality of the butter, and it also destroys the pathogenic germs, thus preventing the spread of diseases, such as tuberculosis, typhoid fever, etc.

(4) The butter-maker can control the fermentation in cream much more easily when pasteurization is employed. It has been demonstrated that the quality of the butter depends in large measure upon the kind of fermentation. When the fermentation in the cream is thoroughly controlled, a better quality of butter can be produced. When the milk is in firstclass condition, fully as good butter can be produced without the use of pasteurization, but it does not keep so well. Milk may appear to be in good condition, and yet at the same time contain germs which are detrimental to the quality of the butter.

It is at the present time a matter of dispute whether milk and cream in a really sour and poor condition is benefited 
much by pasteurization. The flavor of the butter made from such pasteurized cream is usually not improved very much. However, the keeping quality of butter made from poor cream pasteurized is usually better than if no pasteurization had been employed. If the inferior quality of cream and milk can be pasteurized, neutralized with an alkali, such as powdered chalk or bicarbonate of soda, then inoculated with a desirable species of bacteria and re-ripened, the quality of butter can be improved several points. But experiments carried on at the Iowa Experiment Station indicate that the improvement in the quality of butter is not very permanent. Immediately after it has been made there is a very distinct improvement in the quality of the butter from such cream, sometimes as much as five points. But for some reason butter from cream that has been neutralized in such a way does not seem to keep well. Some days after its manufacture it begins to lose decidedly in flavor and to assume a very rank condition. For this reason this method of treating poor cream has not been generally advocated. The deterioration that takes place in such butter after standing seems to be due to chemical changes rather than to biological changes. The butter referred to was kept in a refrigerator at a temperature of about $50^{\circ} \mathrm{F}$.; if the rancid flavors were due to the growth of micro-organisms, they should not reveal themselves in so short a time.

(5) Pasteurization increases the keeping quality of butter. This is one of the greatest advantages of employing pasteurization in butter-making. The advantage of keeping butter from the time of large supply and small prices to the time of small supply and higher prices, makes pasteurization in butter-making of vital importance in improving the keeping qualities of butter. Butter made from good pasteurized cream and washed in pasteurized water will keep about twice as long as butter made from the same kind of cream not pasteurized and washed in unpasteurized water.

(6) If milk is pasteurized previous to skimming, closer skimming can be obtained than if the milk were heated to a 
comparatively low temperature. The reason for this has been previously explained.

Disadvantages of Pasteurization.-The cost and additional trouble involved in pasteurizing are undoubtedly the chief disadvantages that could be brought up against pasteurization. As was calculated above, the cost of pasteurization, after the pasteurizer has once been purchased, is only .1 of a cent per pound of butter. This cost would be reduced considerably if the cream only were pasteurized, and increased if the cream and skim-milk were pasteurized in separate machines. The

\begin{tabular}{|c|c|c|c|c|c|c|c|c|c|c|c|c|c|c|c|}
\hline Score & $\begin{array}{c}\text { 1st } \\
\text { week }\end{array}$ & $\begin{array}{c}\text { 2nd } \\
\text { weekk }\end{array}$ & $\begin{array}{c}3 r d \\
\text { weetk }\end{array}$ & $\begin{array}{c}\text { sth } \\
\text { week }\end{array}$ & $\begin{array}{c}5 \text { th } \\
\text { week }\end{array}$ & $\begin{array}{c}\text { 6th } \\
\text { week }\end{array}$ & $\begin{array}{c}\text { 7th } \\
\text { week }\end{array}$ & $\begin{array}{c}\text { 8th } \\
\text { weekk }\end{array}$ & $\begin{array}{c}\text { 9th } \\
\text { week }\end{array}$ & \begin{tabular}{|l}
10 10th \\
week
\end{tabular} & $\begin{array}{c}\text { 11th } \\
\text { week }\end{array}$ & $\begin{array}{l}\text { 12th } \\
\text { week }\end{array}$ & $\begin{array}{l}\text { 13th } \\
\text { week }\end{array}$ & $\begin{array}{c}\text { 14th } \\
\text { week }\end{array}$ & Score \\
\hline 96 & & & & & & & & & & & & & . & & 96 \\
\hline 94 & & & & & & & & & & & & & & & 94 \\
\hline 92 & & & & & & & & & & & & & & & 92 \\
\hline 90 & & & & & & & & & $\mathrm{~Pa}_{\mathrm{a}}$ & & & & & & 90 \\
\hline 88 & & & & & & & & & & & & & E & & 88 \\
\hline 86 & & & & & & & & & & & & & & & 86 \\
\hline 84 & & & & & & & & & & & & & & & 84 \\
\hline 82 & & & & & & & & & & & & & & & 82 \\
\hline 80 & & & & & & & & & & & & & & & 80 \\
\hline$\pi 8$ & & & & & & & & & & & & & & & 78 \\
\hline$\tilde{\pi} 6$ & & & & & & & & & . & & & & & & $\because 6$ \\
\hline$\pi 4$ & & & & & & & & & & & & & & & 4 \\
\hline
\end{tabular}

FIG. 121.-Comparison of deterioration of butter made from pasteurized cream and wash-water to that made from unpasteurized cream and water, illustrated graphically. (Bul. 71, Iowa.)

initial cost of the pasteurizer is the great mountain to overcome in the introduction of pasteurization in creameries.

When pasteurization is employed in butter-making, it is absolutely essential that the greatest degree of skill and intelligence be applied. If care is not taken pasteurization is likely to produce a poorer quality of butter than is the case when no pasteurization is employed. Especially is this true when sour or abnormal cream and milk are being pasteurized, and little or no starter is used. 


\section{CHAPTER XIV.}

\section{CREA I - R I PENING.}

Definition. - By cream-ripening we mean the treatment cream receives from the time it is put into the ripening-vat until it is put into the churn; and also the chemical, biological, and physical changes cream undergoes during the same time.

\section{Orjects of Ripening.}

(I) To Produce Flavor and Aroma.-The chief object of cream-ripening is to secure the desirable and delicate flavor and aroma which are so characteristic of good butter. These flavoring substances, so far as known, can only be produced by a process of fermentation. It is a well known fact that the best flavor in butter is obtained when the cream assumes a clean, pure, acid taste during the ripening. For this reason, it is essential to have the acid-producing germs predominate during the cream ripening; all other germs should if possible be excluded or suppressed.

It has not yet been proved that any one particular species of bacteria is responsible for the production of the flavors, but it is agreed by all that the flavoring substances developed during the ripening of cream are decomposition products of bacterial growth, and that the types producing the lactic acid are the most desirable ones to have present. There are a great many bacteria in milk and cream which will produce acid. Over one hundred species have been studied and described. There seems, however, to be a comparatively few of those which produce the best results. 
It seems that during cream-ripening the development of acid, aroma, and flavor go hand in hand. This does not necessarily indicate that they are produced by the same cause. It is possible that the flavor and aroma substances are chemically produced from the various by-products of the germs.

Bacteriologists do not agree as to what species of bacteria is responsible for the high quality of flavor and aroma of butter. Conn * claims that the germs which act upon the nitrogenous

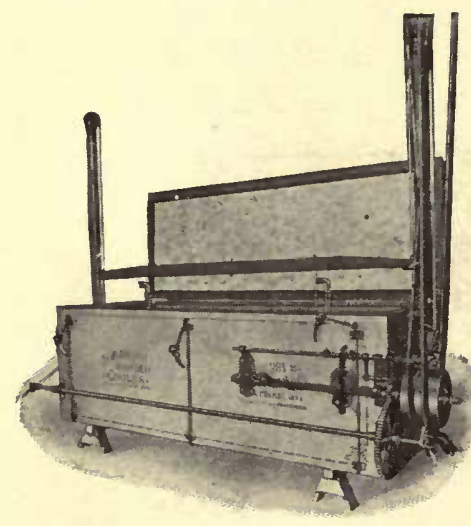

FIg. 122.- The McAreavy creamripening vat.

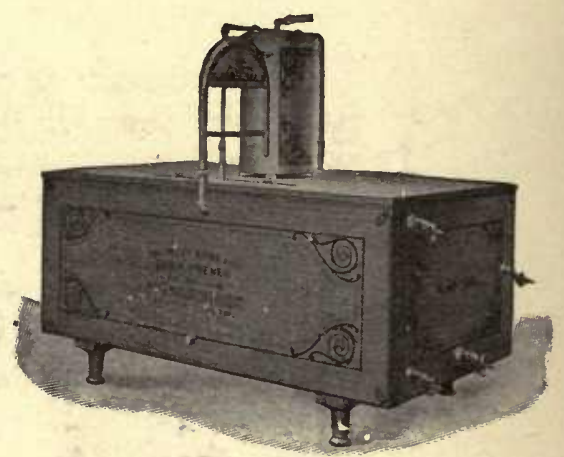

FrG. 123.-The Miller cream-ripening rat.

matter of milk are associated with the lactic-acid-producing bacteria in the production of desirable butter flavors. Weigman asserts that the best results are obtained when a variety of species work together in the cream. He has isolated a single species of germ which produced alcohol and lactic acid as by-products, and which, according to experimental evidence deduced by him, is capable of producing the delicate butter flavors. Freudenrich has also studied a species of germ which produced alcohol and lactic acid as by-products, and was able to produce the characteristic butter flavors. Eckles has studied this question of flavor production during cream-ripening. He comes to the conclusion that the flavor and aroma substances 
developed during cream-ripening may be produced by a variety of acid-producing bacteria. He asserts that of the species tried the most common milk-souring organism (Bacterium lactarii) gave the most satisfactory results as a culture for ripening cream. Storch, who has perhaps studied this question more than any one else, maintains that the germs producing lactic acid are essential to good cream-ripening, and that the flavor and aroma products are the results of the joint action of a great many species of lactic-acid-producing germs. Tiemann * finds that an addition of a small amount of hydrochloric acid to the cream does not produce the characteristic flavor, and in-

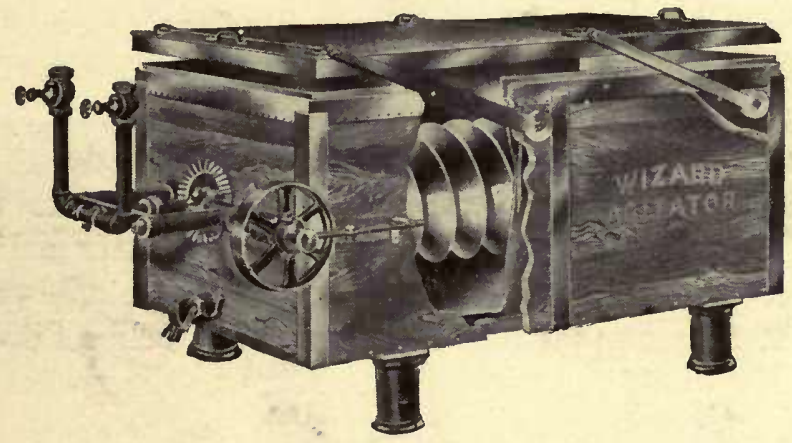

FIG. 124.-The Wizard cream-ripening vat.

dicates that the process of fermentation is necessary to get the proper flavors. Dean, of the Ontario Agricultural College, has recently reported that the flavoring substances can be developed in the starter, then added to the cream. The resulting butter has as good or a trifle better flavor than that which undergoes a process of fermentation by ripening in the usual way.

From the investigations quoted above it will be seen that there is some doubt yet as to the specific origin of the flavor and aroma substances developed during cream-ripening. It is also not known for certain just what those flavoring sub-

* Milch-Zeitung, Vol. 13, p. 701. 
stances are. They are evidently volatile, ether-like compounds, which are produced by bacterial growth during the ripening process. Few years ago it was thought that these flavoring substances were due entirely to the oxidation process, and that in order to get these flavors in butter it was necessary to expose the cream to pure air during the ripening. It has now been proved that air might be excluded from the cream-vat, alid still good results be obtained. This does not, however, demonstrate that oxygen is not essential for the best result in cream-ripening. All cream contains more or less oxygen in solution. It has been thought that the oxygen that cream holds in solution may favor the growth of the desirable germs in cream, and that as soon as this has been utilized, conditions may become unfavorable for the desirable germs and favorable for the undesirable germs.

Practically, all the investigators agree that the flavor and aroma substances which are characteristic of butter and which are developed in ripening cream, are due to bacterial growth, and that the germs producing lactic acid are the most desirable ones. We quote the following instances to show what effect some species of bacteria may have upon the quality of butter, when present in the cream:

\begin{tabular}{|c|c|c|c|}
\hline Number. & Species Used for Starter. & $\begin{array}{l}\text { Score on Flavor, } \\
45 \text { Perfect. }\end{array}$ & $\begin{array}{l}\text { Selling Price, } \\
\text { per Pound. }\end{array}$ \\
\hline $\begin{array}{l}1 \\
2\end{array}$ & $\begin{array}{l}\text { Bacterium lactarii. ...... } \\
\text { Bacillus subtillis. . . . . }\end{array}$ & $\begin{array}{l}39 \\
31\end{array}$ & $\begin{array}{r}\$ .20 \\
.14\end{array}$ \\
\hline
\end{tabular}

These two samples of butter were made from the same kind of cream which was pasteurized and inoculated with starters from the different germs as indicated in the table.* The butter ripened with Bacillus subtillis sold for 6 cents per pound less than the other, a difference of nearly one-third in value, due to the character of fermentation in the cream during ripening. Therefore in developing the proper fiavors in

* Bul. 40, Iowa Experiment Station. 
butter, it is very essential that the undesirable germs be excluded or suppressed and that the conditions for the development of the desirable typical acid ferments in the cream be made as favorable as possible. The undesirable ferments may, as a whole, be said to be those which act upon the nitrogenous matter, or those which cause ordinary decay. They very likely come from filth in the barn, milking utensils, unclean milkers,

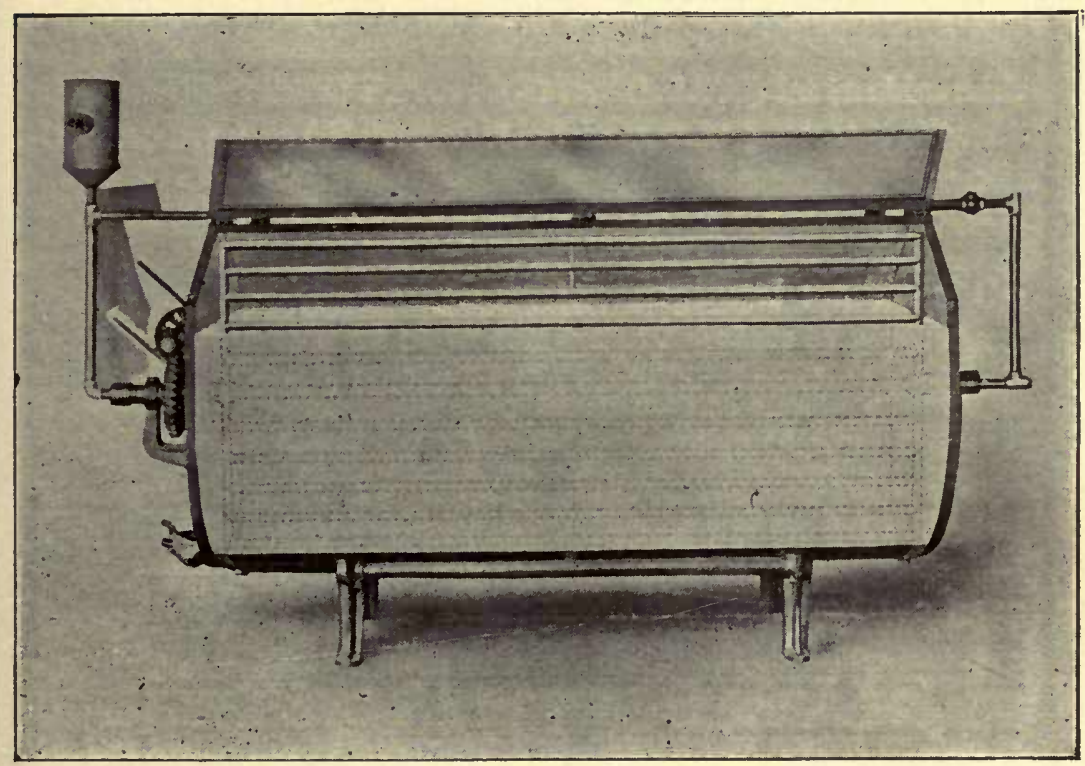

Fig. 125.-The new Jensen cream-ripening vat. (Peerless.)

and unclean and dusty barns. Abnormal fermentations of cream, such as ropy, bitter, chromogenic fermentations, etc., are of course undesirable ferments. For kinds and classification of germs in milk, see Chapter IV on Bacteria, and Chapter V on Abnormal Milk.

(2) To Increase Churnability of Cream.-Cream-ripening is not essential in order to complete the churning process, but ripened cream will churn more easily and niore completely than unripened cream, under the same conditions. This is due to a 
lessening viscosity of the cream. The ripening procesis causes the cream to become thicker but less viscous. Unroubtedly the acid developed during the ripening process tends to cut the membrane supposed to surround the fat-globules. The reduced viscosity of the cream renders it easier for the globules to move and unite in the serum when exposed to agitation in the churn. It is possible to churn ripened cream in a thinner state and at a lower temperature than unripened cream.

Cream which has been ripened to a normal degree of acidity, also allows of a more complete churning than unripened cream.

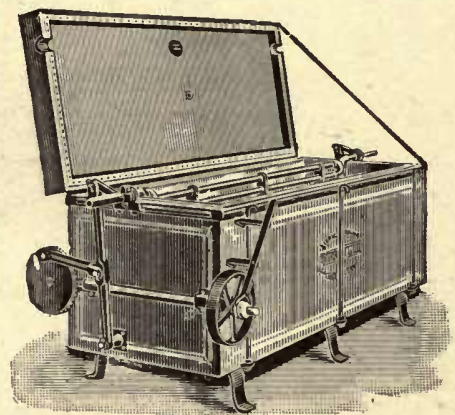

FIG. 126.-The Boyd cream-ripening vat.

If cream is properly ripened, and churned at a medium low temperature, it is possible to churn so that the buttermilk contains only about .1\% of fat by the Babcock test; while if sweet cream is being churned under the same conditions, the buttermilk will contain more than this. This is undoubtedly due to the fact that in sweet cream the viscosity is so great that it prevents the minute fat-globules from uniting when agitated in the churn, while in sour milk the viscosity has been largely removed. Sour cream is thicker than ripe cream, but less viscous. This facilitates the coalescence of the fat-globules when exposed to agitation.

(3) To Increase the Keeping Quality of Butter.-It has been demonstrated by several investigators that the keeping quality of butter depends chiefly upon the number and kinds of germs present in the butter after its manufacture. In order, there- 
fore, to produce butter with good keeping qualities it becomes essential to exclude or suppress all germs which deteriorate butter. It is not of so great importance to exclude germs which do not injure the keeping quality of butter. The germs that produce lactic acid do not cause direct deterioration cf butter. This has been demonstrated by Jensen.*

When cream has been properly ripened, it is practically a

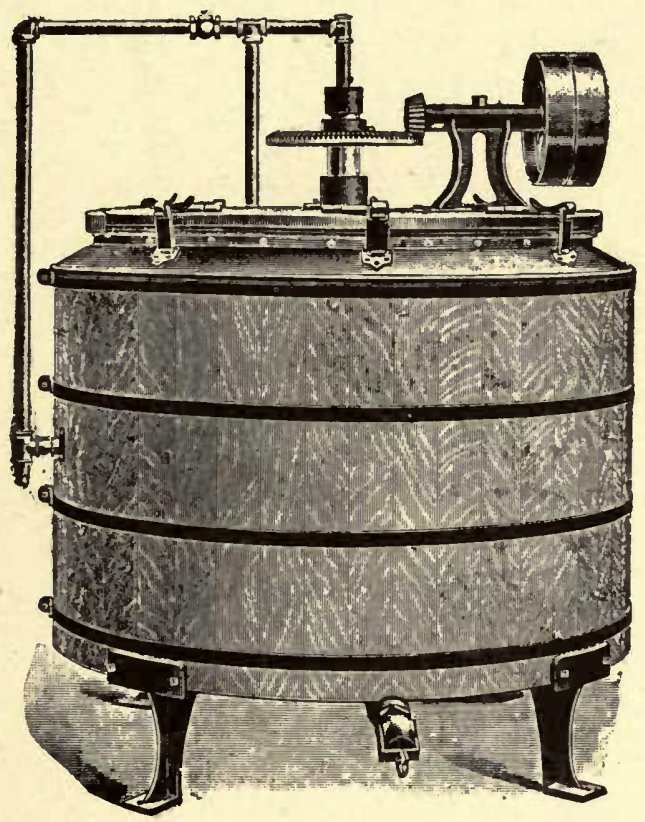

Fig. 127.-The old Jensen cream-ripening vat.

pure culture of lactic-acid-producing germs, while sweet unpasteurized cream contains a bacterial flora, consisting of a great many types of desirable and undesirable germs. It should be mentioned in connection with this, that it is only properly ripened cream that contains with any certainty, a preponderance of germs producing lactic acid. If the cream is over-ripe, the undesirable bacteria may also gain the ascen-

* Landwirtschaftliches Jahrbuch der Schweiz. 
deney of the desirable. When such overripened eream is churned, these undesirable germs are transmitted to the butter, and cause deterioration. If the butter is churned from properly ripened cream, and at the proper ripening stage, and the butter washed in purified water, very few undesirable germs are transmitted to the butter, and, as a consequence, it keeps better.

Ripening Temperature of Cream.-In practice, the ripening temperature of eream varies within wide limits. Some makers prefer to ripen eream at a temperature of about $80^{\circ} \mathrm{F}$, , others ripen at about $70^{\circ} \mathrm{F}$., and still others prefer to ripen at a temperature between $60^{\circ}$ and $70^{\circ} \mathrm{F}$. Undoubtedly, the conditions in the ereamery will to some extent govern the ripening temperature. Up to a certain limit the higher the temperature, the quicker the ripening process. In some instances, it is desirable to ripen and cool eream in a few hours, and then churn the same day. Under such conditions a comparatively high ripening temperature is undoubtedly preferable, as the cream will sour more quickly at such a temperature. Undoubtedly good butter can be made at any of the temperatures mentioned above, but when we are to deeide which temperature is the best, we are, through experimental evidence, foreed to come to the conelusion that a ripening temperature between $60^{\circ}$ and $70^{\circ} \mathrm{F}$. gives the best results.

When cream is ripened at a high temperature it needs to be cooled very little previous to ripening. Milk is usually separated at a little above $80^{\circ} \mathrm{F}$, and if the starter is added immediately after separation, it will ripen in a very short time. If ripened at a lower temperature, a longer time will be required to develop the same amount of acid, and hence with a prolonged ripening period more attention is neeessary. The Danish butter-makers ripen their eream at a comparatively low temperature, usually between $60^{\circ}$ and $65^{\circ} \mathrm{F}$., and obtain the best results.

The germs producing lactic acid grow within a wide range of temperature; viz.: from about $50^{\circ}$ to $100^{\circ} \mathrm{F}$. The extreme temperatures are not favorable to the greatest possible growth. 
The optimum temperature, or the temperature at which they grow best is, according to Russell, from $90^{\circ}$ to $95^{\circ} \mathrm{F}$. At this temperature the germs which cause undesirable results also grow most rapidly in cream. Cream contains germs both of the desiarble and the undesirable type. At a comparatively low temperature (between $60^{\circ}$ and $70^{\circ} \mathrm{F}$.) the greatest relative growth of the desirable germs is produced. Bacteriologišts aiso

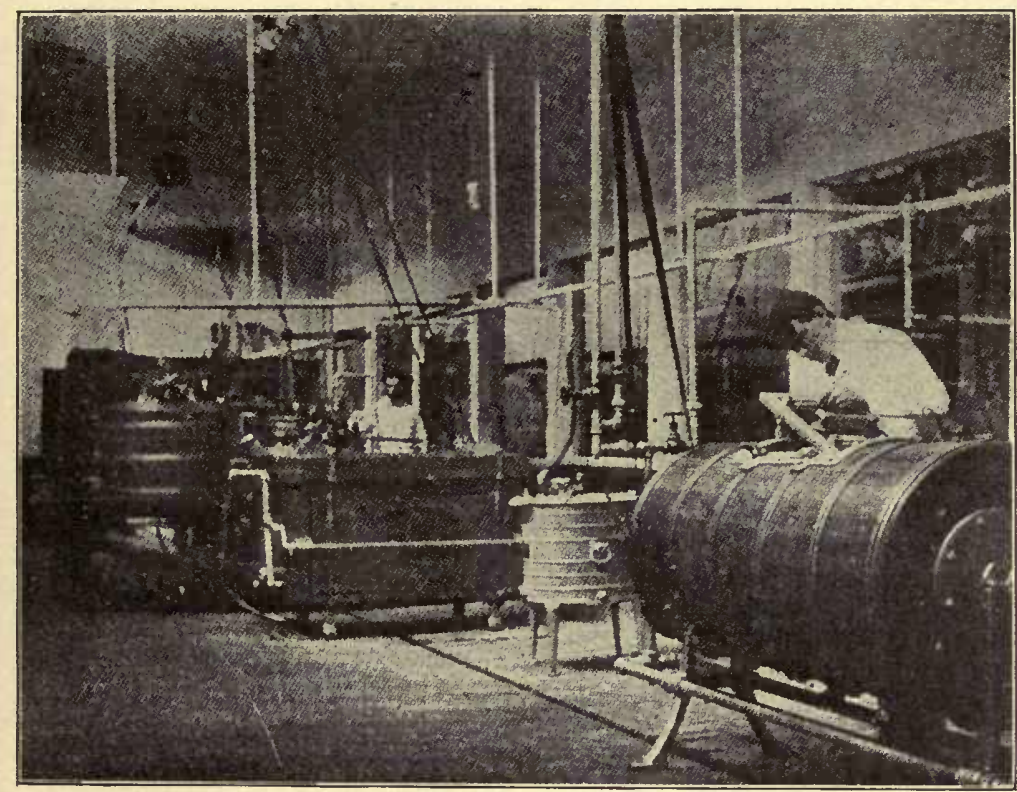

FIG. 128.-Cream-ripening room in the Model Creamery at the World's Exposition, St. Louis, Mo.

tell us that the casein ferments as a rule thrive better at a lower temperature than do the lactic-acid ferments at the same temperature. This, keeping in mind that better results are obtained by ripening at lower temperatures $\left(60^{\circ}\right.$ to $70^{\circ} \mathrm{F}$.), seems to indicate that the flavoring substances are not formed entirely by the action of certain germs producing lactic acid, but that the flavoring substances are probably due to the joint action of several species. Lactic acid itself does not have 
the desired characteristic flavor of good butter, yet we know that these flavoring substances are direct products, or accompaniments, of the development of lactic acid.

Cream ripened at a low temperature does not sour very rapidly; the germs do not grow at a very rapid rate. The desired degree of acidity is approached very slowly, and as a result the fermentation may be checked almost at once when the desired degree of acidity has been reached, and the chance for getting overripened cream is reduced to its minimum. If the cream is ripened at a high temperature, there is greater danger of getting overripened cream.

Extreme and rapid changes of temperature should be avoided as much as possible. The more uniform the temperature can be kept, if suitable for proper ripening, the better the results. Accordingly, the ripening-vats used in this country are practically all jacketed, which permits the operator to regulate at will the temperature of the water in the jacket surrounding the cream.

Amount of Starter to Add to Cream.-The amount of starter to add to cream will vary according to the temperature of the cream, and to the length of time required for ripening. If cream is to be ripened quickly, then a large starter should be added. Good results can be obtained by adding starter to the extent of $50 \%$ of the cream to be ripened. This much, however, is usually not satisfactory, as it so reduces the thickness of the cream as to render it more difficult to churn. It increases the amount of serum which will form the buttermilk when churned. The more buttermilk, the greater will be the loss of fat in churning. On this account it is desirable not to add any more starter than will give cream a proper thickness (from $30 \%$ to $35 \%$ fat) and at the same time supply enough desirable germs to gain the upper hand of, and to suppress the undesirable germs already present.

It is important to skim the cream thick enough to permit the use of an amount of starter equal to from $8 \%$ to $20 \%$ of the cream to be ripened. This, under average conditions, will 
produce desirable results, providing the starter is of the proper kind. A poor starter is worse than none at all.

It is a good plan to pour the starter into the ripening-vat before the cream is separated. Some also practice skimming a heavy cream and then add some good morning milk to it.

Before the starter is added all precautions possible should be taken in order to prevent the entrance of undesirable germs into the cream. The top layer of the starter should be skimmed off; and the very bottom portion of the starter should not be emptied into the cream-vat either, as it usually contains some of the sediments from the milk. It is essential that the starter should be thoroughly stirred previous to adding it to the cream, otherwise lumps of curd are likely to trouble during the remainder of the process of manufacture. The curd, if not properly emulsified previous to adding it to the cream, is likely to show itself in the butter in the form of white specks. This stirring of the starter can be brought about most satisfactorily by pouring it back and forth from one can into another, until the body of the starter assumes a uniform, not lumpy, consistency. The cans used for this purpose must be carefully cleaned and scalded previous to using them. Dippers and stirrers of any kind should always be thoroughly sterilized previous to using them in starters. The stirrer or dipper used should have solid handles. This makes cleaning easier.

Stirring of Cream During Ripening.-As soon as the starter has been brought into a proper condition it is added to the cream. If necessary it should be strained before adding. The cream should then be thoroughly stirred. If cream is not thoroughly mixed with the starter, the ripening will not be uniform. If allowed to stand quietly, the cream soon separates into two distinct layers. The fat, by reason of its being lighter than the rest of the constituents, soon forces its way to the surface, and incorporates with it a considerable amount of casein. But the bottom layer will be similar to skim-milk; for, being better mixed with the starter, the lactic-acid fermentation proceeds more rapidly in this milky or bottom layer, 
and thus prevents the fat which is at the surface from coming in direct contact with the flavoring substances formed at the bottom. If the surface layer of fat and casein were exposed to favorable conditions, the point might be made that the surface exposure is more desirable than if the fat were in i state of perfect emulsion with the rest of the constituents of cream. But such is not the case. The layer of fat and curdled casein, when allowed to form at the surface, is likely to be contaminated with putrefactive organisms. Especially is this so if the cream is allowed to stand in such a condition very long in a warm ill-ventilated room. If the constituents of cream are kept well mixed by stirring, the lactic acid checks the development of putrefactive germs, which may accumulate at the surface; the cream is ripened more evenly, and the flavoring substances have the best facilities of coming in contact with and being absorbed by the fat.

The authors have noticed that high-scoring contest butter is usually made from cream which has been stirred judiciously at intervals. The most notable prize winners have stayed up with their cream all night, or part of the night, to watch the ripening process, and to stir the cream occasionally. It would not be practical to advise this method, but cream should receive a judicious amount of stirring at intervals during the day, and if it is allowed to stand over night, it should be stirred the last thing in the evening before retiring.

\section{Natural and Artificial Ripening.}

Cream-ripening as a whole, as practiced to-day, may be divided into two groups: viz., (1) Natural, and (2) Artificial.

Natural.-Natural cream-ripening consists in letting the raw cream stand at a certain temperature until it is sour, then cooling it to the churning temperature. This method used to be practiced nearly altogether, but now experimental and practical evidence prove that this is not the method by which the best butter can be produced. Natural ripening may, or 
may not, produce good results. It has been termed by some "chance ripening." At certain seasons of the year conditions are favorable for natural ripening, while at other seasons conditions are very unfavorable. It was stated before that putrefactive organisms, or those germs causing ordinary decay, are undesirable species of bacteria to have present in the cream. During the late spring and early summer months, when the cows are first put on pasture, the conditions are favorable for the preponderance of the desirable germs; during the winter, when necessarily the cows and the milk are subject to stable conditions to a greater extent, the conditions are favorable for the ascendency of the undesirable germs. Eckles has found that during the winter about three-fourths of the bacteria in milk consists of these undesirable germs. If these are present in the milk, a proportionate part will be transferred to the cream. When such cream is allowed to ripen or ferment in a natural way, the undesirable germs are likely to gain the ascendency. As the conditions which govern the degree of contamination of the milk and cream vary during the different days of the different months and different seasons of the year, this natural ripening is not to be depended on for obtaining a good uniform quality of butter, even though at times good results may be obtained from natural ripening. A maker who wishes to make a high, uniform grade of butter should not depend upon natural cream-ripening.

Artificial Ripening.-- By artificial ripening we mean (1) ripening of raw cream to which sufficient starter has been added to control the kind of fermentation; (2) ripening of cream in which the germs have been destroyed by pasteurization, and to which a starter has been added in order to introduce the desirable ferments.

(1) Either of these methods is preferable to natural creamripening. The first method has been the nost common in the past, but the latter method promises to give results which will warrant every butter-maker in adopting it as a permanent method in butter-making. If cream lias been handled under

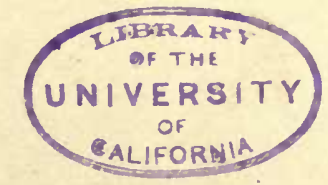


conditions which are favorable for the introduction of desirable germs, and is otherwise in good condition, the best results can be obtained by ripening such cream without pasteurizing it. It is asserted that when all conditions are ideal,- the starter good, and the cream good,--then a higher flavored butter can be produced by this method than if the cream were pasteurized; but the keeping quality of the butter is not so good as that produced from pasteurized cream. The same objection that was made to natural ripening can be made to the artificial ripening of raw cream. If the butter-maker at the creamery has full control of all the conditions governing the quality of butter, and if the milk is received at the creamery in an ideal condition, then this method of ripening is commendable. But at creameries where milk is at times delivered from one hundred or more different patrons, some of the milk is likely to come in in an unfavorable condition. The poor milk is likely to contaminate all the remainder of the cream, and objectionable fermentative products are likely to develop in the cream-vat.

When this method of ripening is practiced the starter should be added to the cream as soon as possible. In fact, this rule applies to all methods of cream-ripening where a starter is used. It is preferable to add the starter to the cream-vat before the skimming is begun. In this way the lactic-acid germs in the starter get a chance to work in the cream immediately after it is skimmed, and, for this reason, are more likely to suppress the undesirable types of ferments present.

2. The second method, that of pasteurization, is without any question the ideal way of manufacturing butter. It has been advocated in a theoretical way for several years in this country, but only within recent years has this method of ripening cream been deemed sufficiently meritorious to warrant its adoption. It is, however, rapidly gaining in favor. The method consists in heating the cream on a continuous pastuerizer from $155^{\circ}$ to $190^{\circ} \mathrm{F}$. A temperature of about $180^{\circ} \mathrm{F}$. is the one usually employed. It is said that a temperature of $140^{\circ}$ to $150^{\circ} \mathrm{F}$. destroys practically all the germs producing lactic 
acid. Some undesirable germs also, in a vegetative stage, are not destroyed at this temperature. For this reason cream should be heated to about $180^{\circ} \mathrm{F}$. At this temperature, the germs causing tuberculosis are destroyed. It is in order to combat this disease that the Danish Government compels all cream to be pasteurized before it is made into butter, and also all of the skim-milk before it is returned to the farmer. The germs causing tuberculosis are destroyed at a lower temperature than this $\left(180^{\circ} \mathrm{F}\right.$.), provided they are exposed to the temperature for some time. In ereameries the intermittent method of pasteurization is used. In this method the time of exposure to the heat is short, and consequently a higher temperature is necessary.

By heating milk to such a temperature practically all of the germs, desirable and undesirable, are destroyed with the exception of those that are present in the spore form. If this crean is inoculated with the desirable germs, then theoretically and practically, good uniform results should be obtained.

It was mentioned above that the spore-bearing bacteria were not destroyed by the degree of heating to which cream is exposed. If the cream is allowed to stand any length of time at a favorable temperature without a starter in it, these spores will develop and cause undesirable results. If pasteurized cream is allowed to ripen naturally, a very bitter flavor usually develops. In order to overcome this undesirable fermentation, it is essential that the starter should be added as soon as possible after the cream has been cooled down to the desirable ripening temperature. It should be remembered that this starter should never be added to the cream while it is still hot, as the lacticacid-producing germs in the starter would then be destroyed.

Ripening Cream When Churning is Done Once Every Other Day.-At certain seasons of the year the milk delivered to the creamery is not sufficient in quantity to produce enough cream so that it is worth while to churn every day. Many makers profitably utilize their time by churning only every other day. The question then comes, how may the cream be preserved in the best possible condition? Some prefer to cool the cream to 
a low temperature $\left(50^{\circ} \mathrm{F}\right.$.) immediately after it has been skimmed or received, then allowing it to stand until the next day. The second day's eream is then poured in with the first day's cream, the starter added, and the ripening process completed. Others prefer to add the starter to the first batch of cream immediately after it has been skimmed, then ripen it almost to the normal degree of acidity, and cool to about $50^{\circ} \mathrm{F}$. The next day the new cream is skimmed into this already ripe cream, stirred thoroughly, and the ripening process completed. The latter method, if done properly, has given the best satisfaction. When cream is ripened according to the method first described, undesirable fermentations are likely to gain ascendency. As has been mentioned before, the undesirable germs grow better at a lower temperature than do the bacteria producing lactic acid. When the next day's cream is skimmed into this, the undesirable ferments may preponderate to such an extent that the desirable germs cannot overcome or suppress them during the remainder of the ripening process. According to the latter method, the first day's cream is ripened as usual. When the next day's cream is skimmed into this, the first lot of cream acts as a starter. The lactic acid present inhibits the growth of other undesirable species, and consequently better results are obtained by this method.

This latter method of holding cream is reeommended when eream is to be held for any length of time, such as over Sunday, or when the creamery is run only every other day, and the churning done once or twice per week. If possible, and all the other conditions eonsistent, it is better to ripen the cream and churn it the day it is delivered than it is to hold the eream over for several days before it is churned. Butter will always keep better than cream, under any conditions.

\section{Mixing of Cream.}

With the introduction of hand-separators the quality of eream received at creameries varies considerably. The question then arises, should the different quantities of cream be 
mixed, or should they be treated separately according to quality, and made up into several grades of butter? Theoretically the grading of cream into two or three, or even four, grades can be argued to be correct and proper, yet in creameries where only a comparatively small amount of cream is handled, it usually does not pay to grade very much. In a very large plant where as much as 50,000 pounds of butter is made per day, there is no question that a system of grading cream pays. Several large central plants are now grading their cream into three or four grades successfully. In smaller plants, however, it is not as a rule advisable to make more than two grades, the first grade to include all good and fair cream, and the second grade to include the very poorest. Usually in the comparatively small creamery plants, the quality of cream can be better controlled, and consequently less grading is necessary, while in a large plant the creamery manager has but little control over the conditions governing the quality of the cream.

The chief conditions that determine whether different qualities of cream should be mixed, might be said to depend upon:

(1) The quality of the cream.

(2) The kind of market for the butter.

(3) The amount of hand-separator cream compared with the amount of good quality cream, usually separated from the milk at the creamery.

(4) The general creamery conditions.

I. Quality of Cream.-The difficulty of grading cream is met with chiefly in comparatively small creameries where part of the intake is cream and another part milk. The cream that is separated from the milk at the factory is usually in an excellent condition, while the cream delivered from hand separators, or raised by any of the gravity methods, is usually of a poor quality. If the cream delivered to the ereamery is in just as good condition as that obtained from whole milk skimmed at the factory, then there is no danger in mixing the two kinds 
of cream. If it comes in a poor condition, such as handseparator cream usually does, then the poorest cream should be ripened by itself. Some maintain that the mixing of the two kinds of cream is favorable, because, if the hand-separator cream were churned separately, it would produce butter which is very poor in quality, while, on the other hand, if the two were nixed a better quality as a whole would be obtained. This is undoubtedly true; but evidently if the quality of butter from the hand-separator cream was raised, that from the whole milk was lowered, so that the quality of butter received from both was poorer than that which would have been obtained from the whole milk if kept separate.

2. Kind of Market.-If a creamery operator is working strictly for quality, and the butter is sold on that basis, it certainly would not be a good plan to mix the poor cream with the better cream. On the other hand, if the butter is sold on the market with no attempt to establish a reputation, no further aim than to get as much as possible out of the present supply, then it might pay. By mixing the two it might be possible to raise the quality so as to bring all of it on the market at a trifle above "Creamery Extras"; while if the cream from the whole milk were kept separate, perhaps no greater price could be obtained for the butter produced from this better cream. If the butter from the poor hand-separator cream were placed on the market by itself, evidently it would not command the same price as that made from the whole milk, or the mixed lot either. As has been stated before, the mixing of poor cream with a good quality of milk, skim-milk, or whole milk, and stirring the mixture thoroughly improves the quality of the butter in a marked degree.

3. Amount of Cream.-If only a small amount of handseparator cream is being received, then usually it will not pay to carry it through by itself. By experience the authors have found that the best way to dispose of a comparatively small amount, providing it is not too sour, is to empty it into a receiving-vat with the milk, and stir it well, re-skim it and 
pasteurize all the cream, add a starter, and ripen in the usua way. If the cream is sour, and there is a danger of souring the remainder of the milk, or clogging the separator, it is advisable to add it directly to the cream-vat. The sourness of the cream is not so dangerous if the flavor is clean. If it is very unclean, and not sour, the mixing with the whole milk, the separation, and pasteurization will eliminate a great many of the undesirable flavors and check the activity of a large portion of the undesirable germs present. When the starter is again added and ripened, a good quality of butter is obtained. If a comparatively large amount of cream in poor condition is received, then it is advisable to retain it by itself.

4. General Creamery Conditions.-Occasionally it happens that a creamery is not properly equipped with vats, so as to enable an operator to handle two lots of cream. Where one man has to do all the work, one churning is about all he can accomplish daily, besides attending to the remainder of the work. Under such conditions it is doubtful whether it will pay to purchase additional vats and hire additional help, in order to keep poor hand-separator cream separate from the remainder, through the different steps of manufacture. Since the butter is not sold strictly on its merits, there would, as a rule, be no profit for the average small creamery to grade the cream, on account of the additional labor and apparatus required. If a high quality of butter is the supreme aim of the creamery operator, then it becomes very essential that the poor cream be kept separate.

\section{Examining and Testing Cream for Acidity During Ripening.}

As has been stated before, the best flavor in butter is produced when cream is ripened to the proper degree of acidity. If it is ripened too much, or overripened, the butter will assume a high flavor and strong aroma, while if not ripened high enough, it will be a little flattish with less aroma. Many makers depend 
upon the taste and smell, and the appearance of the cream, to decide when the cream has been ripened to the desired degree of acidity. Makers with a great deal of experience are able to tell quite accurately by the appearance of the cream and its taste and smell when it has been properly ripened. Well-ripened cream gets an apparently granular and glistening condition. It has a pleasant, mild acid taste, and a good clean sourish aroma.

As the flavor of properly ripened cream will vary somewhat according to the different degrees of richness of the cream, it

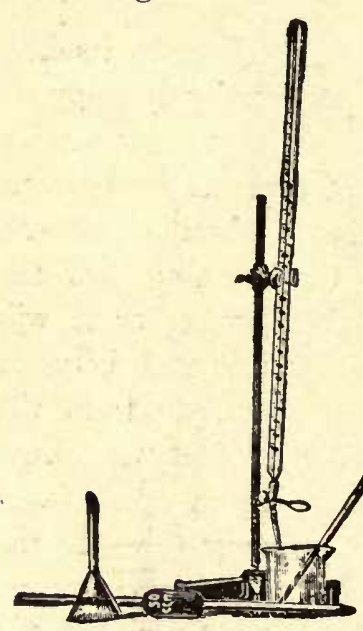

Fig. 129.-Apparatus for Mann's acid test. Instead of the burette the alkali can be kept in a large bottle, as shown in Fig. 131 and 130.

is very easy to be deceived by the senses. For this reason it is advisable to use a special test with which to measure the amount of acid developed in the cream. There are two acid tests in general use now in creameries, viz., "Mann's Test" and the "Farrington Test."

Mann's Test.-Mann's test consists of measuring the acid in the cream by means of an alkali of a definite known strength. The kind of alkali used is usually a .1 normal solution of caustic potash $(\mathrm{KOH})$ or soda $(\mathrm{Na} . \mathrm{OH})$. These solutions can be made up very cheaply or bought from the supplyhouses. Mann's test is based upon measuring out 50 c.c. of cream by means of a pipette. A few drops of an indicator (phenolphthalein) is added. This indicator gives a red color in an alkaline solution, and no color in an acid solution. The .1 normal alkali is poured into a burette, and the solution allowed to run into the 50 c.c. of cream and stirred thoroughly until it begins to turn pink in color. At this point it is neutral. The number of cubic centimeters of alkali required to neutralize the acid in 50 c.c. of cream indicates the number of degrees of acid. 
For instance, if it required 32 c.c. of a tenth normal alkali to neutralize the acid in 50 c.c. of cream, the acidity of the cream would be $32^{\circ}$.

$$
\text { ( } 1 \text { c.c. of } \mathrm{N} / 10 \text { alkali }=1^{\circ} \text { Mann's Test.) }
$$

Mann's test reading can be converted so as to express the results in percentage similar to the Farrington test. As 1 c.c.

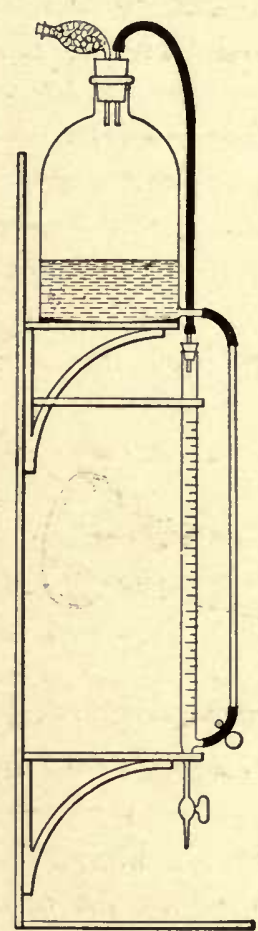

Frg. 130.-Arrangement for keeping alkali for the Mann's test.

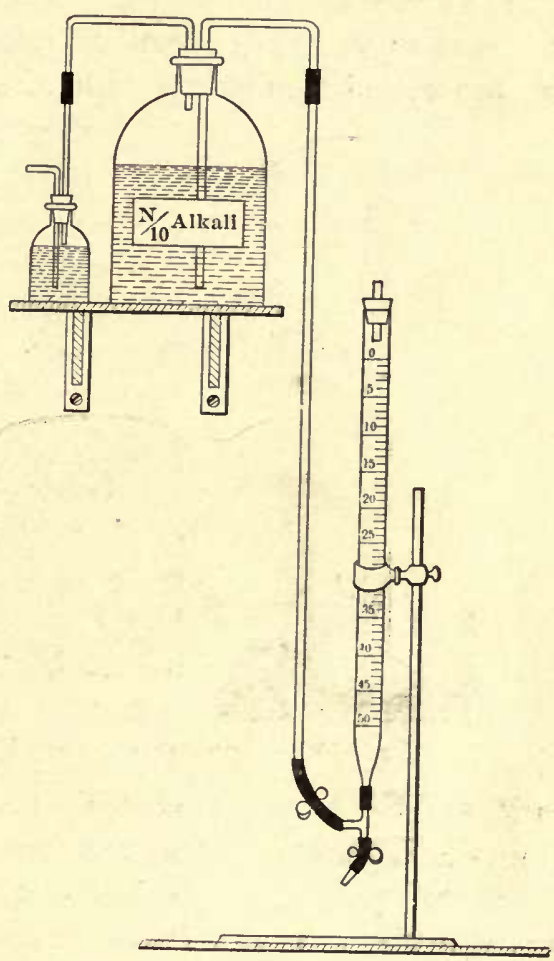

Fig. 131.

of the .1 normal alkali neutralizes .009 grams of pure lactic acid, 32 c.c., as in the above case, would neutralize 32 times .009 . This would give the amount of acid, calculated in terms of lactic acid, present in the 50 c.c. of cream. This product 
divided by the 50 , and multiplied by 100 , would give the percentage of the acid present.

Farrington Test.-The same principle is involved in the Farrington test. The alkali is put up in small tablets, already containing the indicator. These tablets contain a definite amount of alkali, and are represented as retaining their strength. However, they lose their strength if they are exposed to the atmosphere. The amount of alkali embodied in each tablet is such that when five of them are taken into a graduated cylinder, the cylinder filled up with distilled water to the $97-$ c.c.

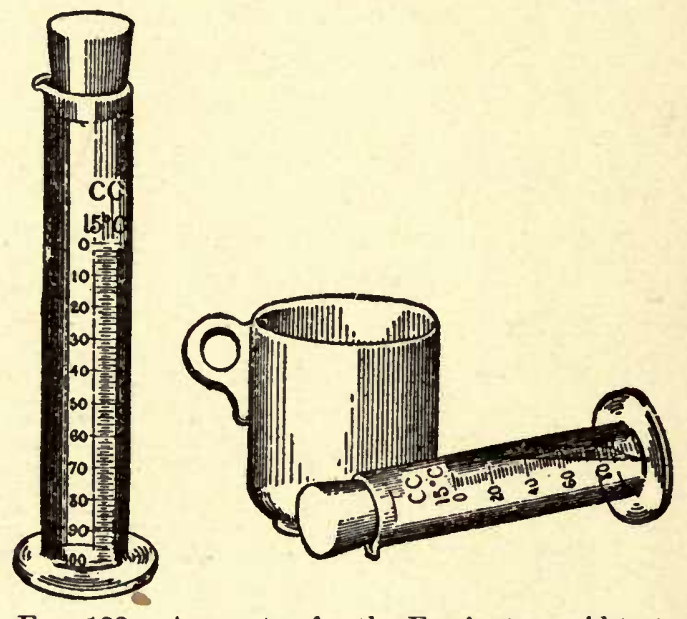

Fig. 132.-Apparatus for the Farrington acid test.

mark, and the tablets thoroughly dissolved in water, a solution is obtained, each cubic centimeter of which represents .01 of $1 \%$ of acid, providing 17.6 c.c. of cream is taken. The tablets can be made up of different strengths for the use of differentsized pipettes, but as the 17.6-c.c. pipette is the one which is used in the ordinary Babcock test, directions are given for the use of that pipette only. For a more detailed description of the acid tests see "Milk Testing," by Farrington and Woll.

Amount of Acid to Develop. - The amount of acid to develop in cream depends upon the amount of fat present in the cream, and to some extent upon the market on which the butter is 
to be sold. Some markets require higher flavored butter than others. Practically all markets, especially in this country, demand butter which has a comparatively rich creamy flavor, with a nice clean butter aroma.

It was found at the Iowa Experiment Station, from a large number of experiments, that cream containing $30 \%$ fat gave the best results, that is, showed the highest flavor when ripened to 37 degrees, Mann's test. It has also been demonstrated that acid is developed only in the serum portion of the cream. This would bring the cream-ripening process down to a question of proportion, as the fat is practically neutral. By subtracting the $30 \%$ fat we have $70 \%$ serum. This would equal .53 degree of acid to each per cent of serum. Thus, $70 \%$ serum multiplied by .53 would give us 37.1 degrees, Mann's test. For instance, if we take $40 \%$ fat, we would have $60 \%$ serum, and this multiplied by .53 would give us 31.8 degrees to ripen to. With thin cream of $20 \%$ we would have $80 \%$ serum, which would cqual 42.4 degrees to ripen to.

We would not recommend following the above formula to the extreme with thin cream. For $20 \%$ cream 42 degrees would be sufficiently high to ripen to, even with exceptionally good cream. When the flavor of the cream is not good it is not desirable to ripen to quite as high a degree of acidity.

Another formula which has worked very satisfactorily in the Dairy Department at Iowa State College, and which does not give as high a degree of acidity, is as follows: Subtract the per cent of fat found in cream and divide the serum by twa and the quotient will be the degree to ripen to. For instance, $30 \%$ cream giving $70 \%$ serum would give 35 degrees to ripen to. 


\section{Chemical, Physical, and Brological Changes.}

Physical Changes.-All the changes in cream during ripening are very complex, and the causes of them are not well understood. The chief cause of the ripening process, as it normally occurs, is the action of micro-organisms. As has been stated before, the germs producing lactic acid are the most numerous. These germs continue to gain the ascendency in the cream during the ripening until cream is almost a pure culture of lactic-acid-producing germs. Accompanying this growth, the sugar present in the cream is broken up into lactic acid and several other by-products which will be mentioned later.

These different by-products have certain physical effects upon the body of the cream. The acid developed causes the cream to coagulate and become thick. As the ripening process is carried on the appearance of the cream changes somewhat. It becomes thick, granular, and glistening in appearance. Undoubtedly the film of casein, or whatever the envelopment may be, surrounding the fat-globules, is loosened or cut.

Biological Changes.-Cream when put into the ripening-vat usually contains a very large variety of bacteria. Which species predominates at that time depends upon the care and treatment of the cream previous to the ripening stage. In pasteurized cream practically all the germs present are of the spore-producing kind, and unless conditions are favorable for the development of the spores, these will be suppressed by the germs added with the starter. During the first few hours of the ripening process there is a gradual growth of all the germs present. It is said that in sweet cream the lactic acid germs are comparatively few in number, but under favorable conditions these grow so much more rapidly in number than any of the others, that in a short time they become more numerous than all the other germs. The by-product lactic acid is unfavorable for the growth of nearly all the undesirable varieties of germs. Practically all these germs are suppressed in their development, 
so that when cream is ripened properly, it contains fèw other germs besides those which produce lactic acid.

From the above it will be seen that there are practically two overlapping periods in the bacterial changes during the ripening of the cream, and especially is this so in the ripening of raw cream. The first includes the period when all the different varieties of germs grow, and the second includes the period when only the lactic-acid-producing germs grow. It is, therefore, maintained that before the churning takes place the ripening of cream should be carried on to such an extent that the lactic-acid germs only predominate. Dr. Storch, who has made a detailed study of this, asserts that milk and cream both have a rather undesirable flavor at the beginning of its ripening period, while in the latter stage of the ripening period it takes on a pleasant, clean, acid taste.

The number of germs, and the relative number of acid-producing germs in the cream when ripened, is as shown in the following table:*

\begin{tabular}{|c|c|c|c|c|c|c|}
\hline Date. & $\begin{array}{l}\text { Quality of } \\
\text { Cream. }\end{array}$ & Number per c.c. & $\begin{array}{l}\text { Number Acid } \\
\text { per c.c. }\end{array}$ & $\begin{array}{c}\text { Per } \\
\text { Cent } \\
\text { Acid. }\end{array}$ & $\begin{array}{l}\text { Number Non- } \\
\text { acid per c.c. }\end{array}$ & $\begin{array}{l}\text { Per } \\
\text { Cent } \\
\text { Non- } \\
\text { acid. }\end{array}$ \\
\hline Feb. 11 & Fine & $280,000,000$ & $257,000,000$ & 92 & $22,400,000$ & 8 \\
\hline 30 & Excellent & $3,002,000,000$ & $2,851,190,000$ & 95 & $150,810,000$ & $\begin{array}{r}19 \\
5\end{array}$ \\
\hline Aug. 11 & Good & $1,107,000,000$ & $1,012,072,200$ & 91.5 & $94,928,800$ & 8.5 \\
\hline Sep. 3 & Fair & $1,027,000,000$ & $955,110,000$ & 93 & $71.890,000$ & 7 \\
\hline & Good & $2,007,958,000$ & $1,827,370,000$ & 91 & $180,588,000$ & 9 \\
\hline Oct. 28 & "6 & $392,958,000$ & $385,098,840$ & 98 & $7,859,160$ & 2 \\
\hline 30 & "6 & $393,700,000$ & $381,889,000$ & 97 & $11,811,000$ & 3 \\
\hline
\end{tabular}

Fckles found that when good-flavored cream is ready for churning the number of bacteria per cubic centimeter varies from $380,000,000$ to $3,000,000,000$. Of this number the acidproducing bacteria constitute from $91 \%$ to $98 \%$.

Chemical Changes.-The changes in cream during the process

* Bul. 40, Iowa Experiment Station. 
of ripening are not due to any instability of the components of cream, nor are they attributed to any of the enzymes. Galactase is a pre-existing enzyme in milk; consequently it would be present in cream, but present only to a very small extent. If it were possible to exclude from the cream all the different kinds of bacteria, ripening would not take place. At least it would proceed at a much slower rate than the ordinary rate of change in the ripening of cream ; this proves that the solids of cream are chemically stable and that the enzymes or unorganized ferments play only a secondary part in bringing about the different changes in cream ripening. There are two classes of solids in cream which are decomposed chiefly during ripening: viz., (1) Albuminoids, and (2) Sugar.

1. Most authorities maintain that bacteria are unable to feed on, or to decompose directly any substance which is not present in the form of a solution. As casein is not normally present in a solution in milk, the pre-existing enzyınes or bacterial by-products must cause the first decomposition of casein before the germs are able to utilize it. The by-products resulting from the casein ferments are many, and very complex. According to Russell * albumoses, leucin, peptone, tyrosin, and ammonia are formed. Freudenrich claims that in addition to these butyric acid is a by-product. Besides these substances, gases such as carbonic gas, marsh-gas, and nitrogen are formed. Whether all these by-products are formed directly or indirectly or both, no one knows for certain.

The typical ferments seem to act similarly upon the casein in milk. They produce first a rennet-like ferment, which curdles the milk. After it has bcen curdled, the curd is digested or peptonized by the action of some enzyme. The cascin in a sample of milk containing a preponderance of casein ferments will in a few weeks, or even less time, disappear entirely. Apparently the milk has been transformed into whey. This particular ferment is called casease by Duclaux. Conn calls 
it a tryptic ferment, because it is similar in its action to the trypsin produced by the digesting glands. The putrefactive germs ordinarily act upon the nitrogenous matter of cream, as described above.

2. The milk-sugar in cream is present in a perfect solution, and consequently it is thought that bacteria are able to utilize it as food directly. The typical lactic-acid-producing germs cause the milk-sugar to split up into lactio acid chiefly, according to the following equation:

$$
\underset{\text { Milk-sugar. }}{\mathrm{C}_{12} \mathrm{H}_{22} \mathrm{O}_{11}}+\mathrm{H}_{2} \mathrm{O}=4 \mathrm{C}_{3} \mathrm{H}_{6} \mathrm{O}_{3} \text {. }
$$

There are a number of germs which are able to produce lactic acid from milk-sugar, but practically all of them, so far as known, produce other by-products besides the lactic acid. Some germs produce much lactic acid and a small amount of other by-products, while other germs produce little lactic acid and large amounts of several other by-products. Some of them break up the milk-sugar and change it into lactic acid and carbonic gas. Other species produce lactic acid and alcohol. This latter species Grottenfelt claims to be closely associated with the production of flavoring substances in butter. Different kinds of gases, such as nitrogen, hydrogen, carbonic-acid gas, and marsh-gas are also formed.

It is doubtful whether there are any germs which are able to transform milk-sugar entirely into lactic acid. If such were the case, 1 gram of milk-sugar would produce 1 gram of lactic acid. According * to some experiments carried on by one of the authors, .8 of a gram was the maximum amount of acid developed from 1 gram of milk-sugar, and $.5 \%$ is the average amount of acid developed from 1 gram of milk-sugar. In the experiments, efforts were made to have the typical lactic-acid ferments present in the cream. The following table may prove of some interest:

* Chemical Changes during Cream Ripening. (Thesis I. S. C.) 


\section{Cream I.}

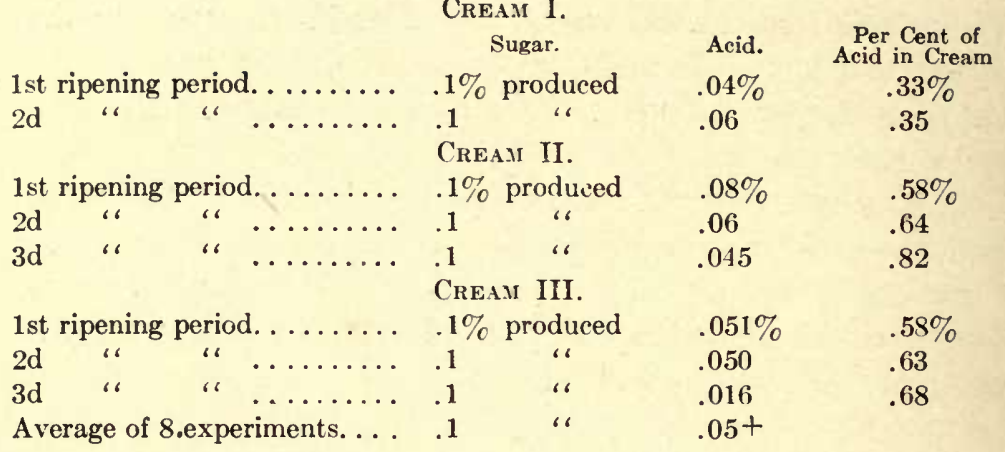

Conn states that the lactic acid produced in cream during ripening is not always of the same kind. Some species of bacteria produce the kind which turns the plane of polarization to the left; other species produce the kind which turn it to the right, and still other species produce the so-called inactive lactic acid. The most common are those which produce acid that turns the plane of polarization to the right.

The souring of cream, according to Conn, is not due to the development of lactic acid alone. Two kinds are produced, (1) fixed, and (2) volatile. The fixed acids appear to be chiefly, if not wholly, lactic acid, and the volatile are chiefly acetic and formic acids. The fixed acids are produced in the greatest proportion.

In the table quoted above, it will be seen that during the first ripening period of sample $3, .1 \%$ sugar produced $.051 \%$ of acid, while during the last or third ripening stage $.1 \%$ of sugar produced $.016 \%$ of acid, being only about one-third of that produced during the first ripening period. The same is true in experiment II, where three separate analyses were made of the cream. It is difficult to account for the constant decrease of lactic acid in proportion to the sugar decomposed in the advanced stage of the ripening period. Is it the lactic acid already present that decomposes into other products when so much acid is formed? Or do the bacteria continue to decompose the sugar, but the by-products being of a different nature? 
Or do certain species of bacteria cease to act, and are other species, which produce less lactic acid and more gaseous products, able to perpetuate their growth and bring about the results observed? The results are probably due to a combination of the different actions just mentioned, but the most likely theory is that conditions for the growth of other species of bacteria become more favorable, and other by-products than lactic acid are formed, products that cause the undesirable rancid flavors in over-ripened cream.

Butyric acid also results from the decomposition of cream constituents during ripening. The origin of the butyric acid formed during ripening is, however, not well known. Freudenreich says it is the residue resulting from the breaking down of casein and milk-sugar in various ways, and therefore he classes the butyric ferments in the same group as the casein ferments.

Butyric acid in overripened cream is by some authorities considered to be a direct product from an excessive amount of lactic acid. Each molecule of lactic acid breaks up into butyric acid, carbonic-acid gas, and hydrogen, according to the following equation:

$$
\begin{array}{r}
\text { Lactic acid. } \\
2 \mathrm{C}_{3} \mathrm{H}_{6} \mathrm{O}_{3}=
\end{array}=\begin{gathered}
\text { Butyric acid. } \\
\mathrm{C}_{3} \mathrm{H}_{7} \mathrm{CO}_{2} \mathrm{H}+2 \mathrm{CO}_{2}+\mathrm{H}_{4} \text { arbonic- } \\
\text { acid gas. }
\end{gathered} \text { Hydrogen. }
$$

It is questionable whether this reaction ever occurs in the ripening of cream.

Butyric acid also results from the decomposition of butyrin, through the action of bacteria, and causes the molecules of fat to split up into butyric acid and glycerine, according to the following equation:

$$
\begin{gathered}
\text { Butyrin (fat). } \mathrm{C}_{3} \mathrm{H}_{5}\left\{\begin{array}{l}
\mathrm{C}_{3} \mathrm{H}_{7} \mathrm{CO}_{2} \\
\mathrm{C}_{3} \mathrm{H}_{7} \mathrm{CO}_{2} \\
\mathrm{C}_{3} \mathrm{H}_{7} \mathrm{CO}_{2}
\end{array}+3 \mathrm{H}_{2} \mathrm{O}=\mathrm{C}_{3} \mathrm{H}_{5}\left\{\begin{array}{l}
\mathrm{OH} \\
\mathrm{OH} \\
\mathrm{OH}
\end{array}+3 \mathrm{C}_{3} \mathrm{H}_{7} \mathrm{CO}_{2} \mathrm{H}\right.\right.
\end{gathered}
$$




\section{CHAPTER XV.}

\section{STARTERS.}

Definition.--By the term starter, in cream-ripening, we understand a medium containing a preponderance of desirable germs present in a virulent condition.

History.-The use of starters in the dairy industry dates back a great many years. The fact that starters helped in the manufacture of dairy products was recognized years ago by practical men even before scientists recommended the use of pure cultures. In European dairy countries the use of the buttermilk borrowed from a neighboring factory to add to the cream in order to overcome abnormal conditions, was a common occurrence. In Holland, sour whey borrowed from some other factory was used to overcome gassy fermentation in cheesemaking. While the reasons for this were not well understood, the underlying principle was involved, viz., that of overcoming the undesirable fermentation by adding ferments of an antagonistic kind.

The introduction of pure cultures, or commercial starters, for cream-ripening dates back to 1890 , by Professor Storch. He recommended their use in creameries in Denmark. Starters were used in that country for a time successfully, and since then starters have been introduced and extensively used in this country, as well as in practically all European countries.

Classification of Starters.-Generally speaking, the different kinds of starters are included under the names (1), Natural, and (2) Commercial. The latter is prepared from a pure culture of bacteria obtained from the laboratory. The former, or natural, include a great many kinds of dairy products which 
are supposed to contain a preponderance of those germs which are involved in the production of desirable flavors in butter. Buttermilk, sour cream, whey, and sour whole or skim-milk, are classed under this heading. While all these may be termed natural starters, and at certain times the use of any one of them may produce better results than if no starter at all were used, it is not safe to rely upon these to bring about better results than could be obtained without the use of starters, because these products are likely to be contaminated in a large degree with undesirable germs.

Preparation of Natural Starters.--The best natural starter is usually obtained by selecting a number of different samples of the best milk coming into the creamery, into cleaned sterile glass jars. The samples are allowed to stand until sour at about $70^{\circ} \mathrm{F}$. The sample which coagulates into a smooth uniform curd, and has a pleasant acid taste and smell is selected and used as a mother-starter. When inoculated into a large quantity of selected pasteurized skim-milk, cooled to and kept at a temperature of about $70^{\circ} \mathrm{F}$. until it begins to coagulate, it will usually produce a starter which is equal, and often superior, to a commercial starter.

Commercial Starters, or Pure Cultures.-Experiments have amply proved that certain species of bacteria are chiefly responsible for the butter flavors developed in cream during ripening. This fact has given rise to the use of pure cultures prepared in a commercial way. These pure cultures contain, in a virulent condition, the germs which produce the desirable flavors and aroma. The cultures are put up in laboratories specially provided for this kind of work. The germs are isolated and inoculated into a medium which is suitable to their growth. Some laboratories inoculate them into a liquid medium, others into a powder medium. The liquid medium consists usually of sterilized bouillon, or milk. The powder medium consists chiefly of milk-sugar. The cultures that are put up in the liquid form will not keep so long, and it is not safe to use them after they are about nine days old. The cultures which 
are put up in powder form have the advantage that they can be kept for a much longer time and still retain their vitality. Both kinds as a rule are good while they are fresh. We give below a list of the commercial cultures with which the authors are familiar:

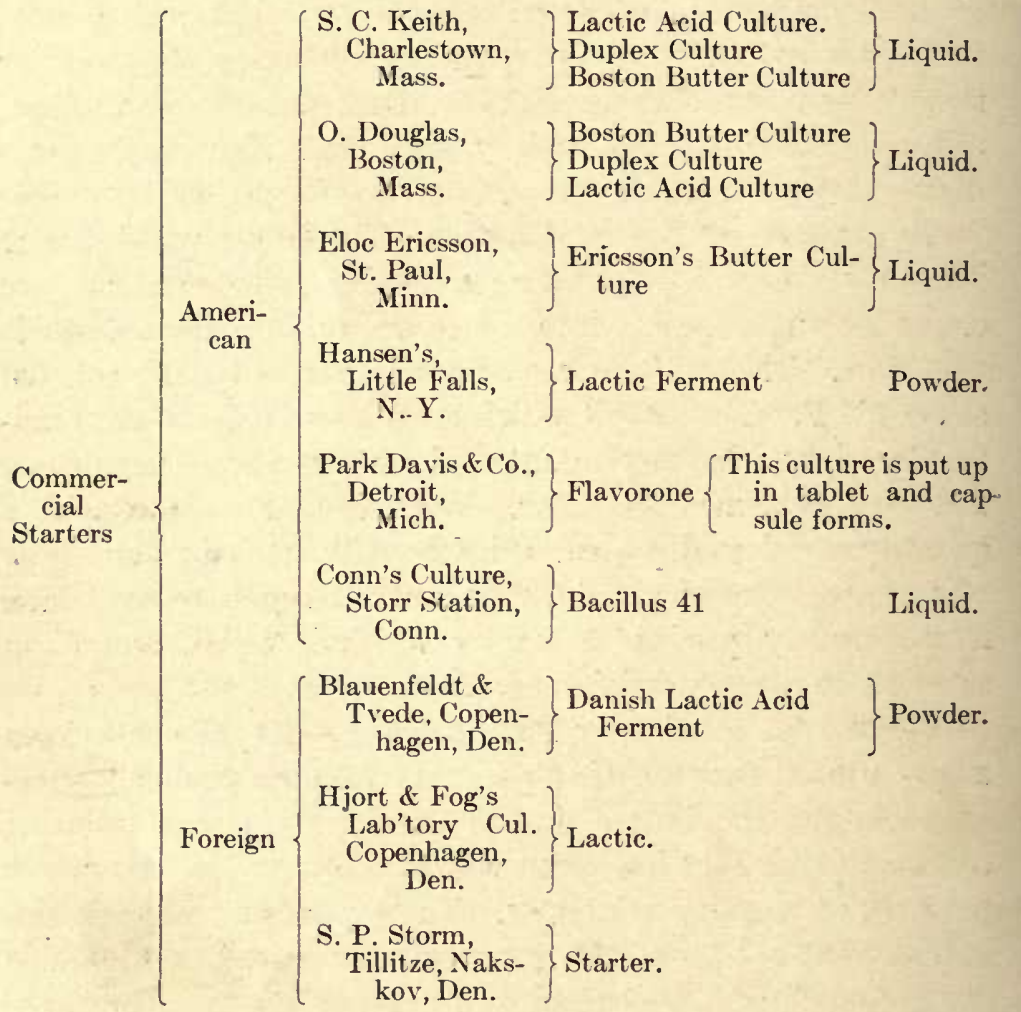

Preparation of Commercial Starters.-All of the starters mentioned above have been tested and are known to produce good results. The first step in the preparation of a motherstarter (starterline) is to prepare preferably a glass jar or bottle by thoroughly cleaning and sterilizing it. Glass jars are used in preference to any other vessel, because if they are unclean in any way, it will show through the glass. Secondly, there are no seams and no places on the inside which will cor- 
rode, and in that way retain unnoticeable dirt. Mason jars and sampling bottles are suitable. The kind of bottle which is used for marketing milk gives very good results.

The second step consists in selecting suitable milk. The milk must be in as pure and sweet a condition as possible. A good starter can be produced from either whole or skim-milk. Skim-milk, however, is preferable to whole milk. The mistake of selecting whole milk for starters has often been made. The mother-starter prepared from whole milk usually has a more pleasant, mild, rich taste, due to the fact that it contains more fat than the starter made from skim-milk. The mother starter prepared from good skim-milk is preferable, and safer to rely upon. Efforts should be made towards separating the starter milk before the rest of the milk has been run through. If not separated till late during the run of the day, the separator is filled with slime. and bowl-slush, which are likely to contaminate the starter milk. At some creameries, the separation of the starter milk is accomplished with a small hand separator. This, however, is not convenient or practicable at most creameries. The milk for the starter can be selected and run through the power separator during the beginning of the run. It is well not to use the very first milk which passes through the separator, as it would be likely to contain a greater number of undesirable germs.

The milk which has been selected for the mother-starter, or starterline, is then pasteurized. The pasteurization is best accomplished by the intermittent method. If considerable milk is to be pasteurized it is best to make use of a clean, sterilized can. If only a small portion is to be pasteurized, just enough for the mother-starter, the milk can be put directly into the jars. The jar half full is about the proper amount of milk to use. The directions sent with some pure cultures recommend as much as half a gallon or a whole gallon of milk. As a rule better results are obtained if only about a pint of milk is taken. If the milk for the mother-starter is pasteurized in the glass bottles or jars, then it is advisable to set the bottles 
containing the milk into cold water,-covering the jar so as to prevent outside contamination,--and then heat up the water gradually. Care should be taken not to insert these bottles suddenly into scalding hot water, or to let the steam strike them, for either is likely to crack the bottles. Care should be taken also to exclude water from milk used for starters. It is advisable to heat this milk, for the starterline, as high as possible in scalding water, say up to about $200^{\circ} \mathrm{F}$. The sample may assume a cooked taste, but this will soon disappear after the starter has been carried on a few days. The milk should be left at this high temperature for about ten or fifteen minutes. A longer time does no harm. Then the nilk is gradually cooled to about $80^{\circ} \mathrm{F}$. This high temperature is desirable, because the germs present in the commercial culture may be somewhat dormant. This high temperature would tend to revive them more quickly than a lower temperature. Great care should always be taken to cool the milk previous to inoculating it with the pure culture, otherwise the germs present in the pure culture.will be destroyed.

Inoculation,-The next step is to inoculate the prepared milk with the pure culture obtained from the laboratory. The bottle which contains the pure culture is carefully opened, then the bottle containing the culture is turned over and emptied into the pasteurized milk. The bottle should be held down closely to the mouth of the jar containing the sterile milk, in order to prevent too much contanination from the air. Then the milk containing the pure culture is thoroughly stirred and set away in a room where the temperature is about $70^{\circ} \mathrm{F}$. This will gradually cool the milk from $80^{\circ}$ to $70^{\circ} \mathrm{F}$., and in about twenty to forty hours the milk will sour and coagulate. Germs in nearly all of the liquid cultures are rather slow in acting upon the milk, undoubtedly due to the dormancy of the germs, and to a comparatively few of them being present in the pure culture. When the powdered cultures are used, a little more care is essential to get the powder thoroughly mingled with the milk. It is a trifle more difficult to get the 
powder thoroughly mixed with the milk than it is to get the liquid cultures mixed. If anything is used with which to stir the sample, it should be sterilized before coming in contact with the milk. This applies in the preparation of all cultures. In testing or sampling the mother-starters, nothing should be allowed to come in contact with it unless it has previously been thoroughly sterilized. The powder cultures are usually more vigorous in their effect than most of the liquid cultures now on the market. The powder cultures usually coagulate the sample in about twenty-four hours, and if the operator is used to handling the liquid cultures, he should watch the motherstarters prepared from powder cultures, so that they do not get overripe. It is very essential that the starters do not get overripe. The time when the germs are most numerous and most active in the starter is about the time when the sample coagulates. As soon as this stage has been reached, or just previous to coagulation, the starter should be cooled down to at least $50^{\circ} \mathrm{F}$, or lower if possible This prevents any further growth of germs and the sample can be kept a short time without injury.

Directions usually accompany each of the cultures, but the above will be found to produce good results with all of those mentioned in the above outline.

By inoculating from $2 \%$ to $5 \%$ or more of the motherstarter into a large sample of pasteurized milk, any desired amount of starter can be prepared. In selecting this amount of milk, as much care as possible should be taken in order to select the best kind of milk, and keep it from being contaminated. When this large sample of starter is at the proper stage of coagulation, it should be used at once, or else cooled down to about $50^{\circ} \mathrm{F}$. The amount of mother-starter with which to inoculate the large sample of starter may vary a little without any bad effects. If the large sample of starter is to be ready for use in a short time, a larger portion of the motherstarter can be used for inoculation. If the temperature at which the starter is set and the amount of mother-starter used 
for inoculation are the same from day to day, the starter will be ripe at nearly the same hour every day, and, consequently, more uniform ripening results can be obtained. The noticeable coagulation of the starter when skim-milk is used will usually take place when there is about $.6 \%$ of acidity. A slight coagulation will take place when there is about $.5 \%$ of acidity, but it is hardly noticeable. The coagulation-point may vary with different samples of milk.

If a mother-starter is to be kept any length of time it should be inoculated into a sample of good fresh pasteurized milk about every other day. If a mother-starter, or starter of any kind, is allowed to stand too long at a low temperature, the desirable germs will become dormant, and some undesirable germs will gradually gain a foothold. It is a good plan to carry any mother-starter along for two or three days before it is used to inoculate a large sample of milk. When the motherstarter is first prepared it sometimes contains an undesirable taste and smell from the medium in which the germs were put up at the laboratory. This smell and taste is eliminated by carrying it on two or three days previous to its use.

While the starter, or mother-starter, is in the stage of ripening it should occasionally be gently stirred. As soon as coagulation of the milk begins, then starters of any kind should never be stirred. If a sample of coagulated milk is stirred before it is ready for use, it is more likely to "whey off."

Length of Time a Starter Can be Carried.-In this country, even if special precautions are taken, it seems almost impossible to carry on a starter for more than four weeks without having undesirable ferments enter. The length of time a starter can be carried undoubtedly depends upon conditions, and the care with which it has been handled. When a starter is properly prepared, cooled gradually before coagulation, and not overripened, it will contain a smooth-soft curd, and retain its mild acid flavor for at least a month. The Danes, who use starters in butter-making more regularly than any other people, are able to carry a starter along for six months or more without renewing it. 
It is a good plan to keep at least two different kinds of starter by carrying them on from day to day in small quart jars. Then if one should happen to "go off," the other one can be used instead.

Poor Starters. - Many unsuccessful results from the use of starters for cream-ripening have been reported. The failure can be traced to the improper use of starters. If starters are good they will never bring about poorer results than are obtained without the use of them. Owing to the fact that it is difficult to keep the same starter in a good condition very long, many starters are used which develop abnormal fermentations in cream. A slightly acid, somewhat bitter taste, and a slimy condition of the starter are defects which are very common. These conditions seem to be brought about chiefly by overripening it at a high temperature, and keeping it a long time at a low temperature before using it. Slimy fermentation is very common in starters which have been carried on for a time, Whenever this slimy ferment develops in the starter it can be noticed in the crean and starter both, by the acid not developing so rapidly as when the proper acid-producing ferment is present. It seems almost impossible to develop any more than about .5\% of acidity in $30 \%$ cream; while if the proper ferment were present, about $.7 \%$ could be developed. A decrease in the quality of butter accompanies the development of this ferment in the cream.

Whenever it is found that a starter is not in as good condition as it ought to be, it should not be used, as a poor starter is worse than none at all. The butternilk from the previous cream can sometimes be used advantageously until a new starter can be prepared.

Underripening and Overripening of Starters. - The effect of overripening starters has already been mentioned under the "Preparation of Mother-starters." The question of underripening starters is also of importance. It is a well-known fact that just about the time when the milk begins to turn sour, that is, when the sourness can just be recognized by the taste, 
it has a rather disagreeable flavor. After more acid develops the undesirable flavor largely disappears, and the milk assumes a clean, desirable acid taste. The reasons for this has recently been accounted for by Storch, the well-known authority on starters. He claims that this disagreeable flavor is due to the action of undesirable organisms, during the first souring stage. As the souring progresses these germs are subdued and gradually crowded out by the desirable acid-producing types.

In the preparation of a starter the probabilities are that some of these undesirable types of germs are present. At least it is safer to go on the assumption that they are present. This makes the underripening of starters just as important to guard against as overripening.

Amount of Starter to Use.- The amount of starter will vary under different conditions. It may vary from none at all the as much as $50 \%$ of the cream to be ripened. The quality of cream is one of the factors that needs to be considered. Raw cream and old cream each require a large starter, especially if the cream is thick enough so as to permit of being reduced in thickness. Good pasteurized cream does not need a larger starter than about $10 \%$ of the cream to be ripened.

The amount of starter to use also depends somewhat upon the general ereamery conditions. In some creameries all the cream is received in a very sour and poor condition, and facilities for getting milk for preparation of starters are often very poor. Under such conditions it is questionable whether it would be profitable to use starters at all. The amount of starter to use chiefly depends upon the degree of rapidity of ripening desired, and upon the temperature of the cream. If it is desirable to ripen quickly, then a comparatively large starter ( $15 \%$ to $25 \%$ ) should be added, and the ripening temperature should be comparatively high (about $80^{\circ} \mathrm{F}$.). If slow ripening is desired, then less starter can be used. Enough, however, should be used to control the fermentation in the cream (about $10 \%$ to $15 \%$ ), and the ripening temperature may be lower, between $60^{\circ}$ and $70^{\circ} \mathrm{F}$. More starter should be used in the winter. 
Use of Starter-cans. - In the past, ordinary tin shot-gun cans have chiefly been used for the preparation of starters, and have given good results. Many makers still use such cans in preference to recently invented starter-cans.

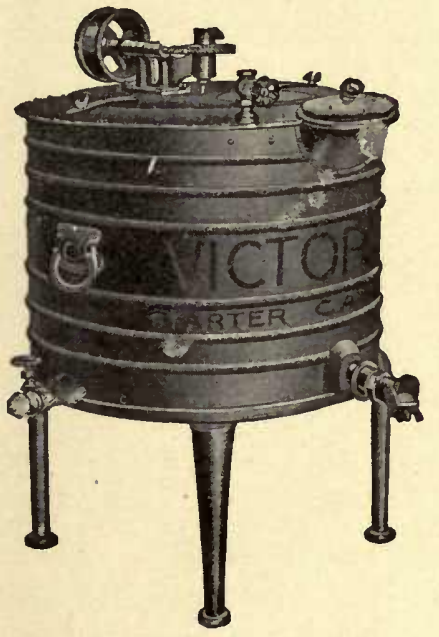

Fig. 133.-The Victor starter-can.

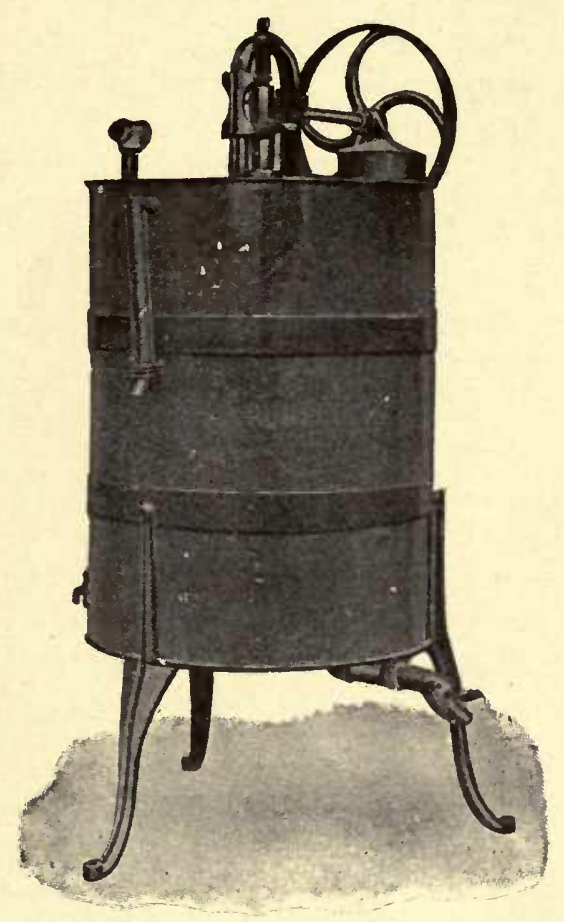

FIG. 134.-Emily's perfection starter-can.

The earliest starter-cans were made of light material and did not last long. These defects, however, have largely been done away with, and the use of starter-cans certainly is an improvement over the old method of preparing the starters in several smaller cans.

These starter-cans are jacketed, so that the temperature can be controlled by using hot or cold water, or ice, as demanded, in the jacket. All of the starter-cans have an agitator, which is operated with a belt. 


\section{CHAPTER XVI.}

\section{CHURNING AND WASHING BUTTER.}

Definition.-By churning we understand the agitation of cream to such an extent as to bring the fat-globules together into masses of butter of such size as to enable the maker to separate them from the buttermilk.

The agitation may be brought about in several different
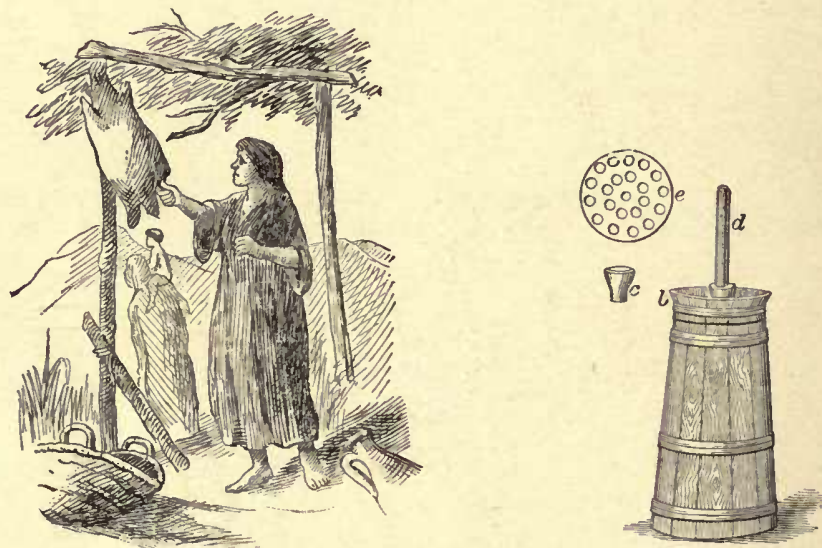

Frg. 135.-Ancient method of churning Fig. 136.-The Dash churn. in skin bags.

ways, and by different shaped devices, which are called churns. The methods of churning, like the process of separation, began with primitive methods. The ancients churned their milk, without separation, in bags made from the skins of animals. The next step in advance was to place milk or cream in bottles or jars, and then to shake them. This latter method of churn- 
ing cream in bottles is yet in use in many of the smaller households of Europe, where the amount of cream is limited to a small quantity donated by cow-owners. The next step toward churning on a large scale was to get a large wooden box or barrel run by power or by hand. The churns which are in use at the present time in American butter-factories are termed "combined churns." They are so arranged as to admit of churning, washing, salting, and working without removing the butter from the churn. This style of churn is now being introduced into Europe. Owing to their superior worth they will soon be in general use there as well as here. They keep flies away from the butter during fly time; the temperature of the butter can be controlled in the churn, and the handling of the butter during salting and working is obviated.

\section{Conditions Affecting the Churnability of Cream.}

Temperature.-The temperature of cream is one of the most influential factors in determining the churnability of cream.

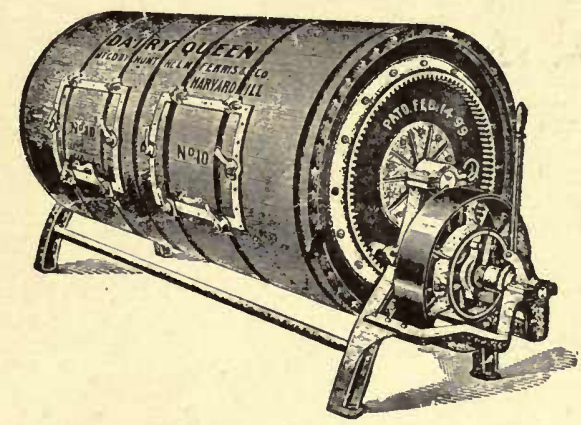

FIG. 137.-The Dairy Queen combined churn.

The higher the temperature of the cream, the sooner the churning process will be completed. Too high a churning temperature, however, is not desirable. It causes the butter to come in soft lumps instead of in a flaky granular form. This is deleterious to the quality of the butter. It causes, first, a greasy texture of the butter, and, secondly, it causes the incorporation 
in the butter of too much buttermilk. This buttermilk contains sugar, curd, and water, which, when present together in butter, are likely to sour and in other ways deteriorate the butter. Curd and sugar should be excluded from butter as much as possible, in order to eliminate food for bacteria which may be present. An excess of curd is also favorable for the formation of mottles.*

Too low a temperature is also undesirable, although it is

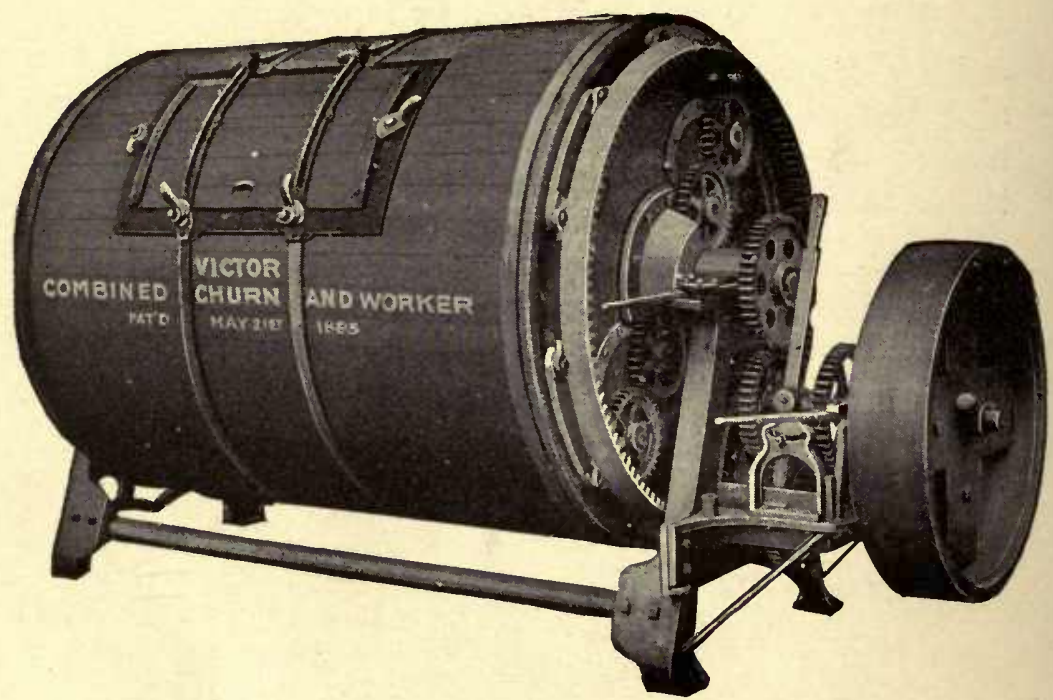

FIG. 138.-The Victor combined churn.

better to have the temperature a little low rather than too high. When the churning temperature is too low, difficult churning is likely to occur. Cream at a low temperature becomes more viscous. On agitation in the churn such cream if it is very thick will adhere to the sides of the churn and rotate with it without agitating; consequently no churning will take place. Too low a temperature brings the butter in such a firm condition that it takes up salt with difficulty, and when this hard butter is being worked, a large portion of the water in the 
butter is expressed, and the overrun will be lessened to a great extent without increasing the commercial value of the butter.

The degree of hardness of the fat in the cream is the governing factor in deciding the churning temperature. The churning temperature will vary a great deal in different localities. The hardness of the fat depends upon (1) the season of the year; (2) the individuality of cow; (3) the stage of lactation period;

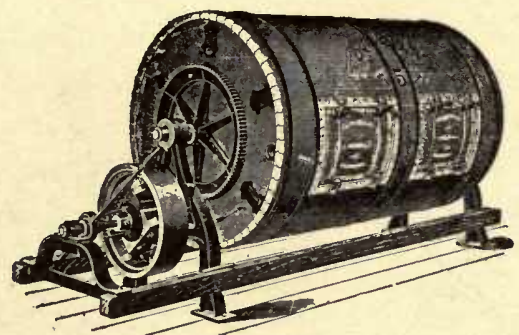

FIG. 139.-The Squeezer combined churn.

and (4) the kind of food fed to the cows. All these factors influence the melting-point of butter-fat. The higher the melting-point of butter-fat is, the higher the churning temperature, and the lower the melting-point of the fat, the lower the churning temperature.

1. During the spring the cows yield milk containing a larger proportion of soft fats; consequently the churning temperature is always lower in the spring than in the fall or winter. During winter, when the cows are fed on dry food chiefly, the harder fats increase in quantity, and consequently a higher churning temperature is necessary during that time.

2. Some animals produce milk containing a larger proportion of softer fats than do other animals. It is said that the difference in this respect is more marked in certain breeds. It is maintained that the cows of the Jersey breed produce milk containing a larger proportion of the softer fats than do any of the other breeds.

3. The period of lactation also affects the melting-point of butter-fat. When a cow is fresh she yields a larger proportion 
of the soft fats than she does later on in the lactation period. With this increase in the proportion of the hard fats in the advancement of the lactation period, the fat-globules become smaller. This, together with the increased hardness of the fat, causes difficult churning at times. It can readily be seen that the larger the fat-globules are the greater are the chances for these globules to strike each other during agitation in the churning process.

4. The nature of the food fed affects the melting-point of butter to a considerable extent. Cotton-seed and its by-

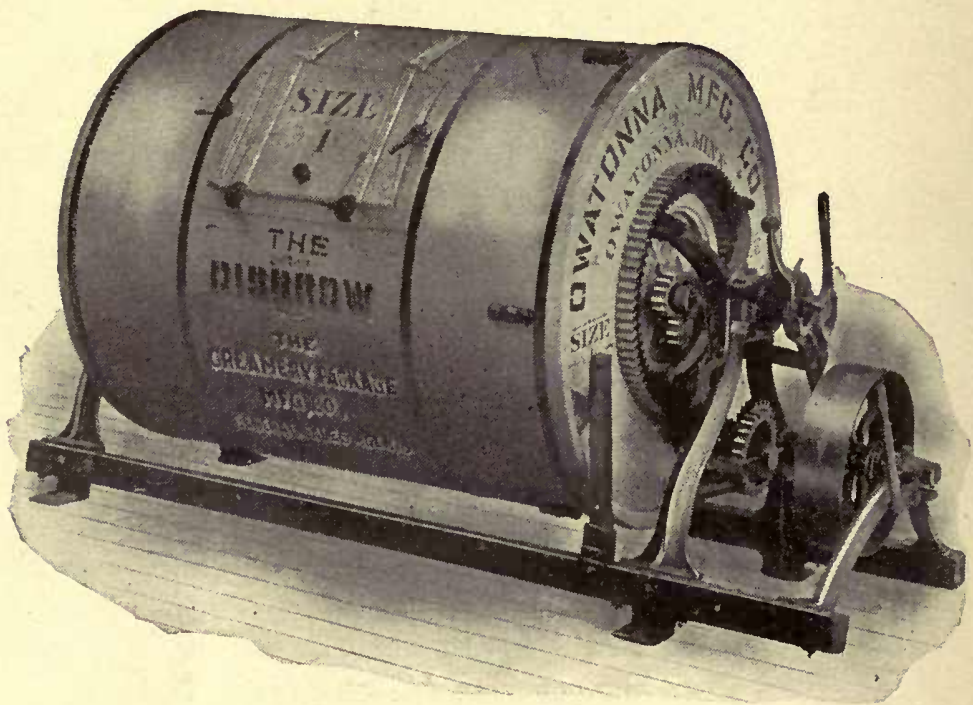

Fig. 140.-The Disbrow combined churn.

products have been demonstrated thoroughly by several investigators to cause butter to become hard. When a large amount of cottonseed is fed, the butter assumes a crumbly, tallowy, hard condition; while linseed meal, and practically all succulent foods tend to decrease the melting-point of butter-fat.

According to the above it can be concluded that the churning temperature may vary between wide limits, but the average desirable churning temperature under normal conditions is 
between $50^{\circ}$ and $60^{\circ} \mathrm{F}$. Any conditions which tend to harden the butter-fat will require a comparatively high churning temperature; and any conditions tending to soften the butter-fat will require a lowering of the churning temperature. The lower the temperature at which the churning can be successfully accomplished, the more complete will be the churning; that is, the less fat will remain in the buttermilk.
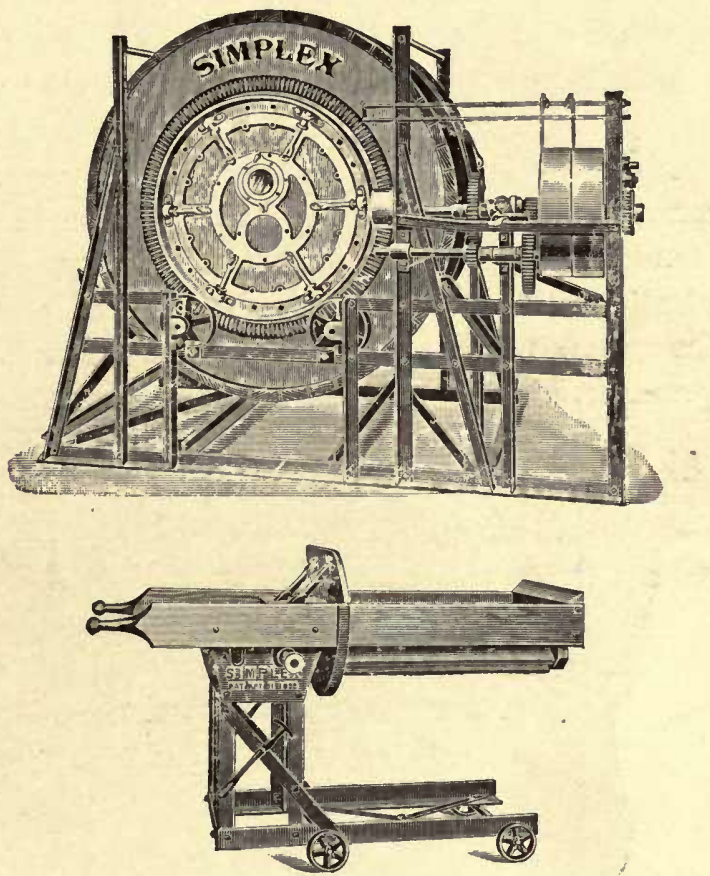

FIG. 141.-The Simplex combined churn, with worker detached.

Richness of Cream.-The amount of fat in the cream affects the churnability of it considerably. The richer the cream the. sooner will be the completion of the churning, that is, providing the cream is not rich enough to be so thick as to cause the cream to adhere to the inside of the churn and thus escape being agitated. If rich cream is churned at a high temperature the butter will come in a remarkably short time, providing all other 
conditions are favorable. Thin cream churns much more slowly, and can be churned at a higher temperature than thick cream, without injuring the quality of the butter. When rich cream is churned at a high temperature, and the butter comes in a short time (about ten minutes), the butter will usually be greasy in body, and will contain a great deal of buttermilk, which will be more or less difficult to remove on washing. When thick cream is being churned, the butter does not break in the form of small round granules, as it does when thin cream is churned.

When thick cream is churned at as high a temperature as is consistent with getting a good texture, the best results are obtained. In the first place, rich cream produces less buttermilk, consequently less fat will be lost in the buttermilk. This would tend to increase the overrun. Secondly, the breaking of the butter at the end of the churning will be such as to cause the granules to appear large and flaky, rather than small round granules. The more flaky granules of butter will retain

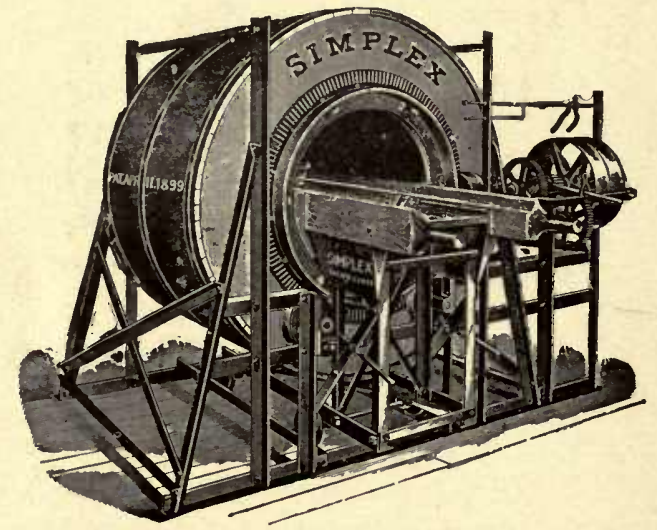

FIG. 142.-The Simplex churn with worker attached.

more moisture than the small, harder granules under the same treatment. Experiments show that when different thicknesses of cream (thin cream containing on an average $22 \%$ of fat, and thick cream $36 \%$ of fat) are churned, there is a difference of about $3 \%$ in the moisture-content of the butter. The 
average churning temperatures of cream and wash-water in these experiments were $56^{\circ}$ and $53^{\circ} \mathrm{F}$. respectively.

When thick cream is churned, and the temperature is moderately high, it is almost impossible to churn the butter into granules. This condition causes butter from thick cream to contain more moisture than butter from thin cream.

Amount of Cream in Churn.-When the churn is about onethird full, the greatest degree of agitation is obtained, and con-

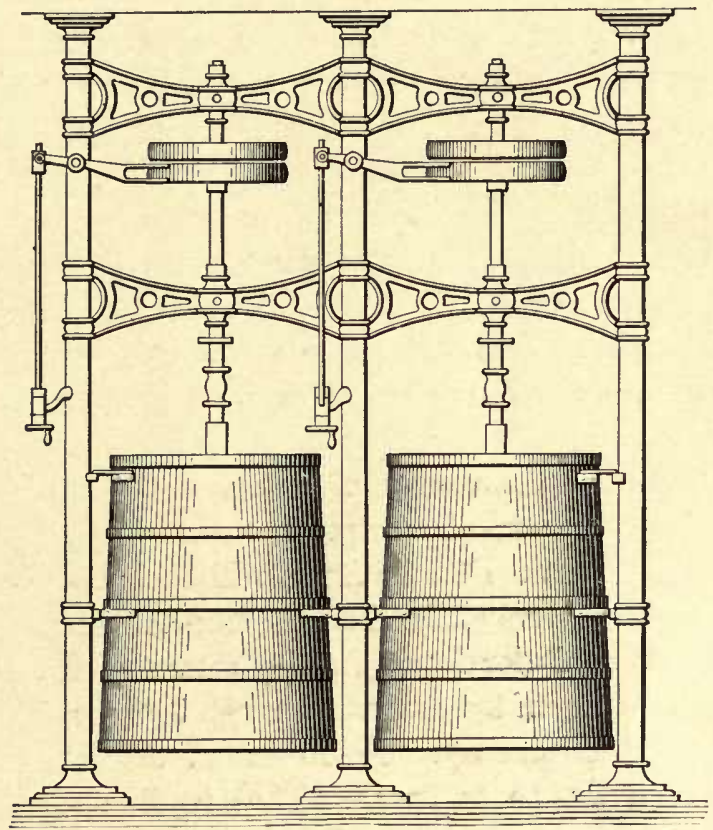

Fig. 143.-Danish churns and frame for holding them.

sequently a quicker churning. If a small amount of cream is being churned, it is often difficult to gather the butter properly. If the cream is thin, the granules are thrown about in such a way that they are gathered with difficulty. If the cream is thick, the small amount of cream will adhere to the inside of the churn, and in that way delay the completion of the churning.

It is a common opinion that less overrun is obtained from 
a small churning than from a large churning. It is safe to say that if it were possible to maintain all conditions alike, especially as to temperature and degree of churning, there would be no difference in the moisture-content of the butter made from churnings of different sizes. When there is only a small amount in the churn, the atmospheric temperature is likely to raise or lower the temperature of the cream. If the atmosphere is warm, then the butter from the small churning is more likely to be soft. A small amount of cream in the churn is also more likely to be overchurned than a larger amount of cream. These two factors would tend to increase the amount of water in the butter. In mixing the salt with a comparatively large amount of butter, less working is necessary. Much of the butter is mixed in the churn without going through the workers, and consequently less moisture will be expressed from the butter. With the same number of revolutions of the churn the butter from the small churning is worked correspondingly more than the butter from a larger churning. Medium firm butter, to a certain limit, loses about $.2 \%$ of moisture for every revolution that it is overworked in the absence of water.

Degree of Ripeness. - The riper the cream is, all other conditions being the same, the easier it will churn. Sweet crean is viscous, and consequently the fat-globules will not unite as readily. The acid developed in the cream seems to cut or reduce the viscosity of the cream, although it causes it to become thicker in its consistency. Cream in an advanced stage of ripening is brittle, so to speak. That is, if a sample of the properly soured cream is poured from a dipper it will not string but break off in lumps.

If very thin cream is overripened, the curd is coagulated. When this thickly coagulated cream is churned, the solid curd breaks up into small curdy lumps. These small lumps of curd are likely to incorporate themselves in the body of the butter and injure its quality, and also its keeping quality. If thin cream has been overripened, it should be strained well, and care should be taken not to churn it to such a degree as to 
unite the granules into lumps before the churn is stopped. By stopping the churn while the butter is in a granular form, the most of these curdy specks can be separated from the butter by copious washing. Some specks are likely to remain in the butter when the cream is in such a condition, but by following the above plan enough of the specks can be removed from the butter so that it will not injure its commercial quality. The degree of ripeness of cream does not have any effect upon the

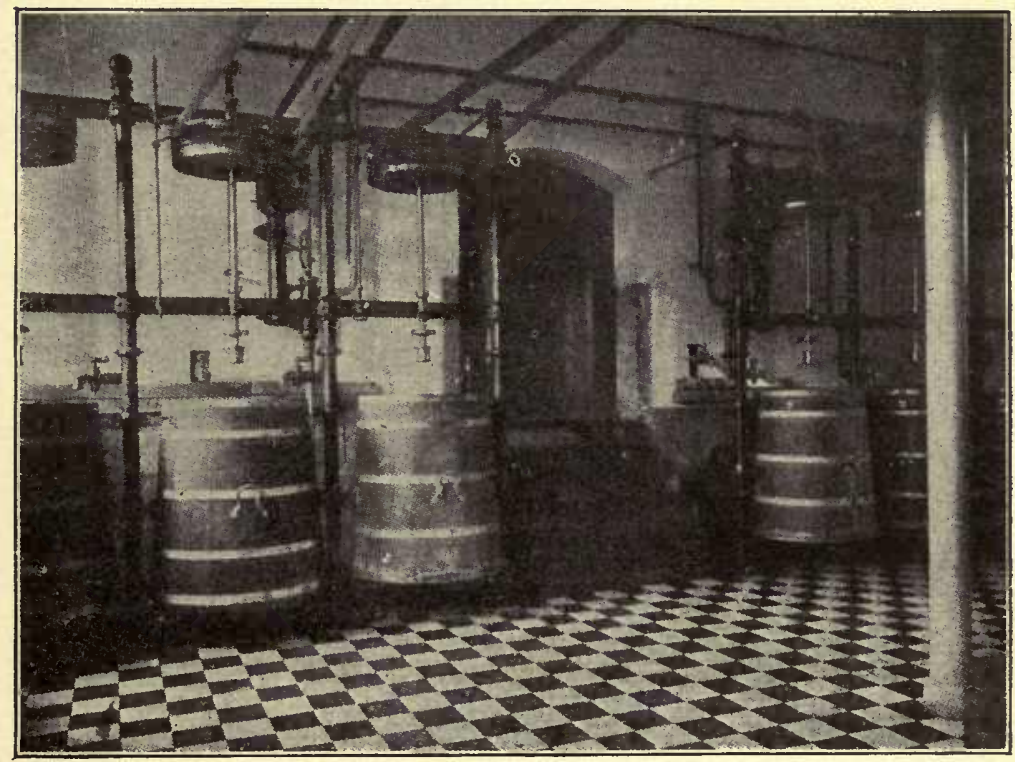

Fig. 144.-The churn-room in Trifolium Creamery, Denmark.

composition of the butter, except in increasing the curd content, as mentioned.

Nature of Agitation.- The nature and degree of agitation of cream affect the churnability considerably. Many different kinds of churns are on the market at the present time. The rotary drumi-churns, now used almost universally in this country, are claimed to give the greatest degree of agitation; that is, providing the churn revolves at a proper rate of speed. If 
the speed is so great as to cause the cream to be influenced by the centrifugal force generated, rotating it with the churn, then no agitation will take place. Consequently the churning process will be delayed, if not entirely prevented. If the speed of the churn is too slow, the degree of agitation of the cream will not be at its maximum, as the cream will tend to remain at the lowest portion of the churn without being agitated.

In the old-fashioned dash-churn the cream was not exposed to much agitation. In Europe the upright barrel-churn with rotary stirrers inside is mostly used. It takes longer to churn in this churn than in American churns. However, it gives good satisfaction.

The proper speed of the combined churn,- that is, the speed at which the greatest degree of agitation is brought about,cannot be given here, as it varies with the different diameters of the churns. The directions given with the churns from the manufacturing companies should be followed. So far as known the quality and composition of butter obtained from churning at a low speed, and at a rapid speed, do not vary.

Size of Fat-globules. - Cream containing large fat-globules churns more quickly than cream containing small globules. A more exhaustive churning can also be obtained from cream containing mostly large globules. It is, however, impossible to obtain cream which does not contain any of the small globules. The minute globules are always difficult to remove from the serum, whether it be in the churning or in the separation. In the churning there is a certain force which always tends to hold the globules in place. This force acts in a correspondingly greater degree upon the small globules. They are held in position and move only when the cream is exposed to agitation. Cream containing larger globules allows them to escape from their position with greater ease than does cream containing the minute globules. The globules which are not removed from the buttermilk during the churning process are largely of the small type. 


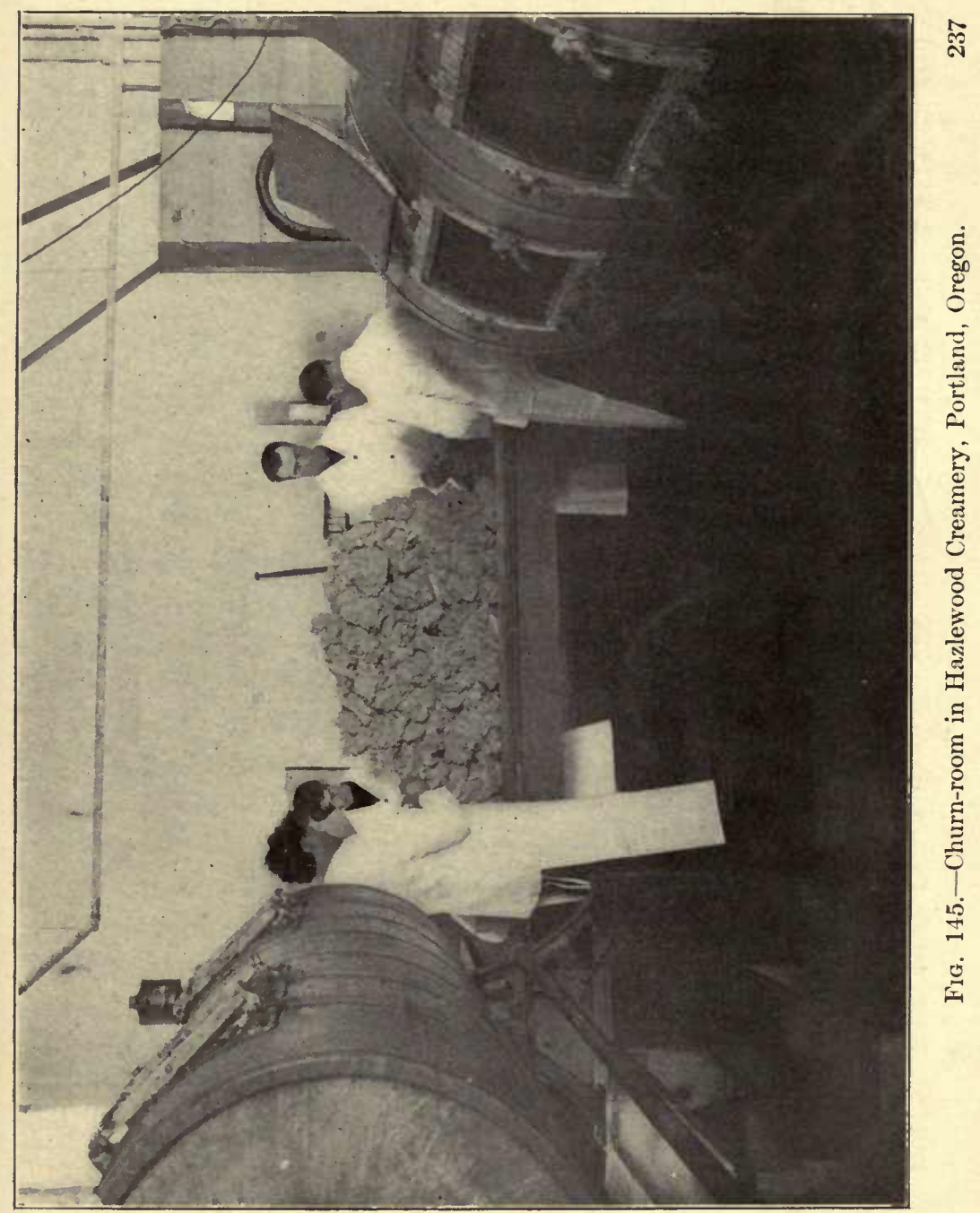


Straining of Cream.--Before the cream is transferred from the ripening-vat to the churn it should be strained through a fine perforated tin strainer. This can be conveniently done during the changing of the cream from the ripening-vat to the churn. Special strainers are now manufactured which can be hooked onto the churn, and the cream can run directly from the ripening-vat through the strainer into the churn. This straining of the cream separates all the lumps which are likely to appear. It also separates any other coarse impurities which may be present. If these impurities were not separated they would probably be embodied in the butter and cause an unsightly appesrance. They would also be likely to injure the keeping quality of the butter, but this would depend, of course, upon the character of the impurities.

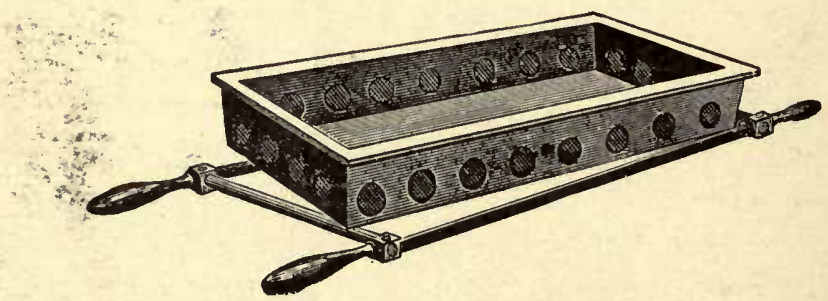

Fig. 146.-Cream and milk strainer.

Color.--In orde ${ }_{i}^{-3}$ to maintain a uniform color in the butter during the different seasons, it is essential that some artificial color be added at certain times. During the latter part of May and the fore part of June the butter has a rich yellow color, which is accepted as the standard color of butter. This is often referred to as the "June color."

There are several different butter-colors on the market, for which special merits are claimed. All the colors, so far as known, are efficient in imparting color to the butter without materially coloring the buttermilk. A good butter-color should be a substance which does not impart a bad smell or taste to the butter. It should possess strong coloring properties, so that very little of it would have to be added in order to impart the desirable color. It should not be injurious to health. 
Some colors are prepared from the fruit of the annato tree, which grows in the East Indies and South America. The flesh of this fruit is dissolved in some oil, such as sesame or hemp.

Before any of the proper commercial butter-colors were put upon the market, extracts of carrots, marigold, saffron, and annato were used. The yolk of eggs has also been used to some extent. It is said that carrot-juice is the most healthful butter-color.

The amount of color to add depends upon the market requirements, and upon the season of the year. As was mentioned before, in June little or no color should be added. As the summer season advances the amount of color added can be gradually increased. During winter, while the cows are on dry feed, the maximum amount of color is generally used. Color requirements of the butter vary considerably at the same season of the year. American markets demand a higher color than European markets. The northern markets desire a light straw color, while the southern markets want a deeper color, almost an orange color. The Jewish trade requires uncolored butter. In some of the European countries no color is used. The English market, which is the greatest butter market in the world, demands butter that has a very light straw color. The main object in coloring butter is to maintain a uniform color during the different seasons of the year. The amount of color to add during the different seasons will usually vary between none to a trifle over two ounces for every 100 pounds of fat.

The color should be added to the cream before the churn has been started. If this has not been done, the butter can be colored by mixing the color with the salt. The salt should then be well distributed and worked into the butter until the body of the butter assumes a uniform color. The chief objection to this method is, that it is difficult to work in the color thoroughly without injuring the butter.

When to Stop the Churning.-Different makers have various ways of ascertaining when the churning process has been completed. Some determine the proper churning stage by the size 
of granules. Others by the height at which the butter floats in the buttermilk. Others again depend upon the appearance of the buttermilk. It is well to let all of these factors influence the operator in deciding when the churn should be stopped. Any one of these factors may not be sufficient indication to insure the proper time to stop.

The size of the granules is the most common factor that determines the time when the churn should be stopped. It has been a general rule in the past to stop the churning when the granules are a little larger than wheat-kernels. As a rule it is safer to carry the churning on a little further until the granules increase to the size of corn-kernels, irregular and flaky in shape. At this stage the buttermilk will usually appear bluish in color, and the butter is raised above the buttermilk a considerable distance. When the butter is churned to too small granules, many of them will go through the strainer into the buttermilk, and cause a considerable loss. When butter in such shape is washed in medium-cold wash-water, the granules continue to remain in a. separate state. When salt is added, the moisture is extracted from them; and the water is likely to be eaught in holes and crevices during the working and cause leaky butter. If the churning is carried on a little further, the granules will not escape into the buttermilk. The churning is more complete, and the moisture will be incorporated in a better condition.

Overchurning should be avoided as much as underchurning. If butter is overchurned in the buttermilk, it will retain a large amount of the buttermilk, which will be very difficult to remove by washing. Overchurning butter, especially at a medium-high temperature, is very effective in increasing the moisture-content of butter, and should be guarded against for that reason. Butter containing more than $16 \%$ water is not permissible on the American market.

When cream is in a poor condition it should not be overchurned, as the incorporation of buttermilk produces a very rank and unelean flavor in the butter. Cream in such condi- 
tion also contains many undesirable germs, which, when incorporated into the butter, will cause it to deteriorate to a great extent. When the cream is in poor condition, the churn should be stopped as early as is consistent with the completeness of churning. The buttermilk should be removed and the butter washed thoroughly in good clean and pure wash-water. If

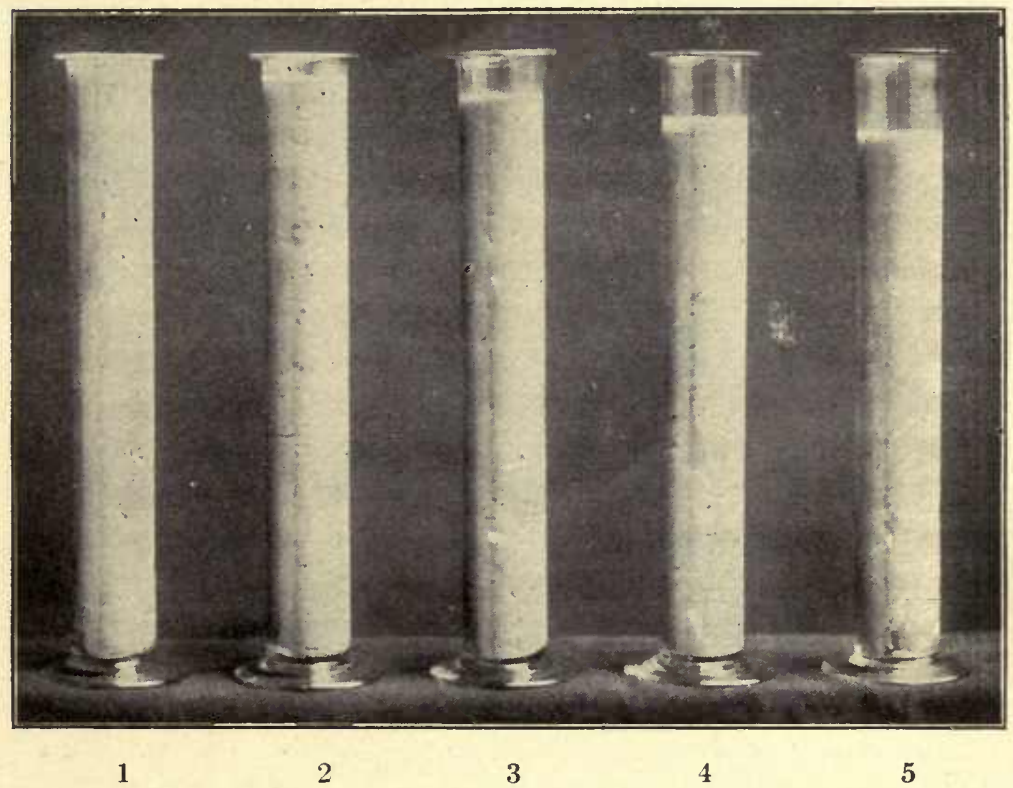

Fig. 147.-Butter from $1 \mathrm{lb}$. of fat in cylinders, showing the effect of different percentages of water upon quantity. The water-content of these samples ranges between $8 \%$ and $19 \%$.

the wash-water is added while the butter is in this granular condition, the buttermilk can be very effectively removed. If one washing is not sufficient, wash three or four times. In such a case the temperature should be low. If the temperature of the wash-water is high, and the butter is washed excessively, it will contain too much moisture when it is finished, and is likely to be salvy. By washing with water at a low temperature the butter will not incorporate so much water. What it does 


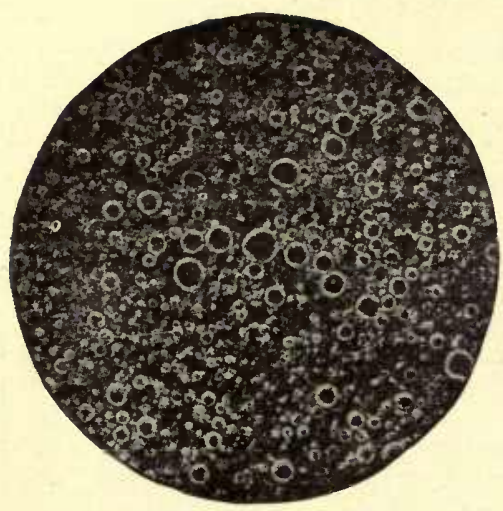

Fro. 148.-Butter sample, $15.61 \%$ water.

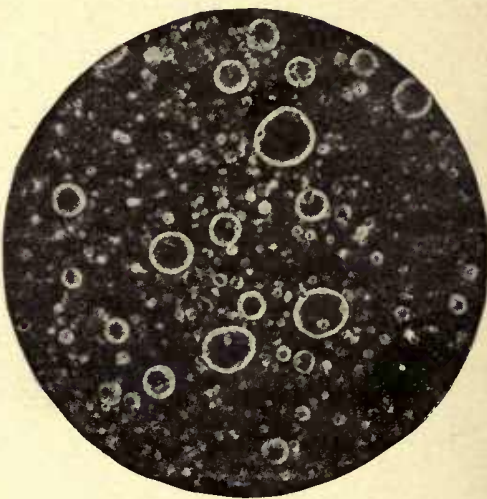

FIG. 149.-Butter sample, $15.31 \%$ water.

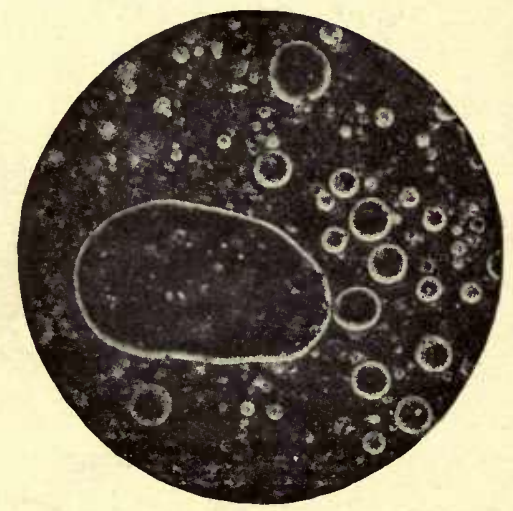

FIG. 150.-Butter sample, $13.37 \%$ water; leaky, $2 \%$ brine.

Microscopical views showing condition of water in butter. Fig. 148 shows that the water has been incorporated in the form of very minute particles. Storch found from nine million to sixteen million water particles per cubic millimeter. Such butter appears dry and a little dull. Fig. 149 shows the water incorporated in medium-small particles. There was on an average three and three-fifths millions of water particles per cubic millimeter in such butter. Fig. 150 shows condition of water in leaky butter. Storch found about two and one-half million water particles per cubic millimeter in butter having such a body. (Views by Storch.) 
incorporate in excess, will, as a rule, be expressed during the working of the butter-a result due to its firmness.

If the attempt is made to incorporate water by working the butter in water after the salt has been added, while the butter is in a hard, granular condition, it will usually appear leaky.

If cream is in a good condition, overchurning to a small extent does not produce any bad results. The germs which are present in pure and well-ripened cream are not deleterious to the keeping quality of the butter. The amount of buttermilk incorporated in the butter is not sufficient to cause any bad effects upon its quality. If the cream is in proper condition it is difficult to incorporate any more than $3 \%$ of curd into the butter. While overchurning is not to be recommended, if it is at any time desirable, it should be done in the washwater rather than in the buttermilk.

Churning Mixed, Sweet, and Sour Cream.-When two lots of cream are to be churned, one sweet and the other sour, they should be churned separately. If the two lots of cream are mixed together, the sour cream churns more quickly than the sweet cream. As a consequence the churn is likely to be stopped before the fat from the sweet cream has been completely separated from the serum.

At some of the creanieries conditions are such that the operator may be tempted to mix the two lots of cream. Where sweet cream arrives at the creamery just previous to churning time, it is advisable not to mix the sweet cream with the sour. It is, as a rule, better to carry the sweet cream over to the next churning, or, if necessary, churn it separately.

Difficult Churning.--Difficult churnings in creameries are not very common. In farm butter-making it is more frequent. Especially is this so in the fall. At this time the cows are usually well advanced in the period of lactation, and early in the winter they are often fed on food which causes hard butterfat, as described under "Effect of Food upon Fat." In the fall or early winter, a large portion of the milk is usually obtained 
from strippers, or cows almost dried up. Such milk contains a large portion of the small fat-globules. Difficult churning resulting from such conditions can usually be remedied by ripening to a higher degree of acidity and churning the cream at a higher temperature.

Complaints are occasionally heard of difficult churning which cannot be remedied by such treatment. Sometimes cream froths, and will not agitate in the churn. Such a frothy condition has in some cases been found to occur even though the cream may seem to be in an ideal condition for churning. It is believed by some, notably Hertz, that such a condition in the cream is brought about by a disease of the cow. Weigman has studied and isolated a ferment which caused a soapy condition of milk and cream. It is possible that such exceedingly difficult cases in churning may be due to a disease of the cow, and it may also be due to certain ferments that produce a soapy condition of the cream.

If thick cream at a very low temperature is put into the churn, it sometimes produces difficult churning. When such cream is first agitated in the churn it incorporates considerable air. This air, together with the various gases developed at a low temperature does not readily escape. The viscosity of it is so great that it will not release the air present. As a consequence it assumes a stiff consistency, much the same as the beaten white of an egg. If cream froths in the churn as mentioned, a little warm water thrown on the outside of the churn will often start the agitation of the cream within. If a combined churn is used the rollers may be put in gear, and the churn revolved in slow gear. This will often start the cream to agitate. If these two remedies are not sufficient, a little water, luke-warm if necessary, may be added directly to the cream. By letting the churn stand a short time, the cream will usually condense into a liquid form again, and many times the churning process can then be completed. This latter method, however, usually requires more time than can be profitably spared. If the churning difficulty is of a serious nature the remedies are: 
(1) If produced by a certain cow, or herd, find out whether it is produced by a fermentative process, or by other abnormal conditions of the cow.

(2) Change the food of the cow. A sueculent food will usually cause the cow to seerete more milk, and of a different nature.

(3) If produced by a ferment, endeavor to control the fermentation as previously described.

(4) Ripen the cream to a higher degree of acidity.

(5) Skim thicker eream and churn at a higher temperature.

The last three methods will eure most cases of diffieult churnings.

Keeping Churn Sweet.-It has been mentioned before that butter absorbs foreign odors very readily. If the churn is not kept in a pure, sweet condition, the butter will be exposed to the undesirable odors and its commercial quality will be impaired. The best butter eannot be produced in a foul-smelling churn. As churns often are not used every day, they very readily assume this impure condition, and it is essential that special eare be taken in keeping them elean.

The best method of keeping churns in good condition is to rinse the ehurn in two sets of water at the end of each churning. The first rinsing should be made with lukewarm water, the second with sealding hot water. Some piefer to turn the churn over with mouth down. Others prefer to allow the cover-hole to turn up. When the churn is turned with the cover-hole down, the remaining steam on the inside of the churn will not escape. It will condense inside of the churn, and cause the churn to remain in a damp condition over night or even longer. By turning the ehurn with the cover-hole up the dust and other impurities, if present, are likely to settle into the churn. A good way is to turn the churn over so that the cover-hole points to one side. The churn should be thoroughly drained first, otherwise some water will remain in the bottom of the churn. When the churn is left with the cover- 
hole at one side, the steam ean escape, and the heat absorbed from the wash-water will dry the churn thoroughly. Many makers rinse the churn only once and use scalding hot water. This method is likely to scald the remaining eurd on to the wood; secondly, one rinsing is not enough to insure a clean churn. The first rinsing with lukewarm water removes the major portion of the buttermilk and brine, and to a certain extent warms the wood of the churn, so that when the second rinsing with scalcling hot water is completed, the churn has been thoroughly scalded. In addition, the churn is clean, and no food left, on which for germs to thrive. The churn is also left warm, and in that condition will dry quickly.

Some makers prefer to keep the churn in a good condition by sprinkling salt on the inside after washing. This is not to be recommended, as all churns contain more or less iron-ware on the inside. Salt, while a good germicide, causes the formation of rust on all iron with which it comes in contact. After a time this rust will scale off to a certain extent and become incorporated with the butter.

If the churn is treated daily in the manner described above and then at the end of the week treated with slacked lime, the churn can be kept in a good sweet condition. The lime should be freshly slacked and in a liquid condition when put in the churn. A pailful or two of this fluid will be sufficient for each churn. By rotating the churn a few times the lime will be spread all over the inside of the churn. Let the churn remain in this condition until ready for use again. When ready for use, put in some warm water, and the lime will readily come off. But if it has been allowed to remain in the churn too long, it will form a lime carbonate, and will be more difficult to remove.

Lime is one of the best disinfectants and deodorizers that can be used in a creamery. Some of the best butter-makers use it every day on all the wooden utensils, such as on butterworkers, churns, etc. Lime can be used more advantageously 
in American creameries than it is to-day. Many creameries would be in a much sweeter and purer condition if they were given a good coat of whitewash on the inside once a month. Refrigerators, wooden utensils, and rooms of any kind can be kept in a good sweet and pure condition by whitewashing or sprinkling a little lime on them.

\section{Washing of Butter.}

Purpose of Washing.-The chief object of washing butter is to remove as much buttermilk as possible. The more impure the cream is, the greater is the importance of getting the butter thoroughly washed. In the winter, when it is cold, and the cream is in good condition, some makers do not wash the butter at all. But this is not a safe method. The removal of the buttermilk constituents should be as complete as conditions will permit.

Temperature of Wash-water.-The temperature of washwater should be as nearly like that of the cream when churned as is consistent with the other conditions. Extreme and rapid changes in temperature should always be avoided. Occasionally it is necessary to use water that is colder than the cream. At other times it is necessary to use wash-water at a higher temperature than that of the cream. If the butter churns soft, do not use ice-cold wash-water to chill the butter, as it has a tendency to give butter a tallowy appearance. Neither should hard butter be quickly softened by using wash-water at a very high temperature, as it is likely to cause the butter to assume a greasy and slushy texture. If it is necessary to change the degree of hardness of the butter, change it gradually by using water at a moderate temperature and allowing the butter to be in contact with it a longer time without agitating it much.

Unless the butter is of very poor quality, excessive washing should be avoided. Cold water is said to absorb a considerable portion of the flavoring substances. If the quality of the butter is poor, many of the undesirable flavors and odors are re- 
moved by excessive washing; while if the butter has a fine, rich flavor, it should be retained, and not extracted by washing the butter more than is needed. No definite temperature can be given, as the temperature of wash-water must vary according to the hardness of the butter when churned.

If the temperature of the wash-water is too high, and the churning in the wash-water is continued a very long time, much water will be incorporated in the butter. If the butter is quite firm in the first place, and the temperature of the wash-water is not above $60^{\circ} \mathrm{F}$., there is not much danger of getting too much water in the butter. Rapid changes in the degree of hardness of the butter in the presence of water are conducive to a high moisture-content. Very soft butter chilled in very cold water, and hard butter softened in very warm wash-water are two conditions which should be avoided.

Kind of Wash-water to Use.-In the washing of butter, it is very essential that water used should be the best obtainable. The creamery water-supply is evidently much better now than it was years ago. Pond-wells and shallow wells are gradually passing out of existence, but there are yet many shallow wells from which water is drawn for creamery purposes. Water from wells may appear to be pure, and yet contain germs which are deleterious to dairy products, and especially to the keeping quality of butter. That water of average purity contains such germs has been demonstrated in this country, as well as in foreign countries. Shallow well-water contains on an average about 15,000 germs per cubic centimeter, but Miquel has found that a rapid power of multiplication characterizes the bacteria in pure spring-water, while in impure water the multiplication is slower. Water containing only this many germs is, as a rule, considered very pure. Most creameries, however, pump their water into a tank overhead in the creamery, where it is contaminated with bacteria and impurities of different kinds.

Shallow wells are usually surrounded with conditions which do not guarantee a creamery pure water during the different 
seasons of the year. In the spring, when rains are frequent and heavy, unwholesome surface-water is likely to seep in through the sides. Such wells may also serve as traps for small animals. The presence of an animal in the well is sure

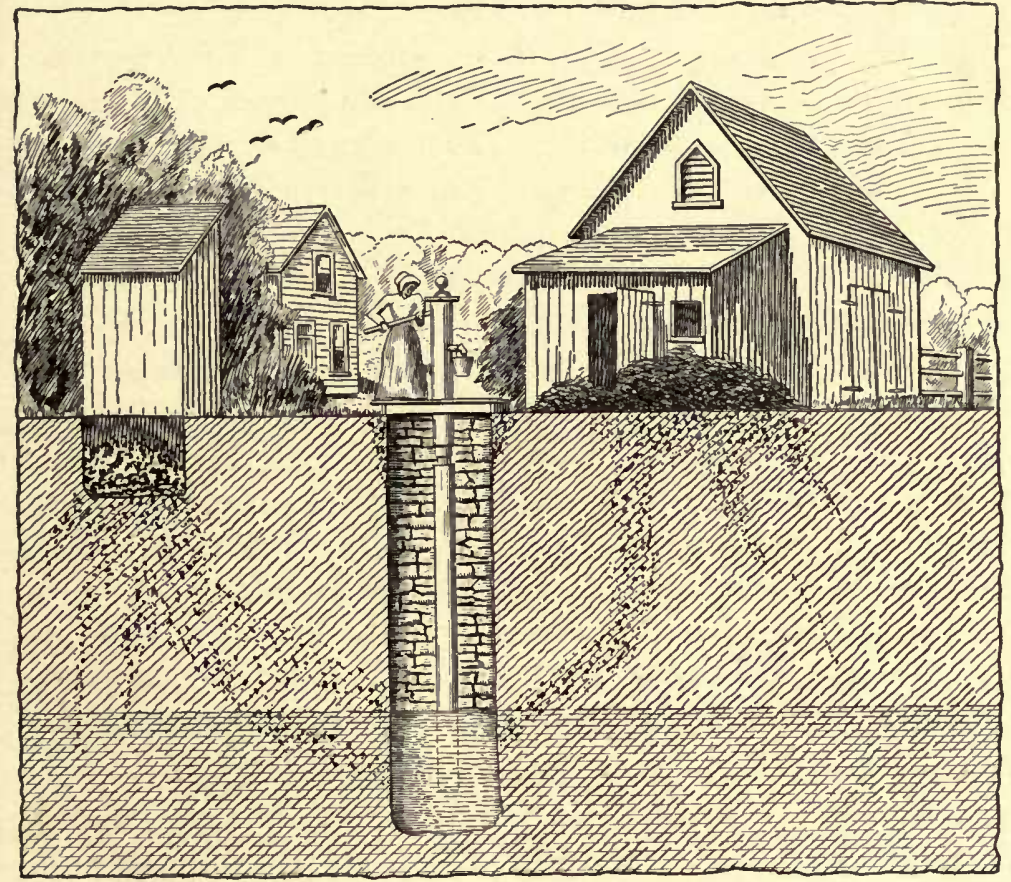

Fic. 151.-The shallow barnyard well with privy-vault and manure heaps near by. The water is likely to be contaminated from these any time. (Farmer's Bul. No. 43, U. S. Dept. of Agriculture.)

to cause undesirable odors and a multitude of undesirable and putrefactive organisms.

Water from deeply drilled wells, even if it is pure in so far as its germ-content is concerned, is in many cases turbid and sandy, and needs to go through a process of purification as much as does the shallow well-water. 


\section{Methods of Purifying Wash-water.}

There are two practical and effective methods of purifying wash-water, viz., (1) Filtration, and (2) Pasteurization. Which of these two methods is the most practicable and the most effective in the creamery depends upon the conditions and upon the quality of the water. In the case of water from deep wells, which contains little or no organic matter, but at the same time is infested with undesirable germs, pasteurization is perhaps more expedient. Filtration, if the same degree of thoroughness is to be reached as in pasteurization, is a comparatively slow process. Pasteurization of wash-water is a trifle more expensive than filtration. Wash-water can be pasteurized at the same time that the churning is being done, thus economizing in time and fuel. Pasteurization is quite effective in rendering the water germ-free, but it is not so effective in removing any organic matter or other tangible impurities which may be present. If the creamery does not already have a pasteurizer, filtration can be employed very profitably, and under average conditions it will perhaps give the best results.

Filtration.-Filtration is inexpensive, and is a very efficient method of purifying wash-water. It seems strange that bacteria can be removed from water by passing through layers of sand, gravel, coke, and charcoal, but such is the case. Filtration is applicable to all kinds of water; even if the water appears pure, it is well to filter it. Fewer germs and fewer varieties of micro-organisms are apparently found in deep well-water than is the case in water from surface-wells; hence the ferments which are present will have a free field for developing in the absence of competing forms. If a sample of water which is rich in micro-organisms is violently shaken with a certain amount of charcoal, coke, chalk, or similar substances, and then left for a time to settle, the pure layer of water at the top will be almost entirely free from germs, and in some cases entirely 
sterile. It used to be thought by older German investigators that these different filtering substances had almost miraculous power of removing organisms from water.

The factors which are to be considered in successful filtration are:

(1) Storage capacity for unfiltered water.

(2) Construction of filter-beds.

(3) Rate of filtration.

(4) Renewal of filter-beds.

(1) Concerning the storage capacity, nearly all creameries have storage-tanks overhead in the creamery; so far as that is concerned, however, filtration can be successfully carried on continuously as well as intermittently.

(2) The construction of the filter-bed used in the experiment earried on at the Iowa Experiment Station, Ames, Iowa, is as shown in Fig. 153. The approximate proportionate depth of each layer in the bed is as follows, beginning at the bottom:

Two inches small flint stones; 22 inches fine sand; 12 inches fine coke; 9 inches charcoal; 2 inches fine stone or coarse gravel. The layer of fine sand should not be less than 15 inches. It has been asserted that a few pieces of old iron mixed in the filter-bed are beneficial. Alum, lime, and copperas have been recommended for clarifying and deodorizing very impure water. As these substances are soluble they should not be used in filter-beds, which are intended for the filtration of water for potable purposes. The filtering-can was made from 22 galvanized iron. The height of can is 48 inches; diameter, 18 inches. The bottom of the can is slanting towards the faucet, or opening. Thus no water is permitted to stand on the bottom and afford opportunities for germs to accumulate. On the inside are three plates. One lies horizontally, near the bottom, and upon it the filtering-material rests. Another lies on the top of the fine sand. Both of these plates were perforated with many small holes. Near the top is placed a concave plate with a hole near the center. This plate directs 
all the water to the center of the filter-bed, and thus the water gets the full benefit of the filtering process. The total cost of this filtering-can when complete was $\$ 11.11$.

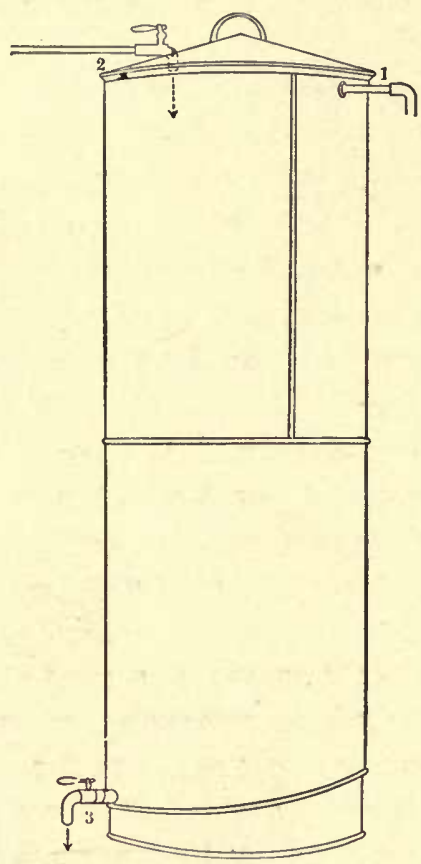

Fig. 152.

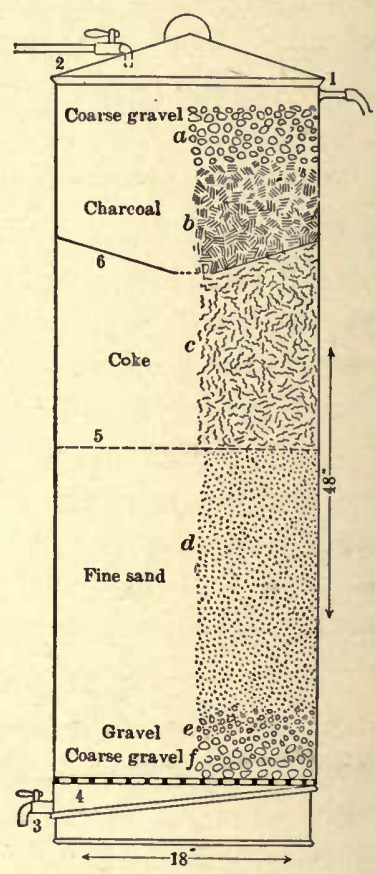

Fig. 153.

Fig. 152.-Filter-can: 1, overflow; 2, inlet of tap-water; 3, outlet of filtered water.

FIG. 153.-Cross-section of filter-bed and ean: 1, overflow; 2 , inlet; 3 , outlet of filtered water; 4 , perforated galvanized-iron plate; 5 , perforated galvanized-iron plate; 6 , concave galvanized-iron plate with hole in center.

(3) The rate of filtration is necessarily governed by the depth of the filter-bed, the character of the material used, and its fineness. The water passes through the charcoal, coke, and gravel quite rapidly, yet the substances are very strong barriers to the passage of micro-organisms. The sand layer does not admit of so rapid filtration. Fine sand, however, is one of the best filtering substances that can be had. The rate of filtration can be regulated by increasing or decreasing the 
depth of the fine-sand layer. In a general way, the slower the rate of filtration is, the more thorough it is; and, vice versa, the more rapid the rate of filtration, the more incomplete is the removal of the bacteria. If the filter-bed is constructed as described above, the rate of filtration will be about 18 gallons per hour, and about $96 \%$ of all the germs present will be removed, together with the impurities present in suspension.

(4) The filter used at the Iowa Experiment Station was in constant use for about three months, without having been changed. At the end of this time it did as efficient work as at any previous time. The length of time a filter-bed can be used. without being changed depends upon the purity of the water to be filtered, and also upon which kind of filtration is used, the continuous or the intermittent. The more impure the water which has to be filtered, the oftener the filter-bed should be changed. Whenever the rate of filtration is decreased to such an extent as to make the process impracticable, the filter-bed should be taken out and cleaned. If the water to be filtered is of average purity, a change of the filtering-material once every four months is ordinarily sufficient, no matter whether continuous or intermittent filtration is used. A filter-bed may do efficient work even a longer time than this. The same filtering-material can be used again providing it is thoroughly washed previous to replacing it in the filtering-can.

Kinds of Filtration.- The two kinds of filtration in use are (1) Continuous, and (2) Intermittent.

By the continuous method of filtration the inflow of water into the can is constant during night and day. The stream of water admitted into the filter-can is sufficient to cause the surface of the filter-bed to be covered with water all the time. This method excludes all oxygen from the filter-bed, except that which is in solution in the water.

During the process of filtration a slimy coat is deposited on the fine sand. This seems to be the real agent absolutely necessary in order to eliminate bacteria by a process of filtration. A filter-bed without this slimy deposit on it simply takes 
out the coarse organic and inorganic matter held in suspension, without removing the bacteria. If some bacteria are removed with the matter held in suspension, others are carried along from the filter-bed. Owing to this, a new filter-bed must be kept in operation a few days before the filtered water can be considered pure and ready for use. The following table illustrates how the germ-content of water is decreased as the process of filtration is carried on during the first few days:

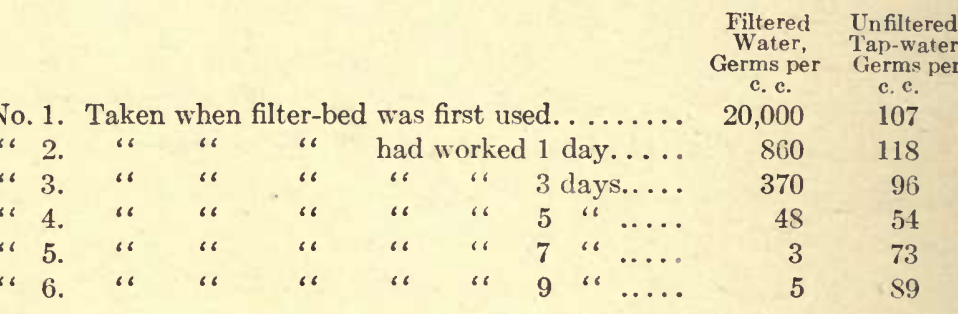

It will be seen from the table that during the first three days the filter-bed was in use the filtered water contained more germs than the unfiltered. Good results were not obtained until the seventh day. In order to be on the safe side it is best to expose the filter-bed to continuous filtration for about nine days before the water is used.

The slimy coat referred to above is formed by certain germs. These germs then constitute the real agent of filtration. In order for these micro-organisms to do efficient work oxygen is essential. Well-water of average purity contains enough oxygen in solution without employing an intermittent process of filtration, and consequently for creamery purposes the continuous method of filtration is to be recommended.

Intermittent.-The intermittent process of filtration is used where conparatively impure water is being purified, such as in purifying water for large cities. If the continuous process of filtration were employed in such instances, the filtered water would not be free from germs, due to the fact that impure river-water does not carry enough oxygen in solution to supply the germs which form the real filtering agency. 
If the intermittent process is used, the first water filtered after the intervening period should not be used. During the intermission, or during the time that the water is shut off, germs develop and come through the filter-bed with the water that is filtered.

Advantages of Purifying Wash-water for Butter.-The chief advantage of purifying wash-water for butter is that the keeping quality of the butter is improved, and if the proper skill and care have been applied in the other steps of manufacture, a pure sanitary product is obtained. The sanitary efficiency reached by purifying the wash-water constitutes no small consideration. Germs producing contagious diseases are thus checked from spreading. 


\section{CHAPTER XVII.}

SALTING AND WORKING OF BUTTER.

Objects of Salting.-The chief objects of salting are: (1) to impart a desirable flavor; (2) to increase the keeping quality of butter; and (3) to facilitate the removal of buttermilk.

Amount of Salt to Use to Produce Proper Flavor.-The proper amount of salt to use in order to impart a desirable flavor depends chiefly upon the market. Some consumers prefer a medium high salt-content in butter; others, again, like butter which contains very little salt. The English market demands rather light-salted butter. In fact, this is the case with practically all European markets. American markets, as a rule, demand comparatively high-salted butter, as much as will properly dissolve in the butter. Parisian markets and some markets in southern Germany require no salt in it at all. The salt-content of butter may vary between nothing and $4 \%$. Butter containing as much as $4 \%$ salt is, as a rule, too highly salted. When it contains this much salt, part of the salt is usually present in an undissolved condition. Those who like good butter prefer butter that contains the salt thoroughly dissolved and well distributed.

The amount of salt to be added should be based upon the least variable factor. Some creamerymen measure the amount of salt according to the amount of cream in the churn. While the box-churn and Mason butter-worker were being used, many makers preferred to weigh the butter as it was transferred from the churn to the worker. The method mostly in use now, and to be recommended, is to base the amount of salt upon the number of pounds of fat. The amount of salt to use per pound of fat 
varies, therefore, according to the conditions mentioned below, and also according to local conditions. Usually from half an ounce to one and a half ounces of salt per pound of butterfat is most suitable. In whole-milk creameries the salt is of ten estimated per hundredweight or per thousand pounds of milk.

To get the butter salted uniformly from day to day is very important, as a small variation in the salt-content has a greater effect upon the quality of butter than has a small variation in any of the other butter constituents. A variation of $1 \%$ to $2 \%$ in the salt-content can very easily be detected by the consumer, while that much variation in any one of the other constituents could not be readily noticed.

The conditions upon which the proper amount of salt depend are: First, the amount and condition of moisture in the butter at the time the salt is added. If there is a great deal of loose moisture. in the butter, more salt is necessary. This is due to the fact that the salt will go into solution in the water and be expressed during working. Secondly, it depends upon the amount of working the butter receives, and at what time the bulk of working is done, after the salt has been added. If the butter is medium firm, moisture in the form of brine is being expressed during the working. Consequently, the more butter is worked, up to a certain limit, the more brine is being expressed, and the more salt should be added to the butter. Thirdly, the amount of salt to add depends also upon the size of the butter granules at the time the salt is being added, and the hardness and softness of the butter. If the granules are very small and quite hard, they take salt with difficulty. The salt attracts also more moisture from these small granules than from larger ones, which will escape in the form of brine. If the butter is present in a rather soft, lumpy condition at the time the salt is added, and there is no water in the churn, very little salt is wasted in the form of brine, consequently less salt is necessary in the first place.

It is undoubtedly due to these facts that the salt-content 
and the condition of salt in butter vary so much at the different creameries; they even vary considerably from one churning to another at the same creamery. If conditions are uniform in the creamery from day to day, the amount of salt to add to butter, and the amount of salt retained in the butter when finished, will be comparatively uniform.

It should be mentioned in this connection that butter made from very good eream should not be salted too heavily. Butter made from a rather poor quality of cream may be salted correspondingly heavier. This is due to the fact that the heavy salty taste covers some of the undesirable flavors in the butter. If the butter-flavors are good, they should not be hidden by a heavy salty taste. If the butter-flavors are poor, then it may be policy to partially cover them up with a medium-heavy salty flavor.

Effects of Salt upon Keeping Properties.-That salt is antisept.c is no longer a doubt. It has been domonstrated in laboratory work with butter that the growth of certain germs, isolated from butter, can be completely checked by the add:tion of a certain amount of salt to the medium in which they are inoculated. Bouska * found that a yeast isolated from butter showed luxuriant growth in a medium containing $2 \%$ of salt in forty-eight hours, and only a trace in $4 \%$ of salt. The same germ showed only a trace of growth in a $6 \%$ salt medium after five days.

The ordinary bread-mould, Penicillium glaucum, was isolated from butter and showed noticeable growth in a $9 \%$ salt medium in two days, and only a trace in a $10 \%$ solution during the same time. A spore-bearing bacillus isolated from butter produced only a trace of growth in a $4 \%$ salt medium. No growth occurred at all in a medium containing $6 \%$ of salt. Another gas-producing organism was also isolated from butter and only a weakened growth was produced in a medium containing $4 \%$ of salt.

* Iowa Ex. Sta., Bul. 80. 
If it were practicable and consistent with the demand of the consumers, so far as the keeping properties of butter is concerned, it would be advisable to salt butter as highly as $6 \%$. This much salt would tend to a large extent to check deterioration of the butter due to bacterial growth.

That salt promotes the keeping quality of butter has also been demonstrated in a practical way during the Iowa Educational Contest in 1903. Fifty samples of butter containing $2 \frac{1}{2} \%$ or more of salt were scored off in New York, on an average, 2.38 points, while the remaining 171 samples containing less than $2 \frac{1}{2} \%$ salt were scored off 3.54 points on an average; a difference in favor of the keeping quality of high-salted butter of 1.16 points. Most American markets demand a salt-content of about $2 \frac{1}{2} \%$ in the finished product.

Salt Facilitates the Removal of Buttermilk.-That salt facilitates the removal of buttermilk can easily be demonstrated by observing the escape of buttermilk from the butter immediately after the salt has been added and mixed with the butter. The first effect of salt when added to the butter is to precipitate the curd in the buttermilk. This precipitation is greater when a large amount of salt is added than when only a small amount is added. The precipitation of the casein in the buttermilk sets free the remainder of the buttermilk constituents; that is, when the casein is precipitated, the whey part assumes a more fluid condition and escapes, and the butter retains a portion of the curd. Owing to this action of the salt, it is essential that the butter should be as completely washed as possible, as otherwise it will retain an excessive amount of curd. The butter acts in a manner somewhat similar to a filter in removing a part of the curd from the other buttermilk constituents.

Salt in Relation to Water in Butter.-Experiment has demonstrated that pure fat is not a salt-dissolving substance. Owing to this fact the only salt-dissolving substance in butter is water. As water will hold only a certain amount of salt in solution, it becomes evident that the amount of salt which 
can be properly incorporated in butter depends upon the amount of moisture present.

The amount of salt which water will ho'd in solution at different temperatures varies somewhat according to different investigators. According to Gerlach* water will dissolve $35.94 \%$ salt at $58^{\circ} \mathrm{F}$. This is approximately the temperature at which salt is worked into butter. Theoretically, butter containing $15 \%$ of water should be able to properly dissolve $5.4 \%$ of salt. Butter containing $13 \%$ of water should be able

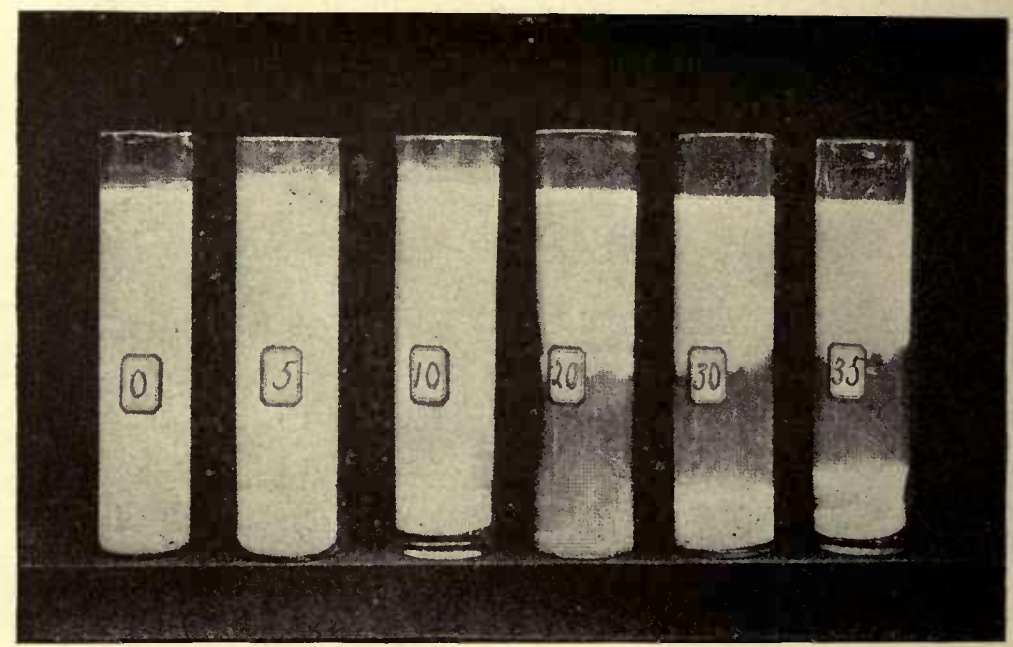

Fig. 154.-Action of salt solutions of different strength on the proteids of buttermilk. (Bul. 263, Gen., N. Y.)

to properly dissolve $4.68 \%$ of salt, and butter containing $10 \%$ of water should be able to dissolve properly $3.6 \%$ of salt, etc. According to experiments conducted at the Iowa Experiment Station the maximum per cent of pure salt $(\mathrm{NaCl})$ that could be properly dissolved in water of butter containing $16.92 \%$ of moisture, when worked 18 revolutions at intervals during two hours, was $16.57 \%$. When butter was worked the same number of revolutions at intervals, and was allowed to dissolve

* Kemiker-Kalender, p. 219. 
only one hour, the amount of pure salt $(\mathrm{NaCl})$ that was dissolved in the water of the butter containing $11.58 \%$ moisture was $14.09 \%$. This undoubtedly will vary with different brands of salt.

It will thus be seen that the property of water to take up salt is seemingly lessened when the water is present in a state of minute division, as it is in butter. In the first instance quoted the butter completely dissolved about $2.7 \%$ of pure

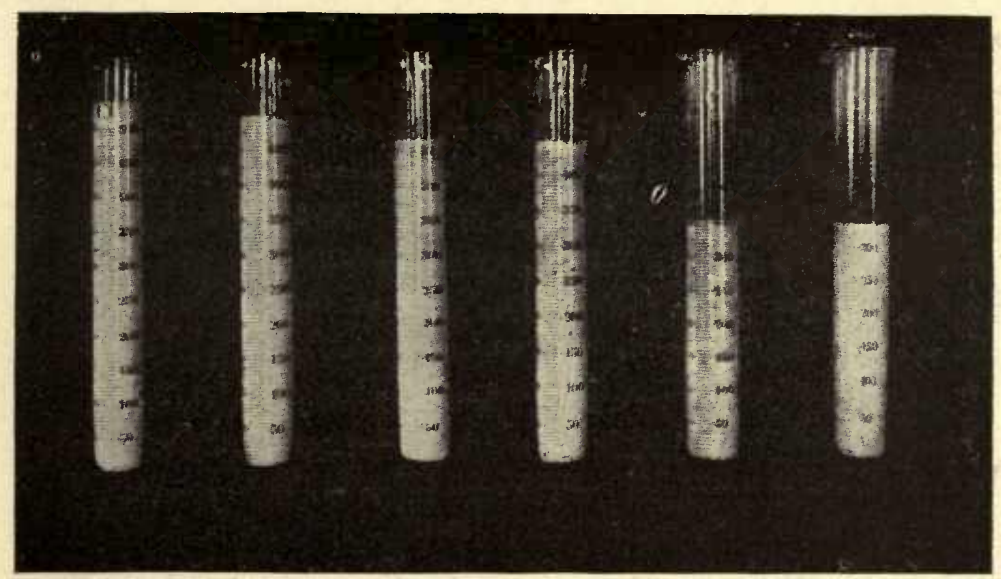

FIG. 155.-Volumes of the same weight of salt of various brands. (Bul. 74, Wis.)

salt; and in the second instance it dissolved only about $2 \%$ during one hour.

Condition of Salt when Added.-The condition of salt when added is a very important question to consider in order to get enough salt properly incorporated. The amount of influence which the quality of the salt has upon flavor has recently been a subject of attractive interest, for many of our best butterjudges have made the charge that certain undesirable flavors in butter can be traced to the use of a poor quality of salt. This assumed effect upon the quality of the butter can only be remedied by stopping the use of impure salt. The chief undesirable and impure constituent present in salt is magne- 
sium chloride. It is known positively that the presence of this substance in salt, even to a small extent, imparts a bitter flavor to butter. Salt containing a large amount of this and other impurities also absorbs moisture from the air more readily than does pure salt. According * to analysis of the best dairy salt in use in Denmark, the composition is as follows:

Pure salt. . ............... 97.49

Magnesium chloride................ . 18

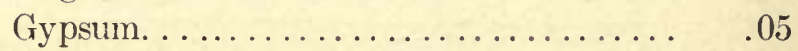

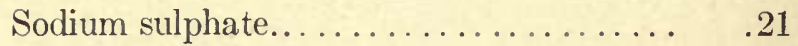

Water................... 2.07

100.00

The purest American dairy salt has the following composition: $†$

Pure salt $(\mathrm{NaCl}) \ldots \ldots \ldots \ldots \ldots \ldots \ldots . . \ldots 9.18$

Magnesium chloride $\left(\mathrm{MgCl}_{2}\right) \ldots \ldots \ldots \ldots . \quad .05$

Gypsum (calcium sulphate, $\left.\mathrm{CaSO}_{4}\right) \ldots \ldots \ldots . \quad .54$

Calcium chloride $\left(\mathrm{CaCl}_{2}\right) \ldots \ldots \ldots \ldots \ldots \ldots . .19$

Insoluble matter................. $\quad .03$

Moisture.................. .01

100.00

In order to judge the quality of salt the butter-maker cannot rely on the chemical analysis for a detection of impurities, but must judge the quality from its appearance, flavor, and odor. Good dairy salt does not have a dark-bluish, coarse, granulated appearance, but a clean, white, silky look, and should dissolve quickly. Salt should be kept in a clean dry place free from odor. 
Gritty Butter.- "Gritty butter" is a familiar phrase used by expert butter-scorers to indicate that part of the salt is present in an undissolved condition. To most consumers this condition of the salt in butter is objectionable. When properly incorporated, salt should be present in the form of a solution in the butter. The gritty condition of the salt in butter may be due to (1) poor condition of the salt before it is added to the butter; (2) adcling so much salt that it cannot be dissolved by the water in the butter. The maximum amount of salt that butter will dissolve depends upon the amount of moisture present. The maximum amount of moisture permissible in butter, as limited by law, is $16 \%$. The condition of the water in butter prevents the water from being saturated with salt during the comparatively short time allowed for salt to dissolve during the manufacture of butter. (3) Insufficient working. If the butter is not worked enough to distribute the salt evenly, some portion of the butter will contain more than the other portions. The portion that contains the excess of salt does not have enough moisture to dissolve the salt; while if the salt hat been evenly distributed in the butter, all the salt would have been properly dissolved. When gritty butter is caused by insufficient working, it usually mottles.

Mottled Butter.-Mottled butter is butter which is uneven in color. This unevenness in color may be due to several different causes. It may be due to specks of curd (speckled butter), and it may be due to certain organisms (dappled butter). These causes of mottled butter are not very common in factories where the manufacture of butter is properly carried on.

The most common fault of mottled butter is the improper incorporation of salt and the presence of an excessive amount of buttermilk. Mottled butter caused in this way is common. It would be of much commercial importance if it were possible to prevent its occurrence. In case all the water had been saturated with salt, and there is still undissolved salt left, then the granular or undissolved salt will cause no 
mottles. The most important thing to observe in urder to prevent mottles is: (1) to have the buttermilk well washed out; (2) to have the salt thoroughly dissolved; and (3) to have the brine properly distributed.

Recent work by Drs. Van Slyke and Hart show that if the proteids are thoroughly washed from the butter, mottles cannot be produced, no matter how unevenly the salt is distributed. Complete removal of the buttermilk by washing is one of the essentials in order to prevent mottles in butter.

The mottles caused by improper incorporation of salt assume two different forms, viz., mottles proper, and wary butter. As has been mentioned before, the mottles result from undissolved salt. Whenever there is undissolved granular salt present, the moisture is attracted and the color deepened at that particular place. In case the water has alrearly been saturated with salt, there is no danger of mottles, no matter how much gritty salt is present.

Wavy butter is caused by an uneven distribution of the brine. If a little salt is added to the butter and dissolved without working the butter sufficiently, the salt will go into solution in certain portions of the water. This water containing the greatest amount of salt will produce a high color in certain portions of the butter, while the portion containing water with less salt will have a lighter color, thus causing streaks in the butter.

In case butter has become mottled on standing, the mottles can be entirely eradicated by reworking the butter. Though some of the moisture is lost during this reworking process, it is usually advisable to rework the butter rather than to place it on the market in a badly mottled condition. The mottles should, however, be prevented rather than cured. This can be done by sufficient working while the butter is in proper condition, and at the proper time.

Brine-salting.--Brine-salting is not as a rule practiced in creameries. It is too expensive a method of salting, and also too laborious. By salting butter with brine it is hardly possible 
to get in salt enough to suit the American butter markets, $2 \%$ being about the maximum amount of salt that can be incorporated by the brine method.

In some instances, brine-salting has been recommended. If a light mild taste is desired, the brine method may give good results. The greatest advantages of brine-salting are that mottles in butter are practically avoided, and that the overrun is usually increased a trifle. Especially is this so if the temperature of the brine is medium high when added to the butter. In order to get enough sait $(2 \%)$ into the butter by the brine method, it is necessary to churn it considerably in the brine and to use two sets of brine. When brine is first added the butter already contains considerable water. This water practically has to be replaced by brine. This is difficult to do, especially if the butter has been overchurned a trifle.

By churning the butter in the first set of brine, the brine will soon become diluted to such an extent that it will impart but little saltiness to the butter. For this reason this first set of brine should be removed and another one added. Then churn again in this brine. This last set of brine will have very little curd in it, and can be saved until the following day and then used as the first set of brine. This first set of brine may be used each day for soaking tubs.

It is essential to leave the brine on the butter for from five to fifteen minutes. Churning excessively in the brine, especially if butter is medium soft, will cause too much water to be incorporated in the butter. After the butter has been exposed to the second set of brine the proper length of time, it should be drawn off and the butter worked in the usual manner. Less working is usually given to butter which has been salted by the brine method. It should be worked enough to distribute the brine evenly in the butter, and to bring the butter into a compact form. If the butter salted by the brine method is not worked sufficiently, it will after standing become streaky in color. 


\section{WORKING OF BUTTER.}

Objects.-The objects of working butter are:

(1) To distribute the salt and brine evenly in the butter. The number of revolutions in the churn necessary to accomplish this will vary somewhat according to the conditions of the butter, and according to the kind of butter-workers employed. If the butter is of medium firmness, about 12 rerolutions in the Victor Combined Churn will usually distribute the salt properly, providing the working is well distributed over the working period. It used to be, and is still, the practice in creameries to add the salt while the butter is in a hard granular condition, and then rotate the churn several times in slow gear without putting the workers in gear. This is done in order to mix the salt thoroughly without working. Then it is allowed to stand for five or ten minutes, then worked about four revolutions and allowed to stand a little while again, then the working is completed by allowing the churn to revolve four or five times more, or as many as is deemed recessary to bring the butter into proper condition.

It has, however, been demonstrated that it is not advisable to add the salt while, the butter is in this hard granular form. The butter should be united into larger irregular granules before the salt is added. If the salt is added to the butter in a more or less gathered condition, then the workers should be put in gear at once, for otherwise the salt will be scattered on the inside of the churn. Butter can be worked three or four revolutions and then allowed to stand until the salt is almost dissolved, at which time the working can be completed by revolving the churn four or five revolutions more. Some prefer to work a little more than ten revolutions in order to be sure that the salt has been evenly distributed.

If the Disbrow churn is being used, it is necessary to work the butter a greater numbar of revolutions than that recommended when the Victor churn is used. In the Victor churn 
the butter is virtually worked twice at every revolution, while in the Disbrow churn the butter is only worked once for about threa-quarters of a revolution. From sixteen to twenty revolutions of the Disbrow churn usually mixes the salt with the butter properly. It is impossible to state exactly the number of revolutions butter should be worked, as it varies according to different conditions.

(2) Working the butter is done in order to bring it into a compact form. When butter is soft it usually gathers, but

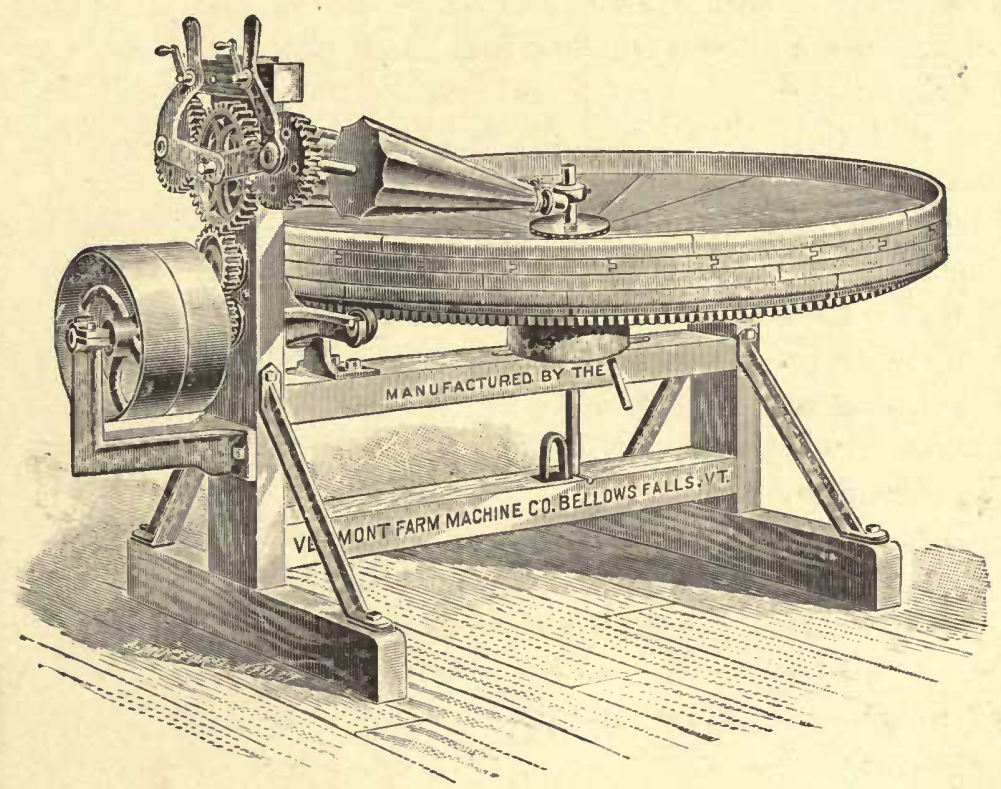

Fig. 156.-The table butter-worker.

if it is present in the firm granular condition, which condition results from churning thin cream and washing the butter in cold water, it is more or less difficult to get the little granules together. More working is necessary when the butter is in such a condition.

(3) The working of butter is also done in order to express an excessive amount of buttermilk or water. By adding sait 
and then working the butter, the excess of buttermilk is largely eliminated. Especially is this so when the butter is in a medium firm condition. Working is also effective in removing water from the butter.

In the manufacture of process butter, excessive working while the butter is in a firm condition is now resorted to. Before the national law, which limits the moisture content of butter to $16 \%$, went into effect, process butter usually contained more than $16 \%$ water; but now the moisture-content of this kind of butter is largely controlled by working it in the absence of water while it is in a firm condition. 


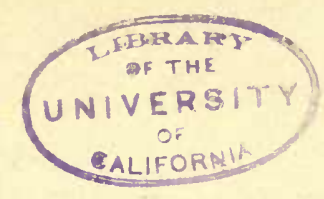

CHAPTER XVIII.

PACKING AND MARKETING BUTTER.

Kind of Package to Use.-For creamery purposes the 60pound ash tubs are customarily used. The package, of course, varies according to different markets. In case that butter is made on a small scale, such as on the farm, earthen crocks give good satisfaction. There is no other package that gives so good results as the earthen jars, when viewed from a standpoint of good keeping quality of the butter. The objection to earthen jars or crocks is that they are heavy and easily broken during transportation. It is undoubtedly on this account that earthenware is not used more for the packing of butter.

There are two kinds of tubs chiefly used in creameries, viz., the ash tub, and the spruce tubs. These tubs are made in different sizes, 10-lb., 20-lb., 30-lb., and 60-lb. The 60-lb. ash tub is used nearly altogether in creameries that pack butter on a large scale. When smaller amounts of butter are being packed, usually the smaller spruce tubs are employed. Square boxes are used also to some extent. They are used more in some of the Eastern States, but very little in the West and Central West.

During the fall and winter when the milk-supply is rather low, many creameries print all the butter. Most of the commission firms will pay about a cent more per pound for butter when it is put up in pound prints and wrapped neatly in parchment paper. The wrapper should bear the name of the manufacturer or the name of the creamery. If the quality of the 


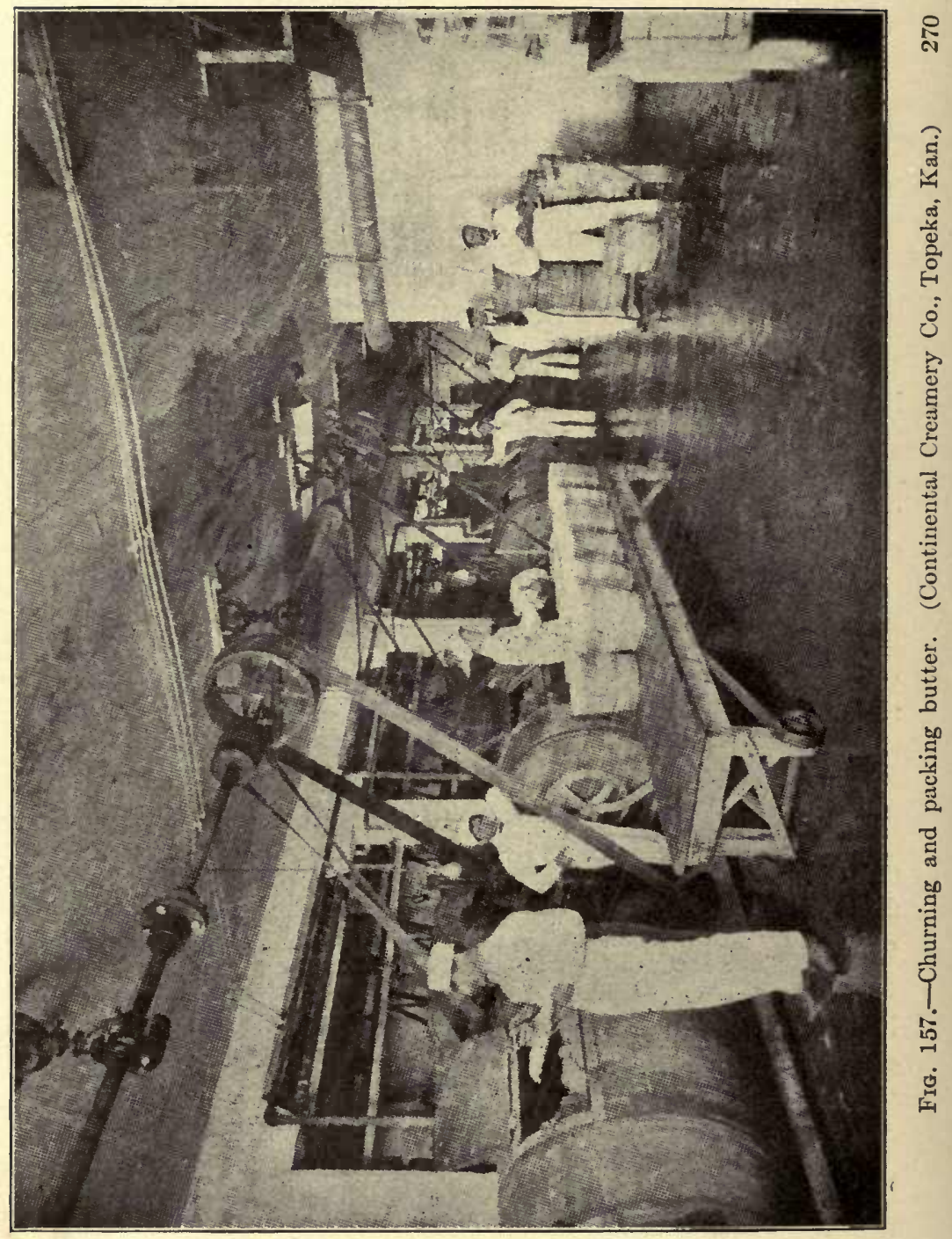


butter is good, it will take but a short time for the consuners to become familiar with that particular brand. It is essential, however, to consider the cost of printing the butter and the losses in printing. Some little waste of butter accompanies the printing process. Besides this, if the butter is firm, as it usually is in order to have the prints assume the proper shape, there is a loss of some moisture.

Preparation of Tubs.-If tubs are stored in a damp room, they are likely to mould in a short time. Occasionally tubs are in a mouldy condition when they come from the factory or creamery supply-house. The mould that forms on the inside of the tub when standing in a damp place is very conspicuous. In many instances the tubs are also cracked. This is due chiefly to the tubs becoming dry, and in some instances is due to the use of imperfect material in the manufacture of the tub. Butter-tubs should not be made from damp, unseasoned, and partly decayed wood, as they are likely to impart to the butter more of the woody odors than do those made from sound, well-matured wood.

In order to kill all the moulds which may be present in the tub, and to close the cracks, so as to make the tub practically air-tight, it is essential that the tub should undergo some process of preparation before the butter is packed into it. There is a single substance which will destroy the germs, moulds, and also close smaller openings in the tubs, viz., a saturated solution of brine. As a rule this gives good results. The day previous to the packing of the butter, the tubs should be filled with saturated brine, and allowed to stand and soak until the following day. The paper-linings and circles should also be soaked in the same brine before they are used. It is a good plan to have the brine lukewarm, although cold brine will answer the purpose. Just previous to using, pour out the brine, wash the tubs thoroughly, then scald them, by putting them into scaldinghot water or over a steam-jet. Cool off the tubs by filling them with cold water; when cooled, pour out the water, line them, and they are ready for use. The covers should be on while they 
are soaking. This prevents the tubs from warping and getting out of shape.

By soaking the tubs in brine and scalding as above, if thoroughly done, there is little danger of getting moulds in the butter. Some recommend the soaking of the tubs in brine only, without scalding; others recommend the scalding without soaking in brine. The chicf difficulty with scalding the tubs

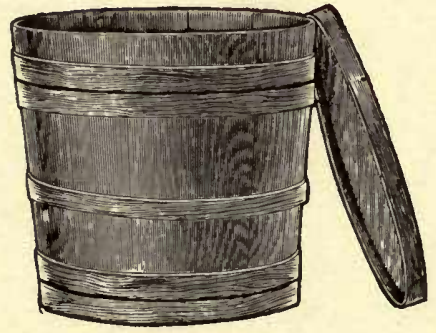

FIG. 158.-Elgin style buttertub.

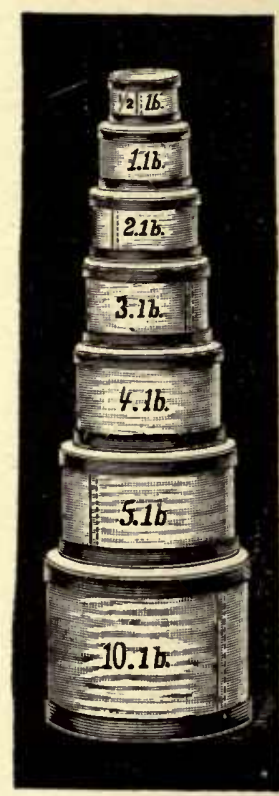

Fig. 159.-Bradley butter-boxes.

without soaking is that when wooden tubs are exposed to such sudden heat they usually warp. The hoops are also likely to burst, and if this method is employed alone, many of the tubs will be rendered valueless owing to the bursting of the hoops. If the tub is gradually soaked in brine first, heat may be applied afterwards with little or no injury to the tub. Owing to the many complaints of mouldy butter, especially during the summer, several other methods of preparing tubs have been recommended. In following out the above method many makers 
omit to use concentrated brine. If the brine is weak, then, of course, it will have little or no effect upon the moulds; but if the brine is saturated, the wood will become saturated with brine and prevent the growth of mould during the transportation of the butter. Moulds usually start to grow on the inside of the tub, next to the butter.

Some of the other methods recommended for the preparation of tubs are: (1) Paraffining. This is accomplished by melting the paraffin, then using $a^{5}$ soft brush with which to spread the liquid paraffin all over the insicle of the tub. After the liquid paraffin has been applied and cooled, it will solidify, and a thin layer of paraffin will cover the inside of the tub. (2) The second method is to soak the tubs in brine containing from $2 \%$ to $3 \%$ of formalin ( $40 \%$ formaldehyde solution); about three ounces of formalin to each gallon of brine is about the proper proportion.

Special efforts should be made towards having the package appear as neat as possible. They should be clean, and the cover should fit well. After the tub has been washed, lined, and otherwise prepared, it should be weighed, and the weight of the tub marked on the outside.

Packing of Butter.-The packing of butter should be conducted under as favorable conditions as possible. Before naking use of the butter-ladles they should be scalded and then cooled off in cold water. This prevents the butter from sticking to them, and also cleanses them from dust and germs which may have lodged on them. When the butter is being transferred from the churn into the tub, it should be firmly packed. That is, there should be no holes near the bottom and sicles of the butter in the tub. When the butter arrives on the market it is sometimes turned out of the tub (stripped). If it has not been firmly packed, the butter will be filled with holes on the sides and show an unattractive appearance. Besides this, if there are any holes in the butter, the moisture and air will gather there. This gathered brine at time causes a change in color on the surface of the butter to which the brine was 
exposed. The tubs should be well filled. Any open spaces left in the butter permit the circulation of air, and the butter is more likely to absorb the woody odors from the tub.

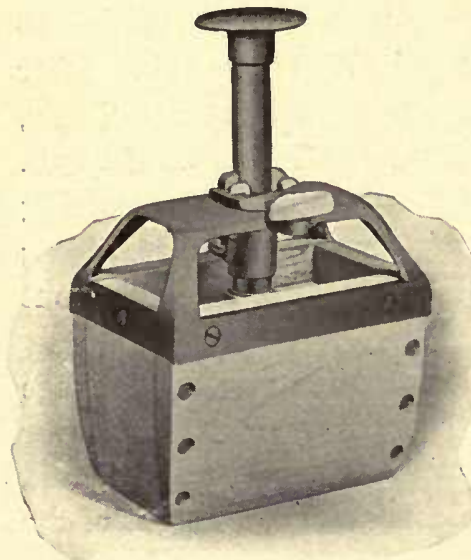

Fig. 160.-The Eureka hand butter-printer.

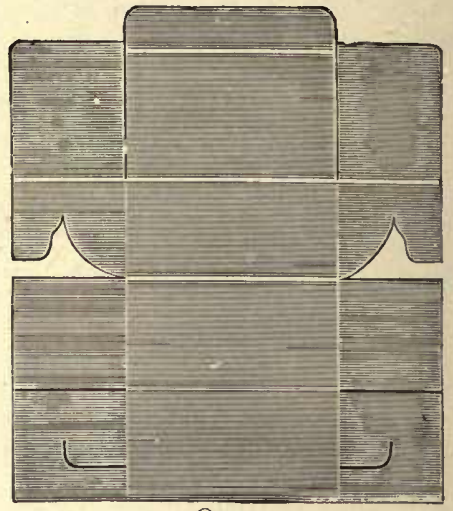

Open.

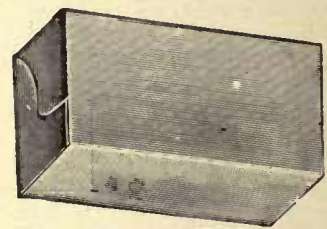

Folded.

FIG. 161,-Butter cartons.

In the preparation of the tubs, many of these woody odors are eliminated, but it is impossible to remove all of them. The heat when applied to the tub opens up the pores of the wood and causes the volatile woody odors to pass off with the escaping steam. When the wood is removed from the influence of the steam, the pores again close, or contract, and in that way most of the woody odors are removed, at least from the inner surface of the tub. The remaining woody odors should not be allowed to circulate inwardly through the butter by allowing empty spaces insicle the tub. The top surface of the butter can be made to appear smooth and full by filling the tub a little more than full of butter, and then cutting the excessive amount of butter off with a string. The extra butter can then be rolled off, and the top appear perfectly smooth and full. 
than do spruce tubs. Sandpapering the tubs on the outside gives a nice appearance. A fine-appearing tub may count considerably when the final decision is rendered. In order to keep the tub in a clean and good condition during transit special precautions should be taken by the sender. A good way of preparing a tub is to tack the address on the cover, wrap the tub well in paper, and fasten the paper by wrapping a string around the tub a few times. Drive no more nails in the tub than is necessary. Three tins are sufficient to fasten the cover to the tub. The tin fasteners should be placed equal distances apart. After the paper has been wrapped around

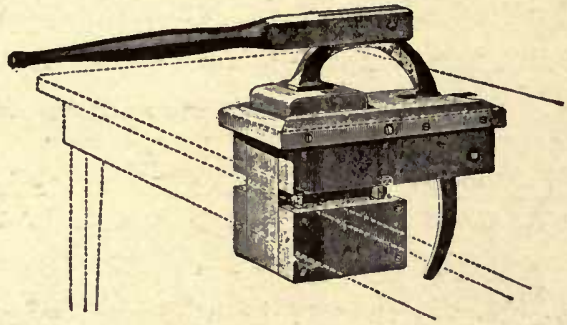

FIG. 165.-The Lafayette lever butter-printer.

the tub the whole should be burlapped. These burlaps can be obtained with the tubs from any of the creamery supplyhouses. The tub should then be labeled, and it is ready for shipment.

Another good way of preparing a tub for shipment is to pack the 20-pound tub into a 60-pound tub. Fill the space between the small and the large tub with paper. This is considered by many to be the best method of shipping butter for contests, as the paper, packed in on the sides of the tub, prevents the heat from penetrating. In cold weather it also prevents the butter from freezing, at least in a measure.

Storing Butter in Creameries.-The temperature of the room in which the butter is being stored should be as low as conditions will permit. A temperature of $50^{\circ} \mathrm{F}$. or below is favorable to the keeping quality of the butter. Usually the 
butter is kept at the ereamery for from half a week to a whole week. It is advisable to ship as often as is considered consistent with the amounts of butter handled. The refrigerator in which the butter is kept at the creamery should be kept as pure and dry as possible. Damp places are always conducive to the growth of germs, especially moulds. Vegetables or foods of other kinds should not be allowed in the refrigerator

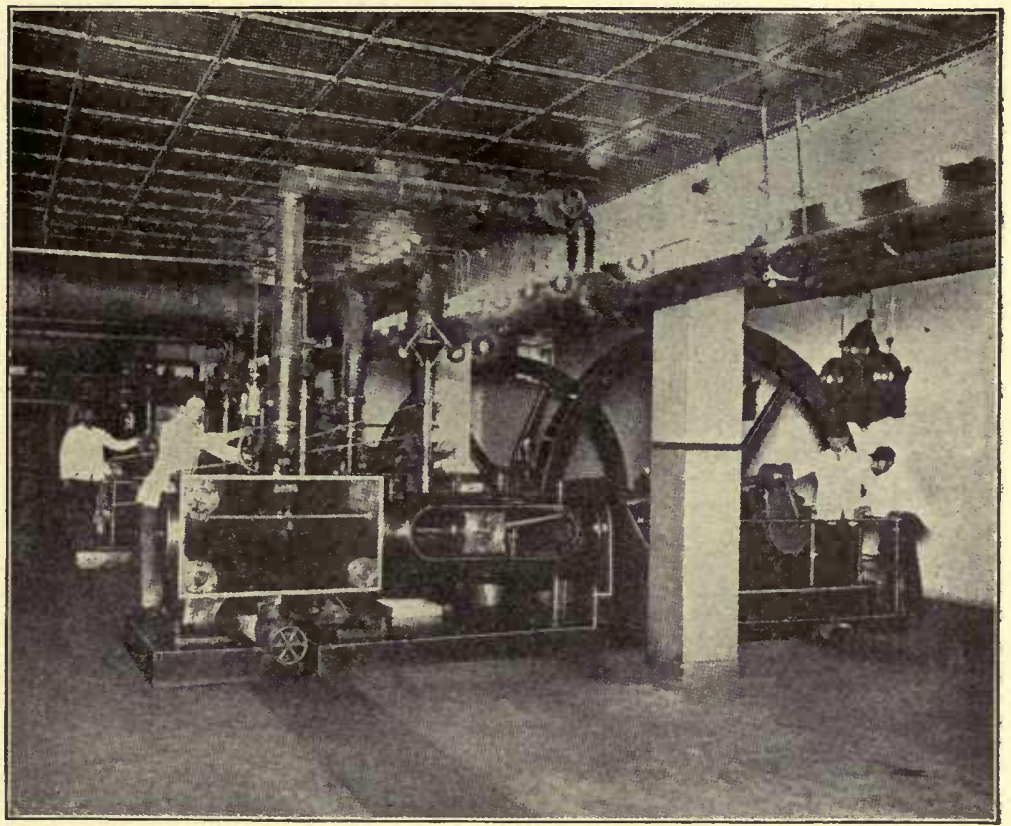

FIG. 166.-The engine-room of Littleton Creamery Co. (Creamery Journal.)

with the butter, as they are likely to impart foreign flavors to the butter. Mechanical refrigeration and eooling with ice are the best eooling facilities. In ease it should happen that it is impossible to obtain ice, water ean be utilized for this purpose. The water used in the ereamery ean be made to run through a galvanized-iron tank. This tank is properly placed in the butter storing-room, or refrigerator, so as to allow as much cooling-surface in the butter-room as possible. This method 
will not cool the room as effectively as icc, but in the absence of ice this is better than no cooling at all.

Cost of Producing One Pound of Butter.-The cost of producing a pound of butter varies at different creameries. Up to a certain limit, the more butter that is being produced at

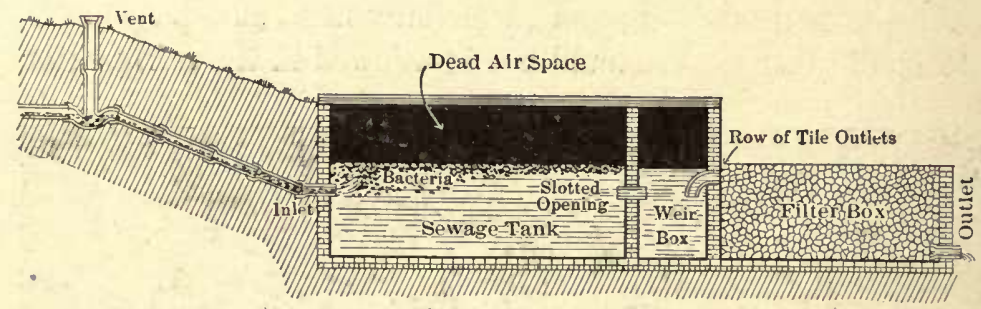

FIG. 167.-Cross-section of a sewage-disposal tank. (Wallace's Farmer.)

one place the less will be the cost of production, that is, providing the creameries are otherwise equally well managed. The Iowa State Dairy Commissioner has investigated this

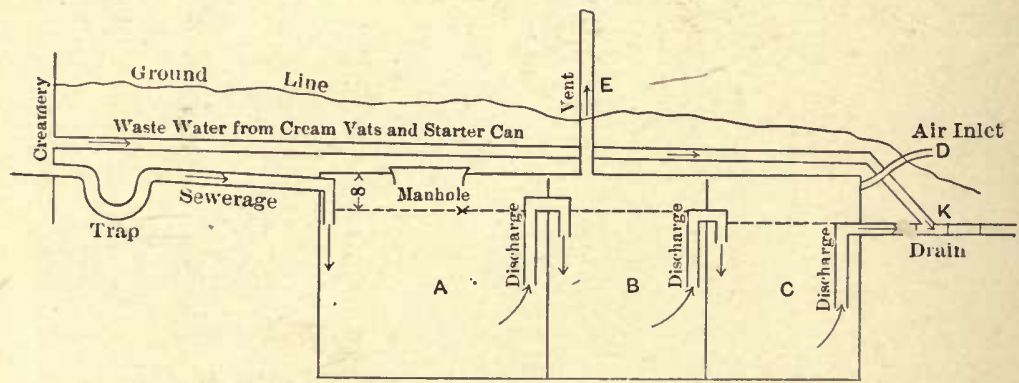

FIG. 168.- Septic tank for creamery sewdge disposal. (By Prof. J. Michels.) The tank should be located in the ground with the top within a foot or two of the surface. It may be constructed of planks. Brick, stone, or concrete is preferable for durability. The tank should be built airtight except in two places, D and E.

question and finds that the cost of production varies from 1.2 cents to 6 cents per pound. According to the reports submitted to the office of the State Dairy Commissioner, the highest cost of production comies from a co-operative creamery that makes a little less than 30,000 pounds of butter per year. The lowest cost of production is submitted by a co-operative 
PACKING AND MARKETING BUTTER.

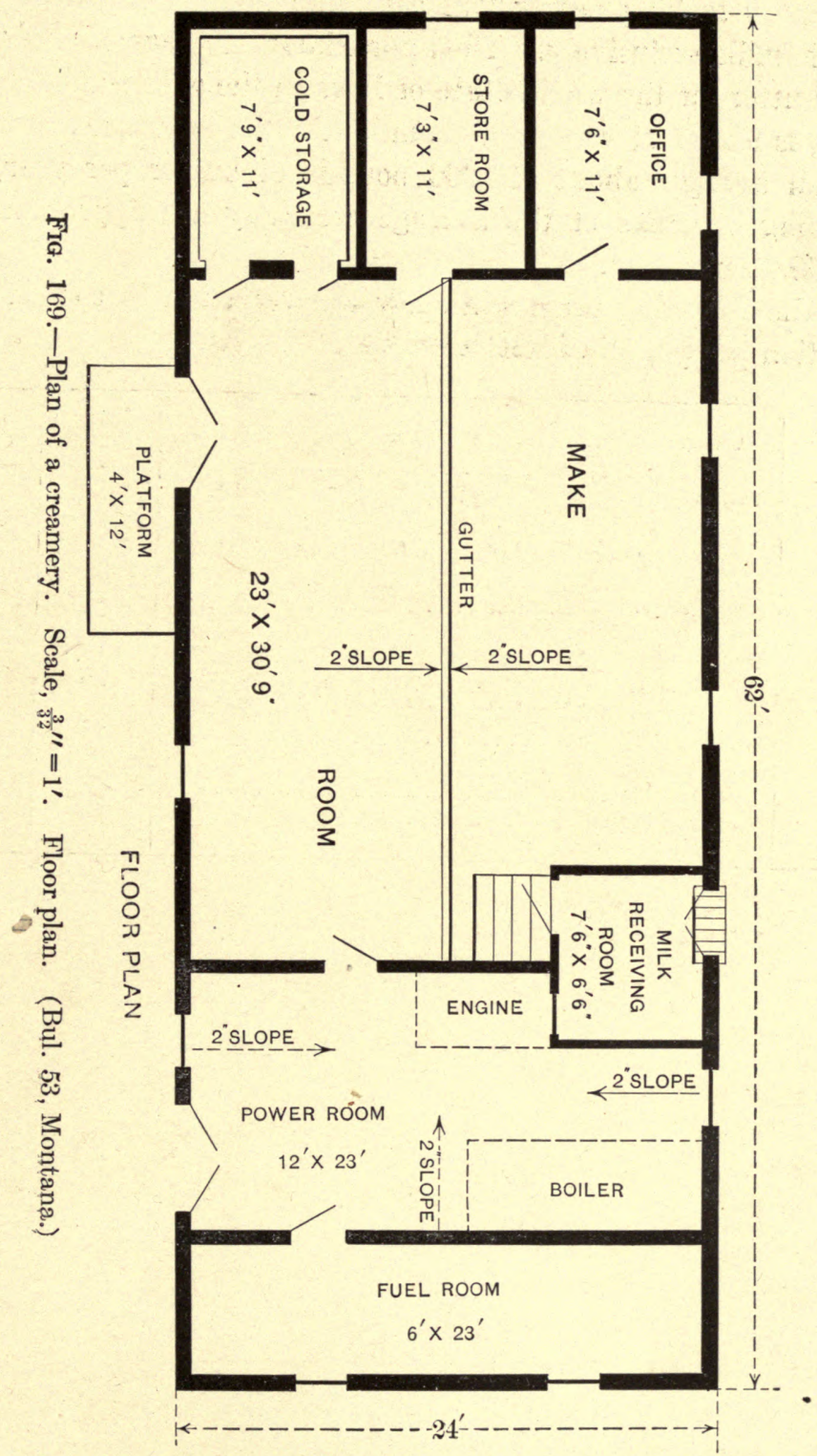


creamery making nearly half a million pounds of butter from whole milk exclusively. The approximate average cost of making butter for the whole State of Iowa in the whole-milk creameries is about $2 \frac{1}{4}$ cents per pound. As the creameries produce on an average about 150,000 pounds of butter per year, the running expenses of the average creamery are approximately $\$ 2350.00$ per year.

The following table will show the variation in cost of production per pound of butter:

\begin{tabular}{|c|c|c|c|}
\hline Class. & Creamery Cost of Manufacturing a Pound of Butter. & $\begin{array}{c}\text { No. } \\
\text { Reported. }\end{array}$ & $\begin{array}{l}\text { Cost, } \\
\text { Cents. }\end{array}$ \\
\hline \multirow{10}{*}{$\begin{array}{l}1 \\
2 \\
3 \\
4 \\
5\end{array}$} & Creameries making no more than $50,000 \mathrm{lbs}$. of & \multirow{2}{*}{44} & \multirow{2}{*}{3.14} \\
\hline & Creameries making between 50,000 and 100,000 & & \\
\hline & 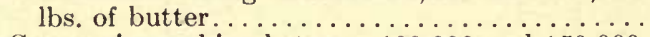 & 98 & 2.36 \\
\hline & Creameries making between 100,000 and 150,000 & \multirow[b]{2}{*}{53} & \multirow[b]{2}{*}{1.99} \\
\hline & 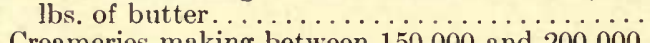 & & \\
\hline & 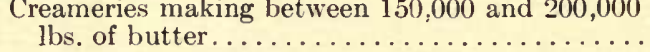 & 28 & 1.78 \\
\hline & Creameries making between 200,000 and 300,000 & 27 & 171 \\
\hline & IDs. or putcer. & 26 & 1.11 \\
\hline & Average for the State...... & 253 & 2.28 \\
\hline & Average for classes 2 and $3 .$. & 154 & 2.22 \\
\hline
\end{tabular}




\section{CHAPTER XIX.}

\section{COMPOSITION OF BUTTER.}

BUTTER is composed of fat, water, proteids, milk-sugar, ash, and salt. The milk-sugar and ash are present in butter only to a very small extent. In the analysis of butter the milk-sugar is usually included with the proteids (curd), and the ash is reckoned in with the salt.

Storch gives the following average composition of butter:

\begin{tabular}{|c|c|c|}
\hline & $\begin{array}{c}\text { From } \\
\text { Fresh Cream. }\end{array}$ & $\begin{array}{c}\text { From } \\
\text { Ripened Cre }\end{array}$ \\
\hline Fat. & 83.75 & 82 \\
\hline Water.............. & .. 13.03 & 13 \\
\hline Proteids (curd). . & .64 & \\
\hline Milk-sugar. . . . . . . . & . $\quad .35$ & \\
\hline Asl & .14 & \\
\hline & 2.09 & \\
\hline
\end{tabular}

The average composition of butter as deter mined from the analysis of 221 samples, representing 55 different creameries in different parts of the State of Iowa, is as follows:

Fat.......................... 84

Water........................... 12.73

Curd ......................... 1.30

Salt and ash. ................ 1.97

Effect of Composition of Butter Upon Quality.

The quality of cream or milk from which the butter has been produced and the methods employed in the manufacture have more effect upon the quality of butter than has the composi- 
tion. A small variation in the components of butter affects the quality very little, provided the butter has been properly made, and the components properly incorporated. In the same creamery the composition of butter varies according to the season of the year, from day to day, and even from one churning to another. According to the present methods of manufacture, water, salt, and fat are the components most likely to vary. Casein varies very little.

Curd and Sugar.--Occasionally the curd content may go as high as $4 \%$. It rarely exceeds $2 \%$, and seldom falls below .5 of $1 \%$. A high curd-content will show itself in the butter in the form of a milky brine, or in the form of white specks. If there is less than $2 \%$ of curd present in the butter, the brine shows no noticeable milkiness. More than that much curd can, as a rule, be detected from the color of the brine.

If the casein or the curd has been incorporated in the form of small lumps or specks, then abnormal amounts of curd appear. When the sample of butter is taken for analysis, such a speck of curd present in the sample raises the final curd-content to a comparatively high figure.

As has been mentioned before, the curd and milk-sugar are incorporated from the buttermilk into the butter during the churning. In manufacturing butter for storage, these substances should be excluded from the butter as thoroughly as possible. The milk-sugar and albuminoids constitute the chief food for bacterial growth. As the deterioration of butter has been demonstrated to be due chiefly to the action of organisms, it becomes essential to restrain their growth as much as possible by excluding food necessary for their growth.

Salt.-In the chapter discussing the salting of butter, it was mentioned that a small increase or decrease in the salt-content of butter can be recognized by most consumers, while the same variation in the other constituents cannot be noticed so easily. The average salt-content of butter is about $2 \%$. As the amount of salt properly dissolved in butter depends upon the amount of water present, the first important step in controlling the salt- 
content is to have reasonable control of the water-content of the butter. If there is no more than $16 \%$ of water present in the butter, it is desirable to have as much salt in as the water will dissolve within the time usually allotted for that purpose. This much salt suits most of the American butter markets. The authors have analyzed commercial butter containing more than $8 \%$ salt. The major portion of this was present in an undissolved condition. Such butter is called gritty, and is objected to by most consumers.

Salt acts as a preservative and adds flavor to the butter, provided it is in good condition. It is said that the addition of salt has some effects upon the body of the butter. Richmond asserts that salty butter loses more water on standing than unsalted butter. This is undoubt-

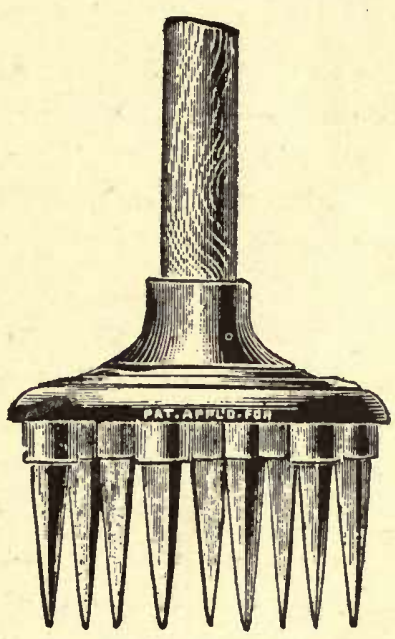

FIG. 170.-Ice-crusher. edly due to the leaky condition which is brought about when salt is added to butter while in a granular condition. Salt attracts moisture. Unsalted butter would not be exposed to this influence of the salt. When kept unsalted, butter usually becomes cheesy in flavor in a short time, while salted butter assumes entirely different characteristics.

Water.-The moisture-content of butter may vary between $6 \%$ and $16 \%$. Frequently butter is found that contains more than $16 \%$, but this amount is in violation of the law. Butter may contain as much as $18 \%$ of water, if properly incorporated, without affecting its apparent commercial quality. Water is present in a greater proportion than any other non-fat constituent. Its variation is also greater than that of any other constituent. The fat will, of course, vary with the water. The more water there is present in the butter, the less fat there will be, and the less water, the more fat. As butter is bought 
with the understanding that it is rich in fat, much objection has been raised to butter containing an abnormal amount of water. This objection by consumers is, of course, a just one. The producers desire to incorporate as much water as is consistent with good quality. Butter containing a high moisture-content, more than $18 \%$, will appear dead and dull. It is sticky, and when sampled with a trier it is next to impossible to draw a full trier of butter. It shrivels and rolls on both sides of the trier

Moisture affects butter in two principal ways, according to the way in which is is incorporated: (1) By causing leaky butter, and (2) by making the butter appear dull.

1. This leaky condition in commercial butter is very common. It has been a common opinion among butter-judges that whenever water appears in large drops on the butter, and somewhat slushy when sampled, the butter contains too much moisture. This, however, is not always the case, as butter will not as a rule hold an excessive amount of moisture in that form. Even if this leaky butter does not contain an excess of moisture, it is a very undesirable condition, as most consumers object to this apparent slushiness. As has been stated before, this leaky condition is brought about chiefly by churning the butter to small granules, washing the butter very little in cold water, salting heavily, while butter granules are still small and firm, and working the butter frequently in the presence of brine. When moisture is properly incorporated in butter, it should be present in exceedingly minute drops. In a fine state of division it will not escape from the butter.

This leaky condition of moisture in butter may give a wrong impression to consumers about its moisture-content. Major Alvord, Chief of Dairy Division of U. S. Department of Agriculture, reports that a great many buyers on the English market have the opinion that American butter contains an excess of moisture. This conclusion evidently has been reached on account of the water in American butter often appearing in this leaky condition, as described above. In reality it is low in its moisture-content. 
2. The dull and dry appearing condition of butter may be due (1) to the presence of an excess of moisture properly incorporated; (2) to the treatment the butter receives during manufacture. When the dull and dry appearance is due to moisture, the water has been incorporated during the churning, or during the washing process, through excessive churning or working

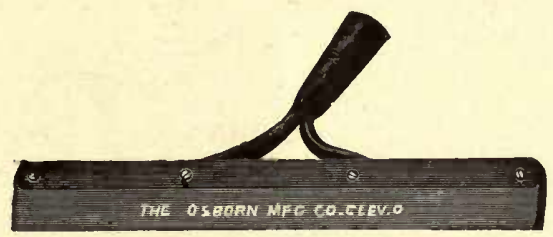

FIG. 171.-Rubber mop.

in the buttermilk or wash-water at a high temperature. The dullness may also be brought about by overworking the butter. If the butter has been overworked, as a rule, it contains little moisture, though its appearance may be like that of butter containing an excess.

The conditions which affect the moisture-content of butter during its manufacture are:

(1) Temperature of cream and of wash-water. The higher the temperature of these two substances, the more water will be incorporated in the butter. When the temperature is too high, the body of the butter is injured materially. The keeping quality of the butter is also injured by having the temperature of the cream too high. The buttermilk constituents are incorporated with the butter and cause it to deteriorate rapidly.

(2) The amount of churning in buttermilk and wash-water. The more the butter is being churned or worked in the presence of moisture, the more water the butter will contain. When the temperature of buttermilk and wash-water is low, a small amount of churning affects the moisture-content very little, while if the temperature is high, great care should be taken not to overchurn.

(3) Per cent of fat in cream. The thicker the cream the more moisture there will be present in the butter. In order to 
churn thick cream, a higher temperature is necessary. It is difficult to stop the churn without overchurning a trifle. These two conditions, thick cream and high temperature, are both conducive to a higher moisture-content.

(4) Amount of work the butter receives. If the butter is in a moderately firm condition, the more the butter is worked, in the absence of water, the less moisture it will contain. If the moisture is present in a leaky form as mentioned above, it is expelled to a great extent by working. But if the moisture is properly incorporated and the butter is not too firm, working has little effect upon changing the moisture-content of the butter, providing there is no water present in the churn.

Several other factors, such as pasteurization of cream, fullness of churn, and character of fat in cream, all have a small influence in governing the moisture-content of butter, but in this summary it is sufficient to say that temperature, degree of churning, and thickness of cream are the only conditions which materially influence the moisture-content. If churning is carried on to an excess, whether it be in the buttermilk or in the wash-water, all other factors are subordinate and have little or no influence in regulating the moisture-content of butter. Low temperature is the chief factor that delays incorporation of moisture in excessive churning.

Fat.-The English, the German, and the United States governments have endeavored to protect consumers in regard to the amount of nutriment in butter, by recommending $16 \%$ of water as a maximum limit. Such a ruling has worked successfully now for several years. Efforts have recently been made in the United States to base by law the nutritive quality of butter upon a certain minimum percentage of fat. The minimum amount of fat recommended by the appointed committee of chemists is $82 \frac{1}{2} \%$. A minimum standard of $82 \frac{1}{2} \%$ of fat in butter would be unintentionally violated, while a basis of $80 \%$ fat in butter would be more consistent with the quality of butter as manufactured. 


\section{CHAPTER XX.}

\section{JUDGING AND GRADING BUTTER.}

ButTer may be judged from a commercial and from an individual standpoint. Individual judgments of the same butter may vary considerably. It is important that the judge should become familiar with the quality of butter as required by our standard markets, and then judge the butter according to the demands of the mass of the consumers, rather than according to personal likes and dislikes. In order to become a good butter-judge, it is essential that the senses of taste and smell be acute. Even if one's taste and smell are keen and sensitive, considerable practice or experience is necessary. Almost any one can tell a good sample of butter from a very poor one, but when it comes to differentiate between two samples which are nearly alike in quality, skill and experience are required.

The chief thing in scoring butter is to become thoroughly familiar with the ideal flavor of butter; then by repeated comparisons of different samples of butter to this one ideal flavor, one will soon become efficient in grading the butter.

Standard for Judging. - In America the distinct qualities which are noticed in butter are designated according to the basis of points given below. It will be noticed that different values are given to the different characteristics, according to their relative importance. The score-card given below is used commercially, and is based upon 100 as perfect:

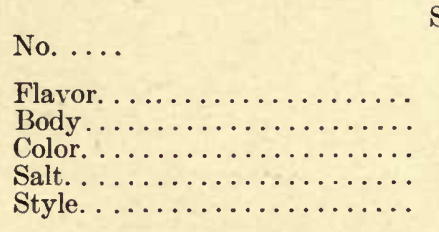

Total.

SCORE-CARD.

Date.

\begin{tabular}{c} 
Perfect. \\
45 \\
25 \\
15 \\
10 \\
5 \\
\hline
\end{tabular}

Scored by
Remarks.

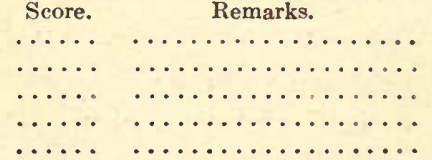

by................................ 287 
At a recent conference of the Société Nationale de Laiterie, held at Brussels, the following scale of points was suggested for butter (Creamery Journal):

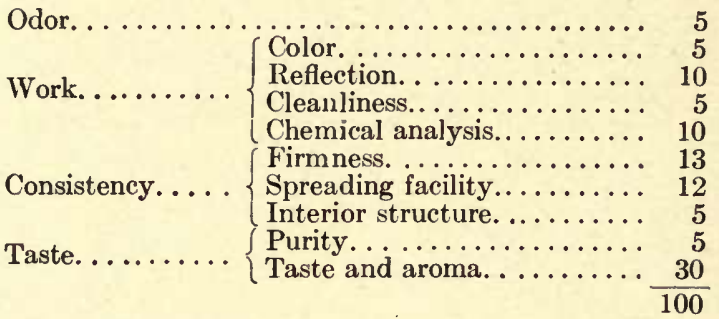

Score-card used by W. S. Moore \& Co., Chicago.

Stencil

Date........

Creamery.

Buttermaker.

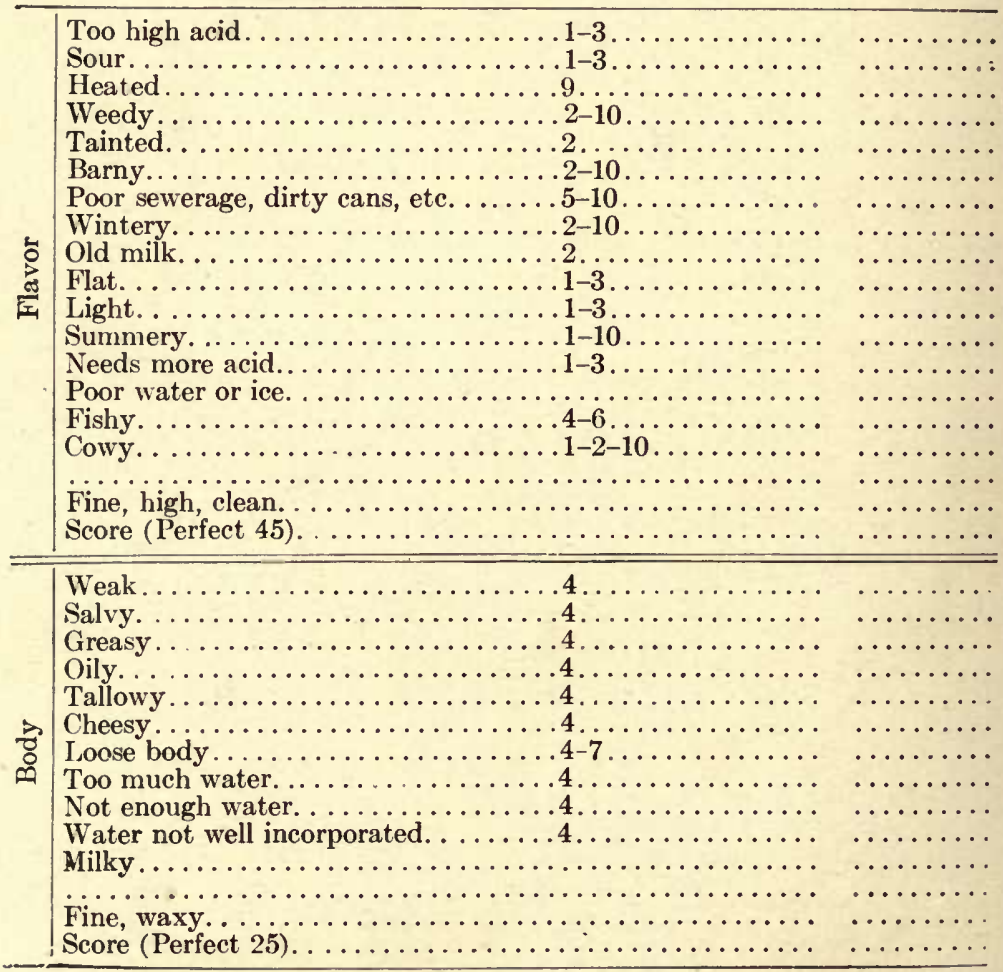




\begin{tabular}{|c|c|c|}
\hline$\frac{\dot{0}}{0}$ & 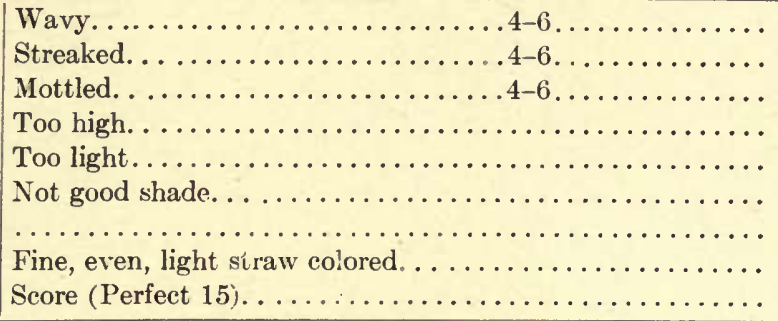 & 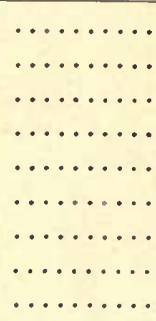 \\
\hline $\mathscr{W}$ & 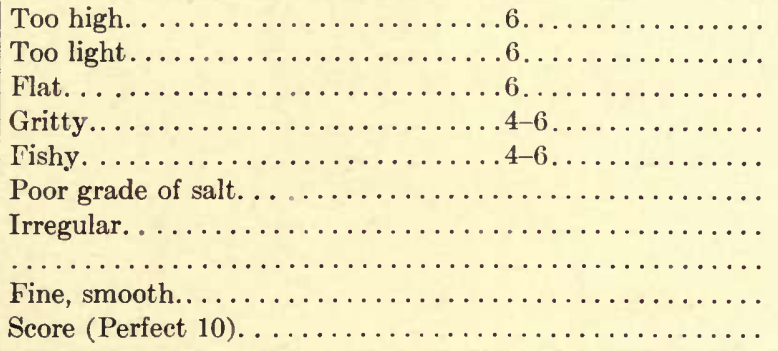 & $\begin{array}{l}\cdots \cdots \cdots \\
\cdots \cdots \cdots \\
\cdots \cdots \cdots \\
\cdots \cdots \cdots \\
\cdots \cdots \cdots \\
\cdots \cdots \cdots \\
\cdots \cdots \cdots \\
\cdots \cdots \cdots \\
\cdots \cdots \cdots \\
\cdots \cdots \cdots\end{array}$ \\
\hline
\end{tabular}

Tops not neat. . . . . . . . . . . . . . .

Too much salt on tops. . . . . . . . . .

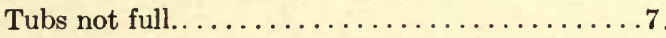

Stroke tops off level; do not bevel. .....................

Fold paper liners under cloth circles, not on top...............

Not paper lined.

Liners poor grade.

Too much brine. .................. $7-8$

Loosely packed.................

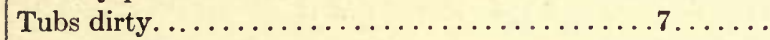

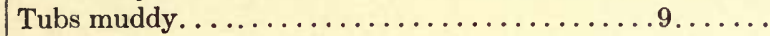

Tubs soaked too much. . . . . . . . . . . . .

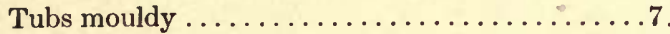

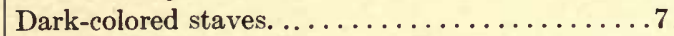

Not Elgin-style tubs. . . . . . . . . . . .

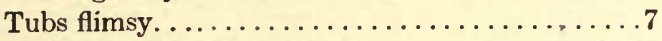

Broken hoops and covers. . . . . . . . . . . .

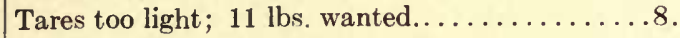

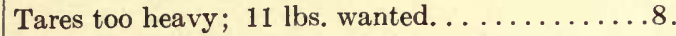

Hooks or poor tin fasteners. .............

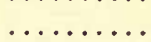

..........

..........

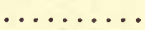

.........

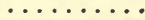

.

...............

..............

$\ldots \ldots \ldots+\cdots \cdots$

$\cdots \cdots \cdots$

$7 \ldots \ldots \ldots \ldots$

Fine, handsome.

Score (Perfect 5) 


\section{Manner of Judging.}

Body.-After the trierful of butter has been drawn out, the first thing to notice is the aroma, and the body or texture of the butter. The butter on the outsicle should be examined at once before it is affected by the temperature of the room. Notice its color, whether it is even or uneven, low or high. Determine by the appearance of the butter and the way it feels to the palate whether it is greasy, tallowy, spongy, or sticky. The amount of brine and condition of brine should also be noted. These characteristics and their causes have been previously discussed. Stroke the plug of butter with a knife to observe the color closer. Squeeze it with the thumb to ascertain the character of the body. The aroma of the butter should also be noticed in connection with scoring the butter on body or texture, as it is more pronounced immediately after the trierful of butter has been drawn.

Flavor.-It is impossible to describe all the different flavors found in butter. There are perhaps as many distinct butter flavors as there are shades of colors. However, there are a few flavors which stand out more prominent and are more commonly met with than any of the others. Good butter should possess a clean, mild, rich, creamy flavor, and should have a delicate, mild, pleasant aroma. Some butter judges, especially foreign judges, allow a separate number of points for aroma of butter in the score-card. This has been suggested in the United States also, owing to the fact that butter may have little aroma and still have a good flavor. Owing to this, it has been suggested that it would be better to allow a certain number of points separately for aroma in the score-card.

Flat flavor is noticeable in butter made from unripened cream. If such butter is otherwise clean, little objection is made to this kind of butter for ordinary commercial purposes. The remedy is to ripen the cream a little higher with a proper ferment. Rancid flavor is applied to butter which has an 
undesirable, strong flavor. Rancid flavor is the most common defect developing in butter on standing. Other flavors developing in butter are "turpentine," "fishy," "unclean," "feverish," and "stale" flavors. In eritieizing butter it is better to mark at once the specifie fault, rather than state that the butter is raneid. Cheesy flavor is another characteristie which is very common in butter. This cheesy condition develops chiefly in butter containing little or no salt. It is claimed to be due to the decomposition of the proteid matter in the butter. Weedy flavors are quite common in butter. They are due mostly to the condition of milk previous to the manufacture of the butter. The remedy is to take the cows away from the pasture in which weeds of different kinds are growing, such as garlie, wild onions, etc. Acid flavor is another common defeet found in butter. It is usually due to improper ripening of cream. The term sour is used in its literal meaning in describing butter which in reality is sour, though not very sour to the taste; by the sense of smell, however, the sourness is readily perceived. The usual cause of this sourness is an improper removal of the buttermilk before the butter is packed. The term sour is oecasionally used to designate butter which has been made from overripened cream. Feverish flavor is a comparatively new term. Its significance seems to be of importance. This flavor is very sickening. It is believed to be due to the eow's system being in an unhealthy condition. This flavor is imparted to the butter when it is produced from milk drawn from eows during sexual excitement. Diarrhœa of the cows is claimed to produce the same effect. Stable flavors are due to the improper and unclean conditions of the barn. They are most common during the winter, when cows are exposed to stable eonditions.

Color.-The eolor should be bright and even. When a plug of butter is drawn with a trier and is held up to the light, it should not be cloudy and dense, but should be almost transparent and bright. The chief fault found with the color of butter is unevenness. It may be streaky, mottled, or it may be too 
high or too low. The shade of color will vary according to the different markets. The color preferred in our markets is chiefly a high straw color. There has been a tendency recently to recommend a comparatively high color in butter, in order to distinguish it from oleo margarine. A reddish color, however, should be guarded against, except when the market demands it. If too much color is added, butter will assume this hue, which is very undesirable.

Salt.-The amount of salt likewise depends upon the market, and unless the salt-content is extremely high, or extremely low, butter should not be criticized on account of the amount of salt. The chief thing to consider in judging butter on its salt-content is the condition of the salt. Notice whether it has been thoroughly dissolved and evenly distributed.

Style.-The style is the appearance of the butter and package. Whatever the shape of the package, the chief thing to consider is that it is clean and neatly finished, as described in the paragraph on "Exhibition of Butter."

\section{Classification and Grades of Butter.}

The classification and grading of butter on the different markets vary very little. As the New York market is the great butter market in the United States, we quote the classification and grades of butter as outlined by the New York Mercantile Fxchange:

\section{"CLASSIFICATION.}

"1. Butter shall be classified as Creamery, Process, Factory, Packing Stock, and Grease Butter.

\section{“Definitions.}

"2. Creamery.-Butter offered under this classification shall have been made in a creamery from cream separated at the creamery or gathered from farmers. 
"3. Process.-Butter offered under this elassification shall be such as is made by melting butter, clarifying the fat therefrom and re-churning the same with fresh milk, cream, or skim-milk, or other similar process.

"4. Factory.-Butter offered under this classification shall be such as is collected in rolls, lumps, or in whole packages and reworked by the dealer or shipper.

"5. Packing Stock.-Butter offered under this classification shall be original farm made butter in rolls, lumps or otherwise, without additional moisture or salt.

"6. Grease Butter.-This shall comprise all classes of butter grading below thirds, or of packing stock grading below No. 3, as hereinafter specified, free from adulteration.

\section{"GRADES.}

"7. Creamery, process, and factory shall be graded as Specials, Extras, Firsts, Seconds, and Thirds; and Packing Stock shall be graded as No. 1, No. 2, and No. 3 .

\section{Definition of Grades.}

"8. Grades of butter must conform to the following requirements in addition to the requirements of score as hereinafter provided.

"9. Specials.-Shall comprise the highest grades of butter obtainable in the season when offered, under the various classifications. $90 \%$ shall conform to the following standard; the balance shall not grade below Extras.

"Flavor.-Must be fine, sweet, clean, and fresh, if of current make, and fine, sweet and clean, if held.

"Body.-Must be firm and uniform.

"Color.-A light straw shade, even and uniform.

"Salt.-Medium salted.

"Package.-Sound, good, uniform, and clean.

"Specials may also comprise such lots of Extras as, owing to some particular and unusual qualification, are more desirable than plain "extras" offered without any qualification. 
"10. Extras.- Shall be a grade just below Specials and must be fine butter for the season when made and offered, under

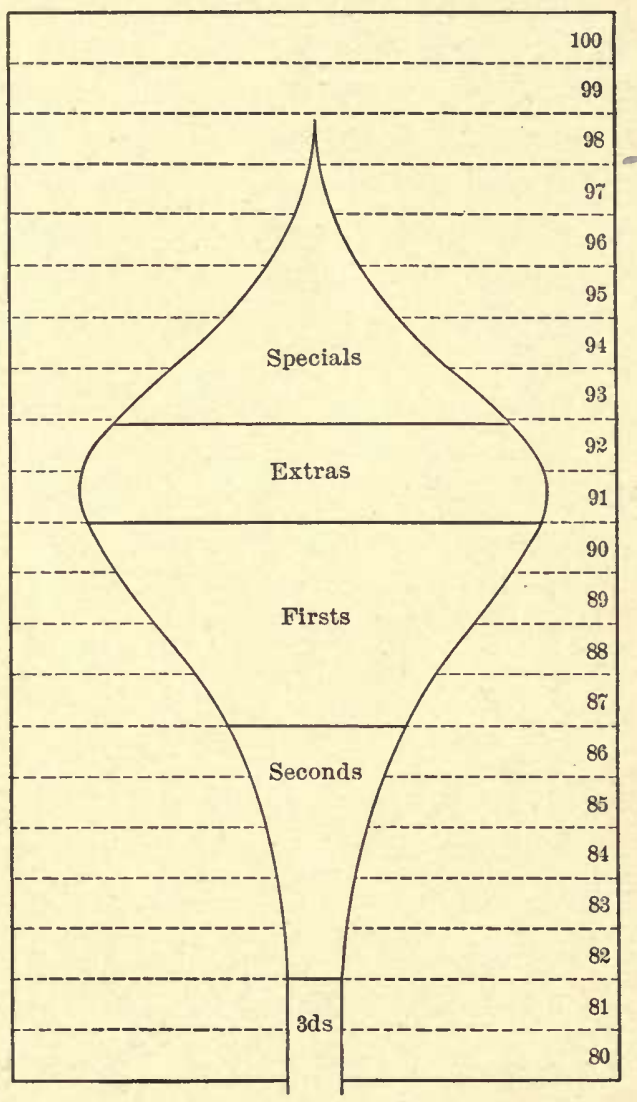

Graphical illustration of the approximate relative amount of each of the different grades of butter arriving on the New York market during the summer season. It also shows the required score for each of the different grades. (From N. Y. Produce Review.)

the various classifications. $90 \%$ shall conform to the following standard; the balance shall not grade below Firsts.

"Flavor.-Must be sweet, clean, and fresh if of current make and sweet and clean, if held.

"Body.-Must be good and uniform. 
"Color.-A light straw shade, even and uniform.

"Salt.-Medium salted.

"Package.-Sound, good, uniform, and clean.

"11. Firsts. - Shall be a grade just below Extras and must be good butter for the season when made and offered, under the various classifications. $90 \%$ shall conform to the following standard; the balance shall not grade below Seconds.

"Flavor.-Must be good, sweet, and fresh if of current make and good and sweet, if held.

"Color.-Reasonably uniform, neither very high nor very light.

"Salt.-May be reasonably high, light or medium.

"Package.-Good and uniform.

"12. Seconds.--Shall be a grade just below Firsts.

"Flavor.-Must be reasonably good.

"Body.-If Creamery, must be solid boring. If Factory or Process, must be $90 \%$ solid boring.

"Color.-Fairly uniform, but may be mottled.

"Salt.-May be high, medium, or light.

"Package.-Good.

"13. Thirds.-Shall be a grade below Seconds and may consist of promiscuous ots.

"Flavor.-May be off-flavored and strong on tops and sides.

"Body.-Not required to draw a full trier.

"Color.-May be irregular or mottled.

"Salt.-High, light, or irregular.

"Package.-Any kind of package mentioned at time of sale.

"14. No. I Packing Stock.-Shall be sweet and sound, packed in large, new, or good uniform second hand barrels, having a wooden head in each end, or in new tubs, either to be parchment paper lined. Barrels and tubs to be packed full.

"15. No. 2 Packing Stock. - Shall be reasonably sweet and sound, and may be packed in promiscuous or different kinds of barrels, tubs, or tierces, without being parchment paper lined, 
and may be packed in either two-headed or cloth-covered barrels.

"16. No. 3 Packing Stock.-Shall be a grade below No. 2, and may be off-flavored, or strong; may be packed in any kind or kinds of packages. Charges for inspection shall be the same as the rules call for on other grades.

\section{"Scoring, as Affecting Grades of Creamery Butter.}

"17. In the inspection of creamery butter for grade, the point system of scoring shall be used on the following basis:

"Flavor, for perfeetion............... 45 points.

"Body, for perfection................ 25 points.

"Color, for perfection . . . . ............ 15 points.

"Salt, for perfection ................. 10 points.

"Style, for perfection............... 5 points.

"Total, for perfection ................ 100 points.

"18. The Butter Committee shall determine and prescribe from time to time a range of scores covering two consecutive full points, which shall be required for the grade of Extra Creamery in addition to the other specific requirements mentioned in Rule 10. The required scores for Extra Creamery shall be fixed with due consideration for the varying average quality of the ereamery butter obtainable from season to season, and with a view of making this grade represent as nearly as may be a uniform quality relatively to the quality of the supply as a whole. The required range of scores so detcrmined upon shall remain in force until changed by the Butter Committee; such ehanges may be made at any time and shall beeome effective on the day following authoritative announcement from the ealler's desk and posting on the bulletins. All creamery butter scoring higher than required for Extras, if it meet the requirements mentioned in Rule 9, shall grade as Creamery Specials; all ereamery butter scoring lower than required for Extras, but not more than four points lower, if it meet the requirements mentioned in Rule 11, shall grade 
as Creamery Firsts; all creamery butter scoring lower than Creamery Firsts, but not more than five points lower, if it meet the requirements mentioned in Rule 12 , shall grade as Creamery Seconds; all creamery butter scoring lower than Creamery Seconds if it meets the requirements of Rule 13, shall grade as Creamery Thirds.

"19. The Butter Committee shall cause to be posted in a conspicuous place upon the bulletins of the Exchange, the range of scores required for the various grades of creamery butter currently in effect.

"20. Lines of fifty tubs or more of one straight mark and invoice of Extra Creamery butter shall be a good delivery on a contract for Creamery Specials, provided the guaranteed score of the butter is mentioned when the goods are offered for sale.

\section{"Known Marks.}

"21. Known marks shall comprise such butter as is known to the trade under some particular mark or designation and must grade as Extras or better if Creamery or Process, and as Firsts or better if Factory in the season when offered, unless otherwise specified. Known marks to be offered under the call must previously have been registered in a book kept by the Supcrintendent for that purpose. If Process, the factory district number and state must be registered.

\section{"Sales Under the Call.}

"22. Parties wishing to offer butter not described in the foregoing classifications and grades, must specify its character.

"23. All butter offered under the Call shall be fresh made, current receipts, and shall be in regular 60-pound ash tubs, unless otherwise specified.

"24. No offer to buy or sell less than twenty-five tubs spot, nor less than fifty tubs for future delivery, nor bids or offers of a less fraction than $\frac{1}{8}$ c. per pound shall be entertained.

"25. Bids and offerings of not less than fifty tubs for future 
delivery may be made for a period of ten days. The call for futures shall take place immediately after the call for spot delivery, and seller this afternoon. On all sales for future delivery, a compulsory margin shall be deposited by each party to the contract as specified in Rule 2 of the Executive Committee.

"26. The first offer to buy or sell at a price shall be accepted before subsequent offers at the same figure are considered.

"27. Offers may be withdrawn at any time before acceptance.

"28. Offers to sell at a lower, or buy at a higher, price shall vacate all previous bids and offerings.

"29. A transaction shall vacate all previous bids and offerings.

"30. All differences as to offers, aeceptances, withdrawals, or irregular bids, shall be decided on the spot by the officer conducting the eall, subjeet to an appeal to the members present. If an appeal is made, it shall be put promptly, and a majority of the members present and voting shall settle the difference finally.

"31. The Superintendent shall have recorded daily, in a book kept for the purpose, all sales under the call, and such other sales on the floor as may be requested by the parties thereto, and shall furnish certificates of sales to both seller and buyer.

"32. Spot sales shall be for spot eash, and butter sold for future delivery shall be paid for when delivered, unless otherwise agreed.

"33. All deliveries shall be from the store of the seller, providing it be in Manhattan Borough below Canal Street, otherwise the goods must be placed within said limits.

"34. All disputes must be settled while the goods are in the seller's possession.

"35. When spot sales are made, butter must be ready for immediate delivery. 
"36. All goods tendered, inspector's certificate attached, shall be accompanied by such certificate, and be accepted by the buyer unconditionally, provided all tubs are branded according to Rule 64 .

" 37 . If butter tendered has not been inspected and does not appear to the buyer to be of the class and grade sold, the seller shall be notified not later than 1 P.M. He may then have it inspected, and if it proves not to fulfill the requirements of the sale, he may make a second delivery not later than 3 P.M.

"38. If a second tender is made and appears not of the class and grade sold, the buyer must establish the quality by an official inspection, for which he shall make application to the Superintendent not later than 4 P.M. of the day of the sale.

"When an inspection is made and shows the butter to be of the class and grade sold, the buyer shall accept the same, and pay for the inspection.

"39. In sales for 'future delivery' the delivery requirements as to time, inspection, etc., shall be the same as on the spot sales on the date of delivery, but the rules governing classification for grades in force at time of such sale shall govern the quality of such deliveries.

“40. In sales 'seller's option' the seller shall notify the buyer of his intention to make delivery not later than 9 A.M. on the day of delivery. If 'buyer's option,' the buyer shall notify the seller of his intention to call for delivery at least twenty-four hours before 10 A.M. of the day delivery is demanded.

"41. On sales of Creamery of twenty-five tubs, delivery may be of not more than two marks; on twenty-six to fifty tubs, three marks; on-fifty-one to one hundred tubs, marks containing not less than twenty-five tubs each; on larger lots, marks containing not less than fifty tubs each.

"42. On sales of Factory, or Process butter, delivery must be of one mark, unless otherwise specified. 
"43. A carload shall consist of 300 tubs of one mark, unless otherwise specified.

" 44 . In case of failure to deliver a carload, settlement shall be made on the basis of 300 tubs.

"45. An application to the Superintendent for an inspection of goods in controversy, if made within the time allowed for inspection, shall be deemed a compliance with these rules in this respect.

\section{"Penalties.}

"46. When an inspection of butter sold for spot delivery shows the goods not to be of the class and grade sold, the seller shall pay a penalty equal to $5 \%$ of the amount of the contract, and the fee for inspection. If the official quotation for the day exceeds the contract price, the seller shall also pay to the buyer in the same way the difference between the contract price, and the average official quotation.

" 47 . If butter purchased for future delivery be not delivered as per contract, the buyer shall promptly notify the Superintendent in writing. At the next regular meeting of the Exchange, an announcement of the same shall be made by the Superintendent, who shall buy in the goods for account of the seller, provided it can be done under the call at current rates. If, however, the price demanded seems to him unreasonable, he shall not make the purchase, but shall refer the matter to the Butter Committee, who shall determine the difference between the contract price and the actual market value on the date on which delivery should have been made, and this amount, together with a penalty equal to $5 \%$ of the amount of the contract, shall be paid by the seller.

"48. If butter, sold for future delivery, be not received when properly tendered, the seller shall promptly notify the Superintendent in writing. At the next regular meeting of the Exchange, an announcement of the same shall be made by the Superintendent, who shall sell out the goods, under the call, for account of the buyer, and if the price obtained be 
less than the contract price, the difference, together with a penalty equal to $5 \%$ of the amount of the contract, shall be paid by the buyer.

"49. Penalties and differences shall be paid to the Superintendent of the Exchange, and by him paid to those entitled thereto.

"50. Any member holding a contract against another, corresponding in respect to class, grade, and quantity of goods, and date of delivery, with one held by the other against him, may offset it against the latter by giving notice to the other party, when both contracts shall be surrendered to the Superintendent of the Exchange and cancelled.

" 51 . All notices shall be in writing, and shall be considered as properly served when left at the place of business of the party for whom they are intended.

\section{"Certificate of Sale.}

" 52 . Certificates of sale must be accepted on contracts for future delivery.

"53. The party transferring a certificate of sale, shall immediately notify the original seller of the transfer, and to whom made. He shall also have it recorded on the books of the Exchange, and shall thereupon be relieved of all responsibility attaching to the same.

" 54 . In case the party to a contract for future delivery, for the fulfillment of which margin has been deposited with the Superintendent, shall die, make an assignment, be absent from the city,or otherwise be disabled, or refuse to perform any act necessary for the proper adjustment or payment of such margin, the matter shall be referred to the Finance Committee, as provided in Section 33, Paragraph 6, of the By-Laws.

\section{"Contracts.}

" 55 . The following shall be the form of contract for all sales of butter for future delivery: 


\section{"Contract for Future Delivery.}

"No.......

"This is to certify that the following sale and purchase has been made by the respective signers hereto, under and subject to the Rules of the New York Mercantile Exchange, this

day of

Seller

Address

Purchaser .

Address

Quantity....

Grade.

Score.

Class

Price.

Delivery

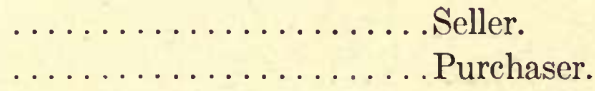

"Original margins deposited with me this day by each party hereto

"6 dollars.

Superintendent.

"New York, ......... $190 \ldots \ldots$....

"Upon the reverse side of each contract, shall be printed the Rules governing such transactions. A proper book shall be kept by the Superintendent of the Exchange, entitled 'Butter Contracts,' in which shall be recorded all contracts as per foregoing form, duplicates of which shall be furnished to both sellers and purchasers, who shall personally sign the same at the time of depositing original margins. All contracts shall be signed, and original margins deposited not later than 2 o'clock on the day following the sale.

" 56 . When further margins are called for, same shall be paid to, and receipted for, by endorsement upon the contract by the Superintendent of the Exchange.

" 57 . All transfers of contracts for future delivery must be 
endorsed on the original contract, by the Superintendent of the Exchange, who shall promptly notify the other party in interest, of such transfer.

" 58 . The following form of transfer shall be used:

"For value received, the within described contract is assigned and transferred to $\ldots \ldots \ldots \ldots \ldots \ldots \ldots \ldots$ who hereby agrees to assume the same, with all the conditions and obligations thereof.

"' Dated, New York ........, $190 \ldots \ldots$. .

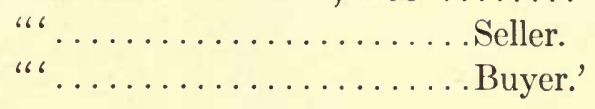

"Inspectors and Inspections.

"59. At the first meeting of the Butter Committee it shall recommend to the President, for his appointment, subject to the approval of the Executive Committee, such Inspectors of Butter as may be required.

"60. Vacancies occurring in the office of Inspectors, shall be filled in the manner in owhich the original appointment was made.

"61. In case of absence or inability of the Inspectors, temporary Inspectors may be appointed by the Butter Committee of the Exchange.

"62. Inspectors, before entering upon their duties, shall be sworn to perform said duties faithfully, and to be governed by the rules herewith, as they shall be interpreted by the Butter Committee, and to make such inspections as may be directed by the Superintendent of the Exchange.

"63. All applications for inspection must be made to the Superintendent of the Exchange between the hours of 8.30 A.M. and 5 P.M., who will direct the same-for members of the Exchange only-as soon as practicable, in the order in which they are received, excepting that applications for the inspection of butter which has been sold under the Call, and is in controversy, shall be given precedence over other applications. 
"64. Inspectors shall brand on the top and side each package inspected, and when requested also on the side of each remaining package in the lot or lots covered by the inspection.

"65. Inspectors shall immediately after completing an inspection, make a certificate of the same in accordance with the specification for grading contained in these rules, upon blanks furnished for this purpose, under the direction of the Butter Committee, which shall be countersigned by the Superintendent, and promptly delivered to the party ordering the inspection.

"66. A Certificate of Inspection shall be good for two days from date of same (including Sundays and holidays) provided the holder of the goods takes proper care of the same.

"67. The Inspectors shall have recorded in a book provided for the purpose, a detailed account of all inspections made by them, stating date and hour of inspection, name, and address of parties for whóm inspection is made, place where inspection is made, stencil number or other marks on goods, number of tubs in lots, and number of tubs inspected. If lots contain more than one shipment, the number of tubs in each shipment shall be noted.

" 68 . There shall be drawn as samples for inspection by the Inspectors:

5 tubs from lots less than 25 of one mark and invoice.

8 " " " " of 25 of one mark and invoice.

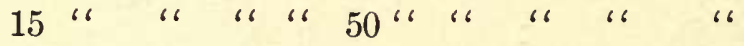

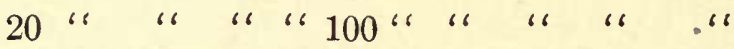

35 " " " " " 200 " " " " " " "

50 " " " " 300 " " 300 " " 6

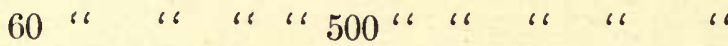

and a like proportion of lots ranging between these figures, and of larger lots.

"69. If butter runs irregular in quality, the Inspector shall increase his sample to such an extent as he deems necessary to secure a fair and just inspection. 
"70. A buyer or seller may have a larger percentage than the above inspected, upon making application previous to the inspection, and payment of 10c. per tub additional fees.

"71. All complaints against the Butter Inspectors shall be referred to the Butter Committee.

"72. Charges for inspection shall be as follows:

On lots not exceeding 10 tubs, 1 invoice....... \$0.50

Over 10 and not over 25 tubs, 1 invoice. . . . 0.75

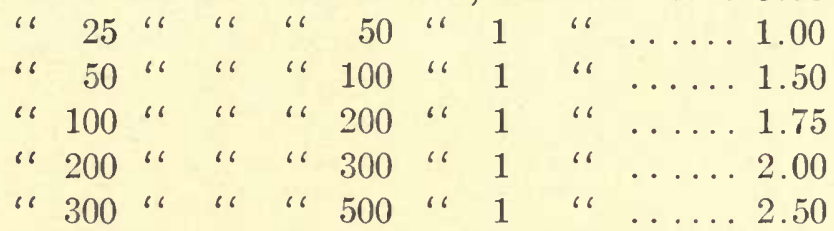

"73. Inspections shall be paid by the party ordering the same, excepting where otherwise provided.

"74. At the first meeting of the Butter Committee, it shall recommend to the President for appointment, subject to the approval of the Executive Committee, a Butter Weigher, who may appoint assistants as he may require them.

"75. The Butter Weigher shall receive his instructions from the Butter Committee.

"76. The Butter Weigher and Assistants before entering upon their duties shall be sworn to perform said duties faithfully, correctly, and in conformity with the customs of the Butter Trade, as defined by the Butter Committee.

"77. The Butter Weigher shall make certificates in duplicate of all lots of butter weighed by him, or his assistants, and promptly deliver to the party ordering the weighing.

"78. Applications for weighing butter shall be made to the Superintendent or Butter Weigher.

"79. Charges for weighing shall be as follows:

On lots not over 25 tubs ............ 3c. per tub

Over 25 and not over 50 tubs ....... $2 \frac{1}{2}$ c. per tub " 50 " " " 100 " .......2. 2c. " "

Testing 7 tubs or less .............. 75 c.

Over 7 tubs ....................10c. " " 
"80. All complaints against the Butter Weigher, or Assistants, shall be made to the Butter Committee.

"81. All former rules conflicting with the foregoing, are hereby repealed.

"Attention is Directed to the Following Executive Committee Rules, and Section 33, Paragraph 6, of the By-Laws.

"Rule 2.-On all sales, or purchases of any merchandise to arrive, or for future delivery, each party to the contract shall deposit an original margin with the Superintendent of the Exchange of $10 \%$ on the contract price at the time of purchase, or sale, and a further margin from time to time to the extent of any variation in the market value from the contract price; said margin to be deposited in such bank or trust company as may have been designated by the Finance Committee of the New York Mercantile Exchange. When margins are called before 12 M., they must be deposited before 3 P.M. of the same day. If called after 12 м., they musi be deposited before 12 u. of the following day; in case of failure to deposit as above, the buyer or seller shall have the right to cover his contract at discretion, for account of the party failing to respond to the call for margin.

"Rule 7.-All merchandise purchased by sample shall be considered sold unless the purchaser notify the seller within twenty-four hours after receipt of the same, that it is rejected as not being up to sample. If a settlement cannot be agreed on, the ease shall be referred to the Trade Committee having charge of the class of goods in question, who shall decide the matter, and in the event of a decision against either buyer or seller, the same penalties shall acerue as the Rules under the Call provide for the kind of goods dealt in. The party against whom the decision is given shall pay to each committeeman serving $\$ 2$ for each case. 
Section 33, Paragraph 6, of the By-Laws.

"When the parties to a contract, on which margin has been deposited through the instrumentality of the Superintendent, as above set forth, cannot agree as to the distribution and payment of such margin, or in case one or both of the contracting parties die or make an assignment, or otherwise become incapacitated, or refuse to perform promptly any act necessary for the adjustment and payment of such margin, the Finance Committee is hereby authorized and directed to ascertain the person or persons to whom such margins should be paid, and instruct the Superintendent to endorse the deposit certificate for payment, or exchange it for other checks, to correspond in amount with the Committee's decision, drawn to the order of the person or persons entitled thereto, and deliver the same to said person or persons without unnecessary delay; and in case, for any cause whatever, the said deposit certificate is not immediately forthcoming, so that such endorsement and distribution may be made, the Finance Committee shall instruct the Superintendent to procure from the said bank or trust company that issued it, a duplicate thereof, as provided for in the original, and endorse it as he would have endorsed the original if it had come into his possession."

\section{Export Butter.}

The observations of the authors have been that the reputa tion of the American butter is not, all that is desirable on the English market. Some American butter is good enough to sell on an equality with Danish butter, and in some instances it is palmed off for such. Much pnor butter, however, has been allowed to go onto the English market, and this has in some measure ruined the reputation of our butter.

Butter for export purposes should be of the very best, and made in such a way as to insure good keeping qualities.

The standing of the different kinds of butter, as observed on the English market, were as follows: 
(1) Fresh French Rolls.

(2) Danish Creamery.

(3) Irish Creamery.

(4) New Zealand.

(5) Canadian, Australian, Argentine, United States, and Siberia.

\section{For Storage Purposes.}

(1) Danish.

(2) New Zealand.

(3) Siberia.

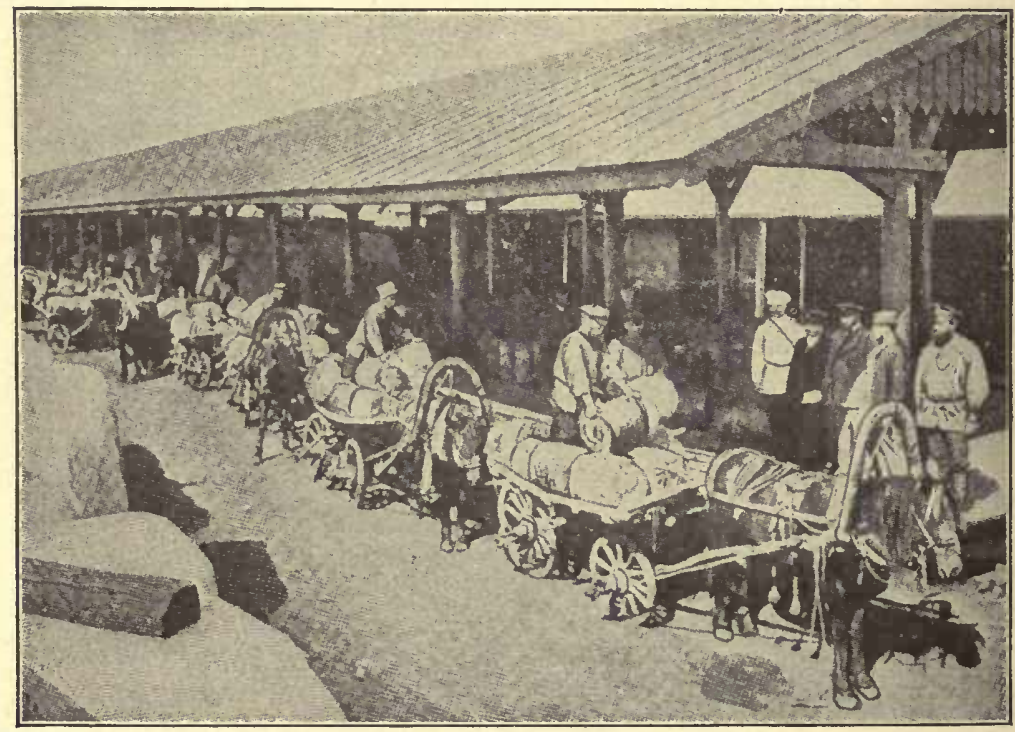

FIG. 172.-Shipping Russian butter from Siberia. (U. S. Govt. Bul.) 


\section{CHAPTER XXI.}

\section{COOLING FACILITIES FOR CREAMERIES.}

ONE of the most important things in connection with the successful operation of a creamery is the control of temperature. This control of temperature is important in the separation, pasteurization, ripening, churning processes, and in the use and preparation of starters. Conditions are frequently such that the raw as well as finished dairy products need to be stored. If temperature or cold storage conditions are not under control, dairy products will suffer in quality. Raw as well as finished products are very perishable. They are best when fresh. Strictly and generally speaking, dairy products deteriorate with age. The nearer the producers of the raw material, manufacturers, and consumers of the finished products can be brought together, the better it is. Conditions of commerce and trade are such that butter needs to be preserved for some time before it reaches the consumer.

The preservation of butter depends on the checking of fermentations affecting the flavor of this product. This can best be done by the use of a low temperature. There are various ways by which low temperature may be obtained in creameries. The system of refrigeration to be employed in a given creamery should be determined by local conditions.

\section{Cooling Systems:}

1. By the use of natural ice.

2. By the use of mechanical refrigeration.

3. By the use of cold water alone.

1. Most local creameries, within the ice-freezing belt, make use of natural ice. It is by far the most common method 
of refrigeration employed in creameries, and undoubtedly, under average local conditions, represents the most economic method of obtaining low temperature. As a rule patrons have little work to do during the winter and are willing to supply teams and help for a few days while the ice is being put up. The use of natural ice gives good satisfaction, especially when good, pure ice can be had within a reasonable distance from the creamery, and a proper and convenient place is provided in which to store the ice.

2. Mechanical refrigeration is undoubtedly gaining favor with creamery-men, as is evidenced by the increased number of mechanical refrigerating-plants installed in various creameries. The reasons for this increase are due in part, first to centralization of creameries, second, to mild winters in certain sections and consequently no natural ice, third, greater convenience if properly operated.

Centralized creameries have so much more cooling to do than a local creamery, that a mechanical refrigerating-plant best serves their needs. Often centralized plants are located in large cities where an ice-manufacturing plant and cold storage plant may be run successfully in connection with the creamery. Prof. Erf * has conducted some experiments relative to the comparative cost of the two systems for creamery use. The following table shows the results, and indicates the comparative cost of cooling 100 pounds of butter to $30^{\circ} \mathrm{F}$, including the cost of cooling the cream during manufacturing processes. These figures are also based upon a run of 10,000 pounds of milk per day.

1. $2 . \quad 3 . \quad 4$.

Natural-ice system . ...... 20.1c. 18.2c. 17.5c. 17.1c. Mechanical refrigeration..... 17.8c. 17.1c. 16.9c. 16.8c.

The different columns $(1,2,3,4)$ indicate different insulating material used, which cannot here be elaborated upon, except to say that it pays to insulate thoroughly.

* Creamery Journal. 
The above results indicate that mechanical refrigeration is a little the cheaper. The cost of mechanical refrigeration is quite constant under different conditions, while the cost connected with storing and using natural ice will vary greatly according to different localities.

3. Under certain conditions, intentional or unintentional, a creamery must be run without the use of ice, and without mechanical refrigeration. In such a case cold water is a necessity. One of the authors successfully operated a creamery one season without any other cooling agent than water. The winter season had been warm and no ice was obtained nor was it obtainable at a reasonable cost. There was no room in the creamery for a mechanical refrigerating-plant, and even if there had been, no money was available with which to purchase such cooling facilities. The only thing to do was to close the creamery or cool with water.

The latter method was resorted to. The creamery was fortunate in having an unlimited supply of pure cold water coming from a mountain stream.

This water was made effective for cooling purposes by directing a constant flow through a galvanized iron tank in the refrigerator. The ice-box on the inside of the refrigerator was removed, and a closed galvanized iron tank put in its place. This tank was connected up with an inflow and overflow at the top. A faucet for draining the tank was provided at the bottom in one corner. The tank was made straight on the side next to the wall, but sloping towards the wall on the side facing the refrigerator room. This was done so as to allow the dampness or sweat collecting on the outside to run down the sides and be collected in a trough, which conveyed it to the outside. A trap was connected with this outlet so as not to let in warm air. Such an arrangement gave very good satisfaction, though not so effective in cooling as ice.

The cream was cooled and kept cold by circulating a constant stream of water through the vat-jackets. The temperature of the water was never above $50^{\circ} \mathrm{F}$. 
The butter was disposed of locally while fresh. In creameries where it is necessary to hold butter any length of time, this system is undoubtedly less satisfactory, but under above mentioned conditions it gave good satisfaction.

The water-tank should never be made from wood, as wood is a very poor conductor of heat. Heavy galvanized iron is best.

\section{iNatural Ice System.}

Kind of Ice-house.-When natural ice is stored, the first consideration is a good ice-house conveniently located to the creamery and refrigerator. When the ereamery is first planned and built the ice-house should at the same time be provided for. The ice-house should preferably be adjacent to the refrigerator, so that the ice can be transferred directly from the house into the cooler, thus obviating much loss of ice and decreasing labor.

The various parts of the building embracing the many details, will not here be enlarged upon, inasmuch as they can be more advantageously shown in plans. Students are referred to the different views shown on pages $313-315,317$ and $318 . *$

As will be seen, the construction of the ice-house depends to some extent upon the location and kind of refrigerator to be used. There are at least two different ways of locating the refrigerator in relation to ice-house: (1) Where the refrigerator is entirely separate from the ice-house, the ice to be transferred and placed either overhead or on one side of the refrigerator. (2) Where the refrigerator is combined with the ice-house and the ice is not moved for cooling purposes. This in turn may be arranged so as to have the ice storage overhead or on one side of the refrigerator. The ice-house needed in eonnection with this seeond method differs chiefly from that of the first in that better insulation is necessary and no ice-packing material is used, except on top. This latter

* N. Y. Produce Review. Showing cooling facilities in Albert Lea Creamery, Minn. 


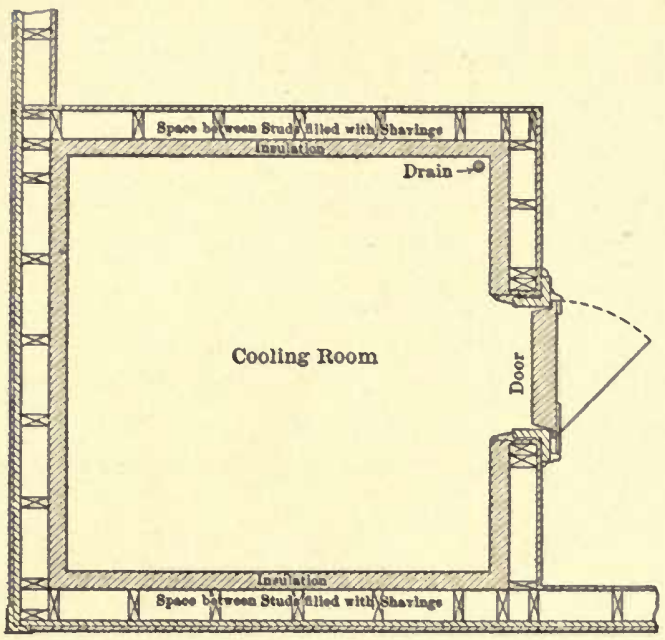

PLAN

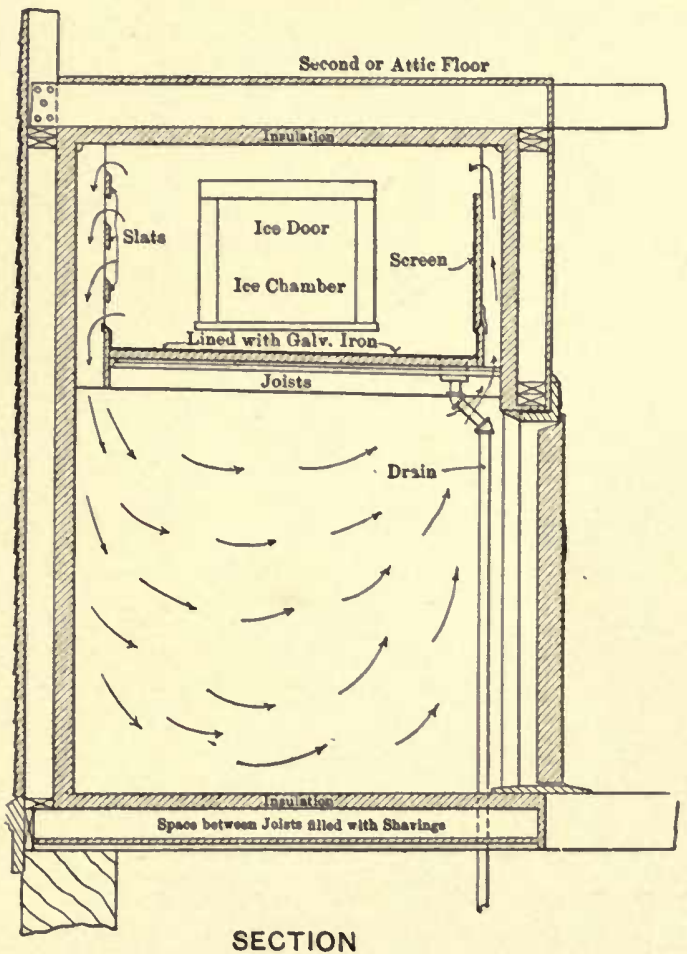

FIG. 173.-Refrigerator with ice overhead. 


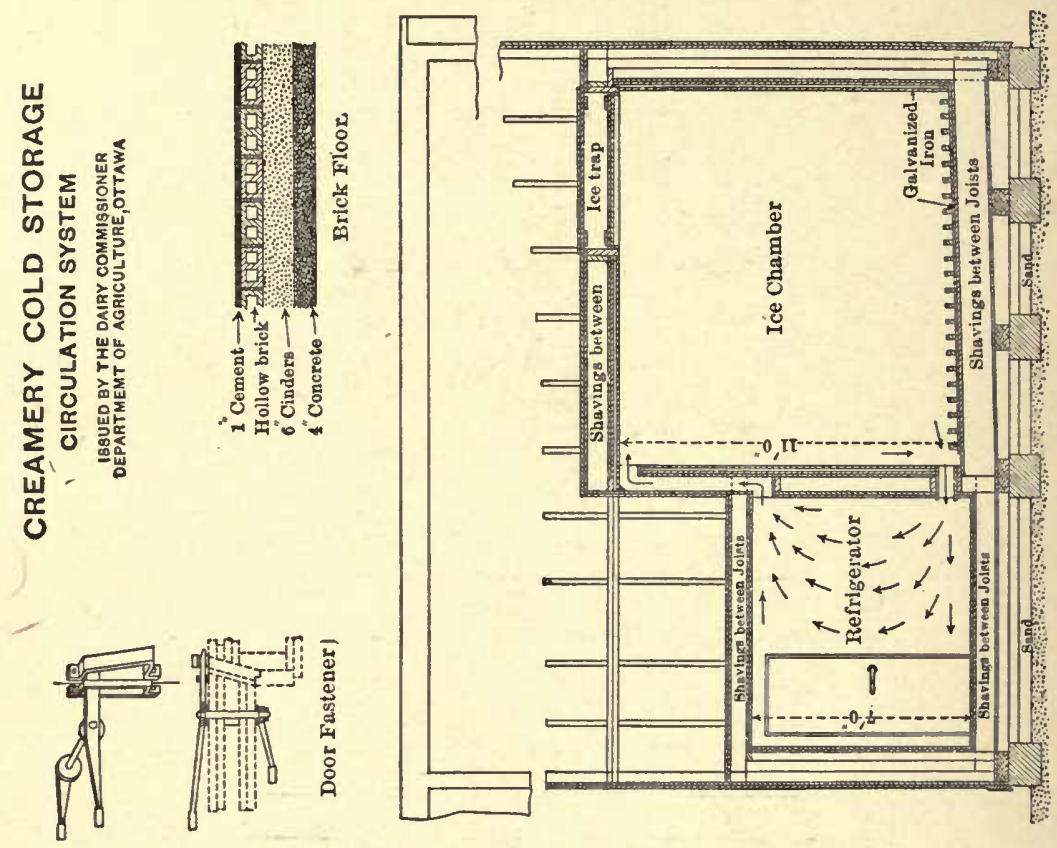

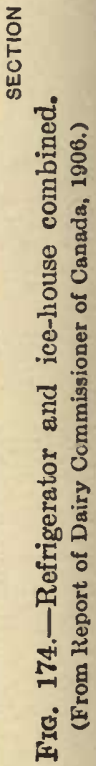
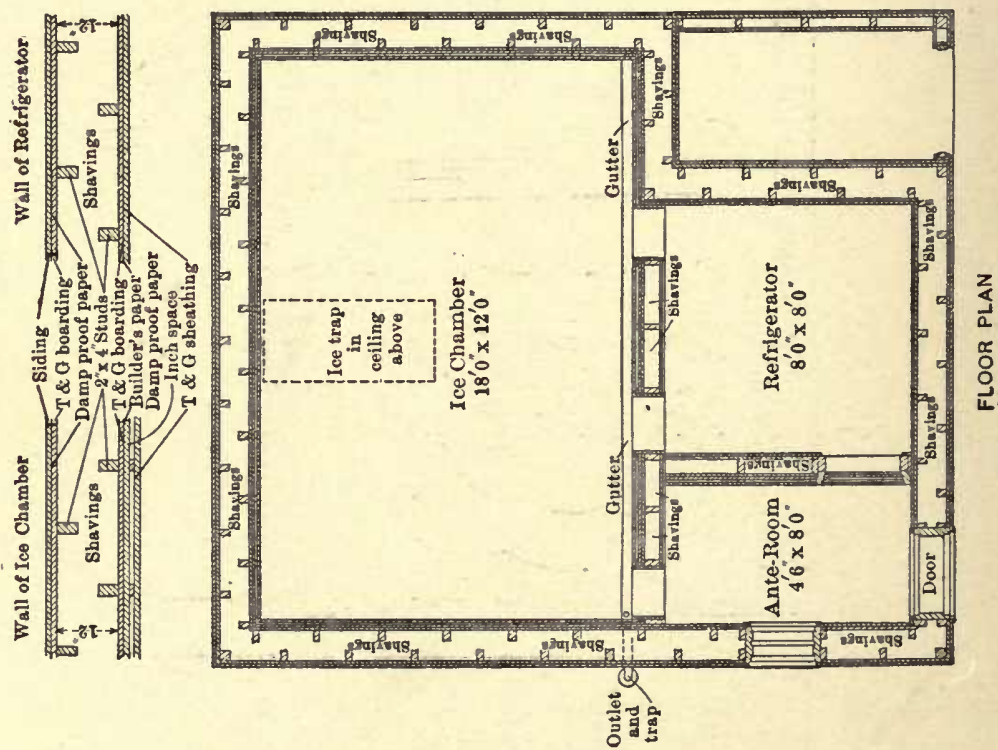

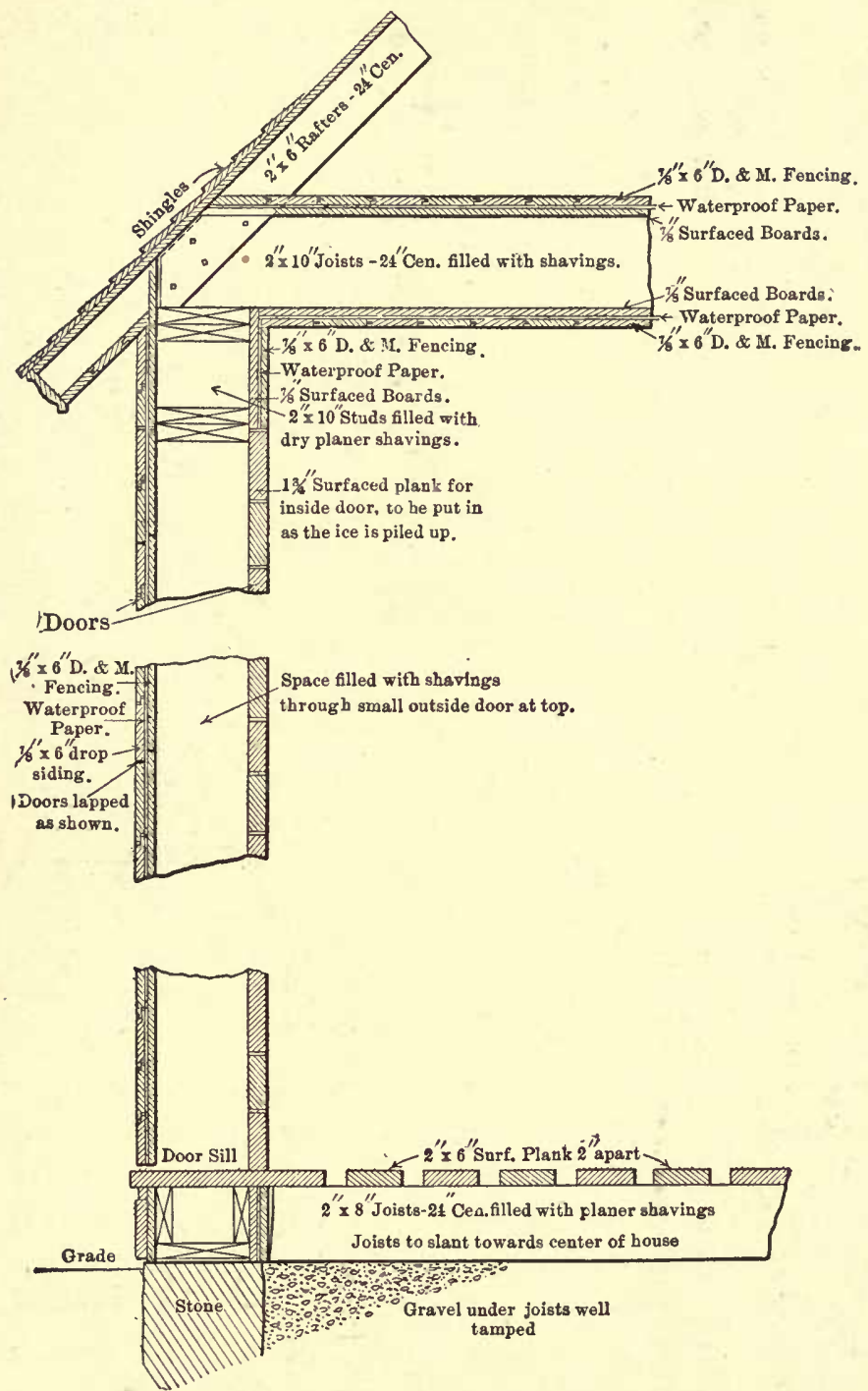

FIG. 175.-Construction detail of ice-house. 
method of creamery refrigerators, even though more expensive, is to be highly recommended, chiefly because labor is decreased, and the low temperature is uniformly maintained.

Reasonable high ground affords a good location for an icehouse. It is of importance that the ground should be thoroughly drained before building the ice-house. If the ground is high, dry, and gravelly, perhaps no drainage is needed, but under most conditions a drain should be run through the bottom. This drain should not be very deep. If area to be drained is so large that one drain will not carry off the water, it is better to use two drains, rather than to have one deep one.

Size and Shape of Ice-house.-The plan of the ice-house should be as nearly square as consistent with room. A square building, having a certain length of wall around it, will hold more ice than an oblong building having an equal number of feet of outside walls. The building should also be high in proportion to width and length. This will tend to preserve the ice as proportionately less top surface is exposed to the air.

The size of the building will vary according (1) to amount of milk handled at the creamery, (2) whether ice is sold from creamery, and (3) whether ice is used for any other purposes, such as ice-cream freezing, cream shipping, etc. For creamery uses, the only basis on which to estimate is the amount of milk received.

For example, suppose a creamery is receiving 12,000 pounds of milk daily. This milk will produce about 2000 pounds of cream and about 600 pounds of butter. Suppose that the cream needs to be cooled from $90^{\circ} \mathrm{F}$. down to $40^{\circ} \mathrm{F}$. or a range of $50^{\circ} \mathrm{F}$. One pound of ice will cool about 142 pounds of water $1^{\circ} \mathrm{F}$. Calculations are made with water as basis. The results will thus be a little too high, but subsequent corrections will be made. If one pound of ice will cool 142 pounds of cream $1^{\circ} \mathrm{F}$., it will require 50 pounds of ice to cool that amount of cream $50^{\circ} \mathrm{F}$. By calculation from these figures we find that about 0.35 of a pound of ice is required to cool each pound of cream $50^{\circ} \mathrm{F}$. and for cooling 2000 pounds of cream it will 


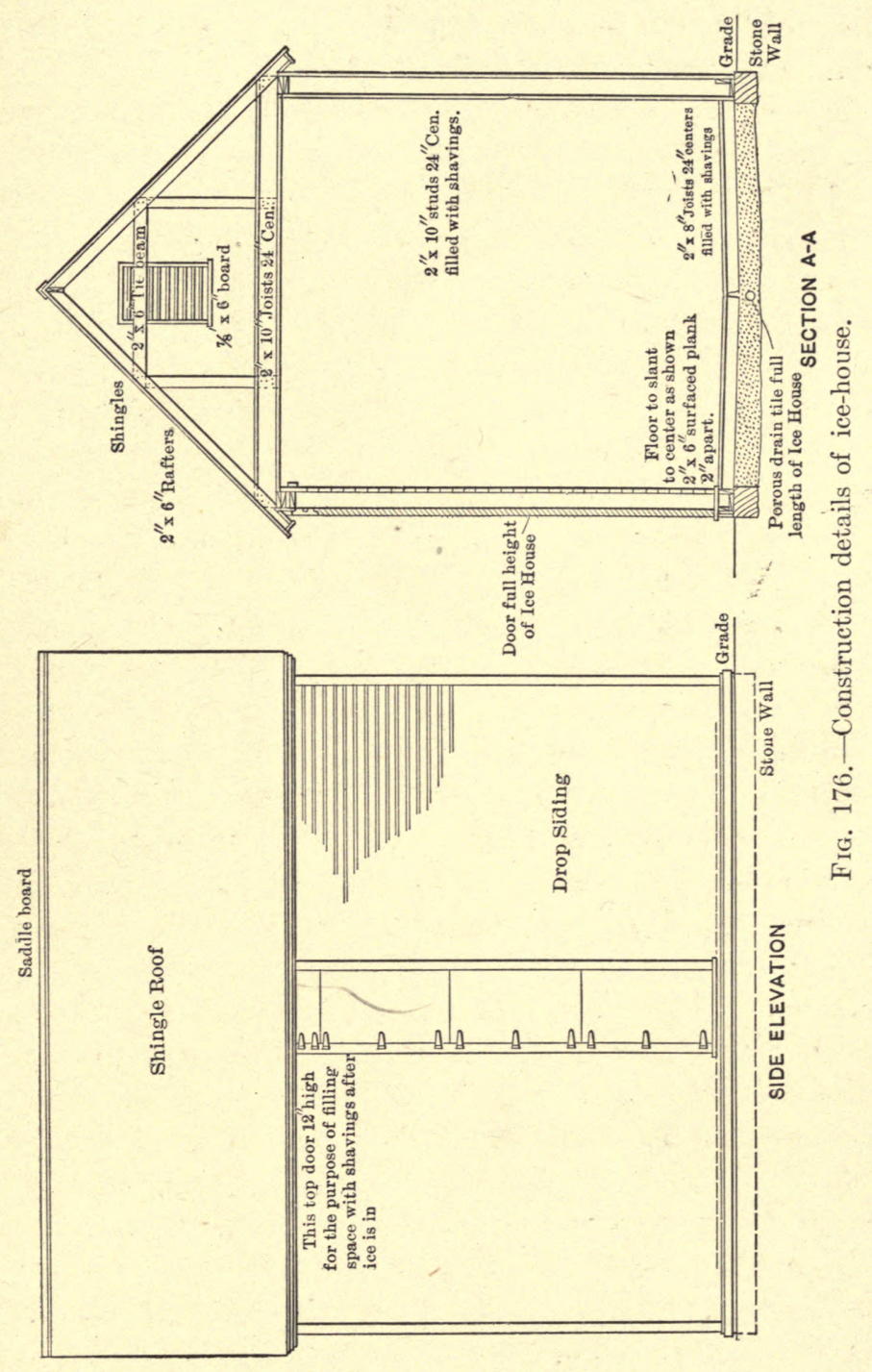


require 700 pounds. If it takes 700 pounds of ice daily for cooling the cream for eight months of the year, which is about the time the cream would have to be cooled by artificial means,

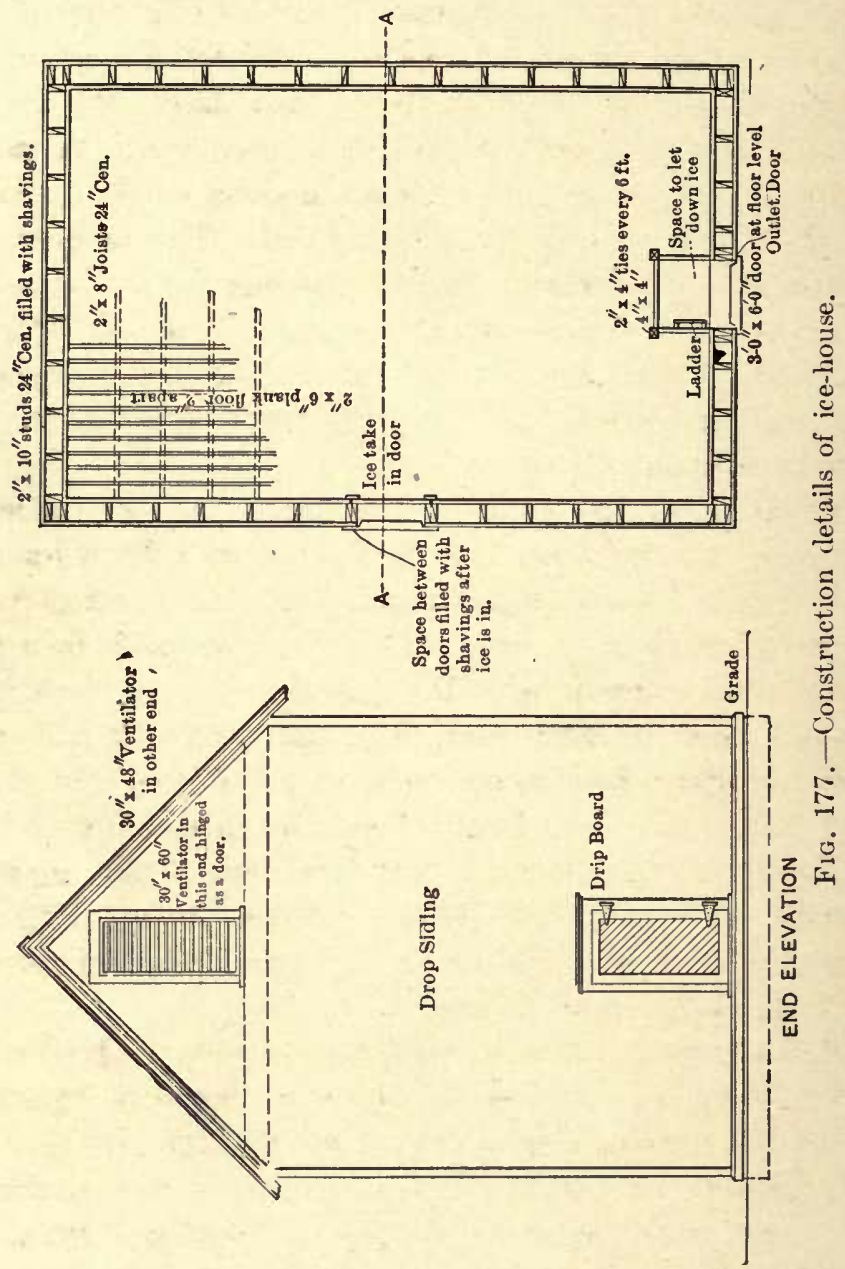

it would take 168,000 pounds of ice per year. As the specific heat of cream is only about 0.7 , the final amount needed for cooling the cream would be only 117,600 pounds, or about 59 tons. 
The next consideration is the ice needed for cooling the butter. Roughly speaking, there will be about 600 pounds of butter. Suppose the butter needs to be cooled $30^{\circ} \mathrm{F}$. Granting that the specific heat of butter is the same as that of water, it would require 30 pounds of ice to cool 142 pounds of butter $30^{\circ} \mathrm{F}$. There will therefore be needed daily 126 pounds of ice for cooling the butter. As the specifie heat of butter is only about $0.4,51$ pounds of ice are necessary daily. For eight months 12,240 pounds will be needed. The amount of ice needed in a refrigerator above that needed for cooling the butter cannot be calculated. We may count on $25 \%$ radiation and $25 \%$ as an allowance for cooling tubs and packages. The total ice needed for cooling the butter will then be 24,480 pounds, or about $12 \frac{1}{4}$ tons.

Counting on $20 \%$ loss incidental to transportation and melting in the ice-house, 89 tons of ice are needed for cooling the cream and butter the number of degrees mentioned above.

One cubic foot of ice at $32^{\circ} \mathrm{F}$. weighs 57.5 pounds. If 1 cubic foot of ice weighs 57.5 pounds, 89 tons would occupy a space equal to 3093 cubic feet, and would require an icehouse of dimensions approximately as follows: $16 \mathrm{ft}$. high, $14 \mathrm{ft}$. wide, and $14 \mathrm{ft}$. long. These dimensions are given only as examples. The height, width, and length may need to be changed to conform with local conditions. One thing should be kept in mind, it is always better to have an ice-house a little too large rather than too small.

Filling the Ice-house.-The chief objects to be sought in packing ice into an icehouse already properly constructed, are: first, to exclude circulation of air through the mass of ice and thus prevent melting; second, to pack it in such a manner that it can easily be removed in whole blocks; third, to pack it with such material that it will leave the ice as clean as is consistent with other important sought objects.

The packing material which is most commonly used in the central western States is sawdust. This is very efficient in excluding air, lasting, and usually cheap, but soils the ice, 
so that considerable water needs to be used with which to rinse it. As a consequence of this latter, considerable ice is wasted. Straw is used successfully. It leaves the ice much cleaner, but is not so effective in preserving the ice. Shavings are good, but as a rule are too expensive and not available. Some use no packing material other than ice and snow. When the blocks of ice are put into the ice-house, they are packed closely together. A man with a hatchet chips the block of ice in such a way as to fit them snugly together. The small cracks are filled with fine ice and snow. The experience of the authors is that, by this method, the blocks of ice are likely to solidly freeze together, so the ice cannot be removed without breaking it up into irregular pieces. This is hard work, and considerable ice is wasted.

Another method of filling ice-houses in successful use is that of running a small layer of water into the building and allowing it to freeze. The doors in the ice-house are opened during a protractive period of cold weather. The bottom of the ice-house is covered with building-paper. Water is run on top of this and allowed to freeze until a layer of ice about a foot in thickness has been obtained. Then another layer of paper is made to cover the ice and more water flooded on and frozen. This process is continued until the ice-house is filled. The paper between the layers prevents the ice from freezing into one solid mass, and facilitates the removal of the ice.

When the ice is stored in an insulated house, combined with the refrigerator, no packing material is used except on the top of the ice. Shavings are good to pile on the top of ice when the ice-house has been filled. They are clean and effective in preserving the ice.

The cost of filling an ice-house with natural ice, obtainable within a distance of about eight miles, will vary in different localities, but may be said to range between $\$ 0.60$ and $\$ 1.25$ per ton. The creamery furnishes a man to pack it into the ice-house. 
Source of Ice.-The ice for creamery use should be obtained from as pure water as possible. A large running stream is always better than a small polluted stream. Usually the creamery can coöperate with butchers, restaurants, hotelmen, and other local ice-users in building a dam in a suitable stream. The ice can also as a rule be harvested cheaper by coöperation.

Some creameries have constructed ice-ponds near the icehouse. If there is a clay or impervious bottom, this works successfully and economically. The pond is filled and kept filled from the creamery water-supply or from a tile drain inlet. Care should be taken not to use stagnant water and water in which weeds and other rubbish have been allowed to accumulate. The pond should be deep enough so that the water will not freeze to the bottom and produce dirty ice. The pond should also be filled with water to overflowing when freezing is begun, otherwise slush and snow are likely to accumulate together with dust from the fields and roads, producing impure ice.

The ice is best when frozen from the top down. A hole is bored and kept open in the ice during the freezing process. Through this opening the pond is supplied with water as rapidly as it subsides. When the water is solidly up against the bottom of the ice it will show in the opening or hole in the ice.

To construet an ice-pond on gravelly soil is useless, and to pack such a pond with a sufficiently thick layer of clay to prevent leakage of water is under most conditions, impracticable.

\section{Usage of ICe in Cooling Cream.}

1. Directly.

2. Indirectly.

1. The cooling of cream in creameries by putting ice directly into the cream has been much practiced in the past. The method is yet used considerably, especially where the old open vats are still in use. Some of these open vats are jacketed 
and some are not. Cream in unjacketed vats could not well be cooled in any other way than by using ice directly in the cream and stirring until cold. To keep cold any length of time, considerable excess of ice needs to be used.

Such a method of cooling cream has its advantages as well as disadvantages. The latter, however, clearly outweighs the former.

The advantages are that the cream can be cooled in a very short time, and it does not require any special investment for up-to-date ripening-vats, nor special machinery for the purpose of pumping the cooling medium.

The chief disadvantages are: First, impurities and undesirable germs are liable to be introduced, which would injure the quality of the cream and otherwise work harm to the quality and keeping property of the butter; second, the melting of the ice would dilute the cream. This would render the cream less sour, impart a marked flat, insipid taste to the cream and butter, and produce more buttermilk which, if it contained a certain per cent fat, would mean a greater loss of fat during the churning process.

The use of ice directly in the cream for cooling purposes should not be resorted to unless it is necessary. With the best quality of cream this method is still more unsatisfactory, as it greatly lowers the quality of butter. With cream in very poor condition previous to ripening, the chances for lowering the quality of butter are not so great.

2. The cooling of cream with ice indirectly is by far the best method. With the use of our up-to-date ripening-vats, the cooling of cream is an easy matter. But where the creamery is already in possession of a good open vat and the management not disposed to discard it to install a new one, the question is different.

Some open vats have a jacket and special open space at one end for holding crushed ice. These vats will control and hold temperature better than those with just a jacket around. The cooling of cream on a large scale by circulating ice-water 
through the jacket, at best, is a slow process. Usually too slow to be effective and practical.

This cooling process is carried out by mixing the ice and water together in a separate vat to which a rotary pump is attached, forcing the water through the jacket and again returned to the ice and water-tank to be cooled. The slowness of this cooling process can in a measure be overcome by mixing salt with the ice and water. This will cause the ice to melt faster, and consequently cool the brine to a lower degree of temperature than was possible to obtain with water and ice.

In case it is desirable, a set of coils can be made which will fit into the open vat. The inlet and outlet of thesc coils can be connected up by means of rubber hose with the pipes conveying the brine to and from the ripener. The coils can be made to move up and down, by means of a rope attached to and leading from the coils through a pulley near the loft and fastened to a small crank at the end of a shaft. When the shaft turns the crank will also turn and cause the coils in the vat to move up and down. In the absence of a special up-todate ripener, this manner of cooling works very satisfactorily.

A butter refrigerator containing a tank, as already described, could be cooled by pumping brine through it in similar manner, as described for cream cooling, except that no coils are needed.

\section{Mechanical Refrigeration.}

Application of in Creameries.-Mechanical refrigeration has been considered expensive and impracticable on a small scale until within a few years. The science of producing cold artificially has been simplified and reduced to such a practical basis that it is now used in many large as well as smaller plants where formerly natural ice was used altogether. Where at least 10,000 pounds of milk, or its equivalent in cream, are received daily during the summer months, mechanical refrigeration is considered practicable. 
On another page a table of comparative cost of natural ice and mechanical refrigeration is given. It was also stated in that connection that the cost of mechanical refrigeration would vary under different conditions. The chief factors affecting the cost of mechanical refrigeration may be said to be similar to those affecting the economic running of the remaining machinery, such as kind of fuel used, skill of fireman, style and condition of boiler, proportion of boiler power to work done, upon the correlative size of all machinery, upon kind of insulation and care of cooling-rooms, and upon efficiency of compressor and whole refrigerating system.

Chemicals Used for Mechanical Refrigeration.-The most common substances used in mechanical refrigeration are ammonia and carbonic acid. A number of others are in use, but from a creamery standpoint, these only are of importance. Ammonia is used chiefly. It is efficient, cheap, and not so dangerous to life and property as are some of the others. Anhydrous ammonia has a boiling-point of $27^{\circ}$ below zero at atmospheric pressure. The latent heat of ammonia is also great. Ammonia has great chemical stability, and is not explosive in nature. Ammonia attacks copper and brass, but has no effect upon iron and steel pipes. If ammonia should escape through a leak into a room, the operator can protect himself from the effects of the gas by breathing through a wet sponge held in the mouth. Ammonia leaks may be detected by holding a glass rod dipped in hydrochloric acid to the place where the leak may be. When ammonia comes in contact with hydrochloric acid, white fumes are formed.

Carbonic acid is used considerably in Europe, and is chiefly favored because the gas is not highly poisonous; in case of leak it does not spoil contents of refrigerator, and it liquefies at a high temperature $\left(90^{\circ}\right.$ to $100^{\circ} \mathrm{F}$.), and is therefore favored in tropical climes.

Principles of Producing Cold Artificially.-The chief principle involved in producing artificial cold is that when a substance passes from a liquid into a gaseous state, a definite amount of 
latent heat is absorbed. When water in a kettle on the stove begins to boil and passes off into steam, no higher temperature can be reached. No matter how much heat is applied under those same conditions, the temperature remains the same. This extra heat is used in transforming the water into steam. If this steam were confined, and that heat removed, by cooling, the steam would again pass into a liquid state. We are familiar with the coolness produced by rapid evaporation of perspiration from the body. Mechanical refrigeration is virtually a process of evaporation of the cooling media, during which heat is absorbed and liquefaction of the cooling medium by compression and cooling to remove that absorbed heat. To increase the ability of the cooling medium to absorb heat it is compressed and liquefied. So we might say that any compression refrigerating system has three separate operations. necessary to form the complete cycle of mechanical refrigeration, viz.:

1. Compression of the ammonia gas.

2. Condensation of the ammonia gas.

3. Expansion of the ammonia gas.

1. The machine which causes the compression of the ammonia gas is called the compressor. In construction it is much like a steam-engine. Small machines are single, but large machines are double acting. Gas is drawn in, on the suction stroke, compressed and discharged on the return stroke. The pressure generated varies between 120 and 175 pounds per square inch. During the compression heat is developed in proportion to pressure exerted. The greater the pressure the higher the temperature of the gas. Part of the heat of compression is carried off by means of a continuous stream of water running through a jacket around the cylinder.

2. From the compressor the gas is forced through the pipes into the condensing coils, in which the warm compressed gas is cooled still more. When sufficient heat has been removed from this gas, it assumes a liquid condition and is ready to expand into a gaseous form for the purpose of absorbing heat 
and producing cold. During the cooling and condensing processes each pound of ammonia parts with about 560 units of heat, which amount can again be absorbed when it expands into gas at the lower pressure.

3. This liquefied gas, which is still under great pressure, is then admitted through what is termed the expansion-valve. This valve is especially constructed for that purpose, and has only a very minute opening in it for the admission of the liquid ammonia. On the expansion side the pressure is low $(20$ to $30 \mathrm{lbs}$.). As the liquid ammonia emerges from the highpressure side through the expansion-valve into the expansion side, it forms a gas. This expanded gas may then be circulated through coils for cooling purposes. From there it passes back into the suction side of the compressor ready to go through another similar cycle.

From the above description it will be seen that there are two sides to the system, the expansion side and the compression side. The compression side extends from the compressor to the expansion-valve; the expansion side from the expansionvalve to the suction side of the compressor, inclusive.

Transferring the Cold.-The methods of transferring the cold to the different places in the building vary. There are two systems, viz. :

1. Direct Expansion.

2. Brine System.

1. By the direct-expansion system the condensing-pipes of the system are extended to the room or place at which the cooling is to be done. An extended set of expansion coils then convey the gas which absorbs the heat. A lower temperature can be produced by this method than with the brine system.

2. In the brine system a large brine-tank is placed somewhere in the creamery at a place most convenient with respect to cooling. This tank contains a strong solution of brine. The chief reason why brine is used in preference to water is that brine has a very low freezing-point. This will vary with different degrees of saturation. 
Either one, sodium chloride (common salt), or calcium chloride, may be used for brine. The latter is considered besi chiefly because it is not so hard on the pipes and it keeps the brine pipes cleaner than does a salt brine. The tables give properties of brine made from these two substances.

Showing Properties of Solution of Salt, (Siebly).

(Chloride of Sodium.)

\begin{tabular}{|c|c|c|c|c|c|c|c|}
\hline $\begin{array}{l}\text { Per cent } \\
\text { of Salt by } \\
\text { Weight. }\end{array}$ & $\begin{array}{l}\text { Pounds } \\
\text { Salt per } \\
\text { Gallon of } \\
\text { Solution. }\end{array}$ & $\begin{array}{c}\text { Degrees on } \\
\text { Salometer } \\
\text { at } 60^{\circ} \mathrm{F} \text {. }\end{array}$ & $\begin{array}{c}\text { Weight } \\
\text { per Gallon } \\
\text { at } 39^{\circ} \mathrm{F} .\end{array}$ & $\begin{array}{c}\text { Specific } \\
\text { Gravity at } \\
39^{\circ} \mathrm{F} . \\
4^{\circ} \mathrm{C}\end{array}$ & $\begin{array}{c}\text { Specific } \\
\text { Heat. }\end{array}$ & $\begin{array}{c}\text { Freezing- } \\
\text { point } \\
\text { Fahr. }\end{array}$ & $\begin{array}{c}\text { Freezing- } \\
\text { point } \\
\text { Cclsius. }\end{array}$ \\
\hline 1 & $0: 084$ & 4 & 8.40 & 1.007 & 0.992 & 30.5 & -0.8 \\
\hline 2 & 0.169 & 8 & 8.46 & 1.015 & 0.984 & 29.3 & -1.5 \\
\hline 2.5 & 0.212 & 10 & 8.50 & 1.019 & 0.980 & 28.6 & -1.9 \\
\hline 3 & 0.256 & 12 & 8.53 & 1.023 & 0.976 & 27.8 & -2.3 \\
\hline 3.5 & 0.300 & 14 & 8.56 & 1.026 & 0.972 & 27.1 & -2.7 \\
\hline 4 & 0.344 & 16 & 8.59 & 1.030 & 0.968 & 26.6 & -3.0 \\
\hline 5 & 0.433 & 20 & 8.65 & 1.037 & 0.960 & 25.2 & -3.8 \\
\hline 6 & 0.523 & 24 & 8.72 & 1.045 & 0.946 & 23.9 & -4.5 \\
\hline 7 & 0.617 & 28 & 8.78 & 1.053 & 0.932 & 22.5 & -5.3 \\
\hline 8 & 0.708 & 32 & 8.85 & 1.061 & 0.919 & 21.2 & -6.0 \\
\hline 9 & 0.802 & 36 & 8.91 & 1.068 & 0.905 & 19.9 & -6.7 \\
\hline 10 & 0.897 & 40 & 8.97 & 1.076 & 0.892 & 18.7 & -7.4 \\
\hline 12 & 1.092 & 48 & 9.10 & 1.091 & 0.874 & 16.0 & -8.9 \\
\hline 15 & 1.389 & 60 & 9.26 & 1.115 & 0.855 & 12.2 & -11.0 \\
\hline 20 & 1.928 & 80 & 9.64 & 1.155 & 0.829 & 6.1 & -14.4 \\
\hline 24 & 2.376 & 96 & 9.90 & 1.187 & 0.795 & 1.2 & -17.1 \\
\hline 25 & 2.488 & 100 & 9.97 & 1.196 & 0.783 & $0 . \overline{5}$ & -17.8 \\
\hline 26 & 2.610 & 104 & 10.04 & 1.204 & 0.771 & -1.1 & -18.4 \\
\hline
\end{tabular}

Properties of Solution of Chloride of Calcium. (Siebly).

\begin{tabular}{c|c|c|c|c}
\hline $\begin{array}{c}\text { Per cent by } \\
\text { Weight. }\end{array}$ & Specific Heat. & $\begin{array}{c}\text { Specific Gravity } \\
\text { at 60 Fahr. }\end{array}$ & $\begin{array}{c}\text { Freezing-point } \\
\text { in Degrees Fahr. }\end{array}$ & $\begin{array}{c}\text { Freezing-point } \\
\text { in Degrees Cels. }\end{array}$ \\
\cline { 2 - 2 } 1 & 0.996 & 1.009 & 31 & -0.5 \\
5 & 0.964 & 1.043 & 27.5 & -2.5 \\
10 & 0.896 & 1.087 & 22 & -5.6 \\
15 & 0.860 & 1.134 & 15 & -9.6 \\
20 & 0.834 & 1.182 & 5 & -14.8 \\
25 & 0.790 & 1.234 & -8 & -22.1 \\
\hline
\end{tabular}

The expansion-coils pass through the brine-tank and cool the brine. Special pumps force the cold brine through pipes to the cream vat, cooling coils, ice-cream freezer, etc. 
For creameries the brine system is the only practical system. It is preferred because, first, cold can be stored in an insulated brine-tank and used at will without running the compressor. In case of a prolonged stoppage due to some accident a brine made by a mixture of ice-water and salt could be temporarily substituted; second, less ammonia is required to charge the system; third, fewer couplings and less ammonia pipes are necessary. This latter would decrease the danger of ammonia leakage and cost of pipes. 


\section{CHAPTER XXII.}

\section{ECONOMIC OPERATION OF CREAMERY.}

INASMUCH as it is impossible within the limited space in this work to take up a detailed discussion of the various principles and practices of operating boilers, engines, mechan:cal refrigerators, and other creamery machinery, only a few of the chief factors common to creamery practice and effecting the economic operation shall here be discussed. For more complete information students are referred to works treating specially of these phases.

Firing the Boiler.-Much fuel can be wasted and saved according to the completeness with which the combustion occurs. This again depends upon the manner of firing, upon the regulation of the draught, and upon the kind of boiler. The fire on the grates should never be too thick nor should too much coal be loaded on the fire at any one time. A thin, even fire permits of a more complete combustion than when clinkers and cinders are allowed to accumulate on bottom of fire, and a heap of unburned coal on top. By this latter method of firing, the grates are likely to be injured.

To get the most heat from the coal the draught should be regulated. The combustible part of the coal is of two kinds: first, the fixed carbon, and second, the volatile matter. The former is the coke or the part of coal which is seen on the grates as a mass of glowing fire. The latter consists of the gases which pass off when a certain temperature is reached, and which, when mixed with a certain amount of air at a given temperature, will burn. The heavy black trail of smoke seen rising 
from chimneys is partially wasted coal. If the grates are choked with a thick fire, no air can pass through, and the volatile parts of coal pass off without being burned.

Burning Wood or Coal.-In some localities this question is of minor importance, as conditions may be such that coal only can be used. In other sections, where both are obtainable, it is of great importance. The following table* shows figures obtained at five factories in Wisconsin where soft coal was burned and five others where wood was used.

Daily Fuel Used at Several Creameries.

\begin{tabular}{|c|c|c|c|}
\hline $\begin{array}{c}\text { Pounds of Milk } \\
\text { Skimmed } \\
\text { per Day. }\end{array}$ & $\begin{array}{l}\text { Pounds of } \\
\text { Soft Coal } \\
\text { Burned. }\end{array}$ & $\begin{array}{l}\text { Cost of Coal } \\
\text { per Ton. }\end{array}$ & $\begin{array}{c}\text { Estimated Cost } \\
\text { per Day. }\end{array}$ \\
\hline $\begin{array}{r}3500 \\
8000 \\
23000 \\
6000 \\
5300\end{array}$ & $\begin{array}{r}500 \\
400 \\
1000 \\
300 \\
500\end{array}$ & $\begin{array}{r}\$ 3.55 \\
3.00 \\
4.05 \\
3.50 \\
3.15\end{array}$ & $\begin{array}{r}\$ 0.90 \\
0.60 \\
2.00 \\
0.50 \\
0.80\end{array}$ \\
\hline $\begin{array}{l}\text { Pounds of Milk } \\
\text { Skimmed } \\
\text { per Day. }\end{array}$ & $\begin{array}{l}\text { Cords of Wood } \\
\text { Burned. }\end{array}$ & Price per Cord. & $\begin{array}{c}\text { Estimated Cost } \\
\text { per Day. }\end{array}$ \\
\hline $\begin{array}{r}2000 \\
3400 \\
6500 \\
\times 3800 \\
4500\end{array}$ & $\begin{array}{l}\frac{1}{4} \\
\frac{1}{6} \\
\frac{1}{4} \\
\frac{1}{1} \\
\frac{1}{6} \\
\frac{1}{3}\end{array}$ & $\begin{array}{r}\$ 1.25 \\
2.25 \\
1.25 \\
2.25 \\
1.80\end{array}$ & $\begin{array}{r}\$ 0.32 \\
0.37 \\
0.32 \\
0.37 \\
0.60\end{array}$ \\
\hline
\end{tabular}

These are the best obtainable figures of comparison under creamery conditions.

In connection with burning wood the dryness of it is an important consideration. If the wood is wet its power of producing heat is greatly lessened. A certain amount of heat is used in evaporating the water in the wood. Air-dry wood will contain from $12 \%$ to $25 \%$ water. The quality of coal is another variable factor. In general, and from table below, it might be said that $2 \frac{1}{2}$ pounds of wood are equal to one pound of lump coal.

* Farrington in Hoard's Dairyman. 
The following comparative table is given by Kent:

Hickory or hard maple, weight per cord $4500 \mathrm{lbs} .=1800$ to $2000 \mathrm{lbs}$. of coal. White oak

Poplar, chestnut and cedar " " " 2350 " " $=940$ to 1050 " " “ "

Pine “ " " 2000 “ $=800$ to 925 “ " “

Whether a creamery can economically use slack or lump coal is another question worth considering. Slack coal is used very little in local creameries, first, because it is more difficult to use in firing. Usually help is scarce, and coal which requires less attention in firing than slack, is preferred. Second, slack coal is subject to spontaneouskcombustion and likely to set buildings afire. Some, if not all insurance companies, discriminate against creameries using slack coal as fuel. Third, special grates (rocking grates) are essential to get best results from using slack. Fourth, slack coal is dirty and the dust from it will lodge all over in the boiler and engine room.

Slack coal, where conditions are at all favorable for its use, is, as a rule, cheap to burn. According to experimental data, 1 pound of slack coal will produce about 4 pounds of steam, and 1 pound of lump coal will produce about 6 pounds of steam. The price of the two will vary, but usually the relation is, slack coal, $\$ 1.25$ per ton; lump coal, $\$ 3.25$ per ton. If 1 pound of lump coal produces 6 pounds of steam, a ton will produce 12,000 pounds. If 1 pound of slack coal produces 4 pounds of steam, to produce 12,000 pounds will require 2992 pounds of slack coal, which would cost \$1.87. The difference in producing 12,000 pounds of steam in favor of slack coal would then be $\$ 1.38$.

Daily Weighing of Coal Used. - The advantage of daily weighing of coal used in creameries cannot be too strongly emphasized. That business phase of creamery work has been much neglected in the past. If the coal used daily is not weighed, a serious loss or leak may continue without detection. Firing the boiler is a daily occurrence, and if a small loss occurs, the total loss at the end of the year would cut short the profits. 
The weighing can conveniently be done by fitting a box similar to an enlarged flat-sided curd pail in shape on a pair of platform scales. After the scale and box have been purchased there are nc additional expenses and very little extra labor required.

Cleaning the Boiler.-The amount of coal used will vary with several factors, viz.: cleanliness of flues, sediment in the boiler, condition of fire, kind of boiler, steam leaks, pipe insulation, etc. The two first factors are frequently neglected. The flues should be cleaned every morning before the day's run. The inside of the boiler should be kept clean. Heavy scale on the inside of the boiler and flues, and heavy sediments on the bottom of the boiler, should never be allowed to accumulate. Some water naturally contains a large amount of minerals and leaves a heavy deposit in the boiler. The operator should learn to know the condition of the water, and the frequency of cleaning the inside of the boiler be governed accordingly. One cleaning per month is sufficient with most water. In some instances, one cleaning per week is necessary.

The collection of scale and sediment within the boiler affect the economic operation in at least three ways: First, more fuel is needed; second, the boiler itself is likely to warp; third, foaming or priming of the boiler is likely to occur. If scale clings to the flues when washed, it may be removed by putting some sal-sodla and water into the boiler and boil for several hours. Some use a boiler compound for preventing scales. This is not necessary, nor to be recommended except in extreme cases of mineral water. The boiler should be frequently blown off at low pressure.

Priming of Boilers.-When considerable water passes over with the steam the boiler is said to be priming. This water in the steam interferes with the running of the engine. So much water in the steam fills the engine-cylinder and results in broken piston or cylinder-head. The engine jerks and thumps to such an extent that there is danger of breaking other parts of the machinery. 
The foaming or priming of boilers is due chiefly to:

1. Too much water in the boiler.

2. Working the boiler beyond its capacity.

3. Allowing mud and minerals to accumulate in boiler.

4. Using too much of certain boiler compounds.

5. Some water naturally contains a large percentage of certain minerals which are conducive to foaming.

The Injector.-The injector on the boiler frequently causes the operator some annoyance by refusing to work. The common causes of this are:

1. Too low boiler steam pressure.

2. Steam obtained from a pipe already supplying steam for other purposes.

3. Leaks in suction pipe due to shortage of supply pipe or holes in pipe.

4. Too hot supply water.

5. Scale in injector, preventing proper working of valves.

6. Steam containing too much water.

Oil-separators.-Considerable saving can be accomplished in a creamery if the exhaust steam is utilized. This steam may be used for pasteurizing the skim-milk, for heating the milk previous to separation, for heating the creamery, and for heating the water for the boiler.

The exhaust steam contains considerable oil and should be purified before it is used for any other purposes. Several forms of these steam purifiers are on the market. They are simple, inexpensive, and can be attached to the exhaust-pipe of any engine.

All steam and water pipes should be carefully drained in the winter to prevent freezing.

Belts, Pulley and Speed Calculation.-The length of a belt may best be determined by measuring over the two pulleys with a tape or a string.

To calculate the size of a drive pulley when the speed of it is known, the diameter of the driver pulley is multiplied by its speed, the product divided by the speed of the driven 
pulley, the quotient will be the diameter or size of the needed pulley.

To calculate the speed of a driven pulley, multiply the diameter by the speed of the driver pulley and divide the product by the diameter of the driven pulley; the quotient is the speed or number of revolutions per minute. 


\section{APPENDIX.}

\section{LEGAL STANDARDS FOR MILK--DAIRY LAWS.*}

The following States and Territories, viz., Alabama, Arizona, Arkansas, California, Colorado, Delaware, Florida, Louisiana, Mississippi, Missouri, Montana, North Dakota, Texas, and Wyoming, have established no legal standard.

The Dominion of Canada, Connecticut, Idaho, Illinois, Indiana, Kansas, Kentucky, Maryland, Nebraska, Nevada, New Mexico, North Carolina, Oklahoma, South Dakota, Tennessee, Utah, Virginia, and West Virginia have general laws prohibiting dilution, skimming, or other adulteration.

In other States the percentage standards are as follows:

District of Columbia.

\begin{tabular}{lll}
$\begin{array}{c}\text { Specific } \\
\text { Gravity. }\end{array}$ & \multicolumn{1}{c}{$\begin{array}{c}\text { Total } \\
\text { Solids. } \\
\text { Per Cent. }\end{array}$} \\
$\ldots \ldots \ldots \ldots$ & 12.5 & 3.5 \\
$\ldots \ldots \ldots \ldots$ & 12 & 3.5 \\
$\ldots \ldots \ldots \ldots$ & 12.5 & 3 \\
$\ldots \ldots \ldots \ldots$ & 12 & 3 \\
$\ldots \ldots \ldots \ldots$ & 12 & 3 \\
$\ldots \ldots \ldots \ldots$ & 13 & 3.7 \\
$1.029-1.033$ & 12.5 & 3 \\
$\ldots \ldots \ldots \ldots$ & 13 & 3.5 \\
$\ldots \ldots \ldots \ldots$ & 13 & $\ldots$ \\
$\ldots \ldots \ldots$ & 12 & $\ldots$ \\
$\ldots \ldots \ldots \ldots$ & 12 & 3 \\
$\ldots \ldots \ldots \ldots$ & 11.5 & $\ldots$ \\
$\ldots \ldots \ldots$ & 12 & 3 \\
$\ldots \ldots \ldots \ldots$ & 12 & 3 \\
$1.029-1.033$ & 12.5 & 3 \\
$\ldots \ldots \ldots \ldots$ & 12 & 2.5 \\
$\ldots \ldots \ldots \ldots$ & 11.5 & 3 \\
$\ldots \ldots \ldots \ldots$ & 12 & $\ldots$ \\
$\ldots \ldots \ldots$ & 12.5 & $\ldots$ \\
$\ldots \ldots \ldots$ & 11 & 3 \\
$\ldots \ldots \ldots$ & $\ldots \ldots$ & 3
\end{tabular}

Washington.
Wisconsin.

Georgia............................ 12

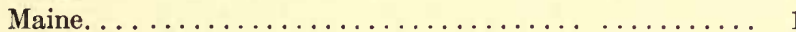

Massachusetts (Apr. to Aug., inclusive). ... ...... 12

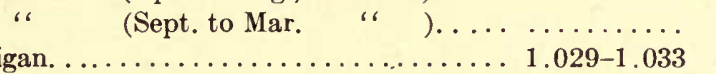

Michigan.

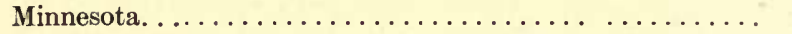

New Hampshire........................

New Jersey........................ 12

New York......................... 12

Ohio (May and June)................... 11.5

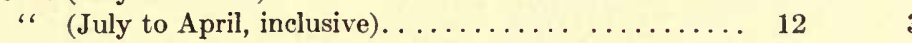

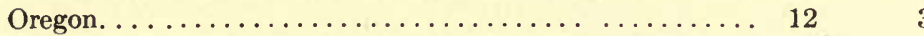

Pennsylvania $\nmid \ldots \ldots \ldots \ldots \ldots \ldots \ldots \ldots \ldots \ldots .1 .029-1.033 \quad 12.5$

Rhode Island. ....................... 12

South Carolina......................... 3

Vermont (May and June). . . . . . . . . . . .

" (July to April, inclusive)............. $12.5 \quad \ldots$

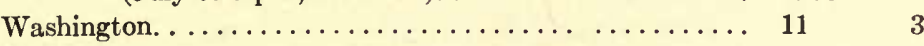

Wisconsin. .................................

* From Wing in "Milk and Its Products."

$\dagger$ Applies only to cities of the second and third classes. 


\section{METRIC SYSTEM.*}

METRIC SYSTEM OF WEIGHTS AND MEASURES AND TABLES FOR THE CONVERSION OF METRIC WEIGHTS AND MEASURES INTO CUSTOMARY UNITED STATES EQUIVALENTS AND THE REVERSE.

In the metric system the moter is the base of all the weights and measures which it employs.

The meter was intended to be, and is very nearly, one t: $\mathbf{n}_{-}$millionth part of the clistance measured on a meridian of th . earth from the equator to the pole, and equals about 39.37 inches or nearly 3 feet $3 \frac{3}{8}$ inches.

The meter is the primary unit of length.

Upon the meter are based the following primary units: the square meter, the are, the cubic meter or stere, the liter, and the gram.

The square meter is the unit of measure for small surfaces; as the surface of a floor, table, etc.

The are is the unit of land measure; this is a square whose side is 10 meters in length, and which contains 100 square meters.

The cubic meter or stere is the unit of volume; this is a cube whose edge is 1 meter in length.

The liter is the unit of capacity; this is the capacity of a cube whose edge is one-tenth of a meter in length.

The gram is the unit of weight; this is the weight of distilled water contained in a cube whose edge is the one-hundredth part of a meter; a gram is therefore the one-thousandth part of a kilogram, and the one-millionth part of a metric ton.

* From The American Chamber of Commerce. 
Measures of Length.

\begin{tabular}{|c|c|c|}
\hline \multicolumn{2}{|c|}{ Metric Denominations and Values. } & Equivalents in Denominations in Use. \\
\hline Myriameter. & 10,000 meters & 6.2137 miles \\
\hline Kilometer. . & 1,000 meters & $.62137 \mathrm{mile}$, or $3,280 \mathrm{ft} .10 \mathrm{in}$. \\
\hline Hectometer. . . . . . . & 100 meters & 328 feet 1 inch \\
\hline Dekameter... & 10 meters & 393.7 inches \\
\hline Meter...... & 1 meter & 39.37 inches \\
\hline Decimeter. . . . . . & .1 meter & 3.937 inches \\
\hline Centimeter. . . . . . & .01 meter & .3937 inch \\
\hline Millimeter. ....... & .001 meter & .0394 inch \\
\hline
\end{tabular}

Measures of Surface,

\begin{tabular}{|c|c|c|}
\hline \multicolumn{2}{|c|}{ Metric Denominations and Values. } & Equivalents in Denominations \\
\hline $\begin{array}{l}\text { Hectare. . . . . . . } \\
\text { Are. . . . . . . . . } \\
\text { Centare. }\end{array}$ & $\begin{array}{c}10,000 \text { square meters } \\
100 \text { square meters } \\
1 \text { square neter }\end{array}$ & $\begin{array}{l}2.471 \text { acres } \\
119.6 \text { square yards } \\
1,550 \text { square inches }\end{array}$ \\
\hline
\end{tabular}

Measures of Capacity.

\begin{tabular}{|c|c|c|c|c|}
\hline \multicolumn{3}{|c|}{ Metric Denominations and Values. } & \multicolumn{2}{|c|}{$\begin{array}{l}\text { Equivalents in Denominations } \\
\text { in Use. }\end{array}$} \\
\hline Names. & $\begin{array}{l}\text { No. of } \\
\text { Liters. }\end{array}$ & Cubic Measure. & Dry Measure. & $\begin{array}{l}\text { Liquid or Wine } \\
\text { Measure. }\end{array}$ \\
\hline $\left.\begin{array}{c}\text { Kiloliter } \\
\text { or stere. . }\end{array}\right\}$ & 1,000 & 1 cubic meter & $1.308 \mathrm{cu} . \mathrm{yds}$. & 264.17 gals. \\
\hline Hectoliter. & 100 & .1 cubic meter & 2 bush. 3.35 pks. & 26.417 gals. \\
\hline Dekaliter. & 10 & $10 \mathrm{cu}$. decimeters & 9.08 quarts & 2.6417 gals. \\
\hline Liter. ... . . . . & 1 & $1 \mathrm{cu}$. decimeter & .908 quart & $1.0567 \mathrm{gts}$. \\
\hline Deciliter... . & .1 & $.1 \mathrm{cu}$. decimeter & $6.1022 \mathrm{cu}$. ins. & .845 gill \\
\hline Centiliter. . . & .01 & $10 \mathrm{cu}$. centimeters & .6102 cu. in. & .338 fl. oz. \\
\hline Milliliter.. & .001 & $1 \mathrm{cu}$. centimeter & $.061 \mathrm{cu}$. in. & .27 fl.dram \\
\hline
\end{tabular}


WeIghts.

\begin{tabular}{|c|c|c|c|}
\hline \multirow[t]{2}{*}{ Metrio } & \multicolumn{2}{|c|}{ Denominations and Values. } & \multirow{2}{*}{$\begin{array}{l}\begin{array}{c}\text { Equivalents in Deno- } \\
\text { minations in Use. }\end{array} \\
\text { Avoirdupois Weight. }\end{array}$} \\
\hline & $\begin{array}{l}\text { Number of } \\
\text { Grams. }\end{array}$ & $\begin{array}{l}\text { Weight of What } \\
\text { Quantity of Water at } \\
\text { Maximum Density. }\end{array}$ & \\
\hline 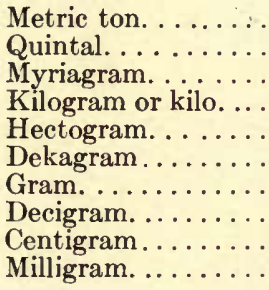 & $\begin{array}{r}1,000,000 \\
100,000 \\
10,000 \\
1,000 \\
100 \\
10 \\
1 \\
.1 \\
.01 \\
.001\end{array}$ & $\begin{array}{l}1 \text { cubic meter } \\
1 \text { hectoliter } \\
1 \text { dekaliter } \\
1 \text { liter } \\
1 \text { deciliter } \\
10 \text { cubic centimeters } \\
1 \text { cubic centimeter } \\
.1 \text { cubic centimeter } \\
10 \text { cubic millimeters } \\
1 \text { cubic millimeter }\end{array}$ & $\begin{array}{c}2204.6 \text { pounds } \\
220.46 \text { pounds } \\
22.046 \text { pounds } \\
2.2046 \text { pounds } \\
3.5274 \text { ounces } \\
.3527 \text { ounce } \\
15.432 \text { grains } \\
1.5432 \text { grains } \\
.1543 \text { grain } \\
.0154 \text { grain }\end{array}$ \\
\hline
\end{tabular}

Common Measures and Weights, with their Metric Equivalents.

The following are some of the Measures in common use, with their equivalents in measures of the Metric System:

\begin{tabular}{|c|c|c|c|}
\hline $\begin{array}{l}\text { (joinmon } \\
\text { Measures. }\end{array}$ & Equivalents. & Common Measures. & Equivalents. \\
\hline $\begin{array}{l}1 \text { inch } \\
1 \text { foot } \\
1 \text { yard } \\
1 \text { rod } \\
1 \text { mile } \\
1 \text { square inch } \\
1 \text { square foot } \\
1 \text { square yard } \\
1 \text { square rod } \\
1 \text { acre } \\
1 \text { square mile } \\
1 \text { culbic inch } \\
1 \text { cubic foot } \\
1 \text { cubic yard }\end{array}$ & $\begin{array}{c}2.54 \text { centimeters } \\
.3048 \text { meter } \\
.9144 \text { meter } \\
5.029 \text { meters } \\
1.6093 \text { kilometers } \\
6.452 \mathrm{sq} . \text { centimeters } \\
.0929 \mathrm{sq} . \text { meter } \\
.8361 \mathrm{sq} . \text { meter } \\
25.29 \mathrm{sq} . \text { meters } \\
.4047 \text { hectare } \\
259 \text { hectares } \\
16.39 \mathrm{cu} . \text { centimeters } \\
.02832 \text { cu. meter } \\
.7646 \mathrm{cu} . \text { meter }\end{array}$ & $\begin{array}{l}1 \text { cord } \\
1 \text { liquid quart } \\
1 \text { gallon } \\
1 \text { dry quart } \\
1 \text { peck } \\
1 \text { bushel } \\
1 \text { ounce av'd'p } \\
1 \text { pound av'd'p } \\
1 \text { ton ( } 2000 \text { lbs.) } \\
1 \text { ton ( } 2240 \text { lbs.) } \\
1 \text { grain troy } \\
1 \text { ounce troy } \\
1 \text { pound troy }\end{array}$ & $\begin{array}{c}\text { 3.624 steres } \\
.9465 \text { liter } \\
3.86 \text { liters } \\
1.101 \text { liters } \\
8.811 \text { liters } \\
35.24 \text { liters } \\
28.35 \text { grams } \\
.4536 \text { kilogram } \\
.9072 \text { metric ton } \\
1.016 \text { metric ton } \\
.0648 \text { gram } \\
\text { 31.104 grams } \\
.3732 \text { kilogram }\end{array}$ \\
\hline
\end{tabular}


Table for the Conversion of Metric Weights and Measures into Customary United States Equivalents and the Reverse.

From the legal equivalents are deduced the following tables for converting United States weights and measures.

METRIC TO CUSTOMARY.

Linear Measure.

\begin{tabular}{c|c|c|c}
\hline Meters = Inches. & Meters=Feet. & Meters = Yards. & Kilometers = Miles. \\
\cline { 1 - 2 } $1=39.37$ & $1=3.28087$ & $1=1.093623$ & $1=0.62137$ \\
$2=78.74$ & $2=6.56174$ & $2=2.187246$ & $2=1.24274$ \\
$3=118.11$ & $3=9.84261$ & $3=3.280869$ & $3=1.86411$ \\
$4=157.48$ & $4=13.12348$ & $4=4.374492$ & $4=2.48548$ \\
$5=196.85$ & $5=16.40435$ & $5=5.468175$ & $5=3.10685$ \\
$6=236.22$ & $6=19.68522$ & $6=6.561738$ & $6=3.72822$ \\
$7=275.59$ & $7=22.96609$ & $7=7.655361$ & $7=4.34959$ \\
$8=314.96$ & $8=26.24696$ & $8=8.748984$ & $8=4.97096$ \\
$9=354.33$ & $9=29.52783$ & $9=9.842607$ & $9=5.59233$ \\
& & & \\
\hline
\end{tabular}

CUSTOMARY TO METRIC.

Linear Measure.

\begin{tabular}{c|c|c|c}
\hline Inches = Centimeters. & Feet $=$ Meters. & Meters $=$ Yards. & Miles= Kilometers. \\
\cline { 2 - 3 } $1=2.54$ & $1=0.304798$ & $1=0.914393$ & $1=1.60935$ \\
$2=5.08$ & $2=0.609596$ & $2=1.828787$ & $2=3.21869$ \\
$3=7.62$ & $3=0.914393$ & $3=2.743179$ & $3=4.82804$ \\
$4=10.16$ & $4=1.219191$ & $4=3.657574$ & $4=6.43739$ \\
$5=12.70$ & $5=1.523989$ & $5=4.571966$ & $5=8.04674$ \\
$6=15.24$ & $6=1.828787$ & $6=5.486358$ & $6=9.65608$ \\
$7=17.78$ & $7=2.133584$ & $7=6.400753$ & $7=11.26543$ \\
$8=20.32$ & $8=2.438382$ & $8=7.315148$ & $8=12.87478$ \\
$9=22.86$ & $9=2.743179$ & $9=8.229537$ & $9=14.48412$ \\
& & &
\end{tabular}


Square Measure.

\begin{tabular}{|c|c|c|}
\hline 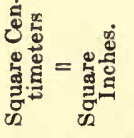 & 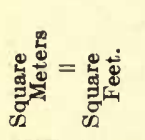 & 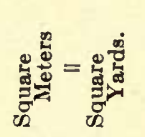 \\
\hline $\begin{array}{l}1=0.155 \\
2=0.310 \\
3=0.465 \\
4=0.620 \\
5=0.775 \\
6=0.930 \\
7=1.085 \\
8=1.240 \\
9=1.395\end{array}$ & $\begin{array}{l}1=10.764 \\
2=21.528 \\
3=32.292 \\
4=43.055 \\
5=53.819 \\
6=64.583 \\
7=75.347 \\
8=86.111 \\
9=96.874\end{array}$ & $\begin{array}{l}1=1.196 \\
2=2.392 \\
3=3.588 \\
4=4.784 \\
5=5.980 \\
6=7.176 \\
7=8.372 \\
8=9.568 \\
9=10.764\end{array}$ \\
\hline
\end{tabular}

Cobic Measure.

\begin{tabular}{|c|c|}
\hline 這产 & 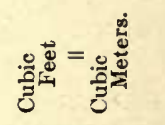 \\
\hline $\begin{array}{l}1=35.315 \\
2=70.631 \\
3=105.947 \\
4=141.262 \\
5=176.584 \\
6=210.899 \\
7=247.209 \\
8=282.525 \\
9=317.840\end{array}$ & $\begin{array}{l}1=0.02832 \\
2=0.05663 \\
3=0.08495 \\
4=0.11326 \\
5=0.14158 \\
6=0.16990 \\
7=0.19821 \\
8=0.22653 \\
9=0.25484\end{array}$ \\
\hline
\end{tabular}

Square Measure.

\begin{tabular}{|c|c|c|}
\hline 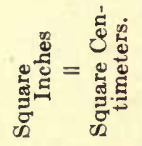 & 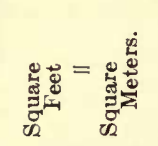 & 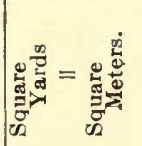 \\
\hline $\begin{array}{l}1=6.452 \\
2=12.903 \\
3=19.354 \\
4=25.806 \\
5=32.257 \\
6=38.709 \\
7=45.160 \\
8=51.612 \\
9=58.063\end{array}$ & $\begin{array}{l}1=0.09290 \\
2=0.18581 \\
3=0.27871 \\
4=0.37161 \\
5=0.46452 \\
6=0.55742 \\
7=0.65032 \\
8=0.74323 \\
9=0.83613\end{array}$ & $\begin{array}{l}1=0.836 \\
2=1.672 \\
3=2.508 \\
4=3.344 \\
5=4.181 \\
6=5.017 \\
7=5.853 \\
8=6.689 \\
9=7.525\end{array}$ \\
\hline
\end{tabular}

Lrquid Measure.

\begin{tabular}{|c|c|c|}
\hline 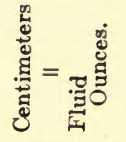 & 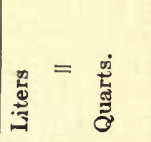 & 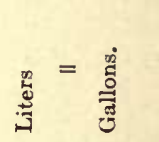 \\
\hline $1=0.338$ & $1=1.0567$ & $1=0.26417$ \\
\hline $2=0.676$ & $2=2.1134$ & $2=0.52834$ \\
\hline $3=1.014$ & $3=3.1700$ & $3=0.79251$ \\
\hline $4=1.352$ & $4=4.2267$ & $4=1.05668$ \\
\hline $5=1.691$ & $5=5.2834$ & $5=1.32085$ \\
\hline $6=2.029$ & $6=6.3401$ & $6=1.58502$ \\
\hline $7=2.368$ & $7=7.3968$ & $7=1.84919$ \\
\hline $8=2.706$ & $8=8.4534$ & $8=2.11336$ \\
\hline $9=3.043$ & $9=9.5101$ & $9=2.37753$ \\
\hline
\end{tabular}

Dry Measure.

\begin{tabular}{|c|c|}
\hline 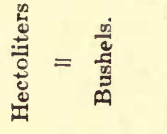 & 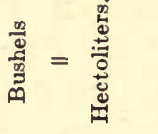 \\
\hline $1=2.8375$ & $1=0.35242$ \\
\hline $2=5.6750$ & $2=0.70485$ \\
\hline $3=8.5125$ & $3=1.05727$ \\
\hline $4=11.3500$ & $4=1.40969$ \\
\hline $5=14.1875$ & $5=1.76211$ \\
\hline $6=17.0250$ & $6=2.11454$ \\
\hline $7=19.8625$ & $7=2.46696$ \\
\hline $8=22.7000$ & $8=2.81938$ \\
\hline $9=25.5375$ & $9=3.17181$ \\
\hline
\end{tabular}

Liquid Measure.

\begin{tabular}{|c|c|c|}
\hline 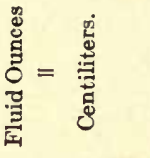 & 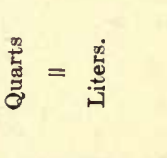 & 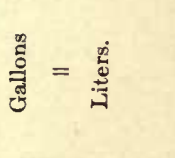 \\
\hline $\begin{array}{l}1=2.957 \\
2=5.915 \\
3=8.872 \\
4=11.830 \\
5=14.787 \\
6=17.744 \\
7=20.702 \\
8=23.659 \\
9=26.616\end{array}$ & $\begin{array}{l}1=0.94636 \\
2=1.89272 \\
3=2.83908 \\
4=3.38544 \\
5=4.33180 \\
6=5.67816 \\
7=6.62452 \\
8=7.57098 \\
9=8.51724\end{array}$ & $\begin{array}{l}1=3.78544 \\
2=7.57088 \\
3=11.35632 \\
4=15.14176 \\
5=18.92720 \\
6=22.71264 \\
7=26.49808 \\
8=30.28352 \\
9=34.06896\end{array}$ \\
\hline
\end{tabular}


Weight (Avoirdupois).

\begin{tabular}{|c|c|c|c|}
\hline 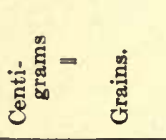 & 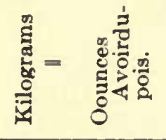 & 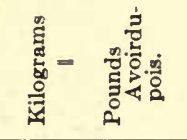 & 递总 \\
\hline $\begin{array}{l}1=0.1543 \\
2=0.3086 \\
3=0.4630 \\
4=0.6173 \\
5=0.7716 \\
6=0.9259 \\
7=1.0803 \\
8=1.2346 \\
9=1.3889\end{array}$ & $\begin{array}{l}1=735.274 \\
2=70.548 \\
3=105.822 \\
4=141.096 \\
5=176.370 \\
6=211.644 \\
7=246.918 \\
8=282.192 \\
9=317.466\end{array}$ & $\begin{array}{l}1=2.20462 \\
2=4.40924 \\
3=6.61386 \\
4=8.81849 \\
5=11.02311 \\
6=13.22773 \\
7=15.43235 \\
8=17.63697 \\
9=19.84159\end{array}$ & $\begin{array}{l}1=0.9842 \\
2=1.9684 \\
3=2.9526 \\
4=3.9368 \\
5=4.9210 \\
6=5.9052 \\
7=6.8894 \\
8=7.8736 \\
9=8.8578\end{array}$ \\
\hline
\end{tabular}

\begin{tabular}{|c|c|c|c|}
\hline 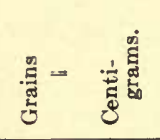 & 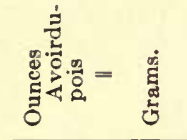 & 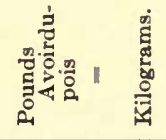 & 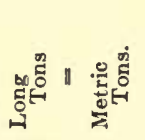 \\
\hline $\begin{array}{l}1=6.4799 \\
2=12.9598 \\
3=19.4397 \\
4=25.9196 \\
5=32.3995 \\
6=38.8793 \\
7=45.3592 \\
8=51.8391 \\
9=58.3190\end{array}$ & $\begin{array}{l}1=28.3495 \\
2=56.6991 \\
3=85.0486 \\
4=113.3981 \\
5=141.7476 \\
6=170.0972 \\
7=198.4467 \\
8=226.7962 \\
9=255.1457\end{array}$ & $\begin{array}{l}1=0.45359 \\
2=0.90919 \\
3=1.36078 \\
4=1.81437 \\
5=2.26796 \\
6=2.72156 \\
7=3.17515 \\
8=3.62974 \\
9=4.08233\end{array}$ & $\begin{array}{l}1=1.0161 \\
2=2.0321 \\
3=3.0482 \\
4=4.0642 \\
5=5.0803 \\
6=6.0963 \\
7=7.1124 \\
8=8.1284 \\
9=91445\end{array}$ \\
\hline
\end{tabular}





\section{INDEX.}

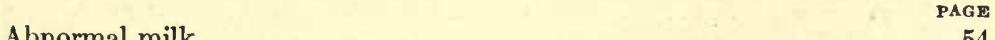

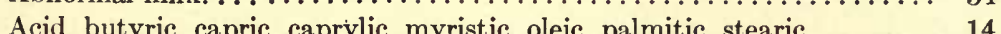

carbonic, hydrochloric, phosphoric, sulphuric. .......... 18

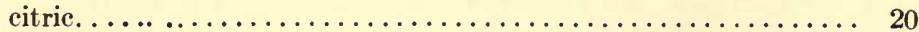

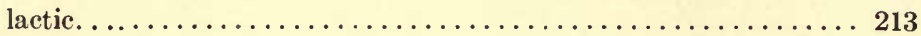

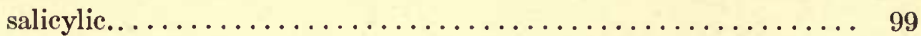

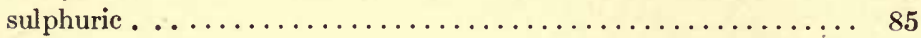

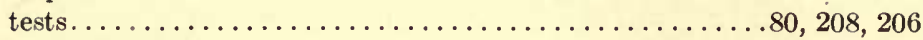

Acidity of milk. . . . . . . . .

of ripened cream in relation to richness of cream. . . . . . . 209

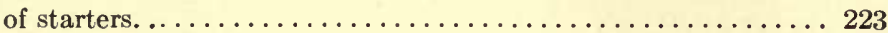

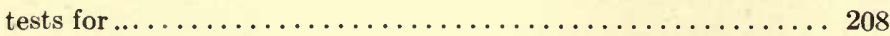

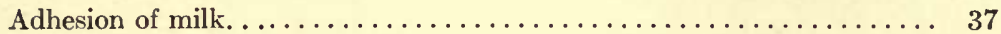

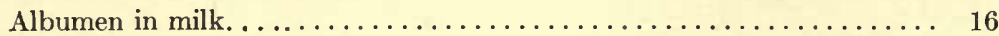

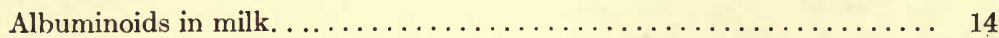

Alkali of various strengths for measuring acid in milk and cream. . . . 80

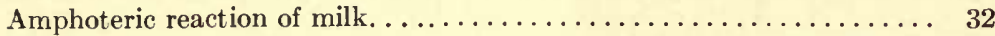

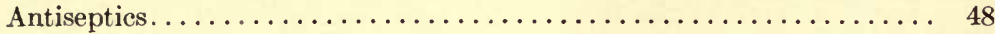

Babcock test for fat. ......................... 84

causes and remedies for common defects in clear-

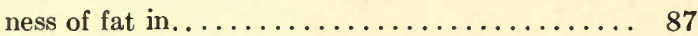

Bacteria in milk, aroma and flavor producing. .............. 187

as a cause of deterioration of butter. .......... 11

classification of. ................... 50

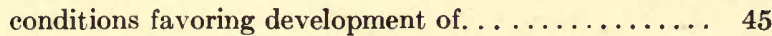

desirable and undesirable in cream ripening....... 189

number of, in milk. ................ 51

size and shape of. .................... 45

sources of. ..................... 52

unfavorable conditions for. . . . . . . . . . . . 48

Biological changes in ripening cream................... 210

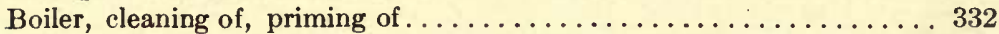

firing with wood and coal...................... 330 
PAGE

Breeds, composition of milk from various.............. 68

Brine. for mechanical refrigeration . . . . . . . . . . . . . 327

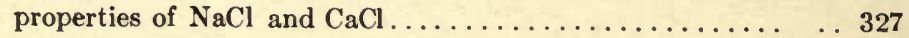

Brine, salting butter with. . . . . . . . . . . . . . . . . . . 264

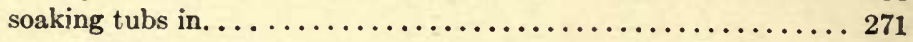

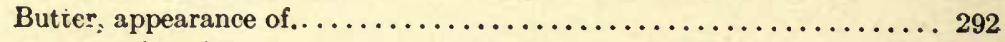

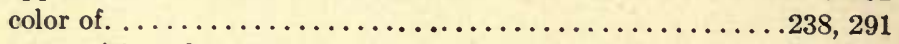

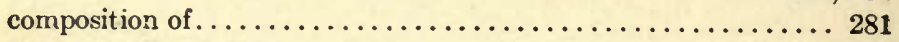

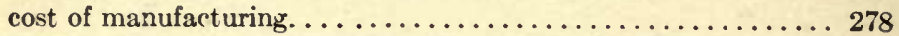

classification and grades of, as outlined by N. Y. Mercantile Ex-

change. .............................. 292

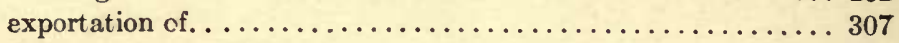

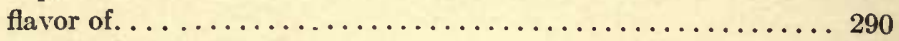

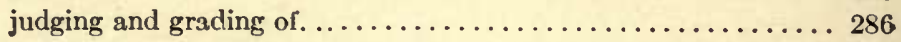

keeping in creameries...............276, 310, 313, 314

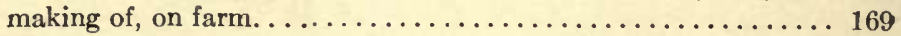

mottled, causes and remedy. . . . . . . . . . . . . 263

packing of. . . . . . . . . . . . .

printing of . . . . . . . . . . . . . . .

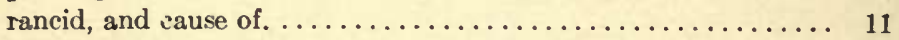

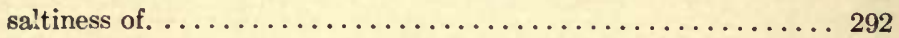

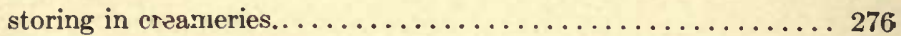

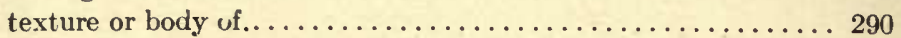

test for water in. . . . . . . . . . . . . . . . . . . 87

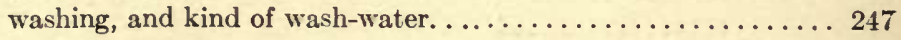

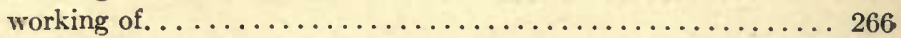

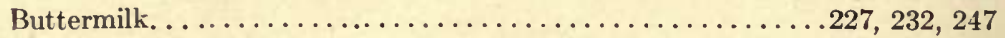

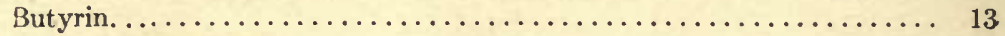

Calculation of amount of salt to add to butter. . . . . . . . . . 256

of average per cent fat. . . . . . . . . . . . . . 105

of churn yield. . . . . . . . . . . . . . 109

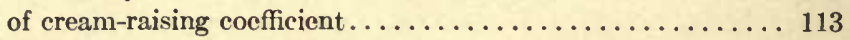

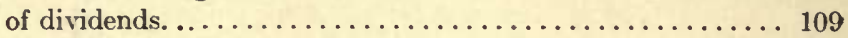

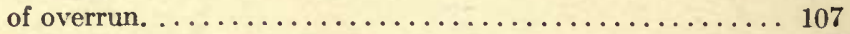

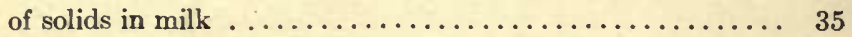

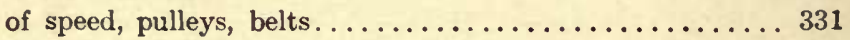

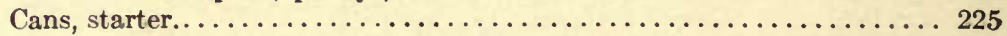

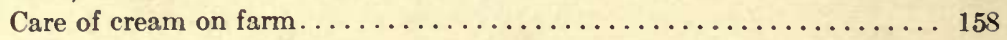

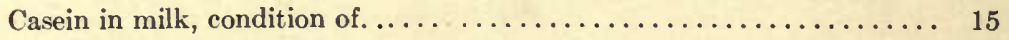

Centrifugal separation of cream. ............................. 129

Changes in milk and cream, chemical, physical, and biological....... 210

Chemical changes in ripe and over-ripe cream. . . . . . . . . . . 213,215

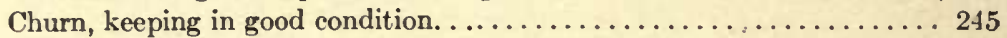

Churn yield, calculation of......................... 109

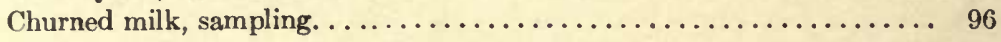




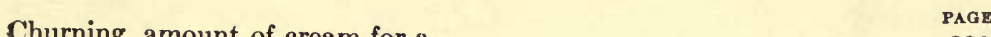

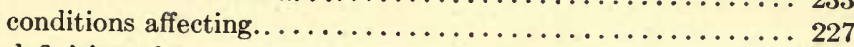

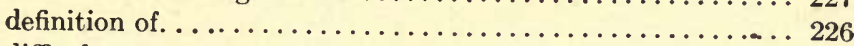

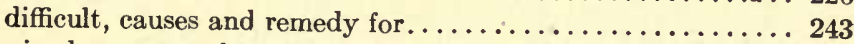

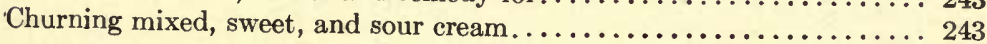

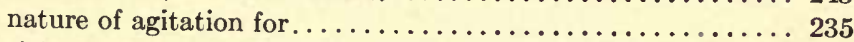

richness of cream for. . . . . . . . . . . . . . . . 231

straining of cream previous to. ................ 238

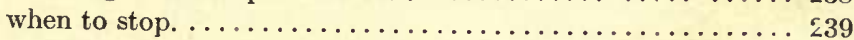

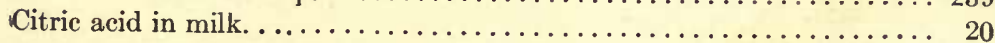

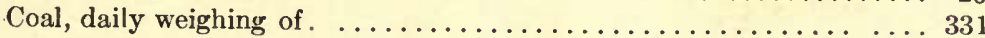

slack $v s$. lump-coal . . . . . . . . . . . . . . . . . . . 331

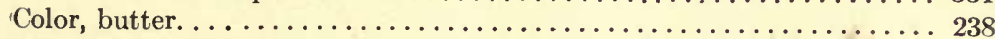

Coloring matter in milk. ............................ 31

Composite samples. . .......................... 99

care and arrangement of. .................. 12

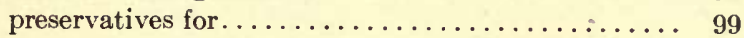

sampling apparatus for. . ............. 94

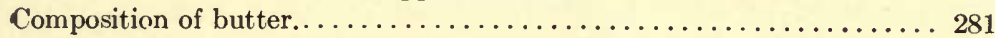

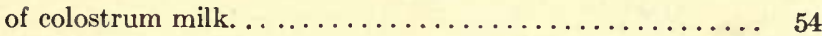

of dairy salts. . . . . . . . . . . . . . . 262

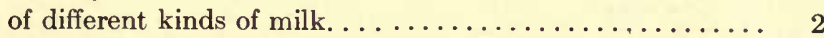

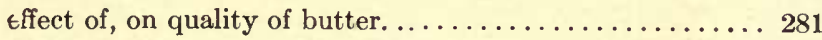

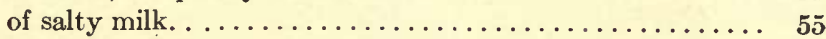

of separator slime......................... 144

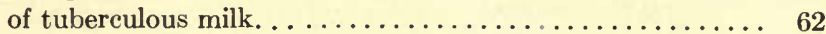

Commercial starters. . . . . . . . . . . . . . . . . . . . . . 217

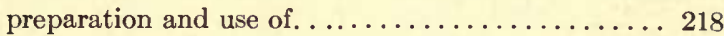

Continuous method of pasteurization. . . . . . . . . . . 173

"Cooley" method of cream separation. ................... 124

Cooling facilities, water, ice, mechanical refrigeration . . . . . . . 309

cost of natural ice-system vs. mechanical refrigeration . . . . . 310

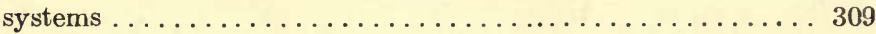

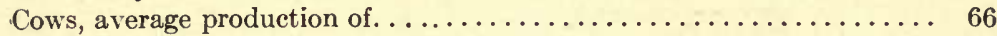

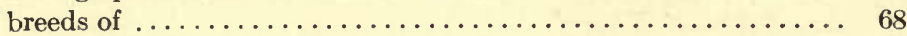

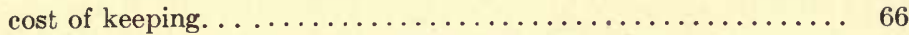

table showing profit and loss in keeping............. 67

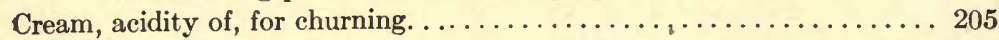

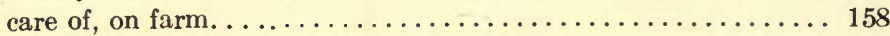

effect of cleanliness on quality of. . . . . . . . . . . . . 159

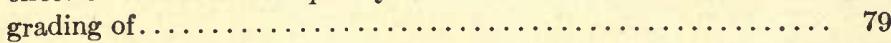

methods of disposing of. . . . . . . . . . . . . . . 167

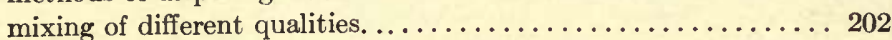

pasteurization of. . . . . . . . . . . . . . . . . . . 173

of sour........................... 180

richness of. ..................... 152 


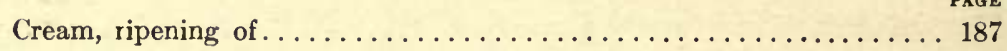

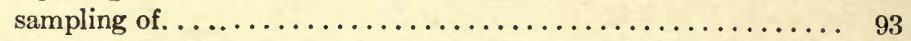

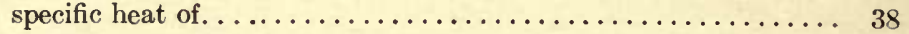

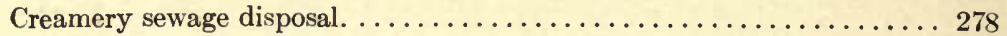

plans........................ 276

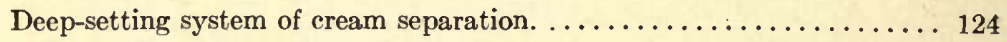

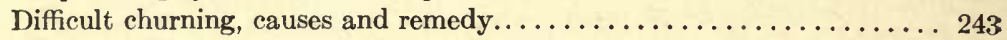

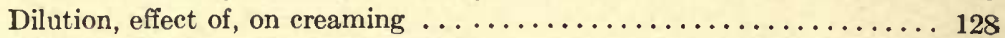

Disinfectants. ........................ 98, 99, 246

Electricity, effect of, on germs in milk. ............... 53

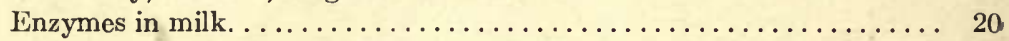

effect of heat on.. ................. 41

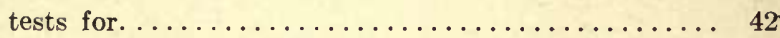

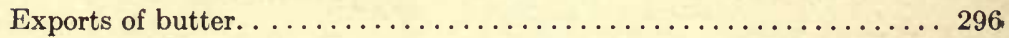

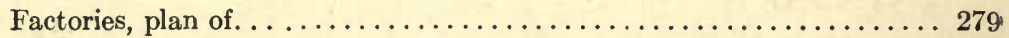

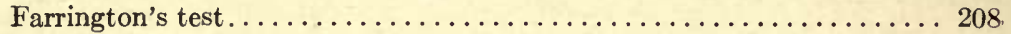

Fat in butter. . . . . . .

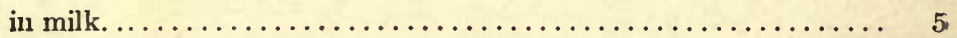

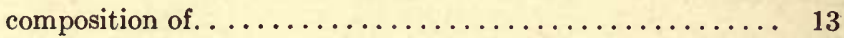

condition of............................. 6

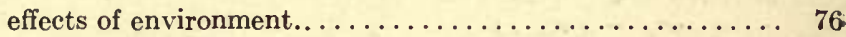

of heat on. ...................... 42

of various feeds on composition of.......... 75

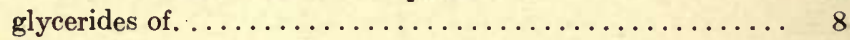

glycerine in. . . . . . . . . . . .

melting-point of. ........................ 12

membrane enveloping fat globules. ............. 9

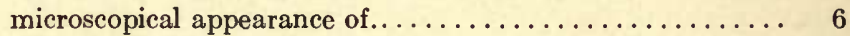

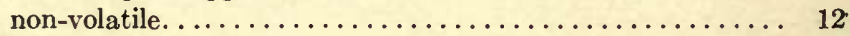

paying for, as compared with fat in cream. . . . . . . 116

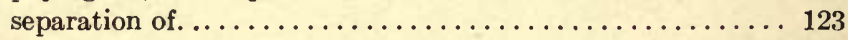

size of globules. ...................... 7

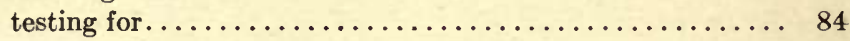

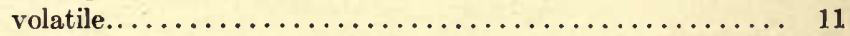

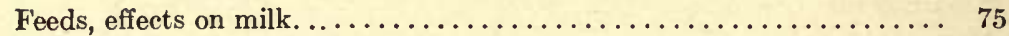

Ferments in milk............................. 44

classes of. ...................... 44, 49

favorable and unfavorable condition for. ......45, 48

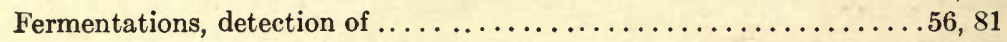

various kinds of.................... 55

Filtration of water. . . . . . . . . . . . . . . . . . . 250

methods and effects of. ................ 251 
PAGE

Firing the boiler. .......................... 329

wood vs. coal, comparative cost of . . . . . . . . . . 330

Flavors of butter............................. 290

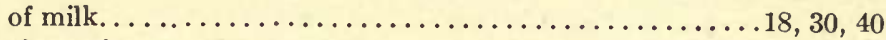

Food for bacteria. ........................ 45

Formula for calculating churn yield.................... 109

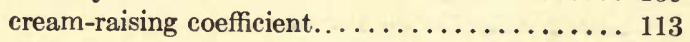

dividends........................... 109

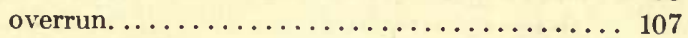

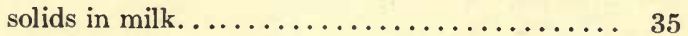

Frozen milk, effects of freezing. ................... 96

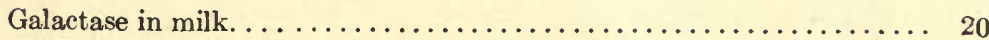

Gases in milk, eliminating. .......................... 184

kinds and sources of $\ldots \ldots \ldots \ldots \ldots \ldots \ldots \ldots \ldots \ldots \ldots \ldots$

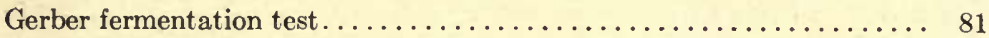

Glassware for Babcock test. . . . . . . . . . . . . . . $86 \ldots \ldots$

Grading milk and cream. . . . . . . . . . . . . . . . 78

Gravity separation, different systems of . . . . . . . . . . 123

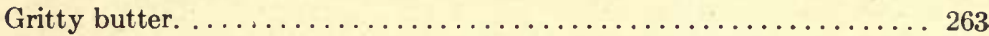

Heat, effects of, on properties of milk. ................. 82

Heating milk previous to skimming. .................... 118

Hegelund method of milking. ........................ 71

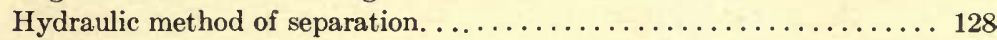

Hydrogen peroxide............................ 42

Ice-house, size, shape, plans of, methods of filling. . . . . . . . . . 312

Ice, source of, usage of . . . . . . . . . . . . . . . . 321

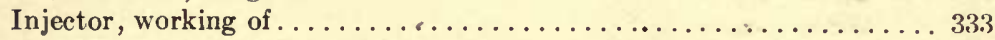

Intermittant method of pasteurization................ 173

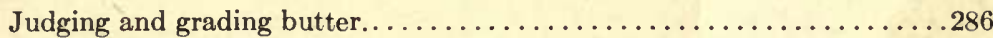

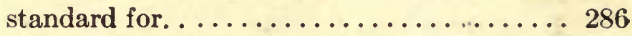

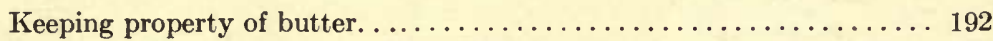

effect of salt on................ 258

Lactation period, effect of, on milk and fat. .............. 74

Lactochrome in milk. . . . . . . . . . . . . 20

Lactometer, comparison of scales on. ................. 34

use of. . . . . . .

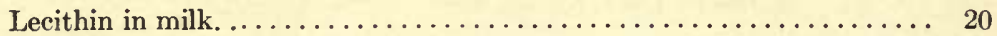

Lime, its use in creameries. . . . . . . . . 245

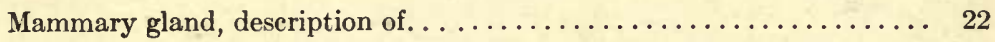

inflammation of. . . . . . 30 
PAGE

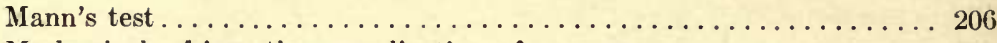

Mechanical refrigeration, application of ............... 323

chemicals used for, principles of ......... 324

direct expansion, and brine system...... 326

Membrane enveloping fat globules.................... 9

Mercantile Exchange, N. Y., grades of butter. . . . . . . . . . . . 292

Metric system of weights and measures.................. 315

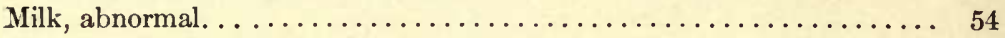

apportioning skimmed. . . . . . . . . . .

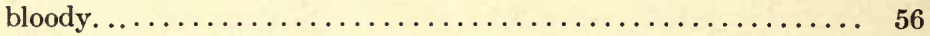

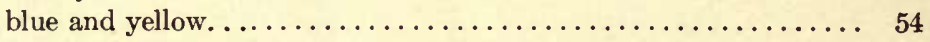

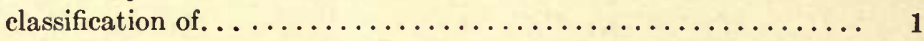

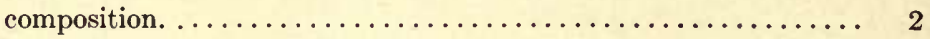

of, from different animals. $\ldots \ldots \ldots \ldots \ldots \ldots \ldots \ldots \ldots \ldots \ldots \ldots \ldots \ldots \ldots \ldots \ldots \ldots \ldots \ldots \ldots$
definition of. $\ldots \ldots \ldots \ldots \ldots \ldots \ldots \ldots \ldots$

effects of thunder-storms on souring of. .............. 53

fat in skimmed. . . . . . . . . . . . . . . . . 123

from barren and spayed cows. ................... 61

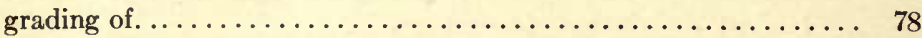

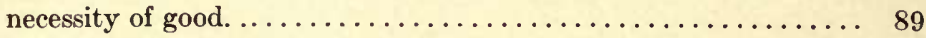

properties of, physical and chemical. ............... 31

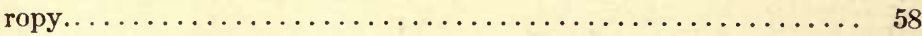

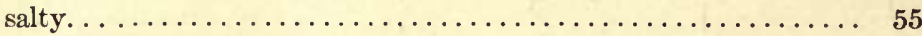

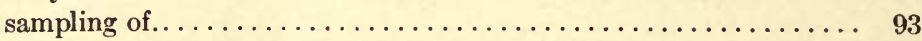

frozen, churned, and sour. ...................... 97

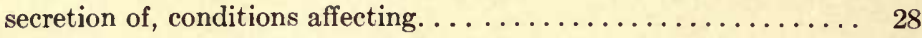

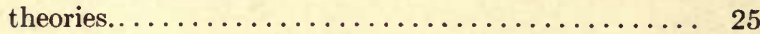

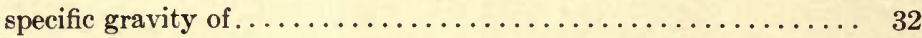

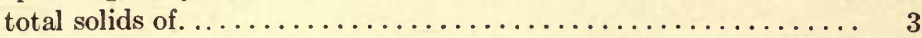

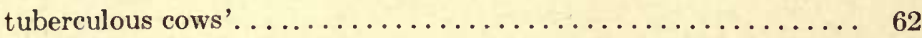

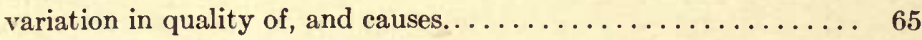

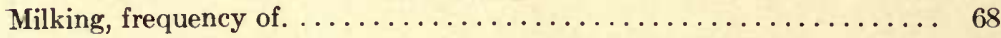

manner of . . . . . . . .

Milking-machine, power, hand, $c$ nd foot............. 70-72

Mottles, causes of, in butter. . . . . . . . . . . . . . . . . 263

kinds of. . . . . . . . . . . . .

prevention of. . . . . . . . . . . .

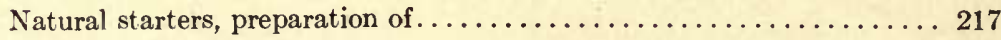

New York Extras defined. . . . . . . . . . . . . . . . . . . 293

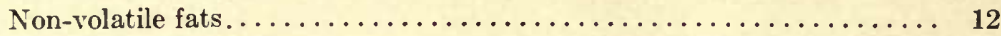

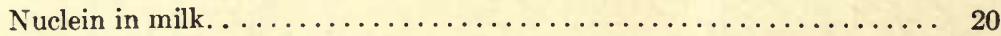

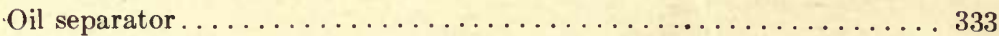

Olein, effect of variation of, on softness of butter........... 12

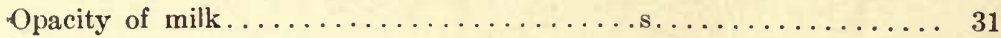


PAGE

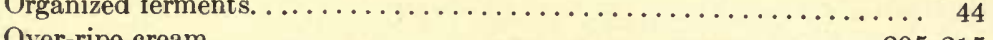

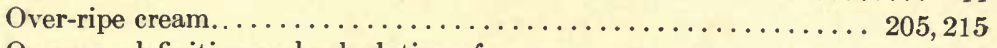

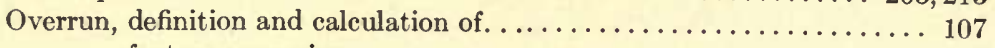

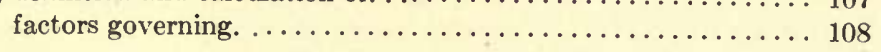

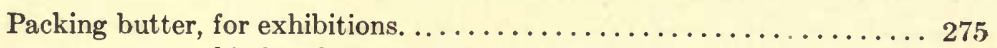

kind and size of package. ......................... 270

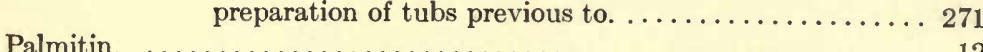

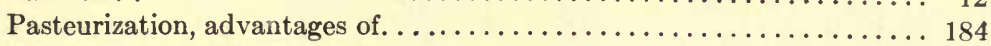

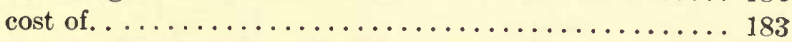

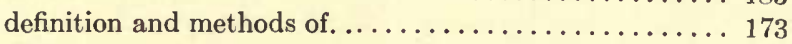

disadvantages of. . . . . . . . . . . . . . . . 186

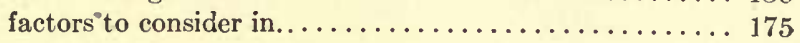

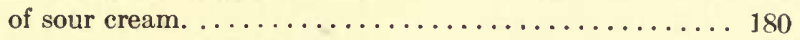

use of, direct steam in................... 174

Pasteurizer, durability and efficiency. . . . . . . . . . . . 175

Paying for fat in cream as compared with fat in milk . . . . . . . . . 116

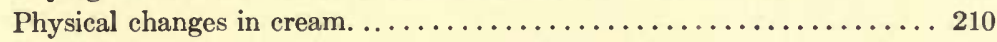

Proteids in milk, as a cause of mottles in butter. ............ 264

kinds of. ...................... 14

Quevenne lactometer. . . . . . . . . . . . 33

Rancid butter, causes of. .......................... 11

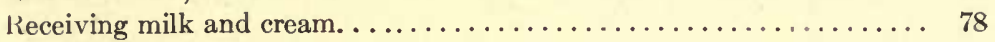

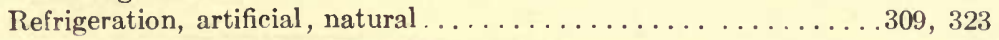

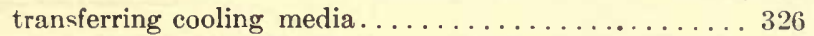

Richness of cream from centrifugal separator. . . . . . . . . . . . 137

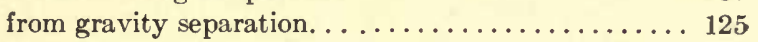

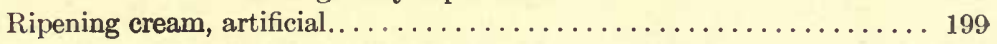

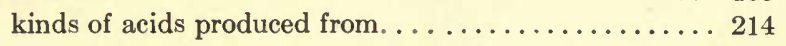

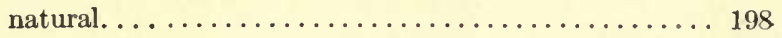

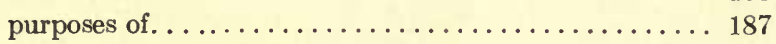

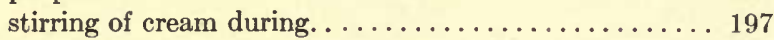

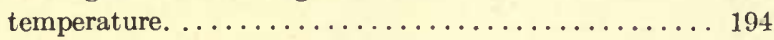

testing cream for acidity during. . . . . . . . 205

when churned every other day.............. 201

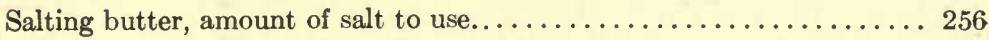

eff $f_{\text {sets }}$ of, on keeping property of butter........ 258

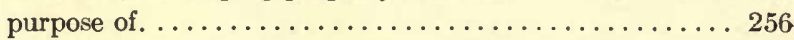

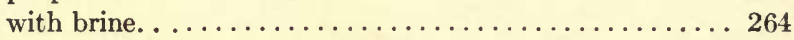

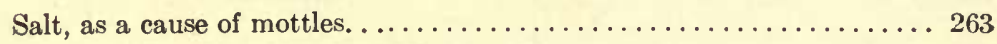

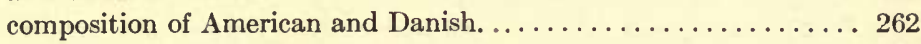

condition of, when added to butter. . . . . . . . . . . 261 
PAGE

Salt, effect of, on keeping property of butter............... 25s

of, on removal of buttermilk. ................ 259

in relation to water in butter.................... 259

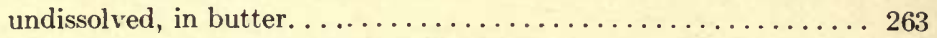

Samples, average. ............................... 104

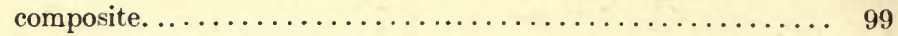

Sampling-tube................................ 94

Separation, advantages of centrifugal. . . . . . . . . . . . . . . . 129

centrifugal. .......................... 129

classification of centrifugal machines. ............. 133

conditions affecting completeness of. . ............ 139

effect of speed as compared with diameter on . . . . . . . 143

factors governing richness of cream. . . . . . . . . . 137

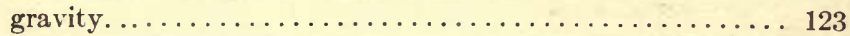

heating milk for. ...................... 118

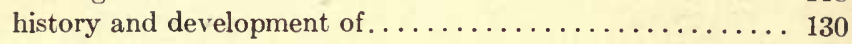

process of centrifugal. . . . . . . . . . . . . . . . . . 134

results from different methods of. . . . . . . . . . . . . 129

Separator farm, introduction and development in Iowa. . . . . . . . . 146

reasons for introducing. ............... 147

Separator slime, composition of. ...................... 144

Sewage-disposal plants, cuts of. ..................... 278

Score-cards for butter . . . . . . . . . . . . . . . . . . . . 287

Shallow-pan creaming. .......................... 123

Skimmed milk, apportioning. ..................... 97

Standards, legal, for milk. . . . . . . . . . . . . . . . . . . 314

Sterilization. .............................. 173

Statements, annual. ............................ 114

patrons' monthly. ..................... 113

Starter cans. . . . . . . . . . . . . . . . . . . . . . . . . 325

Starters, amount to use. ........................ 196, 224

definition, history, and classification............. 216

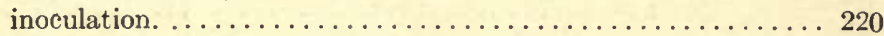

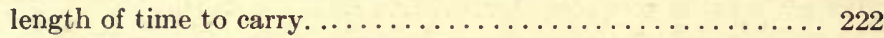

over-ripening and under-ripening of............... 223

preparation of. . .................. 217,214

Sugar and curd in butter. .......................... 282

in milk. ........................... 16

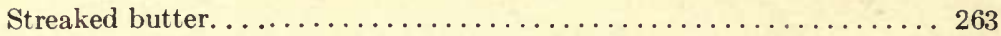

Table showing amount of acid produced from a definite amount of sugar

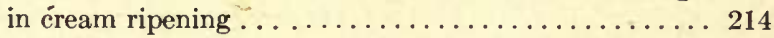

effect of temperature on growth of bacteria....... 46

fat and total solids of milk from various breeds....... 68 number of acid-and non-acid-producing germs in ripe

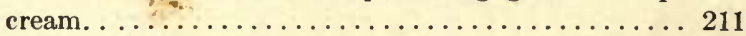

profits and losses in keeping cows............. 67 
Taints in milk, eliminating.

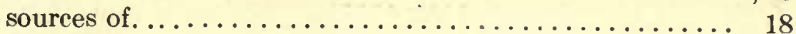

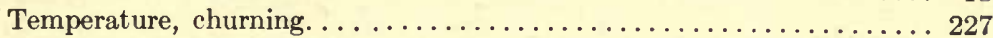

duration of. . . . . . . . . . . . 118

effect of, on bacterial growth............... 46

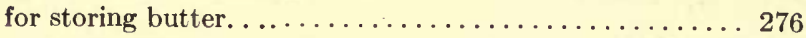

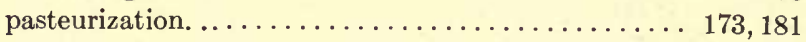

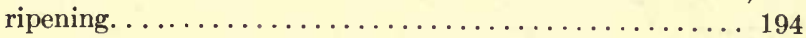

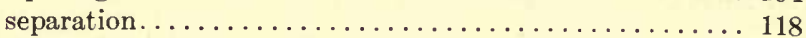

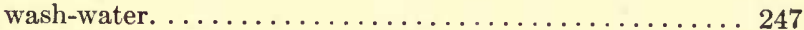

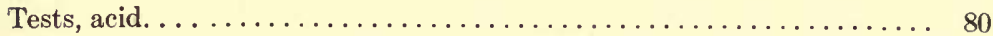

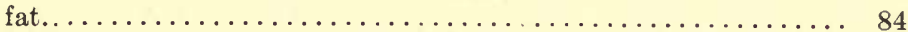

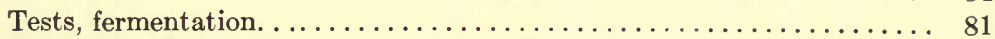

pasteurized milk......................... 42

Total solids of milk, variation of. . . . . . . . . . . . . 3

Tubs, preparation and kinds of. ........................ 271

Udder, external appearance of. .................... 29

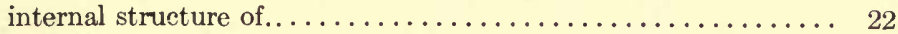

Unorganized ferments........................... 44

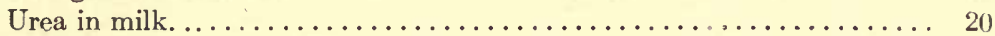

Utensils, cleaning....................... 145, 159

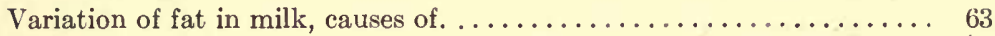

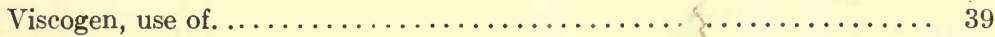

Viscosity of milk. .................................. 37

restoration of .................... 39

Volatile fats................................ 11

Washing butter, kind of wash-water for. . $\quad \ldots \ldots \ldots \ldots \ldots \ldots 248$

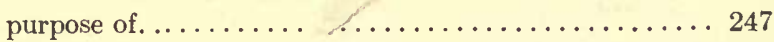

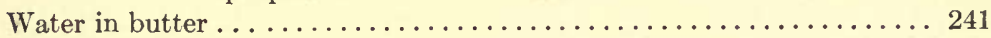

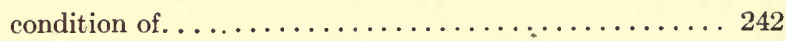

Water, in relation to salt in butter. . . . . . . . . . . . . . . 259

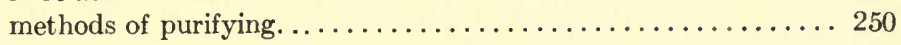

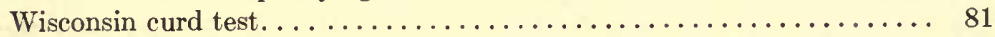

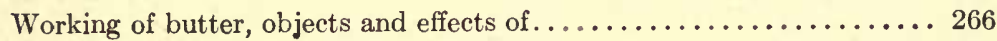

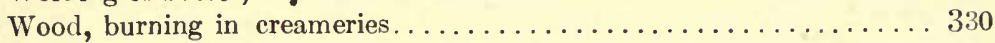

Working of butter, objects and effects of .............. 266

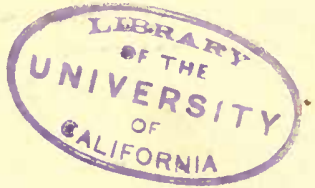


of milk.

S....

ly. 
. 




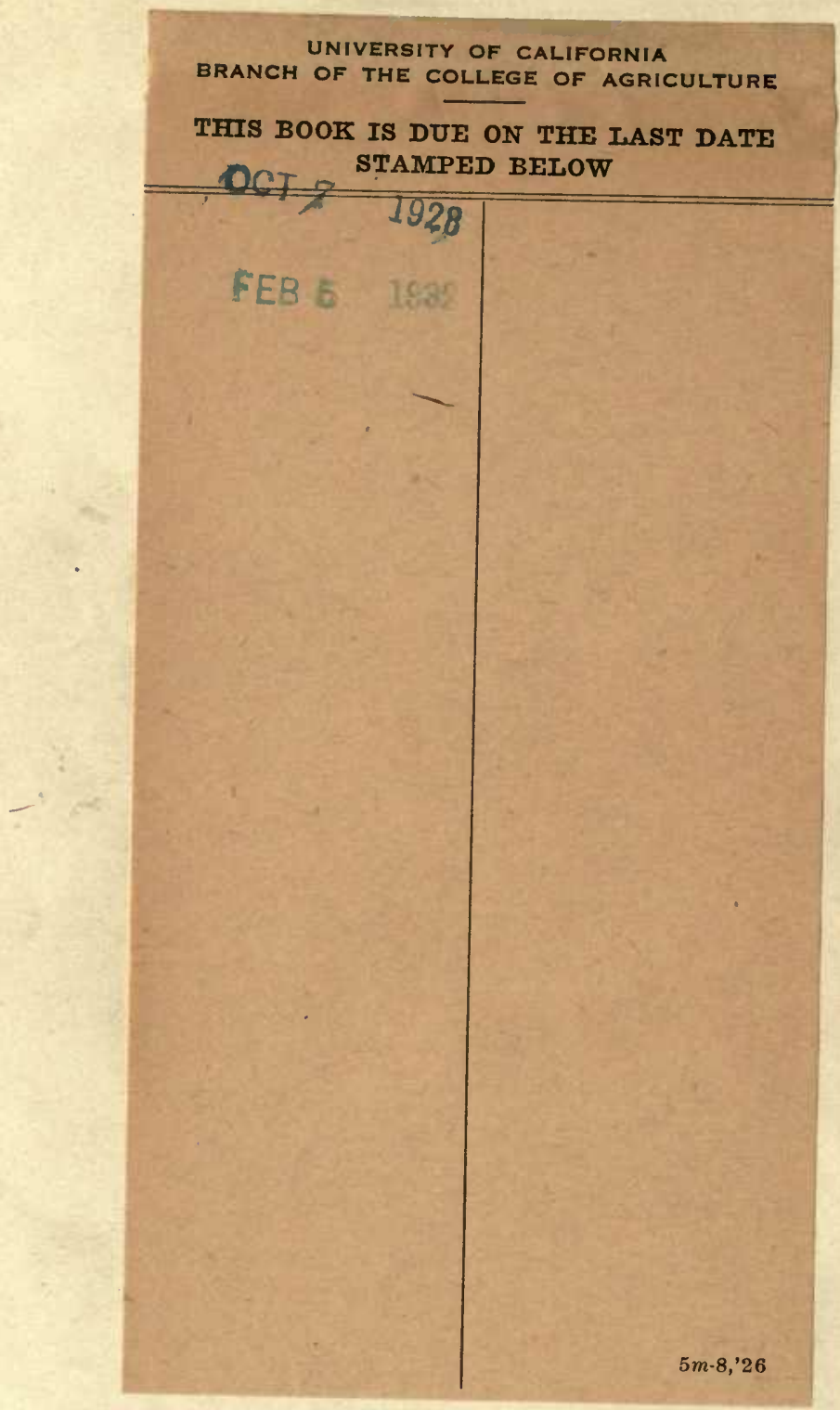




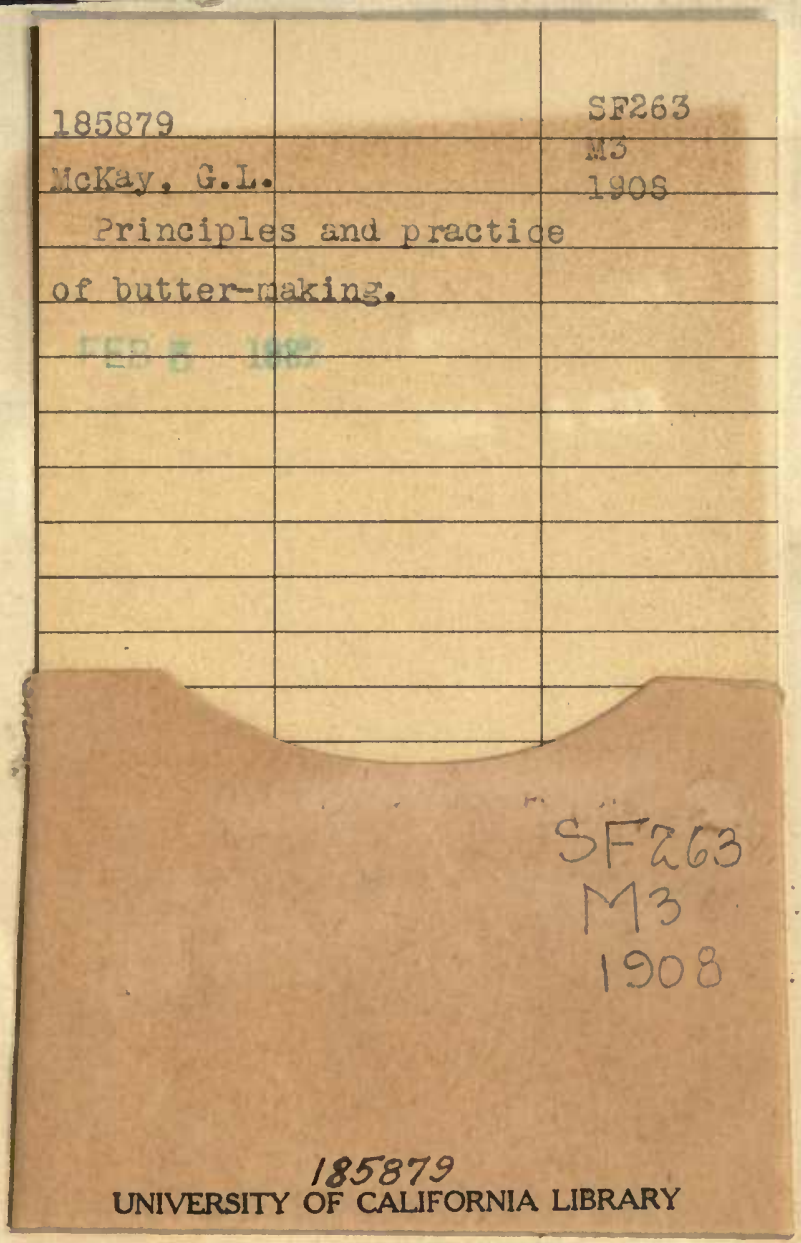




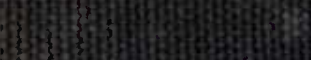

